Portland State University

PDXScholar

$11-16-2020$

\title{
Inclusion for Speech-Language Pathology Minority Graduate Students
}

Teresa Michelle Roberts

Portland State University

Follow this and additional works at: https://pdxscholar.library.pdx.edu/open_access_etds

Part of the Special Education and Teaching Commons, and the Speech Pathology and Audiology Commons

Let us know how access to this document benefits you.

\section{Recommended Citation}

Roberts, Teresa Michelle, "Inclusion for Speech-Language Pathology Minority Graduate Students" (2020). Dissertations and Theses. Paper 5617.

https://doi.org/10.15760/etd.7489

This Dissertation is brought to you for free and open access. It has been accepted for inclusion in Dissertations and Theses by an authorized administrator of PDXScholar. Please contact us if we can make this document more accessible: pdxscholar@pdx.edu. 
Inclusion for Speech-Language Pathology Minority Graduate Students

by

Teresa Michelle Roberts

A dissertation submitted in partial fulfillment of the requirements for the degree of

Doctor of Education

in

Educational Leadership: Special and Counselor Education

Dissertation Committee:

Randall De Pry, Chair

Christina Gildersleeve-Neumann

Ruth Falco

Lindsey Wilkinson

Portland State University

2020 
(C) 2020 Teresa Michelle Roberts 


\begin{abstract}
Speech-language pathologists provide assessment and intervention for communication, cognition, and swallowing disorders for individuals across the lifespan in educational, medical, and private practice settings. The demographics of professionals in the field do not reflect those of the general public in regard to race and ethnicity, gender, socioeconomic status, LGBTQ+, and disability. Lack of representation of minorities limits research, policy, and services designed to serve diverse populations. Although initiatives have sought to address lack of diversity of speech-language pathologists, limited research on the graduate training experience for minority students is available. Since a master's degree is required to become a speech-language pathologist, the experiences of minority students in their graduate training programs offer a unique perspective on inclusion in relation to diversity. This study examined minority graduate students' experiences of inclusion, their advice to a peer, recommendations to programs, and the design of an inclusive recruitment flyer. Results of the study showed how many speech-language pathology graduate programs are designed to operate from a privileged perspective that is white, middle-class, female, cisgender and heterosexual, and neurotypical and able-bodied. When applying critical theory and social justice concepts (Sensoy \& DiAngelo, 2012), this perspective serves as a form of privilege that oppresses minority students through multiple practices that grant benefits and opportunities to a dominant identity group. Recommendations are provided to program administrators, faculty members, and students, which address underlying beliefs about diversity, offer
\end{abstract}


ways to change the environment to promote inclusion, and include mitigation strategies for the negative effects of lack of inclusion. 


\section{Acknowledgments}

Thank you to my dissertation committee: Randall De Pry, Chair, Ruth Falco, Christina Gildersleeve-Neumann, and Lindsey Wilkinson

Thank you to the speech-language pathology students who participated in the study, the students in Speech and Hearing Science courses at Portland State University.

Thank you to colleagues, friends, and family for your support and the Special Education and Curriculum and Instruction EdD cohort members and faculty. 
Table of Contents

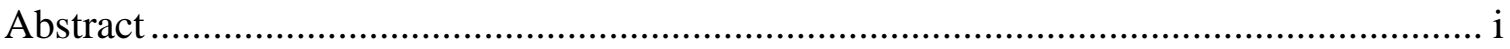

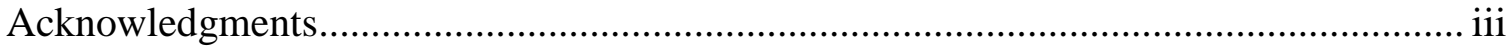

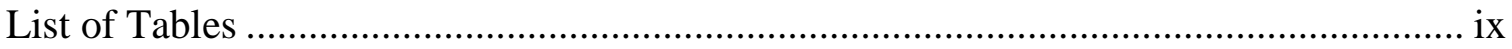

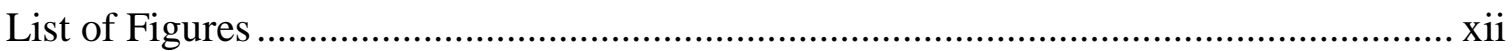

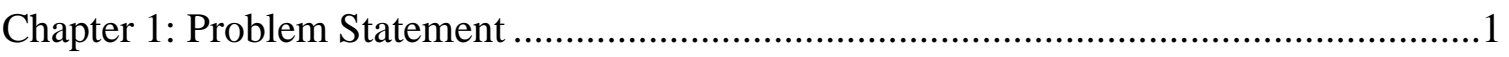

Lack of Diversity Within Speech-Language Pathology............................................

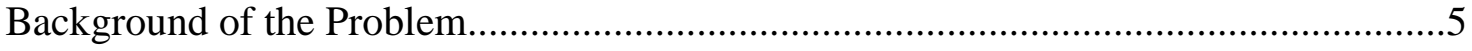

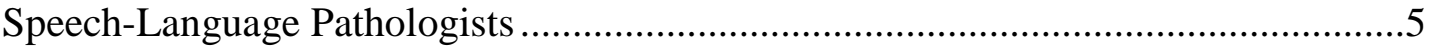

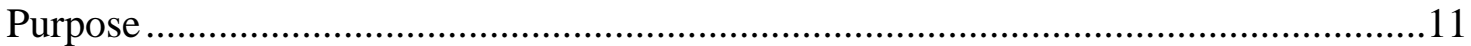

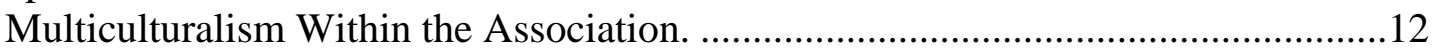

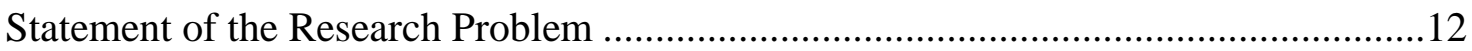

Context of the Problem........................................................................................ 13

Evidence That the Problem Exists ....................................................................... 14

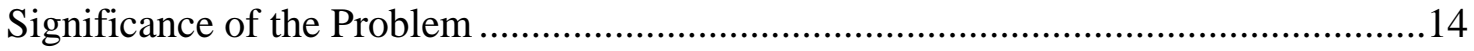

Presentation of Methods and Research Question....................................................18

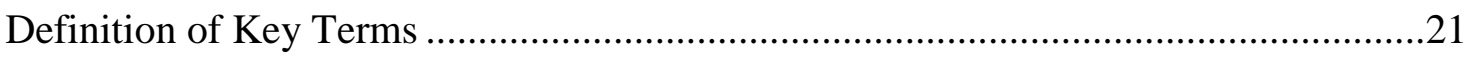

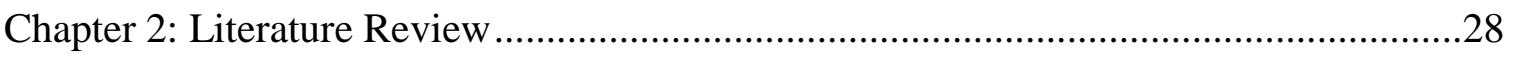

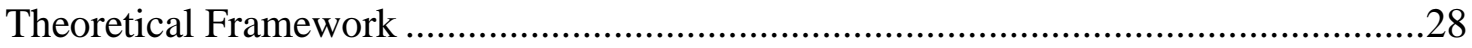

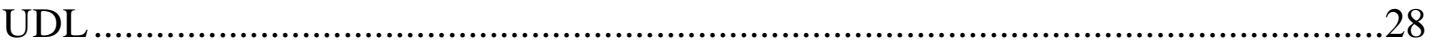

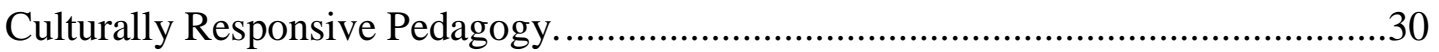

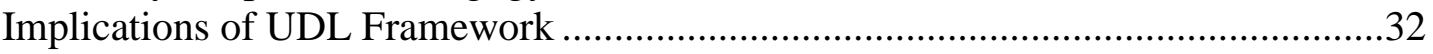

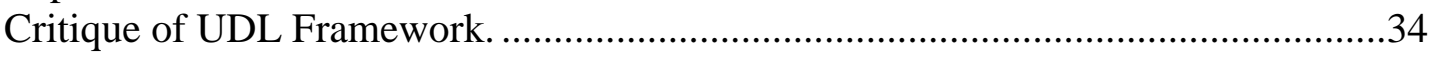

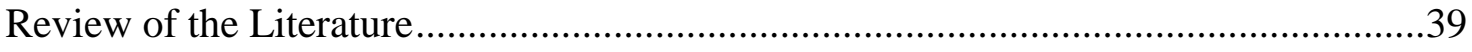

Minorities Within Speech-Language Pathology ...................................................40

Racial and Ethnic Minorities within Speech-language pathology ..............................45

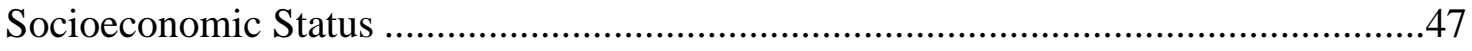

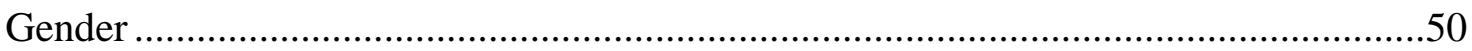

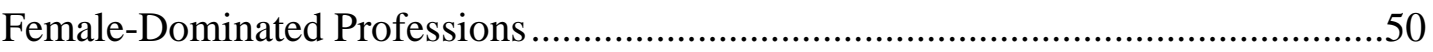

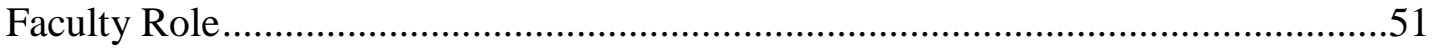

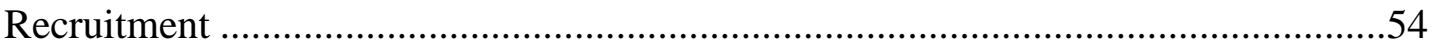

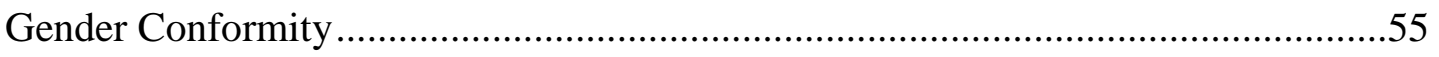

Speech-Language Pathology and Gender .........................................................5

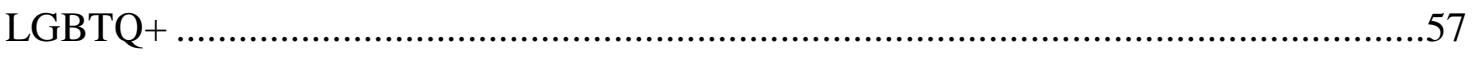

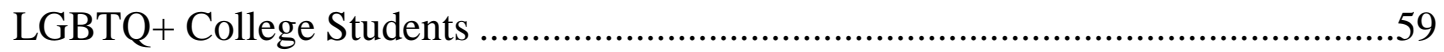

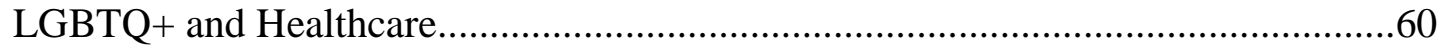




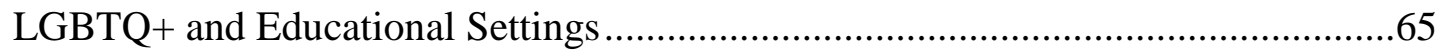

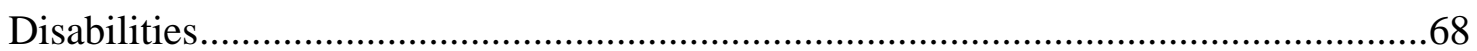

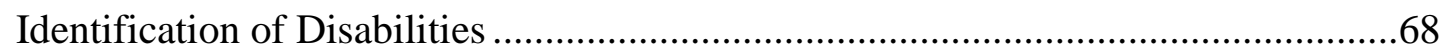

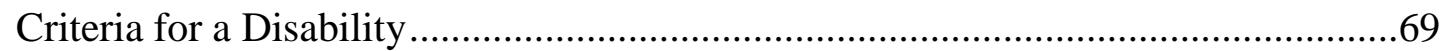

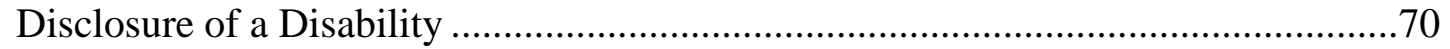

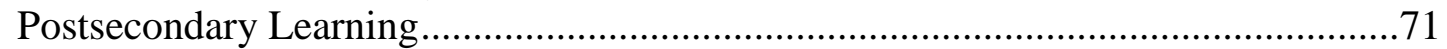

Speech-Language Pathology and Disabilities .....................................................76

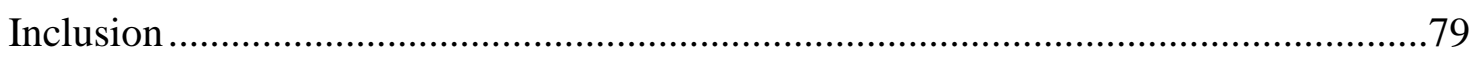

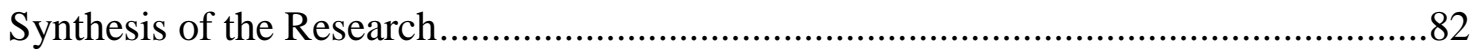

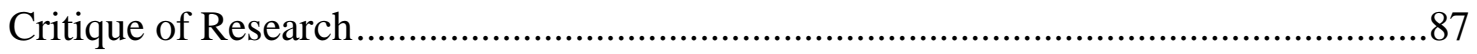

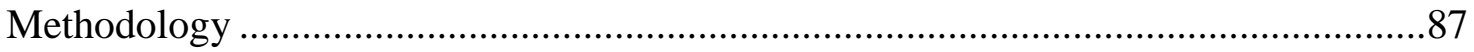

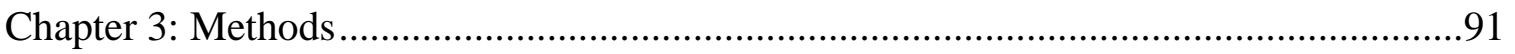

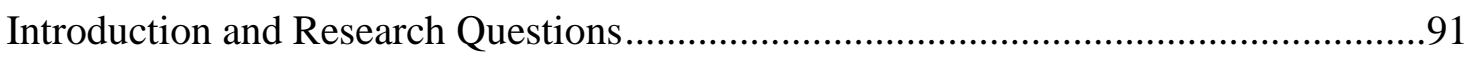

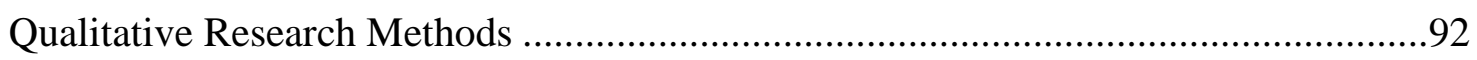

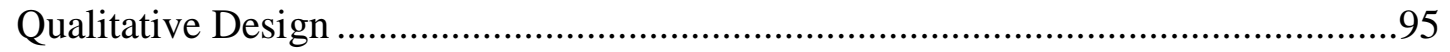

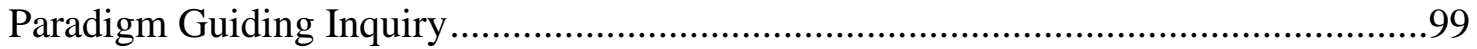

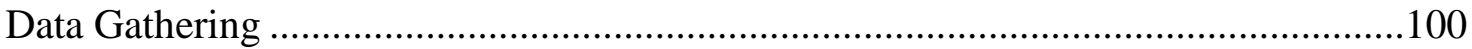

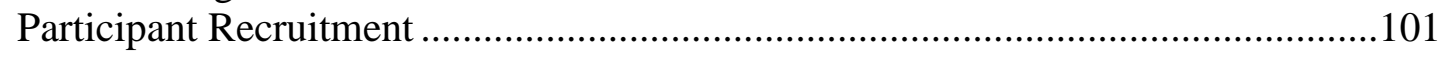

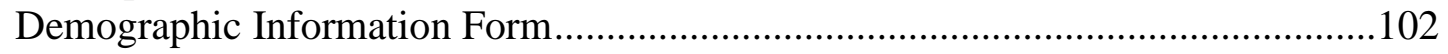

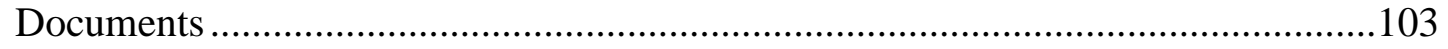

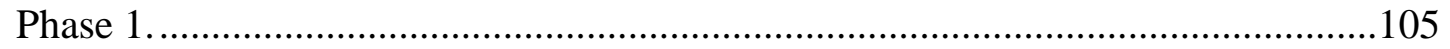

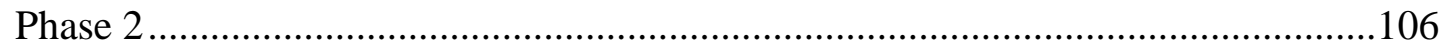

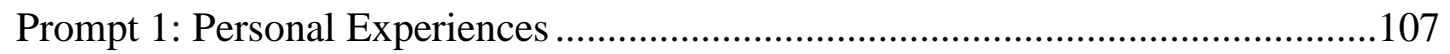

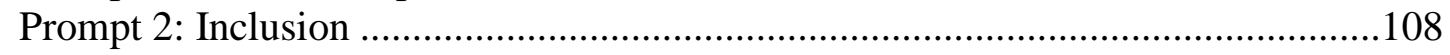

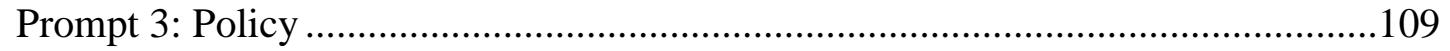

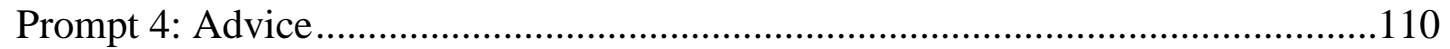

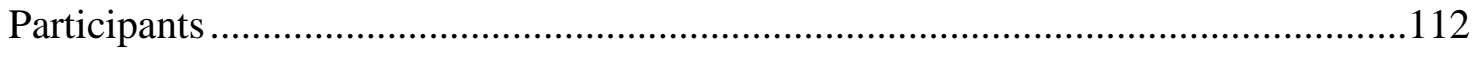

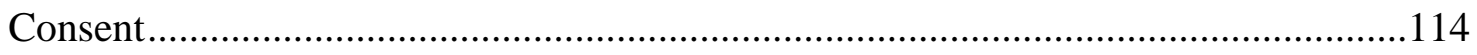

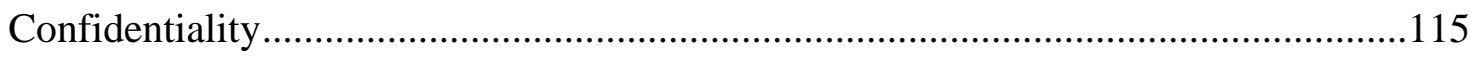

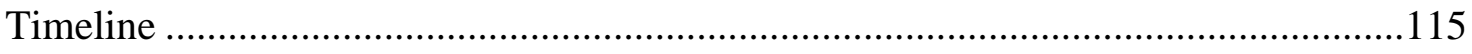

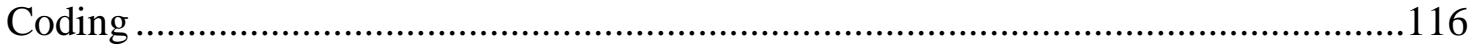

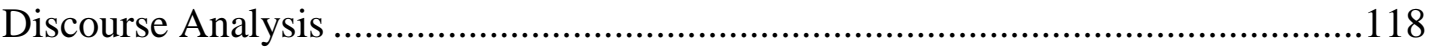

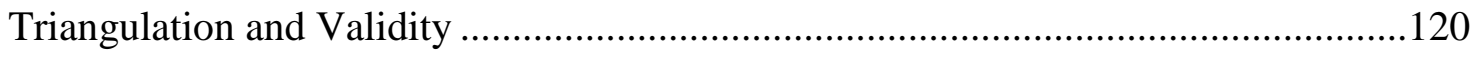

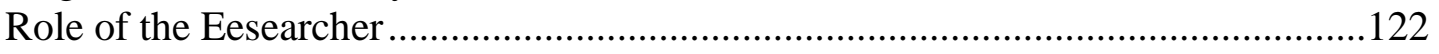

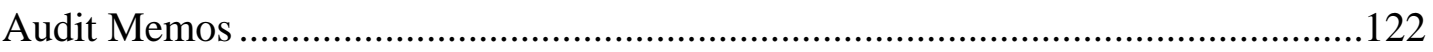

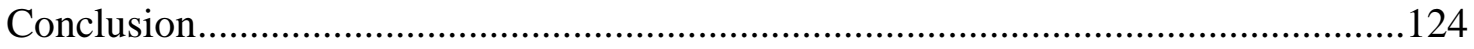




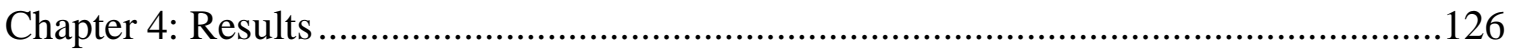

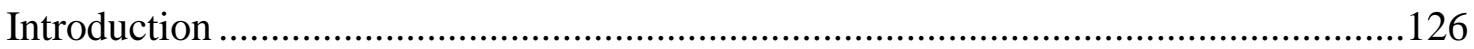

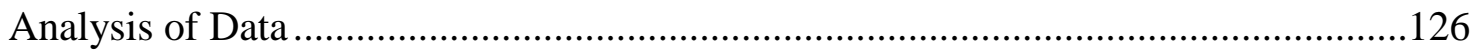

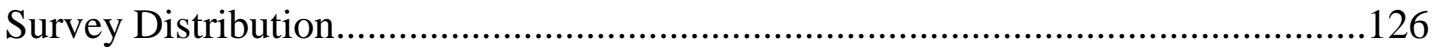

Geographic Region .................................................................................128

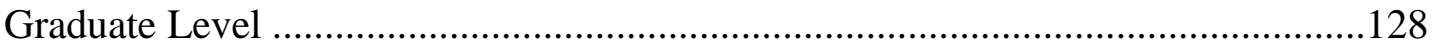

Summary of Participant Demographics.............................................................130

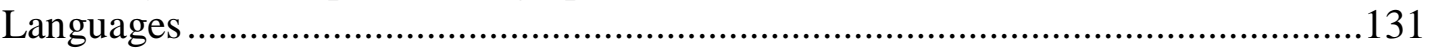

Race and Ethnicity ………………………………….............................132

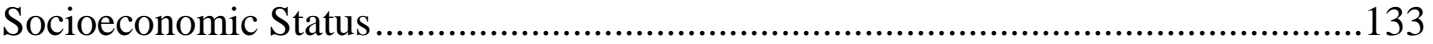

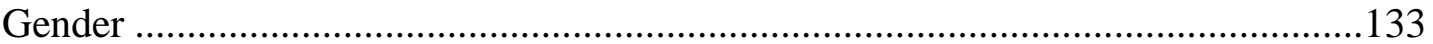

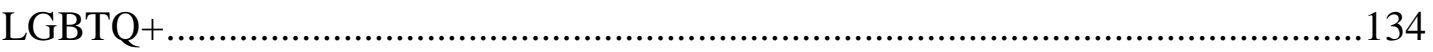

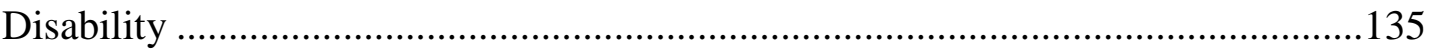

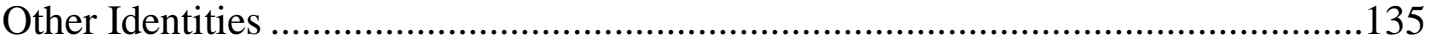

Inclusion Writing Prompts.............................................................................136

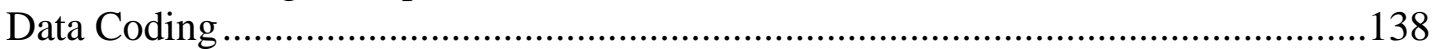

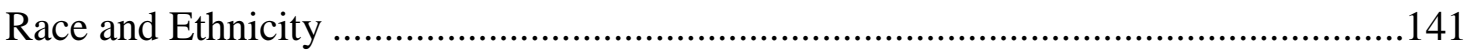

Race and Ethnicity Decreased Inclusion ...............................................................142

Race and Ethnicity Increased Inclusion...............................................................154

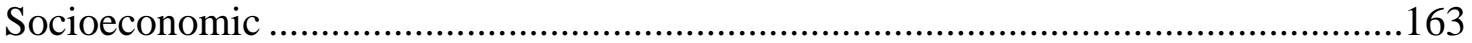

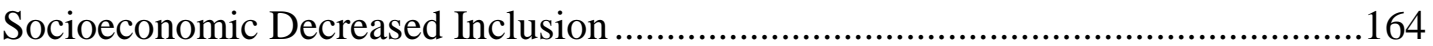

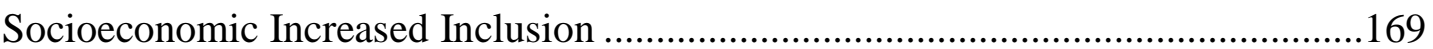

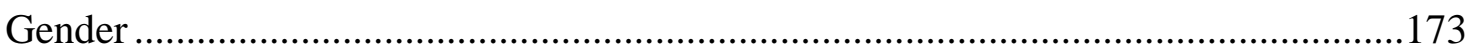

Male Gender Decreased Inclusion....................................................................174

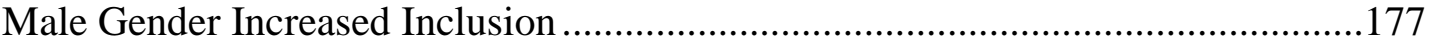

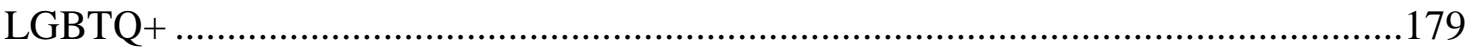

LGBTQ+ Decreased Inclusion .......................................................................... 180

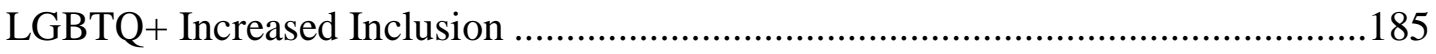

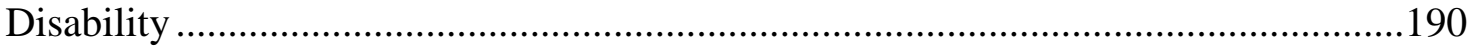

Disability Decreased Inclusion .........................................................................191

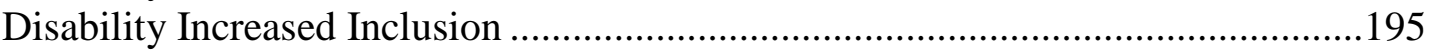

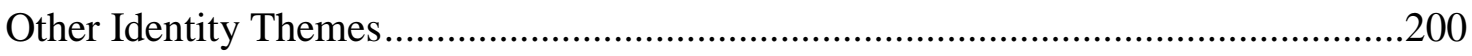

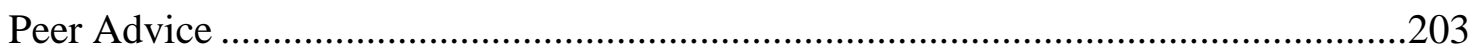

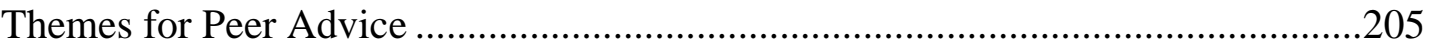

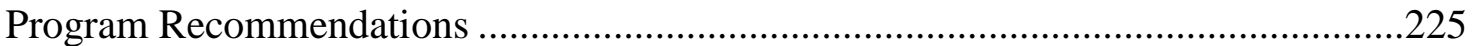

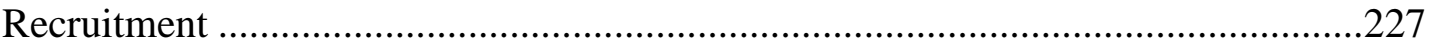

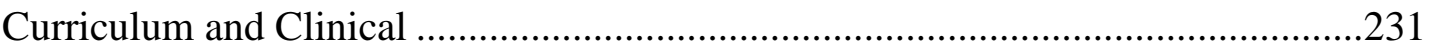

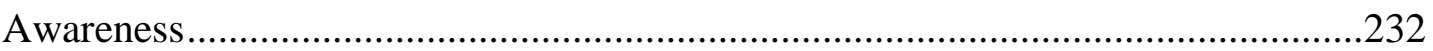

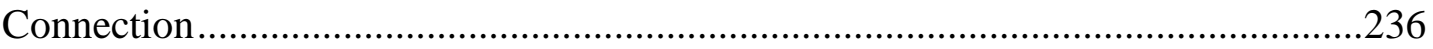

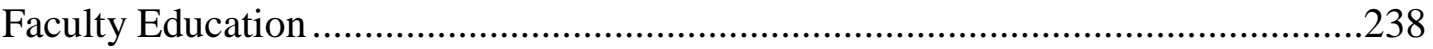




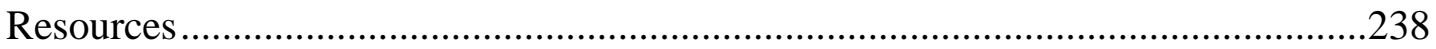

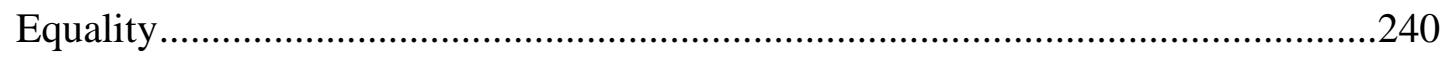

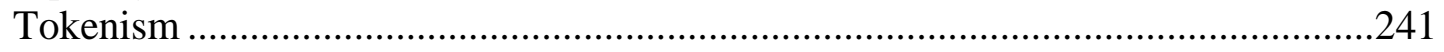

Lack of Problem and Non-Response for Programmatic Recommendations...............242

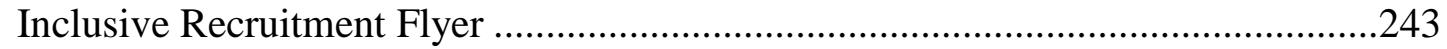

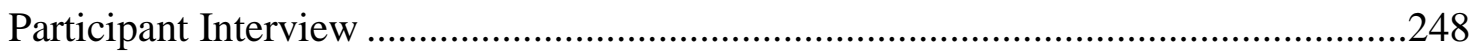

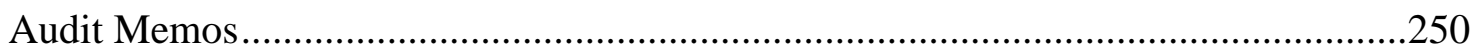

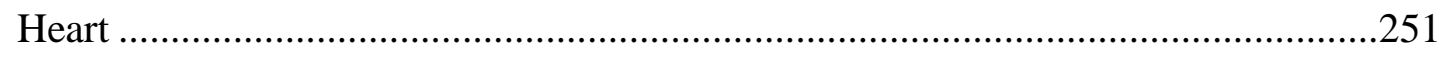

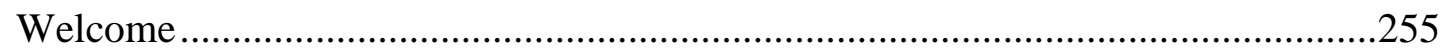

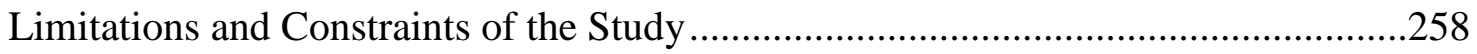

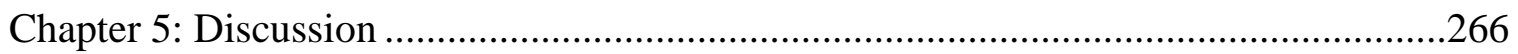

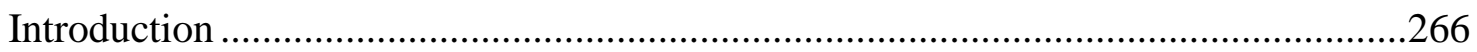

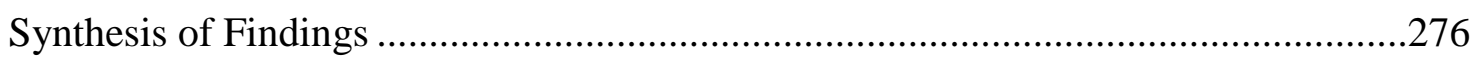

Situating the Research in a Larger Context.......................................................278

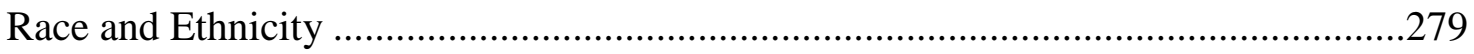

Decreased Inclusion for Race and Ethnicity.....................................................279

Increased Inclusion for Race and Ethnicity ......................................................290

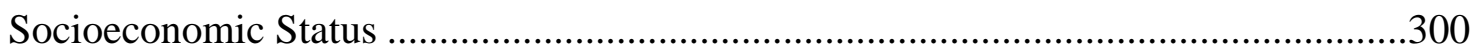

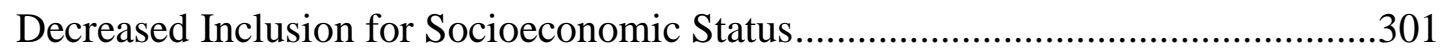

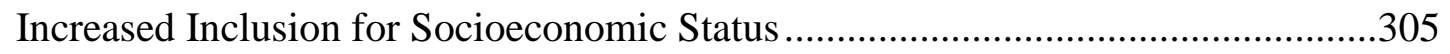

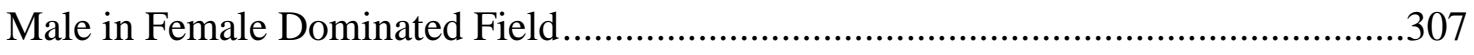

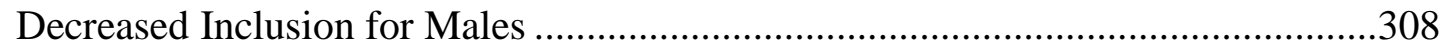

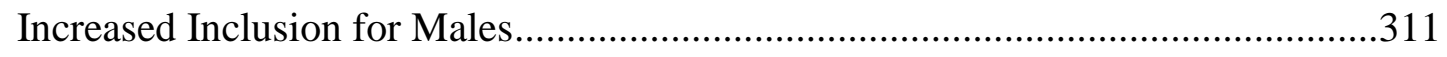

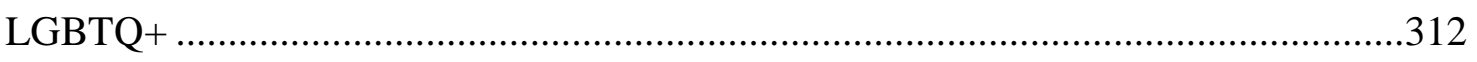

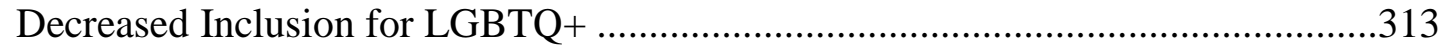

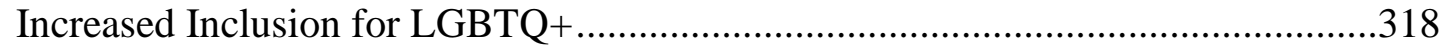

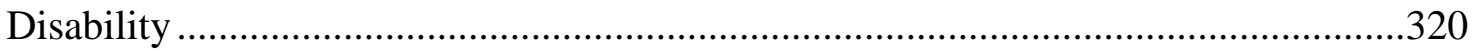

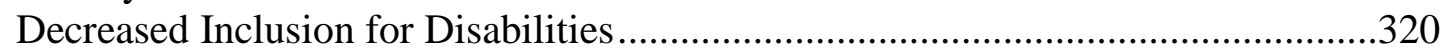

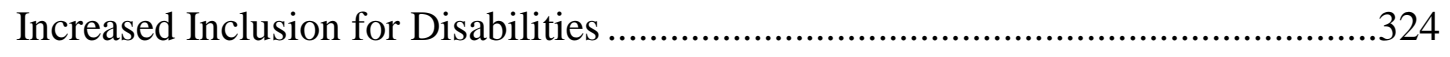

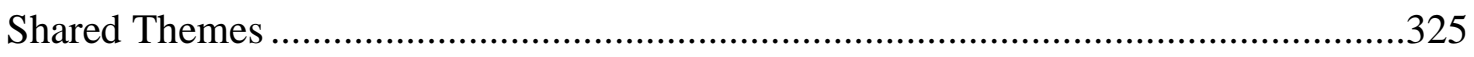

Shared Themes for Decreased Inclusion for Minority Students.............................326

Shared Themes for Increased Inclusion for Minority Students ..............................329

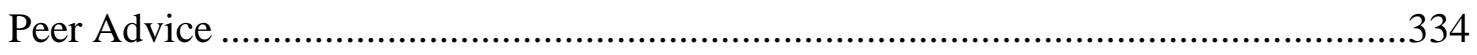

Choosing a Graduate Program and Expectations ...................................................335

Seeking Support, Fortitude, and Perseverance ...................................................337

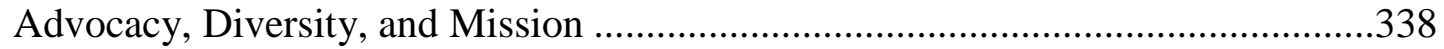

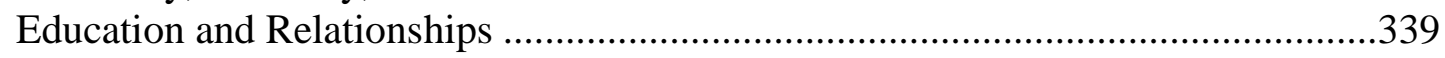

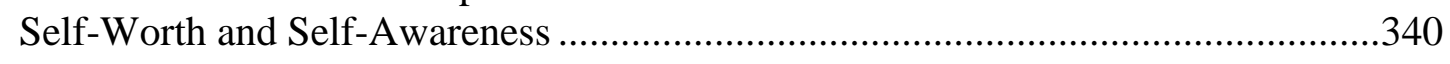




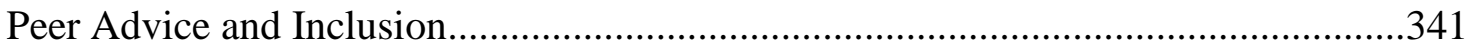

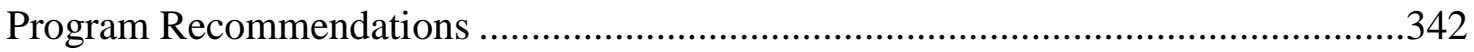

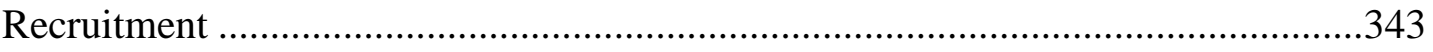

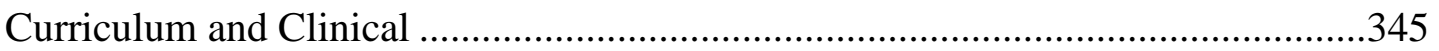

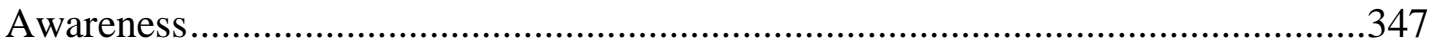

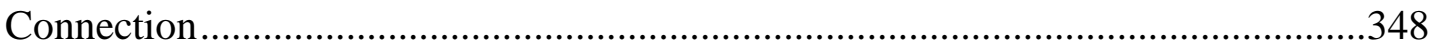

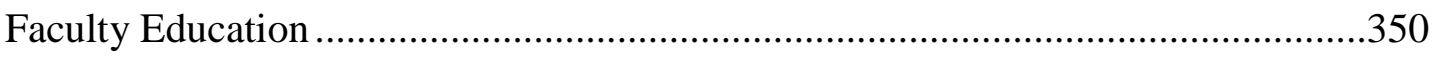

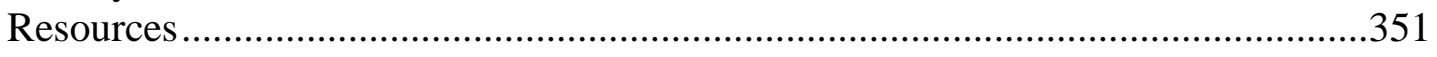

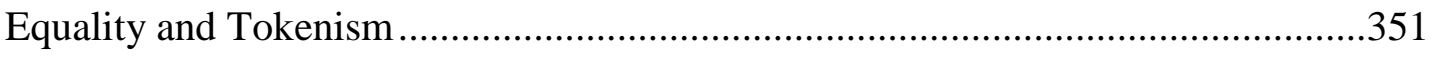

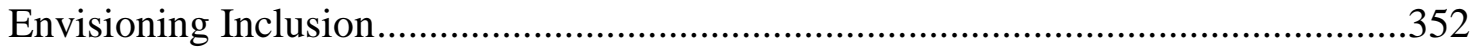

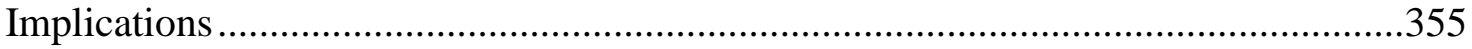

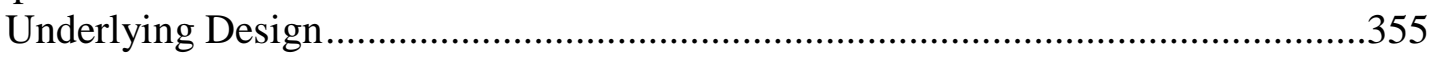

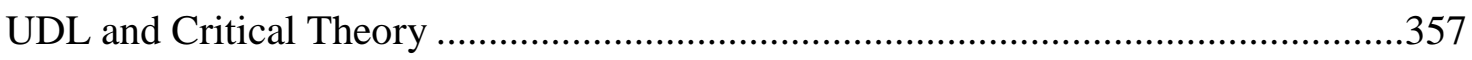

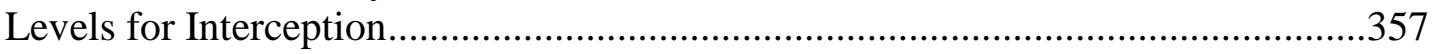

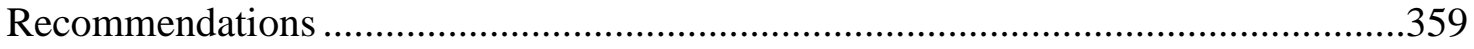

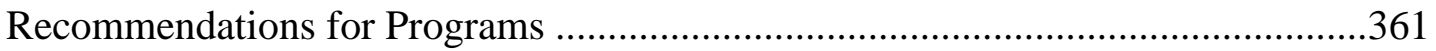

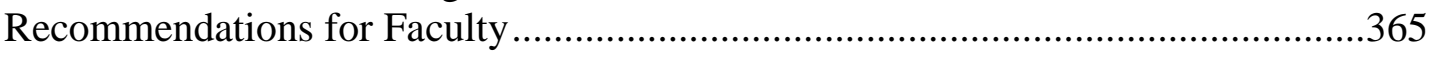

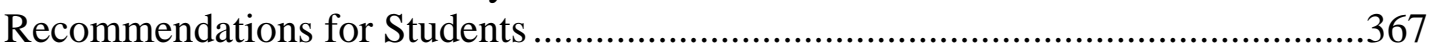

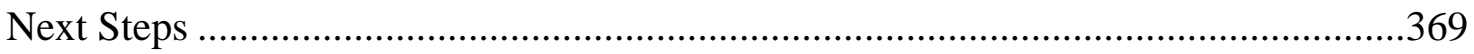

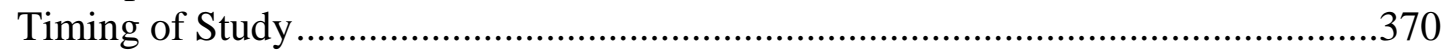

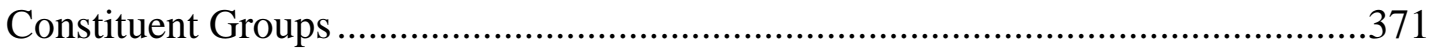

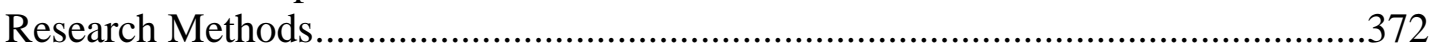

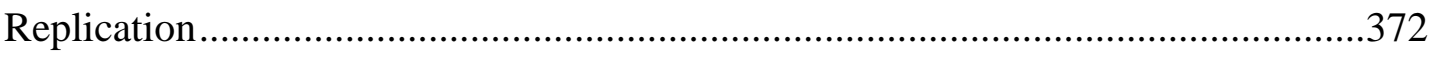

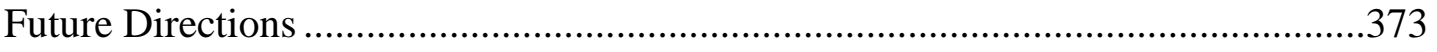

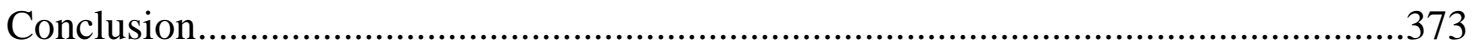

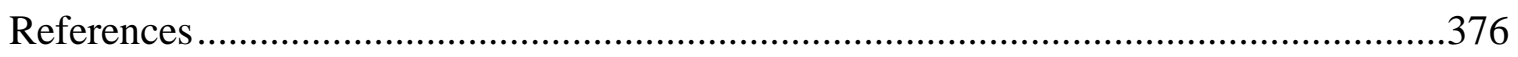

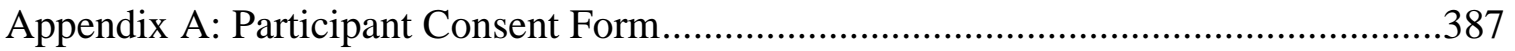

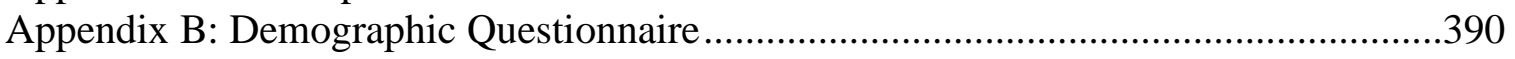

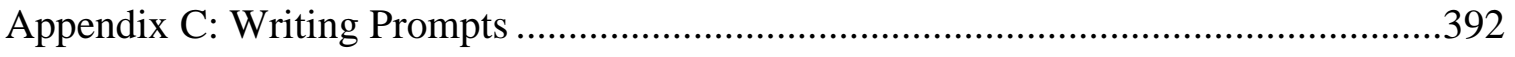

Appendix D: Visual Representation Prompt and Interview Prompt.............................393

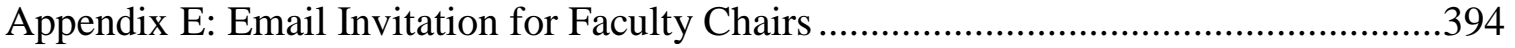


List of Tables

Table 1. Prompt 1: Personal Experiences ............................................................... 108

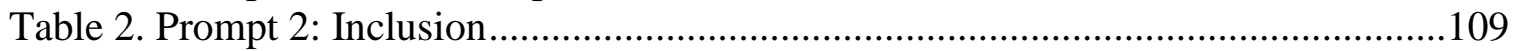

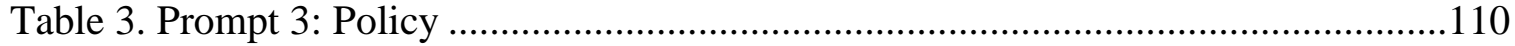

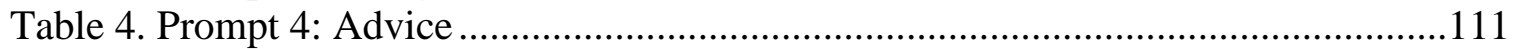

Table 5. Prompt 5: Inclusive Recruitment Flyer.......................................................111

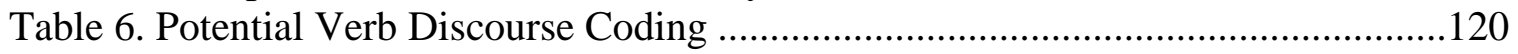

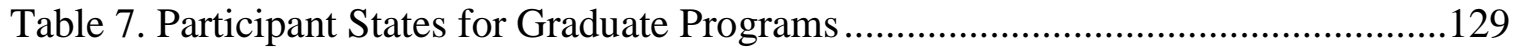

Table 8. Participant Year in Graduate Programs ...................................................130

Table 9. Minority Identity Markers of Participants ....................................................131

Table 10. Demographics for Non-Native English Speakers ........................................131

Table 11. Race and Ethnicity Demographics for Non-White Participants .....................132

Table 12. Socioeconomic Level of Participants .......................................................133

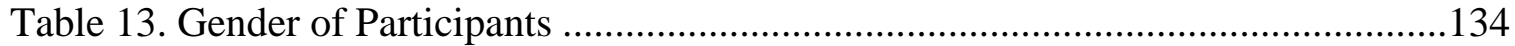

Table 14. Sexual Orientation of Non-Heterosexual Participants ....................................134

Table 15. Disability Types of Participants and Percentages of Total Participants With Disabilities .................................................................................... 135

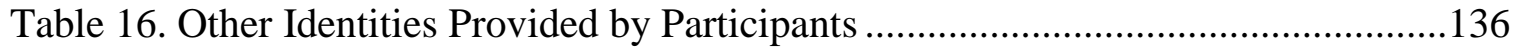

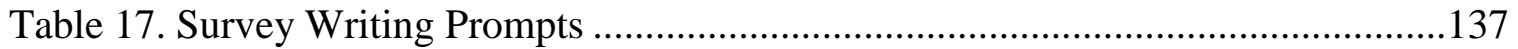

Table 18. Racial Microaggressions From Faculty ................................................... 144

Table 19. Racial Microaggressions From Peers .................................................... 145

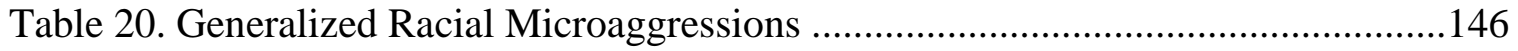

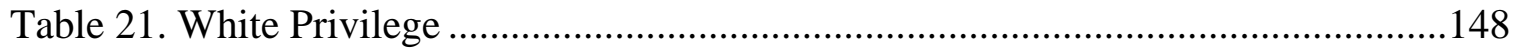

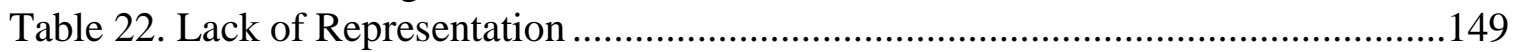

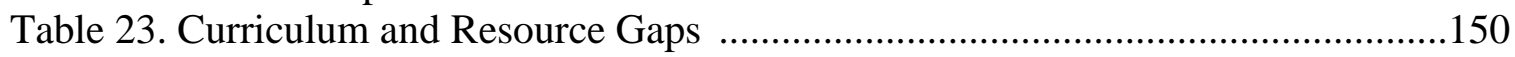

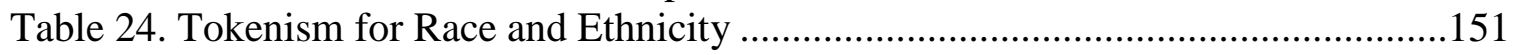

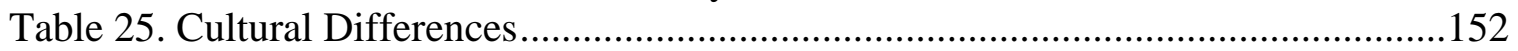

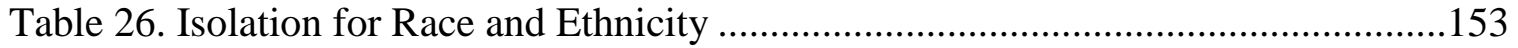

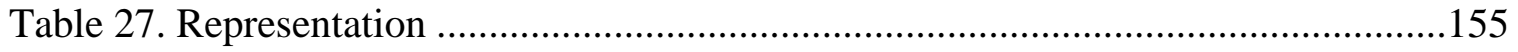

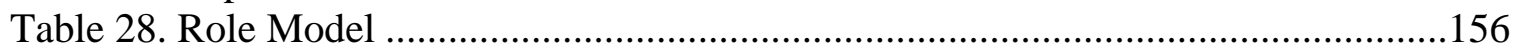

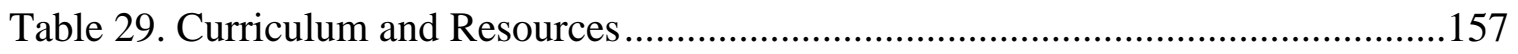

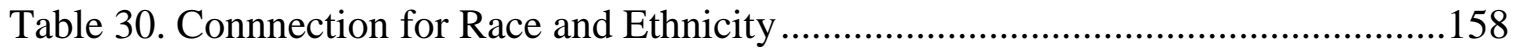

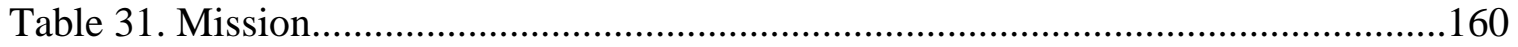

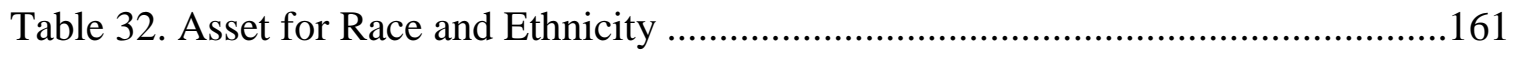

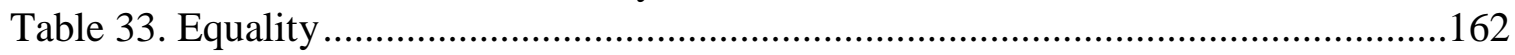

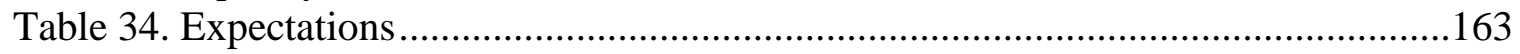

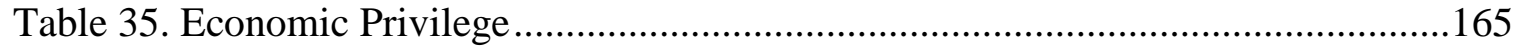

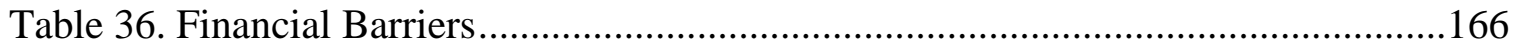

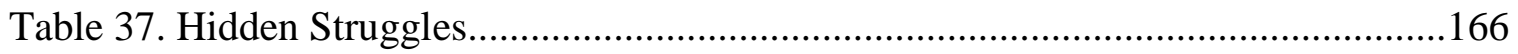

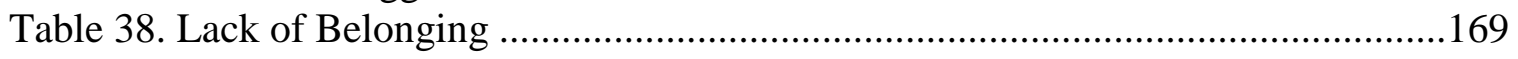

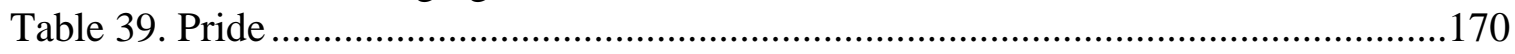

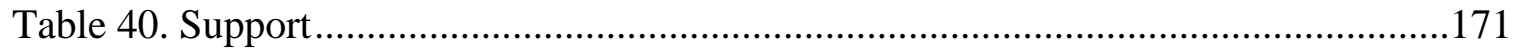

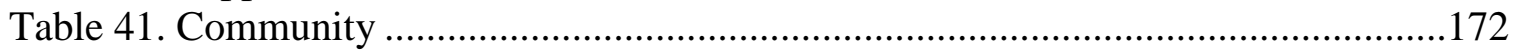




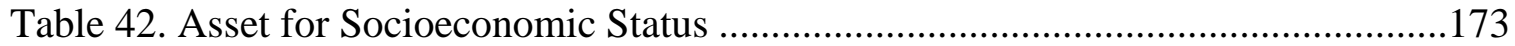

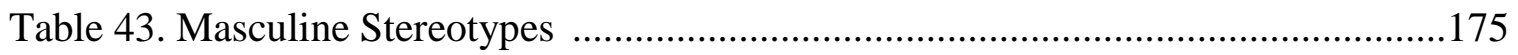

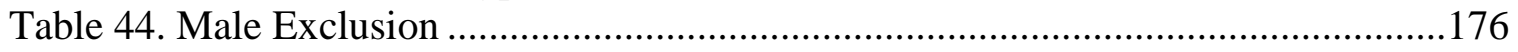

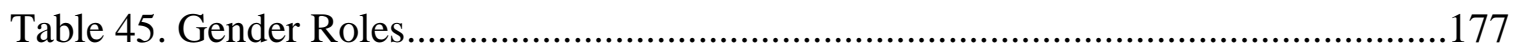

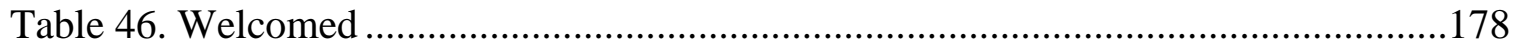

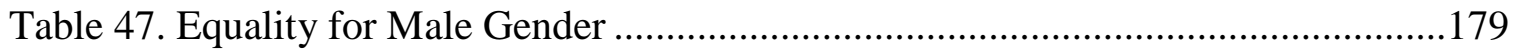

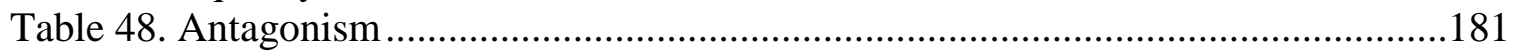

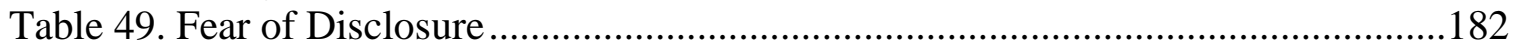

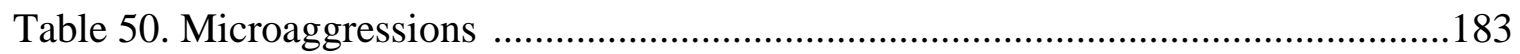

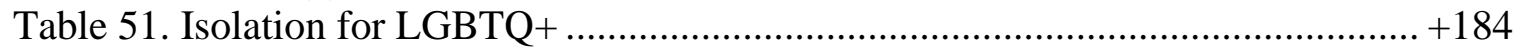

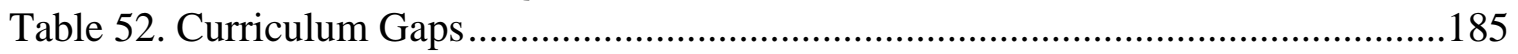

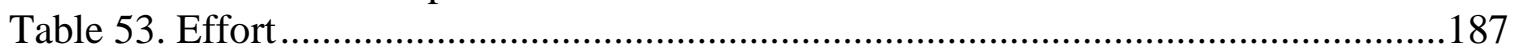

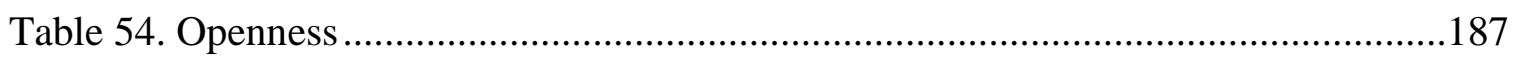

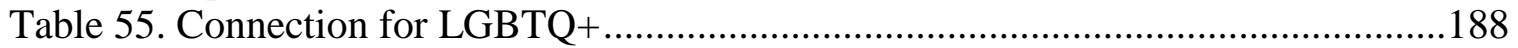

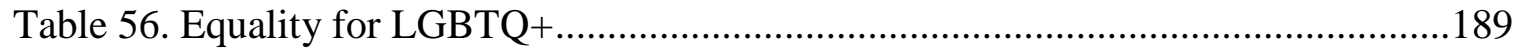

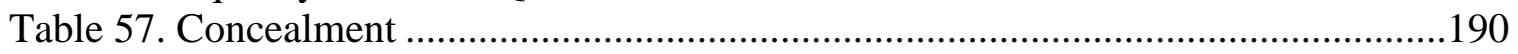

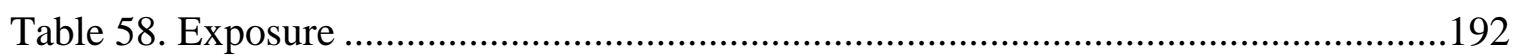

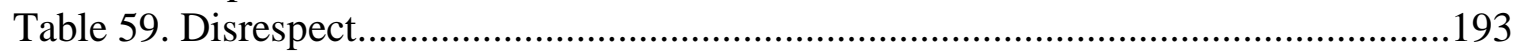

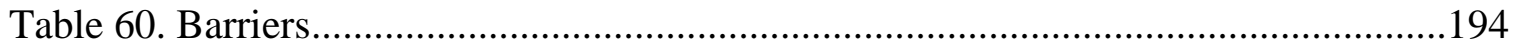

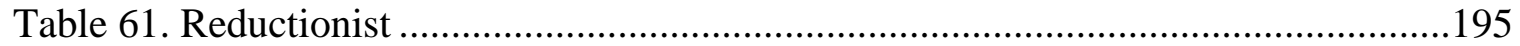

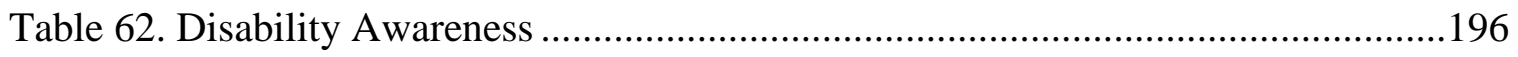

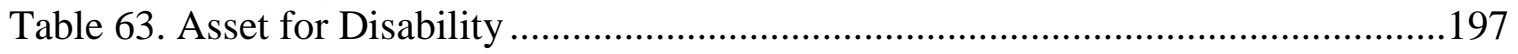

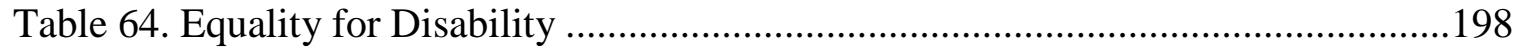

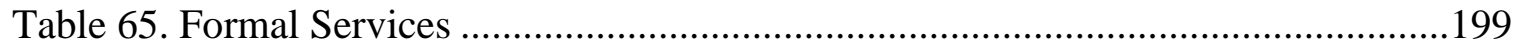

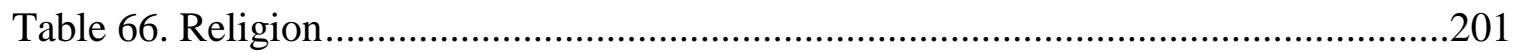

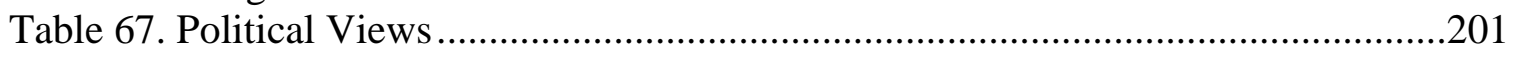

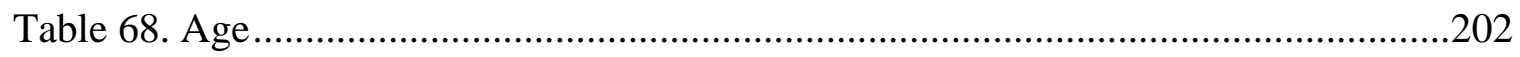

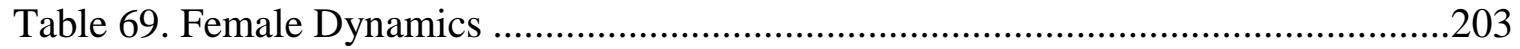

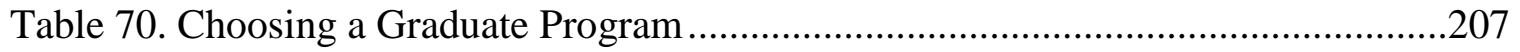

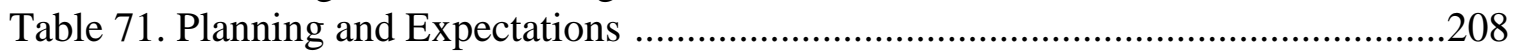

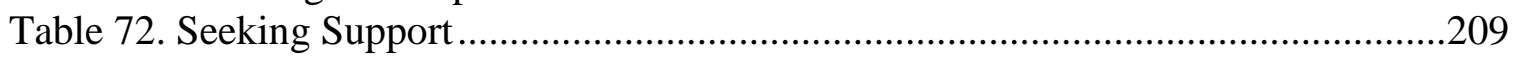

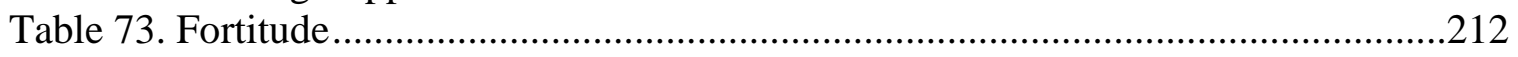

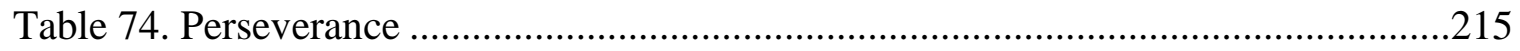

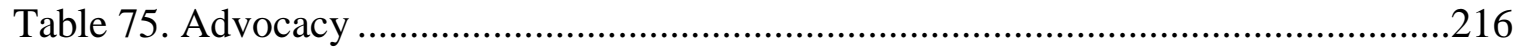

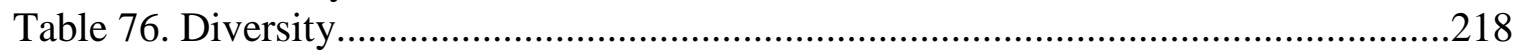

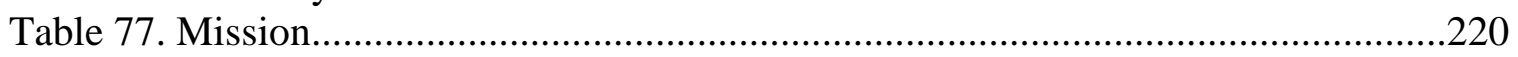

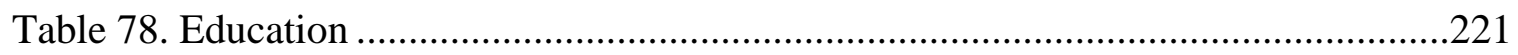

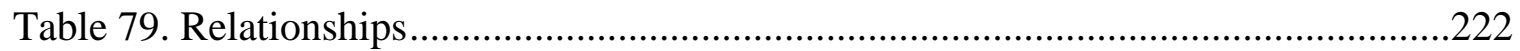

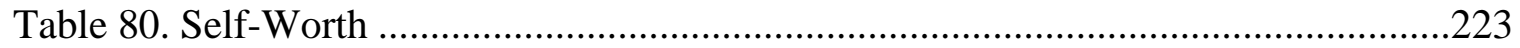

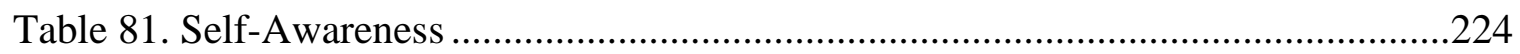

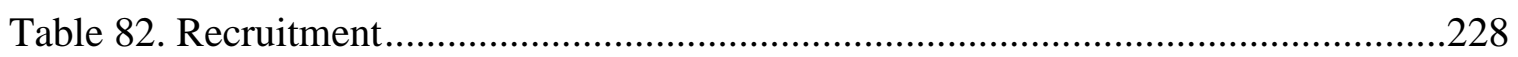

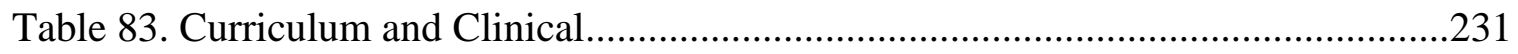

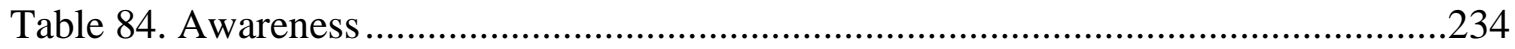

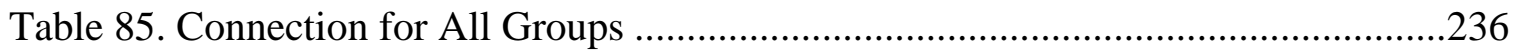




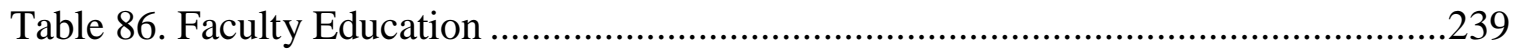

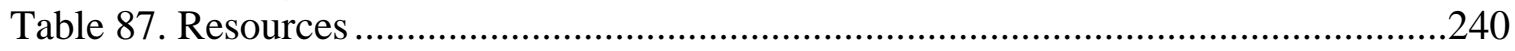

Table 88. Equality for Program Recommendations.................................................241

Table 89. Tokenism for Program Recommendations ...............................................242

Table 90. Discourse Analysis of Flyers Using Building Tasks ...................................247

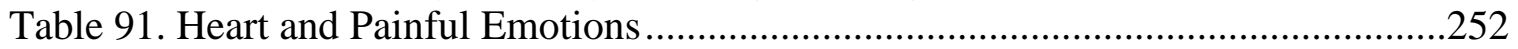

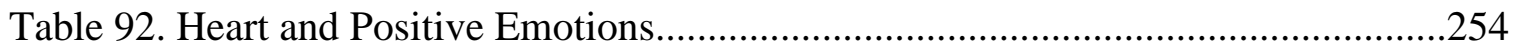

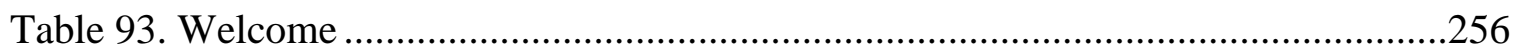

Table 94. Themes for Decreased Inclusion by Identity Groupings ...............................274

Table 95. Themes for Increased Inclusion by Identity Groupings...............................275

Table 96. Summary of Minority Student Themes in Relation to Research Questions ....276

Table 97. Themes for Race and Ethnicity.................................................................279

Table 98. Themes for Low Socioeconomic Background................................................300

Table 99. Themes for Males in a Female-Dominated Field .......................................308

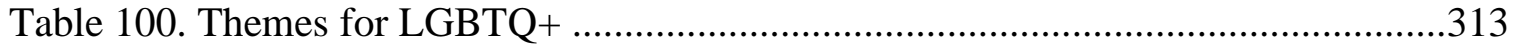

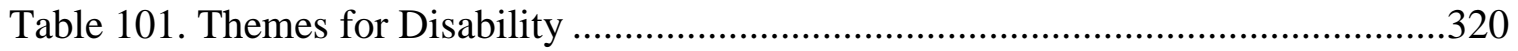

Table 102. Themes in Peer Advice to Another Minority Student .................................335

Table 103. Themes in Student Recommendations to Program ......................................343

Table 104. Summary of Minority Student Themes in Relation to Research Questions ..356

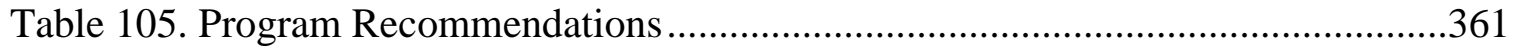

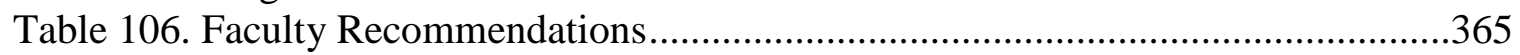

Table 107. Recommendations to Minority Students...................................................368 


\section{List of Figures}

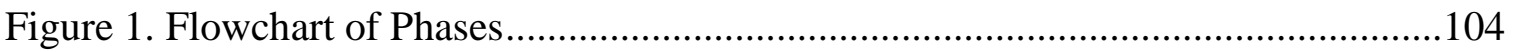

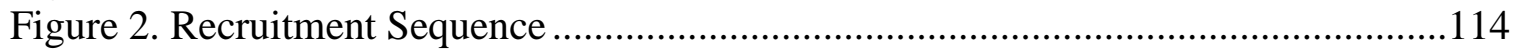

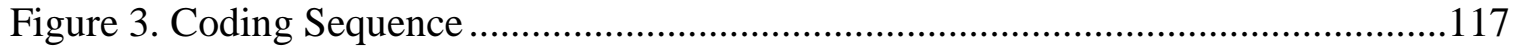

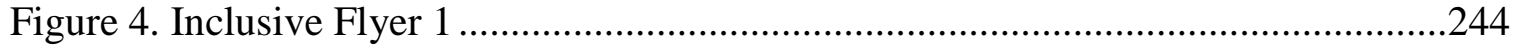

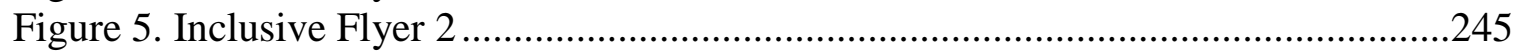




\section{Chapter 1: Problem Statement}

\section{Lack of Diversity Within Speech-Language Pathology}

Speech-language pathologists are specialists in communication, cognition, and swallowing disorders, and serve individuals from birth through end of life care. Speechlanguage pathologists provide therapeutic intervention for infants in neonatal intensive care units, children in elementary school, adults who have sustained a traumatic brain injury, seniors with dementia, and much more. For a profession that serves the general public across all ages and in varied settings, it is noteworthy in its lack of diversity. In 2013, the field of speech-language pathology was listed as the fourth whitest job in the United States by The Atlantic Magazine in their ranking of occupations that are more than 90\% white (Thompson, 2013). The demographics of speech-language pathologists are not reflective of the population of the United States. Although outreach and recruitment

efforts are likely making a difference, $92 \%$ of speech-language pathologists were listed as white in 2017 (American Speech-Language-Hearing Association [ASHA], 2017a), compared to the $94.5 \%$ reported in 2013 in the ranking by The Atlantic Magazine; ultimately changes continue to be needed. Along with the field being composed of one racial majority, it is also currently $96.3 \%$ female and predominantly monolingual English, with only $7 \%$ of the speech-language pathologists considered to be bilingual service providers (ASHA 2018f). Outreach for males in the field has not been fully successful, and the number of males in the field has generally remained constant, near 5\%, yet in some years has even declined (Maier, 2013). 
When considering race within speech-language pathology, the lack of diversity of speech-language pathologists is at odds with the rapidly changing demographics of the United States (ASHA, 2018c; Colby \& Ortman, 2015). The United States is projected to become a minority majority over the next 25 years, meaning that the number of people who are racial minorities will be above 50\% (U.S. Census Bureau, 2018). Issues of diversity are important at the national level. In 2001, the national ASHA (2019), the licensing organization for speech-language pathology, compiled recruitment and retention recommendations for racial and ethnic minorities in university training programs. These practices included increasing awareness of the profession, examination of potentially discriminatory admission procedures, expanding cultural diversity within curricula, mentoring and networking, along with other departmental and institutional factors. Materials are available for university faculty and the Office of Multicultural Affairs works to track the needs of minority members (ASHA, 2018i).

Targeting the identity markers of race and ethnicity is one aspect of lack of diversity within the field. Even though race is a significant factor in discussions of diversity, there are multiple identity markers that indicate a minority status within society. Intersectionality, which is the recognition that individuals hold more than one identity marker, contributes to the complexity of analyzing diversity (Sensoy \& DiAngelo, 2012). When examining differences from a critical social justice perspective that acknowledges structurally based inequities in society, Sensoy and DiAngelo (2012) considered stratification of social groups by race, class, gender, sexuality, and ability. Different groups receive benefits or privileges based on their social identity markers at 
the expense of other groups. Within the field of speech-language pathology, there is a lesbian, gay, bisexual, transgender, queer or questioning, intersex, asexual, pansexual, agender, and genderqueer (LGBTQ+) caucus that supports the needs of speech-language pathologists who are LGBTQ+ (L'GASP, 2019), though there is little data on the percentage of speech-language pathologists who identify as LGBTQ+. There is insufficient data available on socioeconomic status and ability. The lack of data on ability and disability is especially striking, especially considering that the field itself is dedicated to serving individuals with disabilities in the areas of communication, cognition, and swallowing.

When exploring a broader view of expanding diversity within the field of speechlanguage pathology, it is important to examine the training context for speech-language pathologists, as the entry level position in the field requires a master's degree program. Within academia, there has been a recent increase in the recognition of barriers to accessibility of higher education for diverse learners. Universal Design for Learning (UDL), a framework that originated in physical design for accessibility and uses research on cognitive functioning to promote inclusion, has been applied at the postsecondary level to support learners from diverse backgrounds (Meyer et al., 2014). Furthermore, UDL, when combined with critical theory, has been suggested to be a possible solution to addressing academic disparities that extend beyond ability, to include multiple minority groups, such as race/ethnicity, socioeconomic status, and more (Waitoller \& King Thorius, 2016). 
Efforts within the field of speech-language pathology in the area of diversity have resulted in research on recruitment and retention (ASHA, 2019) and the importance of multiculturalism in the training curriculum and clinical practice (ASHA, 2018e). Information is needed on the experiences of students from minority backgrounds within the field of speech-language pathology. Examining experiences in training programs through a UDL framework that accounts for inclusion will provide insight on the perceptions of students and how they view their own identity markers within the field. Gabel (2010) challenged the fundamental definition of disabled using a disabilities studies perspective that described how disability is a social construct with ideological and political underpinnings. Gabel described how educational policy should account for social context, content knowledge, and culture of inclusion. Using a UDL framework, inclusion represents access without the need to identify as having a disability. Inclusion can be extended to include access without needing to identify as a minority (Waitoller \& King Thorius, 2016.

In order to examine the lack of diversity in speech-language pathology, it is important to expand the issue across multiple minority groups. The mismatch between the diversity of the speech-language pathology field and the general population of the United States has inspired my study. The purpose of this study is to focus the discussion of lack of diversity on the experiences of minority graduate students within speechlanguage pathology and explore the implications of how they view themselves within the field. 


\section{Background of the Problem}

To understand the significance of the lack of diversity of clinicians within speechlanguage pathology, it is important to understand the scope of the profession, training requirement, demographic mismatches, and a history of multicultural research, efforts, and diversity initiatives within the field. The following section reviews the research on multicultural education within speech-language pathology and describe recommendations for university training programs on how to address the lack of student diversity. The national ASHA, which provides certification and training for speech-language pathologists in the United States, established an Office of Multicultural Affairs in 1969 to address the absence of cultural and linguistic diversity in the profession (ASHA, 2018h). The goals of their office included incorporating issues of multiculturalism into all operations of the association and advocating for clinical services designed to address pluralistic communities. Their tasks included tracking needs and access to services based on demographic data and contributing to association practice and policy documents. The ASHA created goals for the year 2025, which include inclusive policy and practice initiatives, diversity of perspectives, and recruitment of students from under-represented minority groups, including males (ASHA, 2018c).

\section{Speech-Language Pathologists}

In order to understand the importance of diversity within speech-language pathology it is essential to have a foundation in the scope of practice, including work settings and clients served, required training, and the historical background of the field in the United States. Speech-language pathologists (SLPs) provide assessment and 
intervention for individuals across the lifespan, from birth to end of life, to treat communication, cognition, and swallowing disorders (ASHA, 2010). Communication disorders include speech disorders, fluency disorders, language disorders, cognition, voice and resonance disorders, and hearing disorders (ASHA, 2016b). Speech disorders include articulation impairments with producing sounds and fluency disorders include stuttering. Language disorders may affect all aspects of language and include literacy development and alternative communication modalities. Voice and resonance disorders refer to challenges with producing speech at the level of the larynx and vocal folds. Swallowing disorders include the process of swallowing and atypical eating (ASHA, 2016b). Additionally, SLPs may provide services for accent modification for international speakers and transgender communication for individuals who are transitioning gender identities. The comprehensive nature of the field of speech-language pathology in both scope and populations served requires a professional graduate degree with specified coursework and clinical training.

Training. In the United States, SLPs are nationally certified through the ASHA (2016a). To become certified, prospective students must complete pre-requisite undergraduate coursework, a master's degree at an accredited institution, and a clinical fellowship year under the supervision of a certified SLP (ASHA, 20176a). SLPs work in educational, medical, and private practice settings (ASHA, 2017a). In the educational setting, SLPs work with children from birth through age 21. In the medical and private practice settings, SLPs may work with individuals of all ages providing services for clients with a wide range of diverse backgrounds. 
History of the Profession. Although speech correction has existed in varied forms since early civilizations, it is a relative new profession in the United States (Duchan, 2011). Historically, the ASHA, the licensing board for SLPs in the United States, was founded in 1925, and evolved from its origins in speech correction, education, and elocution to its present form (ASHA, 2017b; Duchan, 2002). An early group of 15 women and 10 men, many of who were affiliated with university departments in communication, education, and psychology, formed the American Academy of Speech Correction, which eventually became the ASHA. Certification requirements that included a master's degree with specified coursework were initiated in 1965. Certification requirements were gradually increased to delineate specific course content material and to include a greater number of clinical practicum hours in providing intervention and assessment under the supervision of a licensed SLP (ASHA, 2018d). The field of speechlanguage pathology has required a graduate degree for 53 years (ASHA, 2017b, Duchan, 2002).

Demographic Comparisons. Approximately 55\% of SLPs work in educational settings, which serve children from birth through adult transitional services, and 39\% work in medical settings, including hospitals, skilled nursing facilities, and other health settings for children and adults. Although the U.S. Census Bureau (2018) noted that the current population is more than 50\% white, their statisticians predict that by 2044 the number of people who identify as white will drop below 50\%. Within the educational setting, racial demographics of public school children have changed with the number of children who are white decreasing from $62 \%$ to $53 \%$ between 2000 and 2013, and a 
corresponding increase in children from most other racial and ethnic groups (MusuGillette. 2016; National Center of Education Statistics [NCES], 2016e). According to the National Institute on Deafness and Other Communication Disorders (2016a), approximately $8 \%$ of children in the United States have a communication or swallowing disorder. SLPs who work in educational settings and in pediatric medical settings serve children with communication and swallowing disorders from a range of racial and ethnic backgrounds.

The demographic profile of SLPs is relatively homogenous in comparison to the general population in the United States. Of the almost 200,000 nationally certified SLPs, more than $90 \%$ are white, female, monolingual speakers of General American English (ASHA 2017a; ASHA 2018f). Additionally, even though SLPs serve individuals with disabilities, current demographics on the number of certified SLPs who report having a disability is not readily available. Based on the lack of data and discussion of SLPs who have disabilities in both the research and professional literature, if there is a significant proportion of SLPs with a disability, they are not represented.

Overall information about the general prevalence of adults with communication disorders in the United States across all areas of communication and swallowing is unreliable due to the varied types of both developmental and acquired disorders, variations in diagnostic criteria across settings, and other factors. Communication disorders are impairments that affect the ability "to receive, send, process, and comprehend concepts or verbal, nonverbal and graphic symbol systems" (ASHA, 1993, para. 2). Frattali and Lux (1998) described how The International Classification of 
Impairments, Activities, and Participation classified disorders and diseases as impairments when there is "a loss or abnormality of body structure or of a physiological or psychological function" (p. 7). According to Goering (2014), disability represents lack of advantages or the presence of restrictions that reduce access to participation in daily activities and social opportunities. The National Institute on Deafness and Other Communication Disorders (2016b) provided estimates on specific disorders, and reports that more than 7 million people have voice disorders, 3 million people have a fluency disorder, such as stuttering, 400,000 people have autism, and up to 8 million people have a language disorder. Communication, cognition, and swallowing disorders may affect any individual at any point within their lives.

The demographics of SLPs are not congruent with national census data of the United States (U.S. Census Bureau, 2018). Differences between the racial and ethnic demographics of SLPs and the clients who they serve has the potential to affect cultural responsiveness and appropriateness of care, as well as lack of awareness of the needs of diverse populations (ASHA, 2017c). The lack of information about ability and disability in the SLPs population may also be a concern. Even though SLPs serve individuals with disabilities, the field itself is primarily composed of individuals who identify as nondisabled, who may lack an understanding of the experiences of individuals with disabilities. Furthermore, the predominance of females within the field of speechlanguage pathology is not reflective of the gender distribution of the general society and the clients served. This lack of diversity is a problem because there is an absence of frame of reference and context to serve clients from diverse backgrounds and differing 
abilities. The predominantly single perspective based on the experiences of white, female SLPs may restrict alternate interpretations and understandings of communication, cognition, and swallowing disorders by minority groups.

Diversity. Within the field of speech-language pathology, it may be necessary to examine diversity of clinicians across multiple areas, including race and ethnicity, socioeconomic status, gender, LGBTQ+ and ability as underrepresented identity markers (Sensoy \& DiAngelo, 2012). The lack of diversity may be problematic across multiple domains of research, policy, and clinical practice (Litosseliti \& Leadbeater, 2013). When a field is relatively homogenous and composed of members of a dominant majority, members may not have an intrinsic understanding of the importance of exploring of the needs of diverse communities. To address the problem of lack of diversity of speechlanguage pathology, it is important to examine the postsecondary settings in which prospective students seek to enter the field. Since certification in speech-language pathology requires success in college and an advanced degree, the experiences of all United States college students who are from minority backgrounds may be directly applicable to an examination of the specific experiences of students within speechlanguage pathology. Exploring aspects of diversity, multiculturalism, acceptance, and inclusion for graduate speech-language pathology students in master's programs will provide information about potential changes that may be needed in these training programs. Addressing the problem of lack of diversity is essential to ensure balanced perspectives of the needs of clients from minority backgrounds. When recommendations for cultural considerations for clinical services are created without significant 
representation of minority groups, there is a risk of lack of understanding of needs, and ultimately perpetuating pre-existing inequities between dominant and minority groups.

\section{Purpose}

The purpose of this research is to describe how minority graduate students enrolled in speech-language pathology training programs experience inclusion and the factors that promote inclusion within their graduate training programs. Although it is also important to understand why they entered the profession, and recruitment for student diversity, this study focuses on the time period in which students are receiving their formative academic and clinical training. The experiences of minority graduate students are directly related to both their education environment and the larger discipline. Understanding their experiences is necessary to shape advancements in the field to increase diversity in order to serve clients from diverse backgrounds. My goal was to examine the dynamic between minority speech-language pathology graduate students' identity markers and how they have been affected by their training programs. Focusing on demographic data alone would not have fully captured the complexity of experiences of minority graduate students within speech-language pathology. I considered the influence of training programs and the field of speech-language pathology itself on historically marginalized groups. I examined experiences of minority speech-language pathology graduate students in order to better understand factors that increase inclusion in order to improve clinical practice in serving diverse populations. 


\section{Multiculturalism Within the Association}

The ASHA (2018e) roles and responsibilities and ethical considerations for SLPs, in the area of cultural competence, focus on culturally responsive practices across domains of clinical practice, including diagnosis and treatment for communication, cognition, and swallowing disorders. The ASHA (2018i) Office of Multicultural Affairs provided resources for faculty on teaching about multicultural and multilingual courses to support the ASHA (2016a) standard for graduate practicum experiences with clients from culturally and linguistically diverse backgrounds. Ethical guidelines cover the importance of understanding cultural and linguistic differences and non-discrimination based on minority status and individual identity. Additionally, the ASHA's (2018c) leadership and governance addresses multiculturalism through the Multicultural Issues Board, which provides input on strategic planning in the areas of cultural and linguistic diversity, and serving historically underserved and underrepresented populations.

\section{Statement of the Research Problem}

In the previous section, I discussed the context of speech-language pathology in regard to clinical practice, required training, history of the profession, and multicultural initiatives. This section delineates the purpose and reasoning for the study and its ability to contribute to promoting diversity within the field. Although there is consensus in the need for multicultural topics with speech-language pathology, many efforts have primarily addressed clinical training on serving clients from diverse backgrounds for a homogenous group of SLPs (ASHA, 2018h). Efforts on outreach and recruitment may also be limited due to a lack of knowledge of the experiences of minority speech- 
language pathology graduate students. My view is that the field itself will benefit from an examination of how graduate students who are minorities within speech-language pathology experience inclusion within training programs. The purpose of my study is to describe how minority graduate students enrolled in speech-language pathology training programs experience inclusion and the factors that promote inclusion within their graduate training programs.

\section{Context of the Problem}

This research focused on minority graduate students in ASHA accredited speechlanguage pathology training programs in the United States and its territories. As a starting point in discussions of diversity, the lack of racial diversity within the field of speechlanguage pathology is in direct contrast to the general demographics of individuals served. This incongruence between the national percentage of the population that is white, which is $76.6 \%$, the changing demographics of the country, and the need to provide services for clients from diverse backgrounds, made the experiences of minority graduate students important (U.S. Census Bureau, 2018). Although the racial and ethnic mismatch between clinicians and clients was concerning, a broader perspective of identity was needed. When considering other markers of minority identity within society, lack of clinician diversity can be expanded across identities, as is described in upcoming sections. Findings are relevant to graduate programs that seek to provide inclusive settings that promote recruitment and retention of students from minority backgrounds. Additionally, as a minority faculty member, I am interested in seeking information from 
graduate students to inform policy and practice in graduate programs that could improve teaching and clinical supervision.

\section{Evidence That the Problem Exists}

The field of speech-language pathology cannot ignore the need to serve clients from diverse backgrounds, the predicted demographic changes in the United States, and the lack of diversity of clinicians (ASHA, 2018e). Although significant research has been conducted to foster cultural understanding, the underrepresentation of minorities within the discipline significantly limits the perspectives of minority groups (ASHA, 2018h), When minorities are not present within research agendas, formation of policies, and guidelines for clinical practice, the needs of these groups may not be included (Litosseliti \& Leadbeater. 2013). In other words, designing studies, mandating regulations, and enforcing guidelines from the perspective of one dominant group, are restrictive. When considering this issue from a social justice perspective, the views of minorities are essential for change (Sensoy \& DiAngelo, 2012). If diversity is truly a value within speech-language pathology to provide services to minority clients, then addressing the lack of diversity of the discipline must be included (Litosseliti \& Leadbeater, 2013).

\section{Significance of the Problem}

This section highlights the educational and societal significance of this research. The purpose of this research is to describe the experiences of minority graduate students in speech-language pathology programs in relation to inclusion. In the previous sections, I explained the importance of the issue of lack of diversity within speech-language pathology. I investigated the history of the field, the incongruence between the 
demographics of the clinicians and the clients they served, and the potential inability to understand the perspectives of minority clients. In this section, I continue to explore the importance of addressing the problem involving lack of diversity in speech-language pathology and what it means for the discipline.

A lack of diversity within the field of speech-language pathology limits discussions on issues of identity and power for minority groups within society, who have historically been designated by race, class, gender, sexuality, and ability (Sensoy \& DiAngelo, 2012). The lack of racial diversity may inhibit the ability of SLPs to understand how “awareness of ones' own privileges increases sensitivity to client perspectives" (Ebert, 2013, p. 68), and that holding privilege plays a role in clinical interactions. In the area of class, the fact that a SLP must obtain a master's degree means that access to postsecondary education and the supports and resources needed for advanced studies are required. Socioeconomic status, specifically a low-income background, is frequently associated with risk factors in postsecondary learning (Scott et al., 2003). Lack of representation of clinicians from low-income backgrounds, who are aware of the needs of clients with differing levels of socioeconomic status, is problematic. Clinicians who do not understand healthcare access, barriers to care, and historical healthcare disparities, may not have a thorough sense of their role in the provision of clinical services. The predominance of females within the field could be considered a disadvantage in clinical, professional, and research domains, specifically, serving male clients, examining professional issues related to gender, and societal recognition of scientific and analytical bases for services (Litosseliti \& Leadbeater, 
2013). Disadvantages in clinical services may be related to difficulties recognizing the life and relationship concerns of adult male clients, as well as challenges with motivating and serving as role model for younger male clients.

The lack of diversity of SLPs who identify as part of the LGBTQ+ community is a risk factor for further isolating the LGBTQ+ community and LGBTQ+ clients from medical and educational services (Frazier, 2009; Steckly 2009). In the area of ability and disability, the lack of data of SLPs who identify as having a disability is important in how the discipline views the construct of disability and attitudes toward individuals with disability. Challenging the biomedical model of disability and examining beliefs about expertise as opposed to honoring the experiences of individuals with disabilities as knowledgeable of their needs are important in forming collaborative partnerships with clients (Baladin \& Hines, 2011; Hutcheon \& Wolbring, 2012).

When considering the homogeneity of the field and lack of SLPs who identify as minorities, greater issues arise. Being a member of a professional discipline involves interaction with others that has the potential to alter the direction and goals of the entire organization. The lack of diversity has the potential to affect leadership and changes within the field. Within organizational systems, complexity theory describes leadership as a dynamic and interactive process where multiple different agents interact to create novel behavioral patterns and operational systems (Uhl-Bien et al., 2007). Complexity theory uses socially constructed contexts where a variety of agents may alternatively serve in a leadership role by influencing outcomes. Uhl-Bien et al. (2007) asserted that "the continuous creation and capture of knowledge" (p. 301) is a goal for organizations in the 
Knowledge Era, an era that encapsulates global perspectives, prevalence of technology, and an emphasis on speed of learning. Complex systems are not understood by an analysis of component elements, as each agent within the system is sensitive and responsive to the beliefs and behaviors of other agents, and each agent contributes to unexpected change (Uhl-Bien et al., 2007). People are not independent of each other they are constantly changing each other through their interactions. Complexity theory describes a multi-causal approach to events and does not specify predetermined discrete outcomes. A given outcome may be the result of the interaction of a variety of factors. Having a group that consists of agents with a shared background and shared worldview may substantially limit the potential growth of new perspectives. The field of speechlanguage pathology is composed of individuals who have similar backgrounds, who may not contribute novel or unexpected changes to the status quo backgrounds (ASHA, 2017a). Restrictions in the range of beliefs and worldviews of members, who will all likely move through different experiences of being agents in changing behavioral patterns of practice, may subsequently limit the types of developments that could emerge within the field. In other words, homogeneity of members is equal to homogeneity of leadership agents, which shapes the direction and extent of change in clinical practice, procedures, and policies, academic instruction in training programs, research, and societal awareness of the field as a whole. The potential lack of novel ideas may be significantly detrimental, especially when attempting to address the needs of clients from diverse backgrounds. 


\section{Presentation of Methods and Research Question}

The following section identifies methods to answer questions relevant to the problem of lack of diversity within speech-language pathology. I briefly describe the methods that were used to address my research questions. The field of speech-language pathology frequently attempts to improve service to clients from diverse backgrounds by examining the experiences of clients, as opposed to examining the field itself. Although client experiences are highly important, other perspectives are needed (ASHA, 2018e). This study changed the direction of research on serving clients from diverse backgrounds to focus inward on the field itself through the perspective of speech-language pathology minority graduate students. An understanding of factors that increase inclusion for minority graduate students in their training programs provides insight into the common beliefs, design, and behaviors of the field. I conducted a qualitative study that aimed to explore the experiences of inclusion for speech-language pathology minority graduate students in their training programs in the United States and its territories. For this study, I used open-ended, exploratory writing prompts in an online survey format to examine positive experiences of inclusive, policy recommendations to promote inclusion, and advice to another minority student.

Qualitative methods are better suited to examine and understand participants' experiences as minority graduate students within a homogenous field (Maxwell, 2013). Qualitative research allows for a critical analysis of power disparities and how these disparities may be enacted within social values (Brantlinger et al., 2005). Stories from people's lives as an inquiry strategy show a construction of reality and lived experiences 
(Creswell, 2014). Implementing a critical discourse analysis approach within this qualitative research allowed for the ability "to speak to, and perhaps intervene in, institutional, social, or political issues, problems, and controversies in the world" (Gee, 2014, p. 9). This study focused on minority graduate students' experiences and their recommendations around inclusion. From a critical justice perspective, minority groups have been historically excluded from larger discussions of societal design and institutional practices (Sensoy \& DiAngelo, 2012). The decision to use qualitative methods centers the research on underrepresented voices. I was interested in understanding the factors that increase inclusion for speech-language pathology minority graduate students, as well as ways to create these inclusive environments. Changes to the learning and social environments of graduate programs to increase inclusion and foster diversity have the potential to alter the direction of the entire field, as graduate students are future clinicians, researchers, and policy makers. Recommendations that positively shape inclusion during graduate school could have long-lasting effects that will improve client outcomes.

For the purposes of this study, a reliance on quantitative methods would have been inadequate in representing factors and themes within minority graduate students' experiences primarily due to statistical considerations and available sample sizes of minority graduate students. The goal of this research was to bring the voice of minority graduate students into the examination of the ideologies of speech-language pathology that they experience in their training programs. This topic lent itself to personal experience and recommendation prompts as a mode of research because it provided 
insight into the shared qualities of a phenomenon within a specified context, in this case, the phenomenon of inclusion within a homogenous field (Brantlinger et al., 2005). Using information from personal experiences and recommendations encouraged minority graduate students to craft their own meaning from their experiences. Analyzing written text using discourse analysis methods showed political elements embedded in language use and how identities were enacted for specific social purposes (Gee, 2014).

My goal was to highlight the views of minority graduate students in speechlanguage pathology programs with the potential of influencing future research, policy, and practice directions in diversity and multiculturalism. Analyzing the experiences of inclusion for minority graduate students in speech-language pathology using personal experience and recommendation prompts generated multiple forms of data and focused the data on different levels that addressed institutional, social, and cultural aspects. I examined themes in the data and reported on my findings of experiences related to minority identity markers. I used discourse analysis to examine identity of individuals within organizations and uncover the order of social practices within speech-language pathology training programs to describe how they affected minority graduate students. My research questions were as follows:

1. What is the experience of inclusion for minority graduate students in speechlanguage pathology training programs in relation to systems (university, field of study, department), context (classroom and social settings), and interaction (faculty, staff, community, and peers)?

2. What are the recommendations of minority graduate students in speechlanguage pathology training programs to increase inclusion to address the lack of diversity in the field?

3. How do minority graduate students in speech-language pathology training programs envision inclusion in the field? 


\section{Definition of Key Terms}

The following are key terms defined to assist in understanding the key constructs used in this research.

SLP [Speech-language pathologist]. In the United States, SLPs have received a master's degree and national certification through the ASHA (2018g). A master's program includes coursework, clinical practicum placements, and knowledge and skills standards. Additionally, many SLPs hold licenses from state licensing boards and state educational agencies. There are differences between how states address licensing (ASHA, 2018b) with some states requiring only a state license and some states requiring a state license and an educational license for all SLPs who practice in public school settings (ASHA, 2018g). Speech-language pathologists must maintain licensure by completing requisite continuing education hours (ASHA, 2018g). Speech-language pathologists work in educational, medical, and private practice settings. According to ASHA (2017a), Member Counts survey data, $39.2 \%$ of SLPs, are in health care settings and $54.6 \%$ are in educational settings, and $74.4 \%$ are clinical service providers, who work directly with clients.

Communication, cognition, and swallowing disorders. Communication disorders affect all aspects of speech production, including articulation, fluency, and voice, all aspects of language use and understanding, hearing, and alternative communication modalities (ASHA, 1993). Cognition disorders affect attention, memory, emotional regulation, judgment, and self-awareness (ASHA, 2003). Swallowing disorders represent problems with the biomechanics of swallowing (ASHA, 2018a). The ASHA (2016b) has 
used a biomedical model to label and categorize the presence of a disorder. A biomedical model requires evidence of a disability through an individual's interaction with the medical system, a medical assessment, and a document that represents a sociological documentation of a diagnosis (Hutcheon \& Wolbring, 2012). The biomedical model establishes power relationships between individuals and the medical community and requires that individuals accept the institutionalized definition of disability in order to receive services (Hutcheon \& Wolbring, 2012). This model is further exemplified within legal frameworks that contain political aspects of privilege and access. The biomedical model establishes institutionalized definitions of disability and how disability is differentiated from normalcy.

Training program in speech-language pathology. The Council on Academic Accreditation (2018c) enforces standards for accreditation of all graduate education programs in speech-language pathology in the United States. The ASHA first formed a board of examiners for speech-language pathology in 1959, and initially outlined requirements for educational training programs starting in 1964. The Council on Academic Accreditation (2018a) was established in 1996 and has outlined and enforced requirements since 1999. All training programs in speech-language pathology used in this study met the requirements of the Council on Academic Accreditation.

Minority within speech-language pathology. The designation of minority status is based on identity markers of minorities using a social justice perspective (Sensoy \& DiAngelo, 2012), and in comparison with the demographics of the field of speechlanguage pathology. Minority social groups are established in society by race, class, 
gender, sexuality, and ability (Sensoy \& DiAngelo, 2012). Within speech-language pathology, males, when defined using a binary construct of either male or female gender, have a privileged minority position. This means that although they are a demographic minority in a female dominated profession, they still hold social power within society (Sharatta et al., 2015). For the purposes of this study, recruitment focused on minority students as defined with student self-identification of race as non-white, class as lower socioeconomic status, gender as male or non-binary, LGBTQ+, and disability. Selfidentification allows for independent assessment of one's own identity markers that are not dependent on an external institution or authority ascribing an identity. Participants self-identified in the areas of racial minority, having experienced a low-income background, gender, LGBTQ+ community, and disability. Self-identification encourages an acknowledgement of intersectionality in minority status, when an individual holds more than one minority identity marker (Sensoy \& DiAngelo, 2012). Intersectionality also encapsulates the ways in which identity markers hold different levels of privilege within society, and how an individual will simultaneously receive privilege for one identity marker, while not for another identity marker, such as privilege for gender, but not for race, or vice versa (Senory \& DiAngelo, 2012). Although this study did not specifically address intersectionality of participants, the use of multiple minority identity markers and the broad view of diversity were part of honoring intersectionality for student identity. Allowing for self-identification recognized the multiple identities that participants held, and contributed to an understanding of shared needs and concerns in relationship to inclusion. 
Inclusion. The concept of inclusion is founded in educational services for individuals with disabilities and includes participation in general education activities (Individuals With Disabilities Act [IDEA], 2004). At the postsecondary level, Baer et al. (2003) reviewed the literature on transition activities for individuals with disabilities and found a positive relationship between inclusion within general education academics and positive post-school outcomes, with inclusion described as access to academic content and typically developing peers. Joshi and Bouck (2017) examined how inclusion in general education classes for students with disabilities was related to postsecondary education and provided recommendations for increased inclusion. Although inclusion within the field of special education has represented individuals with disabilities participating in general educational environments, the concept of inclusion has expanded to encompass minority groups, and also represents the inclusion of race and ethnicity and multiculturalism into academic content (Gay, 2002). Inclusion is a component of culturally sustaining pedagogy, and "includes all of the languages, literacies, and cultural ways of being that our students and communities embody - both those marginalized and dominant" (Paris, 2012, p. 96). At the postsecondary level, inclusion for disabilities has primarily been addressed through UDL, described below. A broad view of inclusion represents the needs of multiple minority groups through participation and access, and the inclusion of multiculturalism content and perspectives within graduate training programs in speech-language pathology (Waitoller \& King Thorius, 2016).

UDL (Universal Design for Learning). UDL is a teaching framework that originated from universal design in architecture that strived to design accessible buildings 
and physical structures for a range of user and user needs. Meyer et al. (2014) founded UDL with the emphasis on learning using neuro-scientific research on cognitive functioning with the goal of supporting learners with a range of needs. UDL promotes flexible instructional methods that include multiple means of representing content, learner action and expression, and learner engagement. UDL strives to make practices that are needed for individuals with learning challenges available to all learners, as they benefit everyone's access to education (Meyer et al., 2014). UDL has been touted as a way to make academic content more accessible to college students who are experiencing learning challenges. Using principles of UDL may increase student engagement and access to content material (Lenz \& Deshler, 2004).

The flexible options in UDL ensure different representations of information with varied ways to access academic content and foster learner engagement, as well as a range of choice for demonstrating knowledge and skills (Meyer et al., 2014). Smith (2012) described how UDL is grounded in proactive course design and focuses on the learning environment, instead of retroactively making changes to meet the needs of given learner characteristics. Research has shown gains in postsecondary students' interest and engagement when faculty use UDL practices (Smith, 2012). As a framework, UDL examines environment, as opposed to individual differences between learners. The proactive elements and the environmental focus of UDL are important in understanding inclusion in the learning environment for minority students in speech-language pathology graduate training programs. 
Privilege. According to Sensoy and DiAngelo (2012), privilege represents certain social and institutional rights, advantages, and protections that are granted to all members of a dominant group automatically based on the position of that group within society. Sensoy and DiAngelo described different types of privileges. Privileges can be external in the design of physical environments, such as stairs that assume levels of mobility, and are not accessible to individuals who use a wheelchair. Privileges can be structural, such as the design of social categories that sort what is considered to be normal or abnormal within society. Internal privilege is when members of a dominant group believe that they have the right to their position and superiority. Attitudinal privilege represents the lack of humility about rights and advantages, as well as the invisibility of privilege.

Within the field of speech-language pathology, Kohnert (2013) described white privilege within speech-language pathology. Kohnert described privileges afforded to white, female graduate students based solely on their status as the demographic majority in the field. If you are a white, female speech-language pathology student then you are similar to the majority of speech-language pathology students in terms of race and gender. This similarity in identity markers brings privileges into classroom, research, and clinical practice (Kohnert, 2013). Specifically, in classroom settings, there would not be any assumptions of not being deserving of admittance into a competitive program based on appearance. In contrast minority graduate students may be affected by bias that their presence is due to a form of affirmative action and not individual merit. In research, privilege comes in the form of having research studies using white as "the standard of comparison. Everything else is specified as some form of 'diversity' issue and considered 
on the margins of mainstream research, teaching, and clinical practice” (Kohnert, 2013, p. 43). In clinical practice, privilege comes from being assumed to be friendly and accessible to clients based on race and gender, as opposed to being viewed as different or someone to be feared. Kohnert advocates for the acknowledgement of privilege within speech-language pathology and the ways that it is reinforced. Recognizing the role of privilege and how it has the potential to increase or decrease inclusion is important in addressing diversity within speech-language pathology. 


\section{Chapter 2: Literature Review}

In the prior chapter, I analyzed the contextual aspects and the boundaries for research in the experiences of graduate students who identify as minorities within speechlanguage pathology training programs. I explored how this problem has educational and clinical significance. The purpose of this research is to understand how graduate students who are minorities within speech-language pathology experience inclusion within their training programs.

This chapter provides a review of the literature relating to diversity within the field of speech-language pathology, along with common experiences of postsecondary students from minority backgrounds. This chapter focuses on the following areas: (a) theoretical framework of the research, (b) literature regarding diversity within speechlanguage pathology and its relationship to postsecondary students from minority backgrounds, and (c) literature in the area of inclusion within academic programs. A rationale for research and methodology is presented at the conclusion of this chapter.

\section{Theoretical Framework}

This section presents the relevant theoretical framework for this research, as well as its rationale, implications, and a critique of its use.

\section{$U D L$}

Within the field of education, there has been an increase in understanding of the importance of diversity and ways to address the needs of learners from diverse backgrounds. UDL is a framework that is founded on neuro-scientific developments of 
cognitive functioning to support diverse learners (Meyer et al., 2014). UDL uses flexible instructional methods for multiple means of representing content, multiple means of learner action and expression, and multiple means of learner engagement. UDL promotes incorporating instructional practices that are "essential for some [because they are] good for all” (Meyer et al., 2014, p. 6). UDL has been applied at the postsecondary level and is a potential solution to the problem of how to make courses more accessible to college students who are experiencing learning challenges. Increased use of principles of UDL may facilitate student engagement and understanding of content material (Lenz \& Deshler, 2004).

UDL uses flexible options to represent information and access academic content, foster learner engagement, and demonstrate knowledge and skills (Meyer et al., 2014). Smith (2012) described how UDL anticipates and addresses learner variability in course design. UDL shifts the focus of disability from the individual to the environment. UDL may improve students' learning experiences within the classroom and access to academic content. Smith reported on positive student and faculty responses with the use of UDL, specifically in the area of student interest and engagement. UDL may positively influence students' understanding of the modifiability of their own learning capabilities.

Furthermore, Waitoller and King Thorius (2016) considered UDL to be an inclusive pedagogy that has the potential to become an emancipatory pedagogy when combined with culturally responsive practices. An inclusive pedagogy is based on designing a learning environment for a range of learner identities, while an emancipatory pedagogy frees students from the constraints of societal markers of identity. UDL works to promote 
inclusion through accessible design of learning environments for students from minority backgrounds (Meyer et al., 2014).

The economic demands for individuals to graduate from college and the growing diversity within society have significantly increased the range of diversity across university campuses. UDL represents inclusive instructional practices with flexible means to address diverse learning styles in the presentation of information, activities, and assessment methods. UDL is an inclusive pedagogy that plans for a range of learner needs through proactive course design to substantially improve outcomes for many students, especially students with disabilities (Meyer et al., 2014).

The purpose of this section is to analyze how UDL, as an inclusive framework, may contribute to postsecondary students' access to academic content, engagement, and self-perceptions of learning ability within speech-language pathology. This section reviews the application of UDL as a culturally responsive pedagogy and how it supports diversity within speech-language pathology training programs.

\section{Culturally Responsive Pedagogy}

Gay (2002) outlined historical resistance to diversity in education, including teachers demonstrating negative responses to students whose academic achievement, learning styles, and classroom behaviors were different from dominant majority expectations. The public school educational system uses specific behavioral characteristics and predetermined criteria to label and define children's skill levels and the presence or absence of a disability (National Center for Education Statistics, 2016f). Differences based on perceived culture, race, ethnicity, and intellectual capacity can be 
inaccurately used as markers of students' learning potential (Gay, 2002). In other words, judgments may be made about a students' skill level or the presence of a disability due to bias.

Smith-Maddox and Solorzano (2002) applied Friere's critical theory of children as actively "co-construct[ing] knowledge with their teachers and others" (p. 70) to understanding resources, strengths, and assets of disenfranchised groups. Critical race theory challenges deficit-based approaches when viewing minority groups. Educators are encouraged to find the strengths within each learner's culture instead of judging them as lacking skills.

Paris (2012) described culturally sustaining pedagogy that supports students "in sustaining the cultural and linguistic competence of their communities while simultaneously offering access to dominant cultural competence" (p. 95). Culturally sustaining pedagogy seeks to counter national policies of creating a monocultural society based on dominant majority norms (Paris, 2012). Students learn through imagery and artifacts, and the careful design of the classroom using ecological approaches to reduce race-related stress and establish a safe community (Paris, 2012).

Analysis and Implications. Waitoller and King Thorius (2016) applied culturally sustaining pedagogy to UDL. They described how asset pedagogies counter pathological thinking that uses power systems to perpetuate marginalization. Waitoller and King Thorius clarified how intersectionality, which is simultaneously holding multiple identities within society (Sensoy \& DiAngelo, 2012), is related to classification systems of students' identities that cause co-existing benefits and marginalization of groups. 
Cultural pluralism and the valuing of students' cultures is part of emancipatory pedagogies (Waitoller \& King Thorius, 2016). Emancipatory pedagogies are free from labeling and sorting of students by learning and cultural styles. There is a substantial history of disability and race used similarly and conjointly as social constructs for discriminatory practices (Waitoller \& King Thorius, 2016). The constructs of normalcy and disability are unstable identity markers that are used by institutions for specific purposes (Waitoller \& King Thorius, 2016). UDL has the potential for pluralizing the concept of ability. UDL guidelines use multiple means of representing and organizing information and students have choices in demonstrating their knowledge and skills (Meyer et al., 2014). The plurality of instructional methods may free students from labels that lead to marginalization (Waitoller \& King Thorius, 2016). Students are provided with access to content that does not require them to change their behaviors to match a single dominant majority instructional style. Variations in students' learning styles and cultural backgrounds are a fundamental aspect of course planning (Meyer et al., 2014).

\section{Implications of UDL Framework}

The UDL principles of multiple means of representation, engagement, and expression can be applied to college programs, including instruction and learning, departmental policies and practices, and social opportunities. UDL includes specific changes to the presentation and accessibility of information. Within the academic realm, content information is represented in multiple ways and instructional language is designed to highlight key vocabulary and promote understanding (Meyer et al., 2014). Students are not required to guess at the meanings of new terms and concepts. Professors 
who use UDL strategies are expected to activate students' background knowledge and explicitly share critical features, patterns, and connections between concepts (Meyer et al., 2014). Students are encouraged to consider their own experiences as they relate to the content. Additionally, UDL promotes multiple means of action and expression (Meyer et al., 2014). Students are encouraged to demonstrate knowledge using different mediums and styles of construction. Multiple means of expression may encourage an acceptance of multiple and varied understandings and perspectives. When viewing UDL as a culturally responsive pedagogy, the multiple means of representation, engagement, and presentation expands to the multiculturalism of society, where information shows different views, a range of cultural engagement styles are valued, and individuals present their knowledge and skills in ways that align to their unique backgrounds and cultures.

The use of UDL is highly important when examining the minority marker of disability and how educational policies do not address social context, accessibility to content, and inclusive culture (Gabel, 2010). Resources to support students who are experiencing learning challenges are typically limited to students who have documentation of a disability using a biomedical model (Hutcheon \& Wolbring, 2012), that subsequently prohibits these same services to students facing challenges due to other factors. A UDL framework could allow an examination of departmental policies and practices that focused on inclusion as opposed to limiting discussions to compliance with federal policies. Novak and Rodriguez (2016) described how UDL at the systems and school level could be used in leadership to establish a shared understanding of values and strategies. They advocate for inclusion of voices from a diverse community when 
examining any initiatives. UDL as a framework could guide departments in exploration of the needs of minority students from an access and inclusion perspective. Furthermore, when using UDL as a method for evaluating departmental sponsored events, any offerings can be analyzed through a lens of student access and inclusion in social opportunities. Using the UDL framework with critical theory (Waitoller \& King Thorius, 2016) allows for methods of analyzing minority graduate students' perspectives of and recommendations for inclusion that value diversity of experiences and cultural strengths.

\section{Critique of UDL Framework}

Although UDL at the postsecondary level is one of the few frameworks that account for diversity of learning styles for college students, there are important considerations when adopting this framework. Critiques of the UDL framework, as theoretical framework, center around two main issues: constructs of normalcy and implementation. Constructs of normalcy are a form of oppression, which is a set of policies and beliefs, designed by a dominant group, that systematically exploit one group over another (Sensoy, \& DiAngelo, 2012). Waitoller and King Thorius (2016) asserted that UDL "tacitly accepts ability hierarchies and norming curriculum at the intersection of racism and ableism (and other-isms)" (p. 375). Accepting pre-existing hierarchies in society may unwittingly reinforce constructs that UDL leaders seek to address. Waitoller and King Thorius described how UDL leaders can play a positive role in dismantling societal constructs of normalcy, and participate in meaningful discussions about the historical effects of the distribution of power and privilege within society and within education. Using a critical theory perspective, the UDL framework can be evaluated 
based on how it acknowledges historic lack of opportunities and access for minority groups. In using a UDL framework for examining the lack of diversity within speechlanguage pathology, it is important to incorporate critical theory and social justice to understand the extent of the problem and how it affects minority groups.

When examining UDL from an implementation perspective, there is not consensus within the literature on how UDL frameworks at the postsecondary level are defined, and how UDL practices are adopted. I examine implementation of UDL at the postsecondary level through the implementation frameworks of Fixsen et al. (2013). Implementation frameworks explain how organizations successfully adopt evidencebased practices. Fixsen et al. (2013) separated implementation into four stages: exploration, installation, initial implementation, and full implementation. The exploration stage involves establishing an understanding of the strengths and needs of an organization to create readiness for a new evidence-based program or innovation. The installation stage represents the acquisition and development of resources needed for the innovation. The initial implementation stage and full implementation stage represent staff members using the new practices, and culminate in the gradual reduction of supports, as the practices have become routine.

Fixsen et al. (2013) specified three drivers, or combination of factors, that facilitate progress at each stage: competency, organization, and leadership. Competency drivers address implementation fidelity with training and coaching. Organizational drivers include the role of administration and design of data collection. Leadership drivers cover both technical and adaptive leadership. Technical leadership addresses 
clearly defined managerial issues, and adaptive leadership is for complex problem solving.

UDL at the postsecondary level as a framework is addressed using the exploration and installation stage of the implementation framework. The exploration stage involves gathering information from constituent groups to understand the organizational context and the types of implementation drivers that are needed. At the postsecondary level, constituent groups are students, professors, and administrators. Abell et al. (2011) conducted research on secondary students' perceptions of their learning environment for classrooms that used UDL and made comparisons of the effects of UDL by grade level. A sample of 867 students in fifth through twelfth grade completed surveys on teacher behaviors and student participation. Racial data on respondents were not provided. High school students showed the greatest ratings of personalization, which signified holding positive beliefs about their relationship with their teacher, and significantly higher ratings of participation in classroom activities, compared to the younger grades. The use of UDL showed the greatest effects at the upper grades. Although results at the secondary level are promising, more research on college students' perception of the effects of UDL pedagogical practices in the areas of professor relationship and participation and engagement is needed.

Rao et al. (2015) described how UDL was applied to online courses and collected information about learner preferences for UDL instructional strategies. A total of 70 out of 77 students across three online education courses completed a survey that addressed course resources, instructional practices, and technology. Students reported preferring 
clearly defined course expectations, many short assignments as opposed to a few long assignments, and high levels of instructor feedback. From a faculty standpoint, Rao et al. noted that extensive time and effort is required to create an online course that uses UDL practices. It is important to consider whether the UDL framework assumes greater faculty time and effort than is explicitly stated.

Professors may experience difficulties in implementing UDL. Gradel and Edson (2009) outlined challenges for university faculty to implement UDL across multiple areas: understanding expectations and processes, time requirements, faculty turnover, coordination of roles and responsibilities, technology, training, and access to resources. At the administrative level, Gradel and Edson noted that successful models of UDL at the postsecondary level involved partnerships with university disability resource services. Jimenez et al. (2007) described an important partnership at the University of Connecticut, where faculty members are supported by the Center on Postsecondary Education and Disability to apply UDL practices in their courses. The Center on Postsecondary Education and Disability has also supported learning communities for faculty across postsecondary institutions for course design that uses UDL practices. Since there have been successful partnerships across university departments at different institutions, additional research on methods for developing departmental partnerships with disability resource services is beneficial. In using UDL as a theoretical framework, it is advisable to acknowledge assumptions around university level support and connections and collaborations across departments. 
At the installation stage of implementation, competency drivers, such as training and performance assessment are activated (Fixsen et al., 2013). Training and performance assessment include outlining specific behaviors to be taught and monitored.

Postsecondary institutions that use UDL have started to delineate components of UDL that are beneficial for student learning, including informative syllabi, multiple modes to convey concepts, opportunities for students to engage, and thorough guidelines for course assignments (Gradel \& Edson, 2009). Edyburn (2010) analyzed the development of UDL as an inclusive pedagogy, and shared propositions to clarify and discern elements of UDL. Propositions included explaining and evaluating elements of UDL, specifying the role of technology, developing diversity blueprints for varied learner needs, focusing on instructional design, gathering learner feedback on tools and scaffolding, and illustrating potential benefits to learner engagement (Edyburn, 2010). Given that there are differing interpretations of UDL practices and implementation, there is inconsistency in how UDL is defined within postsecondary settings.

In using UDL as a theoretical framework, critiques of the framework indicate areas that need to be considered within the research study. Societal constructs of normalcy or neurotypicality, which use a standard distribution of performance on formalized cognitive assessments, are often underlying assumption in education. The construct of normalcy is addressed by actively incorporating a critical theory and social justice perspective. Accepting identity labels for dominant and minority groups without exploring the societal and institutional factors that created these groupings would not show the nuanced ways in which minority status and inclusion may be understood in a 
learning environment. Examining the origin of societal hierarchies for minority groups (Sensoy \& DiAngelo, 2012), and challenging the acceptance of identity markers to differentiate individuals (Waitoller \& King Thorius, 2016), is considered in the analysis of data and the implications. Critical discourse analysis includes these foundational aspects of social and political systems (Gee, 2014). The issues with UDL and assumptions and definitions of disability were addressed by analyzing the student experiences, and using student experiences as a foundation to view common practices. Analysis necessitated an examination of the university level supports and the potential beliefs of different constituent groups, including students, faculty, staff, and administration, that were represented within student experiences.

\section{Review of the Literature}

The review of the literature begins with a discussion of postsecondary students from minority backgrounds, including race and ethnicity, socioeconomic status, gender, LGBTQ+ and ability. These identity markers were chosen based on the work of Sensoy and DiAngelo (2012), which delineated social stratification within society. The identity markers were applied to the field of speech-language pathology. It is important to note that although males are considered to be in a dominant group within the general population, they are a numerical minority within speech-language pathology. The literature review addresses gender as male within a female dominated profession. The subsequent section examines the literature regarding inclusion for postsecondary students. The literature review focuses primarily on research that exists within the field of speech-language pathology in order to examine how the field describes minorities. This 
information was compared with existing research on the experiences of minority college students to form a broader understanding of the range of factors that may affect minority graduate students.

\section{Minorities Within Speech-Language Pathology}

Within this study, minority status was based on the work of Sensoy and DiAngelo (2012) to include race and ethnicity, socioeconomic status, as defined by having a lowincome background, male gender, LGBTQ+, and disability,

Racial and Ethnic Minorities. College student demographics have changed due to multiple societal factors. The percentage of college students who self-identified as white declined from $84 \%$ to $59 \%$ of the total student body from 1976-2013, with an increase in students who self-identified as Hispanic, Asian/Pacific Islander, AfricanAmerican, and American Indian/Alaskan Native (NCES, 2016b). While incoming college freshman have a range of racial, ethnic, and cultural backgrounds that contribute to the diversity of the student body, faculty demographics have not changed as dramatically. NCES (2016e) data reported that approximately $78 \%$ of university faculty members were white, with the remaining $22 \%$ divided between Asian, African American, and Hispanic faculty members, from data obtained in 2013.

Graduation Rates. The experiences of students from minority backgrounds in postsecondary settings may be substantially different from dominant majority white students from families with middle class social economic status. The graduation rate in the United States for first time college students in a 4-year degree program for students who began college in 2008 varies by racial/ethnic group. Graduation rates were lower for 
minority groups: $21 \%$ for students who were African-American, $30 \%$ for students who were Hispanic, $27 \%$ for students who were Pacific Islander, and 23\% for students who were Native American, as compared to $44 \%$ for students who were white (NCES, 2016c). The presence of a documented disability affects degree completion. Graduation rates are available for college students with documented disabilities, students who have met university criteria for a disability and received academic support services. For college students with documented disabilities, $34 \%$ of students graduated within eight years after completing high school (NCES, 2016c). Inequality of graduation rates result from multiple factors relating to the experiences of a diverse student population and their unique backgrounds.

Multilingual Students. College students may speak multiple languages and the percentage of students for whom English is a second or foreign language is increasing At the public school level, for kindergarten through age 21 transition services, the percentage of students who were classified as English Language Learners rose from $8.8 \%$ in 2003 to $9.3 \%$ in 2014 (NCES, 2016a). Students who are not native English speakers face linguistic as well as social and cultural barriers (Kanno \& Varghese, 2010). Incoming college freshman have a range of cultural and linguistic backgrounds that contribute to the diversity of the student body. Given the racial, ethnic, cultural, and linguistic differences between postsecondary students at the undergraduate and graduate level and faculty, faculty members may not have a personal understanding of students' racial and cultural experiences that they bring to the classroom. 
Racial and Ethnic Minorities in Postsecondary Education. Racial and ethnic minority college students face unique challenges in the areas of racial identity development, negative stereotypes, lack of racial and ethnic minority faculty, and exposure to dominant culture views within the curriculum (Quaye et al., 2009). Quaye et al. (2009) conducted an extensive literature review on engaging racial and ethnic minority students and outlined existing issues to inform faculty and promote culturally responsive practices. Racial identity development refers to an individual's awareness of their racial and ethnic identity within a dominant culture, and stage of development in exploring race and ethnicity. Negative stereotypes include deficit approaches that focus on lack of skills, and the burden on students to prove their intellectual capabilities when professors assume lower rates of academic achievement based on race and ethnicity. The historical and current lack of racial and ethnically diverse faculty in academia reduces mentorship and role modeling for racial and ethnic minority students. Within academic content, the perspectives of racial and ethnic minorities are frequently omitted from the curriculum, which invalidates the experiences and contributions of diverse communities. Furthermore, pedagogical practices may be unresponsive to racial and ethnic minority students due an adherence to class design, content, and managements focused on a dominant white perspective (Gay, 2002; Smith-Maddox \& Solorzano, 2002).

Strategies for engagement for racially and ethnically diverse students are important across domains, including assessment of needs, student opportunities, and faculty training (Quaye et al., 2009). Recommendations for assessment of needs include methods for examining campus climate through student feedback, use of consultants, and 
discipline specific demographics. Recommendations for student opportunities involve academic and social factors, such as collaborative learning and peer networks. Faculty training recommendations covered establishing expectations for safe learning environments, recruitment and retention of faculty from diverse backgrounds, and the use of culturally responsive pedagogy.

The experiences of ethnic minority college students in the postsecondary setting differ from those of white majority college students and are reflected in the area of psychological adjustment (Gummadam et al., 2016). Psychological adjustment encompasses perceptions of personal attributes, including self-worth, social acceptance, and academic self-efficacy, and has been linked to group belonging (Gummadam et al., 2016). The concept of group belonging may be related to belonging within any number of different affinity groups. Gummadam et al. (2016) separated group belonging into belonging within two groups: the school community group and the ethnic minority group. The school community group and ethnic minority group subsequently became the two variables of school belonging and ethnic identity, which formed the basis for their study on the relationship between belonging and undergraduate ethnic minority students' psychological adjustment. School belonging was based on feelings of connection to the classroom, department, and school level. Ethnic identity was described as membership within an ethnic group resulting from prolonged exploration and commitment to that group. Gummadam et al. extended the work of prior studies of school belonging and ethnic identity that were previously conducted on children and adolescents to examine belonging for college students. 
In Gummadam et al. (2016), a total of 154 African American, 47 Asian American, and 64 Hispanic psychology students attending a Midwestern college participated in the study. Participants completed multiple psychological assessments. School belonging was measured using an adapted version of the Psychological Sense of School Membership measure, which was originally designed for high school students. Strength of ethnic identity was measured using the Multigroup Ethnic Identity Measure-Revised. Selfcompetence and self-worth were measured using subscales from the Self-Perception Profile for College Students and the Center for Epidemiological Studies Depression Scale.

School belonging was significantly associated with positive psychological adjustment, including higher ratings of self-worth, scholastic competence, and social acceptance, and lower ratings of depressive symptoms (Gummadam et al., 2016). Additionally, ethnic belonging was not as strongly associated with psychological adjustment as school belonging, and only appeared to have a significant relationship to psychological adjustment for those students who did not demonstrate high levels of school belonging. Based on their findings, Gummadam et al. (2016) provided recommendations to universities to offer resources that enhance students' belonging and ensure the presence of courses and events targeted for ethnically diverse groups.

Given the importance of school belonging in psychological adjustment, information about factors that promote inclusion for minority graduate students within the field of speech-language pathology is needed. The school belonging scale includes judgments of interactions, specifically, "perceptions of inclusion/acceptance versus 
alienation in general" (Goodenow, (1993, p. 29). The scale focused primarily on teacher and peer interactions. In order to obtain a broader view of inclusion, qualitative questions about being included could provide information about perceptions of the extent of inclusion for minority graduate students within larger systems and across settings.

\section{Racial and Ethnic Minorities Within Speech-Language Pathology}

Ebert (2013) studied how speech-language pathology and audiology graduate students understood the concept of white privilege and its importance within the field. Ebert used a definition of white privilege that included preferential treatment within society, and a lack of conscious awareness of the benefits of whiteness in a whitedominated society. Given that $92 \%$ of members of the ASHA (2017a) organization are white, understanding how future practitioners view the concept of white privilege within the field is especially meaningful. Ebert noted how self-awareness is frequently considered a first step in cultural sensitivity and how the field of speech-language pathology does not have a history of explicitly discussing race within research. A review of research of white privilege in related professions, such as counseling, and social work, has shown a range of levels of student awareness and student attitudes. Student beliefs about white privilege were correlated with their future ratings of cultural competency by clinical supervisors and also within their own self-ratings of cultural competency within clinical practice (Ebert, 2013).

Eleven different graduate programs that were located within 10 different states, including Oregon, participated in Ebert's (2013) survey on graduate students' perceptions of white privilege for a total of 83 respondents. More than $95 \%$ of respondents were 
female and the majority were white. When asked about clinical training programs, 94\% of graduate students reported that at least $90 \%$ their instructors and supervisors were white, and $85 \%$ reported that at least $90 \%$ of the students within the graduate program were white. Interestingly, students reported more diversity of professionals within clinical settings outside of the university, with approximately $68 \%$ of students reporting that $90 \%$ of professionals in the community were white.

Ebert (2013) analyzed themes across the three categories of denial, limited awareness and developed awareness. The majority of participants felt that white privilege was minimal and not directly relevant within the field of speech-language pathology. More than a third of respondents denied existence of white privilege and many expressed hostility toward the concept. The lack of understanding of the concept of white privilege and the complex roles of race and power within society is especially concerning given that SLP pathologists are expected to have training in serving multicultural populations and diverse communities. Ebert highlighted how respondents included the need for understanding cultural and linguistic diversity, while simultaneously not considering race as a factor in clinical services. Ebert advocated for student education that explicitly included the concept of race and racial privilege within speech-language pathology courses and clinical training.

Graduate students' lack of awareness of the concept of white privilege may play a role in the experiences of students, from minority backgrounds, who chose to pursue speech-language pathology. In order to address the diversification of the field of speech- 
language pathology, it is essential to compare the experiences of students based on racial and ethnic minority status.

\section{Socioeconomic Status}

Many college students have risk factors that may affect their learning, such as poverty and poor high school academic performance (Scott et al., 2003). Students may enter college without a family background of academic preparation for college. First generation college students, whose immediate family members do not hold a college degree, are frequently from low-income backgrounds. Approximately $24 \%$ of incoming college students are first-generation students from low-income backgrounds, who are four times more likely to leave college after the first year, as compared to the general student population (Engle \& Tinto, 2008). Graduation rates for first generation students from low-income backgrounds are also affected, with only $11 \%$ of students graduating after six years (Engle \& Tinto, 2008).

Within the field of speech-language pathology, there is limited research on the socioeconomic status of clients in relation to their professionals. Kent's (1994) foundational work highlighted how the field of speech-language pathology needs to have an awareness of larger societal patterns in the allocation of resources and socioeconomic trends, especially within the health care and educational systems. Kent described the amount and complexity of national expenditures on health care, as well as generational changes, which included a greater proportion of senior citizens compared with younger citizens within the United States. Within the educational system, Kent noted rising costs of fiscal expenditures for public schools. Although Kent's primary response to these 
changes in financial trends was advocacy for research to promote evidence-based practices to secure federal funding, it is also important to consider how clients may be affected by socioeconomic factors within society. Even though there may be other factors to consider, more recent literature on the socioeconomic mismatch between clients and clinicians is highly limited. Clients who receive services from speech-language pathologists may experience substantial changes in access to health care and educational services, which are the result of larger societal trends.

Inglebret et al. (2017) conducted an extensive literature review to determine the proportion of research articles in the area of speech-language pathology services for children with language disorders that included information about participants' socioeconomic status, and the indicators that were used. Considering that $24 \%$ of children within the public school system in the United States attended high poverty schools, where more than $75 \%$ of children were eligible for free and reduced lunch, the research on providing intervention to children with communication disorders would be improved by understanding the socioeconomic status of children within the study (NCES, 2016d). Inglebret et al. summarized research on difference in language development related to children's socioeconomic status, including vocabulary development, literacy development, and verbal problem solving. They also noted that there is controversy within studies of language development differences for children by socioeconomic status due to the use of standardized, normative referencing assessments, and lack of recognition of linguistic diversity. Even though determining socioeconomic status is challenging due to a complexity of factors, traditional indicators include parental 
educational level, household income, and parental occupation (Inglebret et al., 2017). Each indicator of socioeconomic status has specific advantages. Parental educational attainments are relatively stable, income is readily available in the public domain through census data and school demographic reports, and occupation reflects societal status (Inglebret et al., 2017).

Inglebret et al. (2017) found that over a 15-year time period $64 \%$ of articles about pediatric language disorders within speech-language pathology journals included participant socioeconomic status. They noted a steady increase in reporting in recent years and they found the use of proxy measures for socioeconomic status, including parental educational level and occupation, along with household income. Inglebret et al. advocated for research to include comprehensive demographic descriptions of participants, and the need for further research to examine potential disparities based on socioeconomic status, as well as the intersection of socioeconomic status and minority identity markers.

Although there is a growing awareness of the need to understand the role of socioeconomic status for clients who receive speech-language pathology services, there may be broader concerns about cultural factors within studies. Individuals who are experiencing low socioeconomic status or are from low socioeconomic status backgrounds may be considered minorities within research studies, which may affect how they are viewed (Inglebret et al., 2017). For example, within the area of child language development, prior research has focused on a skill deficit model, as opposed to an asset model, which would account for potential strengths gained in settings that differ from a 
middle class socioeconomic status normative model (Paris, 2012). Additionally, on the whole, there is limited information about socioeconomic status of clients, and inconsistencies in the reporting on client socioeconomic status across research. Research on the socioeconomic status backgrounds of speech-language pathologists or speechlanguage pathology students was not apparent in the literature.

\section{Gender}

Although there is a body of research that addresses females' lack of interest in male-dominated professions, especially in science, technology, engineering, and math, there is comparatively little information about males' lack of interest in femaledominated professions, such as nursing and teaching (Forsman \& Barth, 2017). Research in the experiences of males in female-dominated fields has the potential to shape policy and practice to promote gender diversity.

\section{Female-Dominated Professions}

Forsman and Barth (2017) described the role of societal factors of gender expectations, how gender expectations separate occupations by gender, and how this separation contributes to job shortages in certain professions. Factors affecting males in female-dominated professions include male allegiance to societal gender expectations, perceived threats to masculinity in roles associated with female characteristics, views of gender-based characteristics related to specific professions, as well as issues of reduced prestige and salary in female-dominated professions (Forsman \& Barth, 2017). Additionally, men working in female-dominated fields often face issues related to gender identity based on the way that others comment on their career choice. Interestingly, men 
who retain societally defined male identity characteristics may succeed in femaledominated fields and enter into leadership positions that grant power (Forsman \& Barth, 2017).

Research on the experiences of men in female-dominated fields has primarily focused on nursing and education (Shen-Miller \& Smiler, 2015). Shen-Miller and Smiler reviewed historical demographic changes in professions and described how some traditionally male-dominated fields, such as law and medicine, have shifted to become evenly split between genders. In some instances, such as clinical psychology, they noted how females have become the majority gender within the field. They reviewed research on male responses to challenges to masculinity within a female-dominated profession. Male responses included focus on career achievement, emphasis on masculine characteristics, and assertion of heterosexuality if they are inaccurately assumed to be gay based on their choice of profession.

\section{Faculty Role}

Within the field of applied psychology, the gender of psychologists has shifted from primarily male to primarily female, which prompted researchers in the field of psychology to examine the role of masculinity within psychology graduate training programs (Sharatta et al., 2015). Sharatta et al. described how men in female-dominated fields become a privileged minority, meaning that they are demographically a minority in their profession, while holding social power within society. Entering a female-dominated field may put men at risk of negative social responses due to non-adherence to traditional roles. Sharatta et al. (2015) noted that graduate training in a female-dominated field 
frequently prompts male-identified students to examine their own gender identity and experience gender-related stress. They advocated for advisors, mentors, and clinical supervisors to include discussions of masculine issues within advising sessions to allow for processing of feelings and experiences. Additionally, they noted the importance of a balanced view of masculinity that recognized both negative and positive effects of socialization, including beneficial characteristics for the given profession.

Research on the role of faculty members in counseling training programs has indicated that gender beliefs affect instructional practice (Michel et al., 2015). Michel et al. (2015) described how gender role socialization, gender role stereotyping, and gender bias could contribute to ensuring that a discipline remains female-dominated. Gender role socialization is related to gender-based views of specific occupations, and gender role stereotyping corresponds to traditional male and female roles within families and households. Gender bias encompasses beliefs about skills, competence, and aptitude related to gender. Faculty members serve as both role models and gatekeepers for admission into programs, as well as provide socialization in the professional expectations of the field (Michel et al., 2015).

Michel et al. (2015) surveyed faculty members in counseling training programs on their attitudes and beliefs about areas of challenges and retention strategies for male students. Their analysis of faculty responses connected faculty attitudes and beliefs with male students' opportunities, barriers, and supports within the training program. Potential male students' experiences based on faculty beliefs were then sorted into four categories: leader, stigmatized, invisible, and nurtured. Michel et al. found substantial differences in 
the qualitative responses between male and female faculty. Male faculty members did not consistently acknowledge privilege within their field. Female faculty were found to exhibit a slight gender bias toward male students, perceive that male students had more opportunities, endorse traditional gender roles, and use pedagogical practices that elevated female power in the classroom, while decreasing male power. Both male and female faculty members noted tokenism, when an individual is treated as an exemplar from an under-represented group to make false claims about overall diversity within a group, and anti-male remarks from faculty. Some faculty reported beliefs about intrinsic lack of skills based on male gender. Interestingly, faculty members did not report that retention was a problem within counseling, which did align with attrition data.

Recommendations from Michel et al. (2015) included faculty discussions about social constructs of gender and the experiences of male students, and an examination of gender stereotypes and biases. Faculty members were advised to attend to their communication, both linguistic (verbal), such as word choices and word meanings, and non-linguistic (non-verbal), such as facial expressions and body positioning, and how their communication could be significant. Acknowledging the power of direct and indirect communication in the classroom shows how communication could privilege or devalue a group. Direct discussions with male students about the opportunities, barriers, and supports within their training program could help foster an inclusive learning environment that fosters gender equity. 


\section{Recruitment}

Forsman and Barth (2017) explored male students' interest in traditionally female-dominated fields. They investigated how the role of occupational titles and occupational descriptions affected college students' interest in different professions. More than 1,000 college students enrolled in science, technology, engineering and math classes participated in a survey where they ranked their interest in 20 different careers based on varied descriptions of professions, and the presence and absence of job titles. Approximately $80 \%$ of participants identified as male, and $20 \%$ identified as female. Although the majority of participants were white, there were slightly more racial and ethnic minority females than ethnic minority males in the study. All participants completed a rating scale where they ranked their own masculine and feminine attributes To gain information about factors related to students' interest levels, 16 occupations that are stereotypically female, and four stereotypically male occupations where manipulated by inclusion of occupation title and by job description to include either male versus female characteristics. Speech-language pathologist was one of the 16 stereotypically female occupations chosen in the study.

Findings showed that male students' interest in occupations was affected by the presence or absence of the job title, and by the presence of traditional male characteristics in the job description. Job titles for female-dominated fields were associated with lower interest ratings by male students regardless of their own rankings of personal masculine and feminine traits. Male students showed a greater interest in female-dominated professions when the job title was absent, and descriptions of the job included male 
characteristics. Forsman and Barth (2017) recommended initially presenting career opportunities by job characteristics instead of by job title and providing a balanced mix of both masculine and feminine characteristics in describing professions.

\section{Gender Conformity}

Research on gender in professional occupations has primarily used a binary construct of male and female, which may not address the myriad of concerns of gender non-conforming and gender-fluid students and professionals. Additional research is likely needed to examine how stereotypical gender roles in occupations affect individuals who do not use male and female divisions.

\section{Speech-Language Pathology and Gender}

The number of male clinicians in the field of speech-language pathology has steadily decreased since the 1970s (Lof et al., 1999), with only $3.7 \%$ of males currently in the field, as $96.3 \%$ of nationally certified speech-language pathologists identify as female (ASHA, 2017a). It should be noted that research and demographics on gender in speechlanguage pathology traditionally uses binary biological markers for male and female. Non-binary gender expression is discussed in the subsequent section, which addresses the research on the LGBTQ+ community.

The issue of gender diversity, and the predominance of females within the field, is not specific to the United States. Campos et al. (2018) conducted an international survey

of 31 speech-language pathology organizations around the world and found that across all of the organizations the number of males represented an overall mean of $5.8 \%$ of members. Lof et al. (1999) conducted research on gender differences between male and 
female graduate students with respect to academic preparation, professional expectations, experiences in the graduate program, decision to pursue the field, and personality characteristics. A total of 60 male and 57 female graduate students completed an extensive survey that addressed personal experiences with speech-language pathology, graduate school experiences, professional and career goals, and interests and preferences. Differences between males and females appeared in multiple areas. Males were more likely to have lower undergraduate grade point averages, prior personal experience with a communication disorder, and preference for working with adult populations. Similarities in responses between genders showed that both males and females believed that although coursework was equal, students were treated differently based on gender, and classes were not balanced by gender.

Litosseliti and Leadbeater (2013) examined occupational gender separation for speech language therapy/speech-language pathology profession in the United Kingdom. They described how a female-dominated field is at a disadvantage in its ability to relate to the concerns of male patients across the age range and posited that a balance in gender demographics could reshape professional practice and services. Increasing the number of males in the profession could raise societal awareness of the scientific and analytical bases of speech-language pathology, as well as raise the status of the field (Litosseliti \& Leadbeater, 2013). Interestingly, Litosseliti and Leadbeater found that exposure to the profession, such as receiving services, or knowing a speech-language pathologist was related to interest in pursuing the profession. Male students were also more likely than female students to value salary and career advancement opportunities. They 
recommended that male speech-language pathologists should serve as role models for other men, and that men should be involved in the recruitment process.

Prior research into factors for males to choose speech-language pathology as a career choice included job security or having a peer, friend or family member in the profession (Campos et al., 2018). Campos et al. (2018) recommended emphasizing job security and flexible work schedule in recruitment efforts, as well as peer-based recruitment by students who are already majoring in speech-language pathology. Additionally, they noted how male speech-language pathologists rated themselves as more skilled with three important personality traits for success: interpersonal, effective communication, and listening skills. Campos et al. promoted the recruitment of high school students and college students through descriptions of benefits of the field and valued traits.

Within speech-language pathology, training programs could examine the ways in which they present the characteristics of the profession to ensure a balance of stereotypically male and female traits. Further research about the experiences of male graduate students and faculty beliefs within speech-language pathology could provide insight into their perceptions of inclusion and acceptance within the field.

\section{LGBTQ+}

In an effort to inform speech-language pathologists of the needs of the LGBTQ+ community, Steckly (2009) used resources from the field of psychology and government census data to provide descriptions of gender expression and sexual orientation identity markers. It is important to note that prior term LGBTQ is frequently expressed as 
LGBTQ+, as the plus symbol denotes a broader collection individual identities (Trans Student Educational Resources, n.d.). The term cisgender is an important term, as it represents individuals who identify with the sex that was assigned to them at birth by the medical profession (Trans Student Educational Resources, n.d.). Steckly (2009) defined many common terms. The terms gay and lesbian refer to sexual orientation, specifically gay for men, and lesbian for women, who have romantic same-sex partnerships. Bisexual represents physical or emotional attraction to both men and women. Transgender refers to individuals whose gender expression does not align with their apparent biological sex at birth. Transgender individuals may specifically seek the services of speech-language pathologists to address voice services to adjust vocal pitch and resonance, and other important characteristics related to their gender expression (Hancock \& Haskin, 2015). Queer is often considered an overarching term that encompasses fluid and changing views of sexuality and gender (Hancock \& Haskin, 2015).

Steckly (2009) reviewed multiple analyses of census data over time, and noted that the 2000 census data showed that LGBTQ+ individuals live within $99 \%$ of counties within the United States with $30 \%$ of gay and lesbian individuals in same household committed relationships. Data showed that $25 \%$ of same-sex couples were parenting children and lived within $96 \%$ of counties in the United States. Although census data provides general information, accurate data on the population of the LGBTQ+ community in the United States is not available due to inconsistencies in data collection methods, stigma in reporting, and other societal factors (Steckly, 2009). Furthermore, the traditional estimate of $10 \%$ of the population as LGBTQ+, which was based on research 
on sexuality from the 1940 s, may be inaccurate and likely a lower estimate than the actual percentage (Steckly, 2009). Even though the concept of a cohesive LGBTQ+ community is to some extent a misnomer because of the diversity of individuals and their experiences, the use of the term community is a valuable concept based on the shared experience of minority status within a society that treats heterosexuality as a normal state of being (Hancock \& Haskin, 2015).

\section{LGBTQ+ College Students}

Within postsecondary settings, LGBTQ+ college students have unique needs based on "identity development within a heterosexist culture and homophobic collegiate environment" (Schueler et al., 2009, p. 63). Challenges for LGBTQ+ students include lack of visibility on college campuses, intersectionality, homophobia, and heteronormative culture (Schueler et al., 2009). Schueler et al. (2009) described the types of challenges and their effects on students. Invisibility corresponds to lack of positive role modeling, lack of resources, and lack of inclusion within programs and activities. Intersectionality, the holding of multiple identities with different degrees of privilege in society (Sensoy \& DiAngelo, 2012), is complex for LGBTQ+ students based on multiple markers of minority status, such as race and gender expression. Homophobia, or hatred directed at the LGBTQ+ community results in fear of a range of responses, from microaggressions to physical violence. The heternormative culture present on college campuses reinforces societal views that heterosexuality is normal, which isolates and excludes LGBTQ+ students from demonstrations of identity while participating in everyday interactions. 
Strategies to support the needs of LGBTQ+ college students include university level actions (Schueler et al., 2009). Schueler et al. recommended assessment of campus climate, LGBTQ+ mentors, scholarships, student clubs, and advocacy center, genderneutrality in language and living spaces, safe zones, and faculty training. Significant issues for LGBTQ+ students that can be addressed through campus initiatives included living and learning spaces that foster the exploration of sexual and gender identity. LGBTQ+ inclusive universities promote visibility of the LGBTQ+ community and encourage engagement for LGBTQ+ students.

\section{LGBTQ+ and Healthcare}

Individuals within the LGBTQ+ community experience differences in health care, including disproportionally higher mental health concerns and fear of negative reactions from medical providers (Hancock \& Haskin, 2015). Gay and lesbian individuals are more likely to experience discrimination and bias when seeking health care, which may be exacerbated in rural and less populated areas of the county, and may even result in a lack of seeking medical services when services are needed (Kelly \& Robinson, 2011). Fear of bias and discrimination is founded on a history of negative interactions with the medical community and may even involve the prior physician code of ethics guidelines that allowed physicians to choose their patients (Kelly \& Robinson, 2011). In 2009, the Gay Lesbian Bisexual Transgender Committee of the American Medical Association provided non-discriminatory language in their policy statement to prevent physicians from declining to accept patients (Kelly \& Robinson, 2011). In other words, members of the LGBTQ+ community may experience bias from their medical providers and may even 
choose not to interact with medical professions, even when they need medical attention. Furthermore, judgments about gender and relationships are frequently implicit in developmental and case history, and medical intake forms, which use binary distinctions for gender, and may assume heterosexuality in questions about marital status, and prior sexual history (Kelly \& Robinson, 2011).

Kelly and Robinson (2011) surveyed individuals with communication disorders from the LGBTQ+ community and found that approximately $60 \%$ of clients with speech and language disorders did not disclose their status as a member of LGBTQ+ community to the speech-language pathologist providing their treatment. This information was withheld, even though participants reported that they considered LGBTQ+ status to be important information. The majority of respondents also reported perceiving a bias toward heterosexuality as normative from the speech-language pathologist providing services. Additionally, Kelly and Robinson found substantial differences based on geographic location, with respondents in smaller cities and more rural areas less likely to seek services from a speech-language pathologist, less likely to disclose LGBTQ+ community status, and more likely to experience bias. Given that therapeutic intervention should be functional and relevant to a client's life (ASHA, 2016b), the lack of disclosure alters the formation of a collaborative partnership between the client and the clinician. From a clinical perspective, not disclosing partnerships that do not align with a cisgender, heterosexual normative expectation could impede a client's ability to include loved ones and family as a part of the therapeutic process, subsequently affecting the generalization of newly learned skills and strategies across daily settings. 
Kelly and Robinson (2011) advocated for the ASHA speech-language pathologist directory to provide listings of welcoming and accepting providers. They recommended that speech-language pathologists make specific changes to the documentation provided to patients, including non-discriminatory signage, inclusive patient bill of rights, and open-ended and culturally sensitive client intake and case history forms. They further recommended that speech-language pathologists establish partnerships with local LGBTQ+ community centers, and complete cultural competency training related to issues within the LGBTQ+ community.

Hancock and Haskin (2015) conducted an international survey of speechlanguage pathologists across four countries on their knowledge of LGBTQ+ issues and comfort level in serving the LGBTQ+ population. A total of 276 respondents participated in the survey, and the majority of respondents were from the United States, with smaller representation from other countries including Australia, Canada, and New Zealand. Findings showed generational differences, with recent graduates having more familiarity with LGBTQ+ terminology. A total of $11 \%$ of respondents reported moral opposition to same-sex partnerships and the LGBTQ+ community. A total of $8 \%$ of responding speechlanguage pathologists reported having reservations about serving clients from the LGBTQ+ community, and these reservations were primarily based on perceived lack of competency due to insufficient knowledge and skills. Hancock and Haskin recommended training in LGBTQ+ terminology, the historical marginalization of the LGBTQ+ community, the role of voice in transgender services, and inter-professional collaboration with related service providers to promote inclusive practices. 
Sawyer et al. (2014) specifically focused on speech-language pathologists’ awareness of transgender speech and language services for the LGBTQ+ community, and transgender individuals' awareness of speech and language intervention from speechlanguage pathologists. They conducted surveys within Illinois that examined speechlanguage pathologists' awareness and comfort level working with LGBTQ+ clients, and transgender individuals' awareness of speech-language pathologists in providing voice and communication training. Findings indicated that speech-language pathologists working in medical settings showed greater knowledge of LGBTQ+ terminology than those in educational settings. Communication services for transgender individuals are within the scope of practice for speech-language pathologists (ASHA, 2016b), however $30 \%$ of respondents reported that they did not know this information. Approximately $60 \%$ of respondents reported that they had never received any training on working with transgender clients. Most recent graduate were more likely to have received some level of training on transgender services. Lack of training may have affected respondents' beliefs about their own preparedness to provide services, as almost $80 \%$ reported that they were not comfortable providing transgender services.

In the second survey of clinicians and transgender clients in Illinois, (Sawyer et al., 2014) approximately half of transgender individuals indicated that they were not aware that speech-language pathologists provided transgender services. Some respondents noted concerns about finding speech-language pathologists who would be welcoming to the LGBTQ+ community and concerns about the title of the profession, which is based on pathology, or disorder, thus implying that transgender was a disorder. 
Sawyer et al. (2014) highlighted the lack of training of speech-language pathologists in serving the LGBTQ community and importance of ensuring that this training is available.

Voyzey (2015) focused on ways for speech-language pathologists to support the LGBTQ+ population as they age and provided important information about common experiences for LGBTQ+ senior citizens. LGBTQ+ senior citizens were more likely to have life experiences that involved non-disclosure of their identities, were more likely to live alone, and less likely to have family support. The historical lack of legal protections for the LGBTQ+ community has reduced access to financial inheritance and property rights for LGBTQ+ partners. For transgendered senior citizens, there is limited information about the long-term effects of hormone therapy, as well as a common lack of acknowledgement of gender identity in long-term care facilities (Voyzey, 2015). Furthermore, for transgendered adults who transition late in life, there may be legal, social, medical, and employment-based challenges. Given that speech-language pathologists provide services for communication, cognition, and swallowing disorders across the lifespan, they need to understand the concerns of adults and senior citizens from the LGBTQ+ community. It is important to note the individuals in LGBTQ+ communities have the same frequency of all communication, cognition, and swallowing disorders, as the general population. Speech-language pathologists work with individuals from the LGBTQ+ community, though they may not be aware of this fact, or have a full understanding of the range of needs.

Establishing a non-discriminatory environment serves as a way to indicate safety for the LGBTQ+ community (Voyzey, 2015). Voyzey (2015) reviewed and outlined 
recommendations from the LGBTQ+ community. Recommendations included visible LGBTQ+ symbols, such as an LGBTQ+ flag, rainbow, or pink triangle, and changes to guidelines for staff members who interact with senior citizens with communication disorders, such as LGBTQ+ awareness training. Awareness training may include the cultural, spiritual, social, and legal and financial context of the LGBTQ+ community (Voyzey, 2015). Cultural issues may encompass disapproval of individualistic needs that are in conflict with the family or community. Spiritual context may vary widely along a continuum of acceptance to ostracism or threat of harm, or death. In the social realm, LGBTQ+ senior citizens may have supportive relationships that are not based on familial connections. In the context of finances and legal issues, speech-language pathologists need to understand the type of protections that do and do not exist for LGBTQ+ partners within the medical setting. Voyzey concluded by advocating for speech-language pathologists to communicate the needs of LGBTQ+ senior citizens with communication, cognition, and swallowing disorders, within medical settings, and within the greater society.

\section{LGBTQ+ and Educational Settings}

Frazier (2009) provided resources on the LGBTQ+ community for the speechlanguage pathologists who work with children and families in educational settings. Speech-language pathologists in educational settings work with children, families, and staff who may be members of the LGBTQ+ community. Although accurate data on the number of children living within LGBTQ+ families is not known, census data from 2000 indicated that same-sex couples parenting children lived within almost every county in 
the United States (Steckly, 2009). Frazier (2009) highlighted how there are different types of challenges that are unique to LGBTQ+ families in respect to their interactions within the educational system. Heterosexuality is generally considered normative and positive in classroom activities, with a corresponding absence or even negative views of the LGBTQ+ community.

As part of daily interactions with school personnel, parents and caregivers from the LGBTQ+ community may experience microaggressions (Sue et al., 2007), or insults that are not at the conscious level of the individual who commits them. In the classroom setting, common educational practices that teach a binary gender model and include learning and play materials using culturally based stereotypical gender expectations perpetuate beliefs about what is considered normative. Challenges for LGBTQ+ parents and caregivers include laws around biological parent and child relationship status, and potential lack of support from immediate family members. LGBTQ+ parents and caregivers frequently construct identity through use of hyphenated last names for their children and extensive legal documentation (Frazier, 2009), meaning that teachers need to recognize the importance of child last names in family identity.

Speech-language pathologists who work in educational settings are likely to provide direct services to children and adolescents who identify as part of the LGBTQ+ community (Frazier, 2009). The Gay, Lesbian, and Straight Education Network (GLSEN), a national educational organization that supports LGBTQ+ students conducts annual school climate surveys for middle and high school students. According to the GLSEN 2017 school climate survey, 60\% of LGBTQ+ students reported feeling unsafe at 
school, and these feelings of lack of safety affected attendance, participation, and schooling (Kosciw et al., 2018). The GLSEN school climate survey report showed that $35 \%$ of the students surveyed missed school, $70-75 \%$ reported non-participation in school functions and extracurricular activities, and 18\% reported changing schools, all of which were due to concerns of safety. Almost 100\% of LGBTQ+ students reported hearing antiLGBTQ+ remarks within the school setting, and 56\% reported hearing these remarks from teachers and staff. Not only are these findings important for students who identify as part of the LGBTQ+ community, they are also relevant for children from LGBTQ+ families, and educational staff from the LGBTQ+ community. Frazier (2009) recommended that speech-language pathologists access resources on the LGBTQ+ community, model inclusive family configurations, and provide play and interaction opportunities that do not specifically reinforce values that align with heterosexuality as normative.

Research has shown that LGBTQ+ clients and patients who need speech-language pathology services likely experience varying levels of bias and discrimination in both the medical and educational setting. There is currently advocacy for changes to support the needs of the LGBTQ+ community with the field of speech-language pathology. Given that there is a need for increased LGBTQ+ inclusive practices in clinical settings, it is likely important to understand the experiences of LGBTQ+ students who are studying speech-language pathology, and how they perceive the inclusiveness of their course of study. 


\section{Disabilities}

More students with disabilities are attending college, and college students with disabilities demonstrate a greater range of disability types than in the past (Henderson, 1995; Schelly et al., 2011). Henderson (1995) reviewed data from the Cooperative Institutional Research Program longitudinal study of college freshman, which showed that the percentage of college freshman who self-reported a disability rose from $7 \%$ in 1988 to more than $9 \%$ in 1994 . No data were available on formal diagnostic procedures for these students. The percentage of college students who formally reported a disability to access academic support services increased from $10.9 \%$ in 2008 to $11.1 \%$ in 2012 based on data from the National Postsecondary Student Aid Study, which uses institutional records (Newman et al., 2016). Within public schools, the percentage of students identified with a disability rose from $8.3 \%$ in 1977 to $12.9 \%$ in 2013 (NCES, 2016f). More students with disabilities are choosing to attend college, especially students with learning disabilities (Mull et al., 2001). The proportion of invisible/non-apparent disabilities related to executive functioning, learning, and emotional regulation (Schelly et al., 2011) has increased. Invisible and non-apparent disabilities reflect disabilities that are not recognizable by the physical presentation of an individual.

\section{Identification of Disabilities}

Universities do not have accurate information about the number of students who have disabilities due to self-identification requirements and differences in eligibility criteria (Sparks \& Lovett, 2009). Eligibility criteria and laws governing disclosure of disabilities are different at the postsecondary setting from the kindergarten through age 
21 public school setting (IDEA, 2004; NCES 2016f; Rehabilitation Act, 1973). Child Find regulations in the IDEA (2004) require public school personnel to identify and evaluate children who are suspected of having a disability. At the postsecondary level, Section 504 of the Rehabilitation Act of 1973 does not require college personnel to identify students with disabilities (U.S. Department of Education, 1973). College students are required to inform disability services and provide required documentation of their disability to receive academic support services.

\section{Criteria for a Disability}

Sparks and Lovett (2009) reviewed classification criteria for college students with learning disabilities using 108 empirical studies with original data. They described how issues of self-disclosure, part-time attendance, many school transfers, and differences in evaluation procedures for identification complicate accurate calculations of the number of students with disabilities in higher education. Additionally, students with disabilities may not begin college immediately after graduating from high school. They noted how the time that elapsed between completing high school and starting college affected the transition process.

There is a lack of consensus of diagnostic criteria to determine the presence or absence of a disability within higher education institutions. Researchers and practitioners assess learning disabilities using different methods, including intelligence quotient discrepancy scores, achievement impairments, and Response to Intervention (Sparks \& Lovett, 2009). Sparks and Lovett (2009) found that classification of a disability was dependent on the clinician who conducted the assessment and the requirements of 
disability service personnel who review documentation. They found that the varied criteria for non-visible disabilities affected accuracy of demographics.

\section{Disclosure of a Disability}

The college setting requires students with disabilities to self-initiate the process of accessing academic support services. Barga (1996) conducted a formative qualitative study of factors that contributed to success for nine white college students with documented learning disabilities. She described how the students made decisions about when to disclose their disabilities, and how six of the students specifically changed their behaviors so that peers would not know that they had learning challenges. The students' decisions to disclose a disability and access academic support services were affected by prior educational experiences, including negative events both academically and socially. These experiences may have prompted them to take active steps to hide their disability and attempt to appear (or pass) as non-disabled or neurotypical (Barga, 1996). Behavioral changes to hide their disabilities were noted to be stressful for the students (Barga, 1996) and established this stress as a major area of concern.

Greenbaum et al. (1995) conducted qualitative interviews with 49 students with learning disabilities about their experiences with college. All students but one were white. Students responded to interview questions about their decisions about disclosure, accessing academic support services, participation in social activities, and helpful versus unhelpful experiences. Greenbaum et al. found that $45 \%$ of the students in their study chose to disclose their disability on their college application forms. The students who chose not to disclose their disability cited concerns about not being admitted because of 
their disability. They also cited a perceived lack of need for academic support services. Although the majority of students in the study eventually accessed academic support services, they described barriers related to faculty lack of understanding of disabilities and discrimination. Many students with disabilities may initially find non-disclosure to be the preferable option. These earlier studies are relevant in the discussion of disabilities and the UDL framework because of how they described decision around disclosure in systems that continue to use medical models requiring disclosure.

Kranke et al. (2013) conducted a 2-year qualitative survey with 17 college students using interviews to gather narrative data about the decision to disclose disabilities. Of the 17 college students, 14 were reported to be white. Student likelihood to disclose disabilities and receive accommodations was viewed through a stress and vulnerability model in decision-making. Kranke et al. found that students were simultaneously affected by stress from fear of academic failure, and feelings of vulnerability from potential negative professor and peer perceptions, and the desire to be viewed as normal. Students who were more concerned about their academic performance were more likely to disclose a disability. Students who were more concerned about faculty or peer perceptions were less likely to disclose a disability.

\section{Postsecondary Learning}

Learning environments at the college level differ from preschool through twelfth grade settings in the areas of teaching practices, instructional accommodations and modifications, and availability of support personnel and specialist consultative services specific to particular disabilities. College signifies a substantial change in the amount of 
external and instructional supports available to students to support their learning and to faculty to meet the needs of students who have learning challenges. General education teachers in the public system are legally obligated to adapt their instructional practice and modify academic content to meet the needs of students with disabilities who have Individualized Education Programs (IDEA, 2004). Teachers in public school settings have access to special education team members, including Learning Specialists, Autism Specialists, Speech-language pathologists, Occupational Therapists, and other related service providers, who are required to provide specially designed instruction and related services for students eligible for special education services (IDEA, 2004).

At the postsecondary level, a college is required to inform applicants and students of the availability of academic support services for qualified individuals, but is not required to locate and evaluate students as part of the Rehabilitation Act of 1973 (U.S. Department of Education, 1973). University faculty members may have specific expectations for students' ability to engage in the learning environment and may have limited understanding of modifications and accommodations for disabilities (Murray et al., 2008). Murray et al. (2008) described how colleges are required to modify academic requirements to prevent discriminatory practices for students with disabilities, but they are not required to make adjustments that they believe compromise program integrity. Shaw and Dukes (2001) reviewed program standards for disability services at the postsecondary level. They concluded that most institutions need faculty and staff training to meet the needs of students with disabilities through disability awareness, changes in instruction, and development of policies for accommodations. 
If college students with disabilities want services, they are required to provide documentation for evaluation of eligibility to receive services. Federal policies for disability rights have made substantial changes in accessing postsecondary education. The Americans With Disabilities Act of 1990, the Rehabilitation Act of 1973, and the Higher Education Opportunities Act of 2008 have made college attendance an option for individuals with disabilities. Leake and Stodden (2014) provided a historical context for federal policies, and how these policies emerged from the Civil Rights movement of the 1960s. At that time, individuals with disabilities faced substantial obstacles and barriers to accessing higher education, as many individuals with disabilities were excluded from colleges and universities. Federal policies increased postsecondary enrollment rates for students with disabilities and physical accessibility of public environments (Leake \& Stodden, 2014). Although federal policies on disability increased access, they have not directly targeted social models of disability, and do not specifically target social inclusion.

The Americans with Disabilities Act of 1990 (ADA) ensures that postsecondary settings are accessible to students who qualify as having a disability. Title II of the ADA encompasses institutions that receive state funding, such as publicly funded colleges and universities. Title III of the ADA applies these accessibility requirements to private institutions, such as private colleges and universities and vocational schools. The ADA was designed to provide equality in access to public institutions and prohibits discriminatory practices based on disability. Common practices related to ADA policy include prohibiting questions about disability on admissions applications, accessible 
building design, such as wheelchair ramps and elevators, disability resources, and supplementary aids and services, including alternate communication modalities, such as American Sign Language interpretation and Braille materials.

Section 504 of the Rehabilitation Act of 1973 mandates that individuals with disabilities are included and able to participate in activities within all organizations that receive financial assistance from the federal government (U.S. Department of Education, 1973). Section 504 of the Rehabilitation Act of 1973 prohibits discriminatory practices that would negatively affect individuals with disabilities in postsecondary settings. Additionally, Sections 504 and 508 of the Rehabilitation Act of 1973 require that electronic and information technology is available to individuals with disabilities.

The 2008 re-authorization of the Higher Education Opportunities Act sought to address a variety of barriers to postsecondary education, such as college affordability and tuition, distance education, and financial aid. An important addition to this reauthorization was the expansion of federal student loan programs to include individuals with an intellectual disability (Higher Education Opportunities Act, 2008).

Common practices at the postsecondary level that are a direct consequence of these laws include prohibiting questions about disability on admissions applications, ensuring accessible building design, offering disability resources, as well as supplementary aids and services. College applicants are viewed without admissions' departments knowing whether or not the applicant has a disability with the aim of reducing any potential negative judgments of applicants. The Higher Education Opportunities Act of 2008 has increased college accessibility for individuals with 
intellectual disabilities and contributed to the discussion of inclusive postsecondary learning environments.

The self-identification requirements and the use of a biomedical model inherently exclude multiple other groups who may experience learning challenges due to environmental, background, or other factors (Gabel, 2010). Students may experience learning challenges in postsecondary settings due to a range of factors, such as racial and ethnic diversity within a predominantly white (dominant majority) teaching environment, culturally and linguistically diverse backgrounds, first generation (students whose parents/caregivers did not attend college), financial hardships, age differences, etc. Since disability resource services are typically limited to students with medical documentation of a disability, in many instances minimal or no support for accessing academic content may be available for students experiencing learning challenges due to other factors.

Gabel (2010) challenged the fundamental definition of disabled using a disabilities studies perspective that described how disability is a social construct with ideological and political underpinnings. Gabel described how educational policy should account for social context, content knowledge, and culture of inclusion. The federal policies may not sufficiently address the learning context, accessibility to the academic content knowledge, and building of a culture of inclusion. Gabel asserted that equitable access to a postsecondary education requires far more than asking students to selfidentify as disabled.

The Rehabilitation Act of 1973 and the reauthorization of the Higher Education Act of 2008 do not provide specific guidelines on faculty delivery of instruction. 
Supplementary aids and accommodations are provided through outside departments, such as a disability resource center. Pedagogy in postsecondary settings has historically used a lecture format, which may not meet the needs of diverse learners (Bok, 2013). Federal policies that place accommodations external to classroom instruction further separate faculty from the issue of accessible teaching methods.

\section{Speech-Language Pathology and Disabilities}

For a field that is focused on serving a client population of individuals who have communication, cognition, and swallowing disorders, there is minimal research available on both the demographics of disabilities of speech-language pathologists and beliefs about the construct of disability. Speech-language pathology is one of many health care and education fields that are predicated on a biomedical model of disability based on medical documentation that creates a binary distinction of ability and disability as fixed identity markers (Hutcheon \& Wolbring, 2012). The biomedical model of disability is lacking for multiple reasons, such as its requirement to access medical care, the burden on students to maintain medical evidence of need, and the potential inherent conflict between students' own beliefs in themselves around ability, and the need to self-identify as disabled to access services (Hutcheon \& Wolbring, 2012).

There is frequently an assumption of ability and neuro-typicality in research on speech-language pathology pedagogy in training programs. Baladin and Hines (2011) advocated that students should develop positive attitudes toward individuals with disabilities, especially given the role of speech-language pathologists in providing therapeutic services, serving as a gatekeeper to accessing services, and involvement in 
medical, health, and educational policies and practices. Involvement and interaction with individuals with disabilities has been related to effective partnerships with clients and may help students address their own attitudes about disability (Baladin \& Hines, 2011). For individuals who use Augmentative and Alternative Communication, such as visual picture symbols and voice output communication aids, speech-language pathologists have not consistently understood the concerns of clients with lifelong disabilities and the needs of the family (Baladin \& Hines, 2011). Baladin and Hines studied student responses to class presentations by individuals with significant lifelong disabilities. Students shared that the presentations provided by individuals with disabilities increased their understanding of the effects of lifelong disability. An important aspect of the study was how individuals with disabilities were in the role of experts, which contrasts with therapeutic intervention where the speech-language pathologist is in the role of expert.

Unfortunately, there is little to no readily available information on the number of students, clinicians, or faculty within speech-language pathology who identify as having a disability. Given that the field of speech-language pathology is centered on providing assessment and intervention for individuals who have disabilities, the lack of demographic information about disabilities is noteworthy.

When examining the field of speech-language pathology from a critical theory perspective, it is essential to examine the role of speech-language pathologists in upholding a societal paradigm that values clear speech and language (Ferguson, 2009). Ferguson (2009) used critical discourse analysis to examine practice statements from national speech-language pathology associations in the United States, Canada, and 
Australia. Findings included the predominance of a scientific paradigm that used lengthy sentence forms, which would likely be challenging to understand for individuals who were not familiar with the material, a focus on therapy without recognition of the active role of the client; and a conservative view of the scope of the profession. Of particular importance to the discussion of disabilities is the concept of speech-language pathology's role in symbolic violence, which represents how speech-language pathologists have tacitly accepted the societal oppression of individuals who have communication disorders by working with clients to improve communication skills (Ferguson, 2009). In other words, by helping people speak more clearly, speech-language pathologists are reinforcing a dominant majority view of clear speech and spoken language as a primary communication modality. Even though speech-language pathologists also advocate for societal acceptance of diversity of speaking styles, this does not mitigate the primary role in reinforcing a pre-existing practice of privileging clear speech. Working to promote access through therapy with clients on their communication shows that the field accepts the oppression that exists. Speech-language pathology services are predicated on definitions of normalcy and disorder as represented spoken language.

The field of speech-language pathology may benefit from increased discussions about the power dynamics related to expertise and provision of services, and societal views of disability (Ferguson, 2009; Gabel, 2010). Understanding the role of medical and educational policy, how the biomedical model of disability affects beliefs, and how society grants privileges to spoken language, may also be important in exploring why or why not data are collected on disability demographics for speech-language pathologists 
and students studying speech-language pathology. There is an absence of the voices of speech-language pathologists with disabilities within the field, and the perceptions of graduate students with disabilities.

\section{Inclusion}

Inclusion, which was initially used to describe access to general education services for individuals with disabilities (IDEA, 2004), has been expanded to encompass a multicultural perspective of access and representation of minority groups (Gay, 2002). Artiles et al. (2006) examined inclusion as it relates to social justice. They described how the term inclusion "has multiple meanings that range from mere placement of students with disabilities in a general education classroom to the transformation of the philosophy, values, and practices of entire educational systems" (Artiles et al., 2006, p. 260). Artiles et al. connected inclusion to social justice through both justification and implementation discourse in the literature. Justification arguments have included the role of the educational system in maintaining inequity for students and a critique of special education due to lack of efficacy. Implementation arguments were described as political and practical. Political aspects were based on the bureaucratic and organizational work required to address oppression. The pragmatic aspects covered the changes required to make inclusion a daily practice.

Justification arguments for inclusion can be either distributive, which is the distribution of resources to all, or libertarian, which is focused on individual merits (Artiles et al., 2006). Implementation arguments use a communitarian stance that operates through shared beliefs within a society. According to Artiles et al. (2006), each view has 
limitations based on a range of factors, including hegemonies of expected student performance, meritocratic assumptions that use standardized measures of achievement, and difficulties in achieving community consensus of shared beliefs. They recommend that inclusion can be a method within social justice through transformative models of social identity that use "participatory strategies in which distribution of resources, access, and social cohesion constitutes the foundation of democratic egalitarian alternatives" (p. 267). A further specific recommendation is around the need for qualitative research in student experiences, since "scholarship that helps us understand the experiences of racial minority students as they negotiate multifaceted identities (disabled, racial minority) in inclusive programs that are committed to social justice is virtually nonexistent" (p. 266). Artiles et al. (2010) continued the discussion of inclusion, arguing for a broader understanding of culture and how cultural factors led to unintended outcomes of inclusion policies. Within the history of education, policies that were originally designed to create opportunities and increase access for students with disabilities inadvertently negatively affected other marginalized groups. Both the IDEA (2004) and the Brown v. Board of Education (1954) had multiple unintended consequences, including higher referral rates for minority students for special education and disciplinary concerns. Artiles et al. described how children of color are over-identified for special education eligibilities that rely on practitioner judgment (Intellectual Disability, Learning Disability, Emotional Disturbance) and that this issue is affected by referral from general education teachers and evaluations by special education providers. Furthermore, Artiles et al. argued that special education is stigmatizing and does not provide purported outcomes. Concerns 
noted for minority students in special education included lack of reduction of achievement gaps, more restrictive placements, higher dropout rates, and lower college enrollment rates.

General hypotheses to explain disproportionality typically center on poverty; however, these explanations have multiple flaws, including overgeneralization of one defining feature to entire groups, a blame-the-victim mentality, and deficit-based perspectives. Artiles et al. (2010) gave agency to children and the adults within their community in their expression of culture. They advocated for a layered and fluid view of culture and a rejection of single marker variables in disproportionality. Culture, across multiple layers from the individual through society and its institutions, is relevant to disproportionality. Artiles et al. reviewed the research on how culture has been defined as a factor in prior research on disproportionality. They found that cultural considerations in research were fragmented (different focal points), discontinuous (too simple or highly complex), and underspecified (not included).

Fragmented and discontinuous views of culture used different definitions of culture across research (Artiles et al., 2006). A simple definition was a way-of-life model, where children's cultures were considered determiners of their life trajectories (regulative aspect of culture). A more dynamic view described how culture involves the creation of meaning, where cultural lenses affect interactions (interpretive aspect of culture). The most sophisticated view of culture included how individuals negotiate social arenas, and how they recognize cultural stability/instability through agency (instrumental aspect of culture). Overly simplistic views of disproportionality often used a "culture of poverty" 
perspective to assign traits to students while ignoring other factors. Additionally, Artiles et al. (2010) acknowledged the inherent problems of culturally loaded assessments and the entire testing process.

Artiles et al. (2010) advocated for researchers to understand their own theoretical frameworks for viewing the problem. They supported theoretical transparency in research, partnerships with families of color, and broadening the scope of research to related social service fields. Researchers should reject binary views of causal factors and adopt multi-causal and multi-layered analysis methods. Student learning needs to be studied within a broad cultural, social, and historical context and not reduced to numerical data points that obscure precipitating factors.

Given the need to understand the experience of students in the discussion of inclusion, research that focuses on inclusion in speech-language pathology graduate training programs should begin with the voices of minority students. Using a broad view of culture within education, inclusion of minority students can be examined through social and historical factors.

\section{Synthesis of the Research}

The literature review was conducted through an examination of minority backgrounds within speech-language pathology, specifically race and ethnicity, socioeconomic status, gender, LGBTQ+, and ability. As previously stated, these identity markers were chosen based on the work of Sensoy and DiAngelo (2012), which delineated social stratification within society based on a set of five minority groupings. It is important to note that within the area of gender, males, who are considered a dominant 
group in society, are a minority in the field of speech-language pathology. The literature review included research on the experiences of minority postsecondary students and primarily examined how the field of speech language described minorities.

After reviewing the literature regarding the needs of minority postsecondary students and how the field of speech-language pathology described the needs of minorities, complex factors affecting access and inclusion for each minority group became apparent. For racially and ethnically diverse students, postsecondary institutions have traditionally used pedagogical practices designed for a dominant group and have not emphasized culturally responsive practices (Bok, 2013; Gay, 2002). Students who are racial and ethnic minorities benefit psychologically and academically from being included within their learning environment (Gummadam et al., 2016). Within the field of speech-language pathology, there is limited awareness of white privilege (Ebert, 2013), and a lack of research available on the experiences of racial and ethnic minorities within the field. Although there is strong support at the national organizational level (ASHA, 2018c), it appears that research has yet to explore the voices of minorities who train to become speech-language pathologists, who work as practitioners, and who teach in postsecondary settings.

For postsecondary students from lower socioeconomic status, access to higher education has been a historical challenge, due to lack of resources and preparation for college (Scott et al., 2003). Students from low socioeconomic backgrounds are more likely to leave college and not graduate (Engle \& Tinto, 2008). In discussion of multiculturalism within speech-language pathology, there has been limited research on 
the socioeconomic status of clients and professionals. Additionally, the field has not examined societal patterns in resource allocation and access to medical and educational services (Kent, 1994). The issue of socioeconomic status is further exacerbated within speech-language pathology due to controversies surrounding culturally responsive assessment measures for communication disorders (Inglebret et al., 2017). For example, vocabulary tests that measure word knowledge have long been criticized for using stimulus items that are common in the experiences of children from dominant group backgrounds, but may not be familiar to children from minority backgrounds (Campbell et al., 1997). Testing environmental exposure and not actual vocabulary development is biased against clients from low-income backgrounds (Campbell et al., 1997). Research on assessment and treatment methods for clients, which does not include participants' socioeconomic status as part of demographic reporting, may not be relevant across client profiles. Obtaining demographic information about clients' socioeconomic status is inconsistent due to the range of proxy indicators that have been used (Inglebret et al, 2017). Although there is an increased awareness of the need to include socioeconomic demographics in research, the larger issue of deficit-based versus asset-based models (Paris, 2012) has yet to be addressed. Furthermore, research on the socioeconomic status backgrounds of speech-language pathologists or speech-language pathology students was not readily available.

For male postsecondary students in a female dominated field, issues are related to societal factors of gender expectations and the effects of these expectations on male identity (Forsman \& Barth, 2017). Males within female dominated fields are a privileged 
minority, as minorities within their professions and members of a dominant group in society (Sharatta et al., 2015). Faculty beliefs about gender and the idea that there are traits inherently linked to gender negatively affect male students, as do faculty pedagogical practices that reduce male power in the classroom (Michel et al., 2015). In the area of recruitment, Forsman and Barth (2017) recommended focusing on job characteristics using gender-balanced descriptions, instead of a job title. Even though the field of speech-language pathology recognizes the need for males within the profession, recruitment efforts have not appeared to change the demographics (Lof et al., 1999). Female dominated fields are at a disadvantage in meeting the needs of male patients (Litosseliti \& Leadbeater, 2013). Recruitment recommendations include exposure to the profession by peers, role modeling, and information about career advancement (Campos et al., 2018; Litosseliti \& Leadbeater, 2013). Research that addressed male graduate students' perception of inclusion could provide insight into factors that are positively or negatively affecting recruitment efforts.

The needs of the LGBTQ+ community are highly important to speech-language pathologists. Medical care and educational services for LGBTQ+ individuals are negatively affected by lack of understanding of exclusionary practices within the medical and educational fields (Frazier, 2009; Hancock \& Haskin, 2015). For LGBTQ+ postsecondary students, societal and institutional issues affect inclusion within living and learning environments and supportive environments to explore identity development (Schueler et al., 2009). When speech-language pathologists are not aware of the history of oppression of the LGBTQ+ community in healthcare, they are at risk for perpetuating 
these healthcare inequities (Hancock \& Haskin, 2015). ASHA (2018c), the national organization of speech-language pathologists, includes the needs of the LGBTQ+ community in their multicultural initiatives. Research that examines the experiences of LGBTQ+ graduate students could inform the field of the potential successes and shortcomings of its efforts.

For postsecondary students with disabilities, both legal and epistemological issues affect experiences within their college experiences (Hutcheon \& Wolbring, 2012). More students with disabilities, and a greater range of disabilities, are attending college (Henderson, 1995; Schelly et al., 2011), however universities do not have accurate information about the number of students with disabilities due to self-identification requirements and eligibility criteria (Sparks \& Lovett, 2009). Federal policies that grew from the Civil Rights movement have increased access and inclusion for postsecondary students with disabilities (Leake \& Stodden, 2014). Within disability studies, epistemological differences founded in the biomedical model of disability, as opposed to a social model of disability, may affect students in negative ways academically and socially through retroactive accommodations as opposed to proactive inclusive practices (Gabel, 2010). Furthermore, pedagogy in postsecondary settings has historically used a lecture format, which privileges an ableist or normative view of learning (Bok, 2013).

The field of speech-language pathology appears to have accepted the biomedical model of disability and a belief of expertise in understanding disabilities, as opposed to honoring the experiences of clients as experts in their own lives (Baladin \& Hines, 2011). It is also important to note that the existence of the profession of speech-language 
pathologists is based on a societal paradigm that values clear speech and language (Ferguson, 2009). Unfortunately, the demographic information for students, clinicians, or faculty within speech-language pathology who identify as having a disability was not apparent. The field of speech-language pathology will definitely benefit from increased discussion about models of disability and the perceptions of individuals with disabilities within the field and studying to enter the field.

\section{Critique of Research}

In conducting the literature review, few articles discussed the experiences and perceptions of minority postsecondary students. There was also a lack of questioning of the role of the field itself in contributing to the lack of diversity. There is evidence of a need for the voices of minority graduate students in speech-language pathology to understand the range of factors that affect inclusion within a homogenous group composed of individuals from a dominant group. As demonstrated from the literature review, there is a gap in knowledge in the research in regard to graduate students' experiences in training programs to enter the profession and how these training programs may play a role in maintaining or challenging the existing homogeneity of the field. If recruitment and retention efforts to promote diversity are created from a dominant majority perspective and exclude the voices of minority students, there is the potential for continued lack of representation and lack of diversification of membership.

\section{Methodology}

This section includes a review of the methods best suited for identifying inclusion for minority graduate students in speech-language pathology training programs and the 
relationship between inclusion and minority status within the field. Understanding the perspective of minority graduate students informs the larger discussion of diversity efforts within the field to provide culturally responsive services to individuals with communication, cognition, and swallowing disorders.

The goal of this study was to understand how minority graduate students in speech-language pathology training programs experience inclusion, their recommendations for increasing inclusion, and how they envision an inclusive environment. To capture authentic voices, a qualitative research design has the potential to describe how individuals construct a reality within a given social context (Maxwell, 2013). Qualitative research addresses the practical goal of improving understanding of ways to increase diversity within a homogenous field, and the intellectual goal of understanding the phenomenon of being a minority within a field that predominantly consists of individuals from a dominant majority background (Maxwell, 2013). A basic qualitative research approach allowed for an examination of the meaning of a phenomenon from those who are experiencing it (Merriam \& Tisdell, 2016). Descriptive data from expressive oral and written language output and visual representations were used to extrapolate internal underlying thought processes and understandings of reality. Written language was analyzed using personal documents and oral language was analyzed from interviews about visual representations that participants create.

This qualitative research study employed three major strategies: creation of personal documents through writing prompts, visual representation of a concept, and interviewing. The creation of personal documents was the primary source of information 
to analyze perceptions of inclusion and recommendations for inclusion for minority graduate students in speech-language pathology training programs across the United States. Participants completed writing prompts, and had the option to create a visual representation of an inclusive speech-language pathology environment through creating a recruitment flyer for the field, and respond to interview questions about the creation of the flyer. The multiple types of qualitative data served as investigative tools to understand how experiences of inclusion affect minority students, and the role of inclusion in diversity of the field.

Discourse analysis, which describes communicative interaction, identity enactment, and social hierarchies across settings allowed for an examination of social and political aspects of inclusion (Gee, 2014). Inclusion may be visible using discourse analysis that shows how speakers and writers position listeners and readers as part of a community or separate from a community. The concept of inclusion, which was founded in the provision of access to educational services and environments for individuals with disabilities (IDEA, 2004), has expanded to encompass minority groups and multiculturalism (Gay, 2002). Discourse analysis uses position design, which enables a critical examination of how language is used to place minority students into specific positions and roles that have political ramifications in access to goods and services (Gee, 2014). Qualitative research that focuses on minority student experiences ensures that response design, how a listener or reader accepts or rejects how they have been positioned (Gee, 2014), showed how minority graduate students experience situations that promote inclusion. Although discourse analysis has a focus on language, it also 
encompasses the enactment of roles, which included communication through "clothes, gestures, bodies, environments, props, tools, technologies, objects, the social display of beliefs and values, and configurations of all of these which we create or use as we find them for our purposes" (Gee, 2014, p. 24). Discourse includes not only language, but also the tools people use to enact socially meaningful identities. Visual representations of concepts, such as inclusion, can be analyzed through discourse analysis that includes an examination of the words and images that are chosen to impart specific meanings. Discourse analysis allows for an exploration of the ways that key words, phrases, symbols, and pictures represent identities and roles within interactions (Gee, 2014). The creation of personal documents that described experiences of inclusion and provided recommendations for inclusion were analyzed for themes. Themes were related to systems at the university, discipline, and departmental level, settings that included classroom and social, and interactions with faculty, staff, peers, and the community, along with themes focusing on minority markers. When coding, participant phrasing and wording was used to organize information into categories. Although there are themes based on the literature, the goal of the research was to explore minority graduate student experiences, highlight factors that have increased their perceptions of inclusion, and uncover any assumptions related to their idea of inclusion. 


\section{Chapter 3: Methods}

This chapter reviews the problem and purpose of this study and presents a description of the research methods that were used to address the question of inclusion for minority students in training programs for speech-language pathology. In the previous chapter, I examined research on the theoretical framework of UDL with critical theory as a culturally responsive pedagogy, and how this framework supports diversity within speech-language pathology training programs. I also included critiques of the UDL framework for perspective and to address any assumptions inherent in this framework. The organization of information used minority identity markers that are representative of historical underrepresentation and marginalization, and how the field of speech-language pathology has worked to address the needs of these minority groups. I explored the research on multicultural factors in training programs within speech-language pathology. This section provides a rationale for the methods that were used in this study.

\section{Introduction and Research Questions}

The prior chapter provided a review and critique of the literature relating to minority groups within speech-language pathology. Given the limited research on the experiences of minority graduate students in the field, I employed data gathering methods to understand how their insights could provide direction in addressing the problem of lack of diversity of speech-language pathologists. The methods, participants, procedures, instruments, data collection, and analyses used in this research are explained. The procedures for this study were based on approval from the Portland State University 
Institutional Review Board. Possible biases and limitations of these study procedures were addressed. Additionally, procedures to protect participant confidentiality were provided.

The research questions were as follows:

1. What is the experience of inclusion for minority graduate students in speechlanguage pathology training programs in relation to systems (university, field of study, department), context (classroom and social settings), and interaction (faculty, staff, community, and peers)?

2. What are the recommendations of minority graduate students in speechlanguage pathology training programs to increase inclusion to address the lack of diversity in the field?

3. How do minority graduate students in speech-language pathology training programs envision inclusion in the field?

\section{Qualitative Research Methods}

Since speech-language pathologists provide assessment and intervention for individuals with disabilities, the field of speech-language pathology has benefitted from qualitative research that examined the needs of individuals with disabilities (Baladin \& Hines, 2011). Applying qualitative methods to the experiences of minority students within speech-language pathology graduate programs benefits the field in a different manner. Qualitative research methods provide information about diversity and inclusion of graduate programs from the perspective of minority individuals who are encountering the culture, values, and traditions of the discipline as part of their academic and clinical training. Qualitative research captures minority students' potential experiences within the socialization process, which is the systematic training in the behaviors of a given culture (Sensoy \& DiAngelo, 2012). In this study the culture of speech-language pathology was examined through speech-language pathology graduate programs. 
Prior research on diversity in speech-language pathology has focused on recruitment efforts without necessarily directly seeking the voices of minority students. The purpose of this study was to examine how minority students experience inclusion and factors that promote inclusion within their graduate programs. I conducted a qualitative study that aimed to explore the experiences, which have the likelihood of increasing inclusion for minority graduate students in speech-language pathology training programs in the United States and its territories, with the prompts, questions, methods, and analysis. For this study, I used sets of qualitative data from each participant through written prompts: (a) a personal reflection that provides an experience representing a lack of inclusion within their graduate training program, (b) a personal reflection that provides an experience of inclusion within their graduate training program, (c), a personal reflection of overall feelings of inclusion within their graduate training program, (d) a response providing policy recommendations, and (e) a response providing advice where participants offer guidance to a future minority graduate student. The writing prompts served as the primary basis for data collection, and were analyzed through open coding, pattern coding, and themes, along with discourse analysis methods in verb choices for specific, meaningful verbs that show relationships (Gee, 2014). The personal experience reflection and policy recommendation prompt are based on the work on Hutcheon and Wolbring (2012), which used the analytical tool of ableism, the hegemony of ability preference, to examine how institutional policies and practices affected college students. Reflection on personal experiences provides the context of a meaningful social interaction. 
From a discourse analysis perspective, examining reflections of personal experiences, policy recommendations, and advice will show order and arrangement of social relationships, including socially significant identities, pre-established roles, associations, and larger debates and issues (Gee, 2014). Within discourse analysis, four tools for understandings social relationships and social identities are: (a) the type of social language, such as vernacular, technical, and more, (b) discourse, which is ways of thought, action, and behavior for a given identity, (c) intertextuality or allusions to other text sources and their meanings, and (d) conversations that represent larger societal debates (Gee, 2014).

Providing advice to an institution is a communicative interaction with an inherent hierarchy of social roles, since university institutions hold power. The prompt to provide advice to a future minority graduate student gave participants an opportunity to provide recommendations to another individual who shares the same social standing. The data provided important information about graduate students' experiences of inclusion that inform both teaching practice and educational policy at the postsecondary level for speech-language pathology training programs.

In addition to the creation of personal documents, all participants were invited to participate in a second phase of the study that involved creating a recruitment flyer designed to encourage minority students to pursue the field of speech-language pathology, and then respond to interview questions about their flyer. The inclusive research flyer, along with the written reflections, addressed the third research question of how minority graduate students envision the concept of inclusion. The creation of a 
recruitment flyer showed how minority graduate student participants represented the concept of inclusion through their choices in design, imagery, and wording. Interview questions about the experience of creating an inclusive recruitment flyer, factors that contributed to their decisions about its appearance, and their feelings about their product indicated underlying beliefs about inclusion.

\section{Qualitative Design}

Qualitative methods are generally better suited to understand participants' experiences and foreground the voices of individuals in a descriptively rich manner that allows for an exploration of social, cultural, and individual dynamics and factors (Maxwell, 2013). Additionally, qualitative research is well suited for purposeful sampling given the scarcity of minority graduate students within the field of speech-language pathology training programs. Seeking out the voices of the relatively few minority graduate students was a necessary step and served to lay a foundation for future work that may be either qualitative, quantitative, or mixed methods that could consider transferability of findings to contexts beyond those included in this study.

Qualitative design, as a systematic approach, has the power to bring understanding to the qualities of a phenomenon within a specified context (Brantlinger et al., 2005). This understanding serves as a form of evidence that has the potential to shape policies and practices by producing knowledge based on perspective (Brantlinger et al., 2005). Qualitative research examines attitudes, opinions, and beliefs with a critical analysis of power and social elements of the phenomenon (Brantlinger et al., 2005). Creswell (2014) outlined paradigms within qualitative research. This research study 
aligned with transformativism, which seeks to make changes within society to address inequity and oppression (Mertens, 2010).

Brantlinger et al. (2005) advocated for qualitative research's ability to initiate social change. They outlined the complexity of the descriptive process, and the transformative power of understanding other people's experiences. Understanding the experiences of minority graduate students in speech-language pathology programs informs university faculty, and departmental and administrative staff, as well as the field as a whole, including national organizations and associations. Qualitative studies allow practitioners, policy makers, and the general public to gain insights through accounts, narratives, reflections of personal events, and studies of experiences. The emphasis on the role of qualitative research in social change highlights its importance in addressing diversity and inclusion, as the sharing of experiences of participants' reality may itself initiate social change.

Brantlinger et al. (2005) defined qualitative research as "a systematic approach to understanding qualities, or the essential nature of a phenomenon within a particular context" (p. 195), which may place an inherent value on the concept of "quality" as the content, substance, or characteristics. Providing a given quality for a social situation may include describing events, actions, situations, and individuals, along with their thoughts and behaviors. Defining any object or abstract concept involves listing its qualities or characteristics. Thorough descriptions involve layers of interpretation and may further imply a constructivist perspective, as discussed by Guba and Lincoln (2005), where individual and collective contributions are used to construct a given phenomenon. The act 
of describing something means that vocabulary and language are used to create imagery. Bratlinger et al. (2005) elevated the complexity of the descriptive task of capturing qualities through a discussion of the dynamic and flexible process of obtaining data, and the transparency of assumptions and biases in the descriptive process.

Within qualitative research, Guba and Lincoln (2005) provided a historical retrospective on how academia has sought to redefine both the meaning and purpose of research. They began by highlighting growing interest in ontological and epistemological foundations in research and the expanding use of qualitative approaches. They described how methodology is typically tied to specific disciplines. Furthermore, they suggested the potential for the complex evaluation of similarities and differences between belief systems that could come from mixing or blending aspects of research paradigms.

Multiple issues affect every research paradigm and important issues raise awareness of the role of values in research and demonstrate how paradigms influence one another (Guba \& Lincoln, 2005). Using Guba and Lincoln’s (2005) discussion of values, this research attempted to encompass the values of control, validity, voice, and reflexivity. Control, which describes the ways in which research is moving toward democratic values that seek to equalize power and control within society, is an underlying value in addressing the problem of lack of diversity within the field of speech-language pathology. Guba and Lincoln's value of control is reflected in critical theory, which seeks to illustrate how historical practices have led to marginalization and oppression. The value of validity, which emphasizes the need to accept the subjectivity of methods and interpretation in understanding social discourse, was important in the coding of themes 
within the data, in addition to all of the steps throughout the study process, including research design, sampling, data collection, and reporting and dissemination findings. An essential value is voice, which is the use of authentic linguistic representations of the research and the participants. To embody the value of voice, the research included researcher audit memos that described subjective aspects of the analysis process, and textual artifacts from participants. The value of reflexivity, which honors the multiple identities of the researcher, and requires dynamic self-reflection, was essential within this research given my multiple identities as researcher, graduate student, faculty member, clinician, and minority.

Merriam and Tisdell (2016) described how qualitative research counters an established interpretation of events to focus on multiplicity of interpretation of the construction of reality within a social context. These multiple interpretations of experience value how individuals interpret their own realities. Maxwell (2013) asserted that qualitative research is founded on the study of processes that describe connections between individuals and events. Maxwell separated goals for research into personal, practical, and intellectual goals. Personal goals are motivating to the researcher and frequently based on life experiences. Within this research my personal goals were motivating due to my role as minority faculty member within a graduate training program in speech-language pathology. Practical goals result from a desire to change or improve a situation or issue, and are outcome-based. On a practical level, the application of the findings of this research has the potential to improve the experiences of minority graduate students through changes in practices within university programs. Intellectual goals 
address furthering an understanding of a situation, issue, or phenomenon. Within the intellectual level, this research adds to the discussion of inclusive practices within postsecondary education, along with the research on diversity within clinical professions. Following Maxwell's (2013) guidelines, research explores attributes of events, meanings and perceptions of experiences, and congruence/incongruence of understandings across individuals and groups.

Merriam and Tisdell (2016) described basic qualitative research, which addresses the meaning of a phenomenon to those who experienced it. From a practical standpoint, researchers are able to examine how people may be affected by an event. Examining how minority graduate students are experiencing inclusion within speech-language pathology training programs showed how they are affected by their experiences. Additionally, sorting and cataloguing data showed potential congruence between participants' interpretations of experiences. A basic qualitative research study frequently uses data that comes from people's expressive language output. In this research study, descriptive data were based on written language that served as artifacts of participants' experiences and beliefs.

\section{Paradigm Guiding Inquiry}

This research had a basis in Meyer et al.'s (2014) UDL as a conceptual framework and the use of UDL as an inclusive pedagogy within postsecondary settings. UDL was combined with critical theory, which uses an examination of historical and societal inequities to address how dominant majority expectations affect minority groups, and the conflation of minority identity markers with negative traits (Gay, 2002). This 
research was grounded in critical theory, which includes asset pedagogies that acknowledge the strengths that minority individuals bring to educational settings (SmithMaddox \& Solorzano, 2002). Combining UDL with critical theory challenges traditional educational settings to examine how the use of labels of pathology and minority perpetuate marginalization (Waitoller \& King Thorius, 2016). The UDL framework of variations in learning styles and cultural backgrounds becomes a foundation for addressing societal power dynamics (Meyer et al., 2014; Waitoller \& King Thorius, 2016).

\section{Data Gathering}

As previously stated, I implemented a method to gather multiple forms of data. Participants were asked to respond to written prompts to generate documents for study. Merriam and Tisdell (2016) described how documents may serve as the main source of data for a qualitative study and provide information on critical incidents and reflections on a phenomenon. The documents came from prompts for personal experiences, perception of inclusion, a policy recommendation, and advice to another minority student. The purpose of this data-gathering method was to obtain different forms of data to understand the lived experiences and beliefs about inclusion that minority graduate students in speech-language pathology hold. After completing the writing prompts, participants were invited to participate in a second phase of the study where they could create an inclusive recruitment flyer and a subsequent interview about the experience of creating their flyer. 


\section{Participant Recruitment}

Research participants were recruited from accredited speech-language pathology graduate training programs across the United States through outreach to department chairs at each training program. The department chairs at all 281 accredited graduate programs in speech-language pathology in the United States and its territories were contacted through email to solicit participation in the research, excepting Portland State University (Council on Academic Accreditation, 2018b). Portland State University was excluded due to potential bias, as the researcher is a faculty member within the Speech and Hearing Sciences Department. An initial invitational email to all department chairs was sent on August 15, 2019. Department Chairs were requested to confirm distribution of the survey to their graduate students. A second invitation was sent on September 16, 2019, to all programs that did not to the first request. Department chairs were specifically instructed to offer participation in the study to all graduate students. The survey was also distributed through social media at the National Student Speech Language Hearing Association on August 15, 2019, and two national faculty listservs, specifically ASHA Special Interest Groups for Issues in Higher Education and Cultural and Linguistic Diversity on August 17, 2019, and August 20, 2019, respectively. Purposeful sampling was based on participants' self-identification of minority status within the field of speechlanguage pathology, and subsequent completion of identity markers. Recruitment information described the aims of the study and described the targeted minority groupings of race, socioeconomic status, male, LGBTQ+, and disability. Socioeconomic 
status was described as having early experiences in a low-income background. Sampling assumed participants' honesty in identification of identity markers that were authentic to them and participants were not required to provide documentation or proof of any identity markers. Participant self-identification was a deliberate method to avoid relying on societal judgments of minority status or proxy indicators. Given that voices of minority students was the goal, allowing students to select whether or not they were minorities and the identity markers that were meaningful to them encouraged students to reflect on their own identities without relying on external sources of classification. Selfidentification is highly important for students who have disabilities due to the reliance on biomedical models, which often require access to medical systems and use narrow diagnostic categories (Gabel, 2010). Although general demographic options were included, participants were also offered the opportunity to include their own identity markers following the model of Hutcheon and Wolbring (2012) that provided an identity marker title without listing any specific criteria.

\section{Demographic Information Form}

In the writing prompts portion of the study, participants' responses were separated from their names and the state in which their graduate training program was located. Confidentiality was expected to be important to participants due to the role of the researcher, as a faculty member at a university, and the possibility of judgment of responses within an academic or future professional setting. Participants were instructed to omit any specific identifying names and if any names are present in the responses, they 
were removed before analysis. Participants' names were not connected to their responses during the first phase of the study to avoid any conflict of interest due to prior, current, or upcoming relationships with the researcher. A simple participant demographic form, found in Appendix B, provided general background information through self-selection of identity markers for minority groups. It is important to note that a separate identity marker titled "other identity" was included to allow for participants to describe a different minority marker, such as religion, veteran status, or age. Participants were instructed to specify all minority group identities to allow for exploration of intersectionality, the holding of multiple identities (Sensoy \& DiAngelo, 2012). Additionally, participants were able to include other identities that were not listed. The identity markers were used to organize the data and provide a general frame of reference for groupings.

\section{Documents}

Participant generation of documents served as a method or tool. Personal documents are forms of first-person narratives that function to show what that author recognizes as important (Merriam \& Tisdell, 2016). "Personal documents are a good source of data concerning a person's attitudes, beliefs, and view of the world" (Merriam \& Tisdell, 2016, p. 166). These documents highlighted subjective participant perspectives. Personal documents are a form of written discourse, and as such can also be analyzed using discourse analysis (Gee, 2014). The study had phases, as shown in Figure 1. 


\section{Figure 1}

Flowchart of Phases
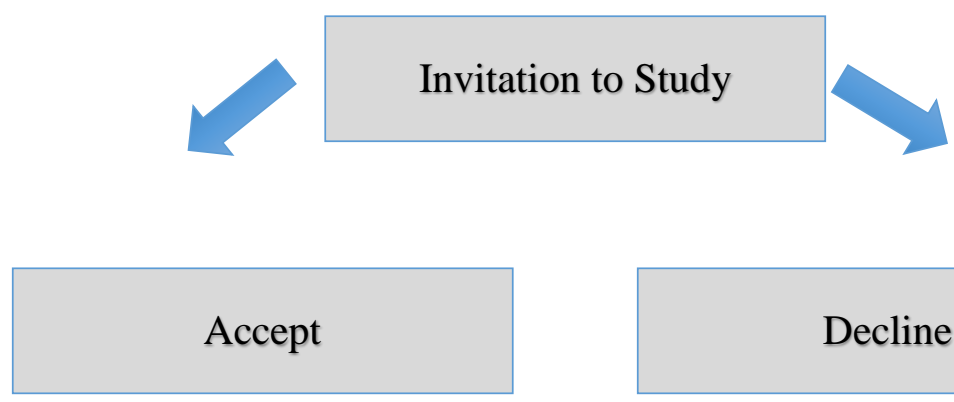

Decline

Phase 1: Completion of writing prompts
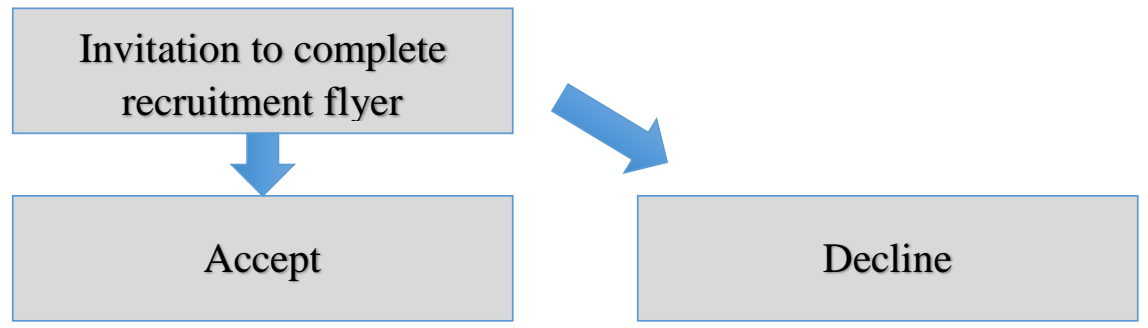

Phase 2: Completion of recruitment flyer

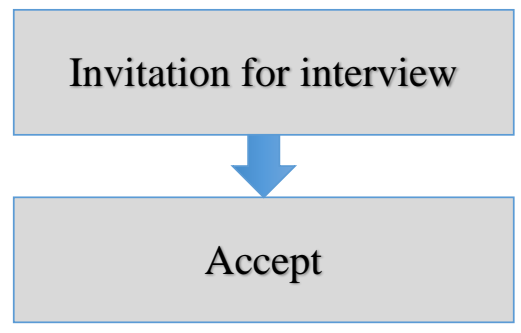

Decline

Complete interview 


\section{Phase 1}

For this study, I asked participants to generate personal documents based on written prompts to elicit self-reflections about experiences that affected inclusion. Participants were asked to share their overall feelings of inclusion and provide advice for programs and advice for a peer. Participants were asked to describe why the experiences were important to them and to connect their experiences and feelings to their identities.

The prompts for the personal documents with full participant directions are listed in Appendix C. As previously noted, these prompts addressed experiences that decreased and increased inclusion, overall feelings of inclusion, a policy recommendation to increase inclusion, and peer advice. Within the generation of personal documents, the prompts established a personal context of the experiences of the participant. The recommendation prompt encouraged participants to consider the larger institutional structure in which their experience occurred, and the advice prompt required participants to reflect on the significance of what their experiences have meant to them in order to support another person in a similar situation. Factors affecting inclusion were chosen as a focal point for the recommendation prompts, as opposed to factors that contribute to exclusion based on Gay's (2002) work on culturally responsive teaching, which described how the academic success of minority students was negatively affected by the introduction of stereotypes into the learning environment. A focus on factors that promote inclusion in the recommendation prompts sought to minimize risks of potential negative emotions associated with recollecting and retelling experiences of exclusion. 
After Institution Review Board approval, graduate students at speech-language pathology training programs in the United States and its territories received an email invitation to the study from their department chair, or through social media. Graduate students were informed of the intent of the study, Institution Review Board approval and consent, and encouraged to consider their own identities in relation to the study. Participants used Qualtrics survey tools to type their responses to the demographic information questions and to respond to each of the writing prompts.

\section{Phase 2}

Upon completion of the writing prompts, participants were invited to participate in the creation of a visual representation of inclusion by designing an inclusive recruitment flyer, and responding to telephone interview questions about the creation of their flyer, as described in Appendix D. The submission of an inclusive recruitment flyer was achieved through an electronic medium, specifically uploading a file through Qualtrics survey tools. An interview about the experience of creating an inclusive recruitment flyer was conducted through a telephone interview.

The goal of generating personal documents was to have an understanding of the phenomenon of being a minority within speech-language pathology graduate training programs and the participants' lived experiences. I chose personal documents as a main source of data because I was interested in the stories of the participants, and believed that separating names from the data would ensure the freedom to express events without judgment and the confidentiality of participants in a relatively closed field. 
The use of specific writing prompts to generate personal documents provided a structured approach within qualitative research. Given that participants had different identity markers, the use of a structured approach allowed for the possibility of comparisons across minority groups, in that "structured approaches can help ensure the comparability of data across individuals, times, settings, and researchers, and are particularly useful in answering questions about differences between people or settings" (Maxwell, 2013, p. 88). Pre-structuring the data provided an organizational framework for the data. The specific conceptual and analytical purposes of each of the writing prompts, and the inclusive recruitment flyer were as follows:

\section{Prompt 1: Personal Experiences}

The personal experiences prompts were designed to elicit meaningful personal events within the graduate training program that negatively affected and positively affected the experience of inclusion for a minority student, as shown in Table 1. Examining personal events relating to inclusion with coding to establish themes, and through the tools of discourse analysis shows multiple layers within the experience, including enactment of roles, positioning of the listener, and transfer of social goods, which represent concepts of value within society. Within critical discourse analysis, the writer is enacting a role, which reflects a desired identity (Gee, 2014). The written responses were analyzed based on how participants presented their own identities within their experiences and their relationships to others. Experiences that included an interaction with another person were analyzed based on how the participant was positioned within the communication exchange. Positioning is how speakers or writers 
influence listeners to think and behave in certain ways that align with an identity chosen by for them by the speaker or writer (Gee, 2014). In the promotion of inclusion, this concept can be viewed with discourse analysis as a social good. Social goods represent power, status, roles, opportunity, and more that are transferred through language (Gee, 2014). Themes that emerge through coding and categorization, and discourse analysis were the basis for a discussion of the connectedness of social relationships and inclusion.

\section{Table 1}

Prompt 1: Personal Experiences

\begin{tabular}{|c|c|c|}
\hline Writing Prompt & Research Question & Methods and Analysis \\
\hline $\begin{array}{l}\text { Prompt 1: What was a } \\
\text { meaningful experience that } \\
\text { decreased/increased your } \\
\text { feelings of being included } \\
\text { within your graduate training } \\
\text { program? }\end{array}$ & $\begin{array}{l}\text { Question 1: What is the } \\
\text { experience of inclusion in } \\
\text { relation to systems } \\
\text { (university, field of study, } \\
\text { department), context } \\
\text { (classroom and social } \\
\text { settings), and interaction } \\
\text { (faculty, staff, and peers)? }\end{array}$ & $\begin{array}{l}\text { Positioning of communication } \\
\text { partners and transfer of social } \\
\text { goods (opportunities and } \\
\text { resources) through interaction } \\
\text { to be analyzed with discourse } \\
\text { analysis (Gee, 2014) }\end{array}$ \\
\hline
\end{tabular}

Note. Prompts with full participant directions are included in Appendix C.

\section{Prompt 2: Inclusion}

The overall inclusion prompt served as a method to understand the extent to which minority students in speech-language pathology graduate training programs experienced inclusion, or felt included, as shown in Table 2. Having minority students explain their own perceptions of inclusion contributed to establishing a context for their personal experience, recommendation, and advice. Understanding the minority students' immediate frame of reference for their own inclusion informed interpretation of their 
personal documents. The inclusion prompt sought general information and responses were coded for themes. Responses were categorized into gradations of negative and positive, and comparisons were made across demographic categories. The inclusion prompt collected information about overall perceptions that were analyzed for positive and negative trends by minority group.

\section{Table 2}

\section{Prompt 2: Inclusion}

\begin{tabular}{|c|c|c|}
\hline Writing Prompt & Research Question & Methods and Analysis \\
\hline $\begin{array}{l}\text { Prompt 2: To what extent } \\
\text { have you felt included in your } \\
\text { graduate training program in } \\
\text { speech-language pathology } \\
\text { and why have you felt this } \\
\text { way? }\end{array}$ & $\begin{array}{l}\text { Question 1: What is the } \\
\text { experience of inclusion for } \\
\text { minority graduate students } \\
\text { in speech-language } \\
\text { pathology training } \\
\text { programs? }\end{array}$ & $\begin{array}{l}\text { Coding of general themes for } \\
\text { thematic analysis of gradations } \\
\text { of inclusion in relationship to } \\
\text { minority groupings } \\
\text { (Merriam \& Tisdell, 2016) }\end{array}$ \\
\hline
\end{tabular}

Note. Prompts with full participant directions are included in Appendix C.

\section{Prompt 3: Policy}

The policy prompt was designed to examine how minority graduate students interacted within the organizational structure of their university programs and navigated the inherent power relationships of being students and being minorities within their field, as shown in Table 3. The policy prompt elicited a policy recommendation, following the model of Hutcheon and Wolbring (2012), which provided insight on how policies affected students with disabilities. Hutcheon and Wolbring allowed participants to explain how labeling and designations of services affected perceptions of identity. Participants in the study provided a recommendation for a university program to increase 
inclusion for minority students. The policy prompt was analyzed for themes and explored the political aspects of granting access to social goods. Wording used within the policy prompts was considered from a political perspective, which shows how language usage gives or takes power from others (Gee, 2014).

\section{Table 3}

Prompt 3: Policy

\begin{tabular}{|c|c|c|}
\hline Writing Prompt & Research Question & Methods and Analysis \\
\hline $\begin{array}{l}\text { Prompt 3: What } \\
\text { recommendations do you have } \\
\text { for graduate training programs } \\
\text { in speech-language pathology } \\
\text { to increase inclusion for } \\
\text { minority students based on } \\
\text { your own experiences? }\end{array}$ & $\begin{array}{l}\text { Question 2: What are the } \\
\text { recommendations of minority } \\
\text { graduate students in speech- } \\
\text { language pathology graduate } \\
\text { training programs to increase } \\
\text { inclusion and address the lack } \\
\text { of diversity in the field? }\end{array}$ & $\begin{array}{l}\text { Institutional and political } \\
\text { role in the granting of } \\
\text { social goods through } \\
\text { policies and procedures to } \\
\text { be analyzed with discourse } \\
\text { analysis (Gee, 2014) }\end{array}$ \\
\hline
\end{tabular}

Note. Prompts with full participant directions are included in Appendix C.

\section{Prompt 4: Advice}

The advice prompt created a social scenario in which the participant was addressing a peer with the same or similar social status and minority identity, as shown in Table 4. Participants provided advice to a future student from a minority background about inclusion with a graduate training program in speech-language pathology. An important aspect of the advice prompt was the potential use of vernacular social language, which represents a language style that is common when an individual seeks group affiliation within an interaction (Gee, 2014). The advice prompt provided specific recommendations about what to expect in a graduate training program based on holding a 
minority status or minority identity markers, and how other people and the larger institution may respond to minority individuals.

\section{Table 4}

Prompt 4: Advice

\begin{tabular}{|c|c|c|}
\hline Writing Prompt & Research Question & Methods and Analysis \\
\hline $\begin{array}{l}\text { Prompt 4: What advice } \\
\text { would you give to another } \\
\text { minority student about } \\
\text { inclusion to prepare them } \\
\text { for a speech-language } \\
\text { pathology graduate training } \\
\text { program? }\end{array}$ & $\begin{array}{l}\text { Question 2: What is the } \\
\text { experience in relation to } \\
\text { systems (university, field of } \\
\text { study, department), context } \\
\text { (classroom and social settings), } \\
\text { and interaction (faculty, staff, } \\
\text { and peers)? }\end{array}$ & $\begin{array}{l}\text { Positioning of } \\
\text { communication partners } \\
\text { with similar identity markers } \\
\text { on the expectations of the } \\
\text { granting of social goods to } \\
\text { be analyzed with discourse } \\
\text { analysis (Gee, 2014) }\end{array}$ \\
\hline
\end{tabular}

Note. Prompts with full participant directions are included in Appendix C.

After completing the written prompts, participants were invited to participate in

the second phase of the study, where they could create an inclusive recruitment flyer, and respond to interview questions about the creation of the flyer, as shown in Table 5.

\section{Table 5}

Prompt 5: Inclusive Recruitment Flyer

\begin{tabular}{|c|c|c|}
\hline Flyer Prompt & Research Question & Methods and Analysis \\
\hline $\begin{array}{l}\text { Prompt 5: On your own, } \\
\text { individually create an inclusive } \\
\text { recruitment flyer to encourage } \\
\text { minority students to pursue the } \\
\text { field of speech-language } \\
\text { pathology. }\end{array}$ & $\begin{array}{l}\text { Question 3: How do minority } \\
\text { graduate students in speech- } \\
\text { language pathology training } \\
\text { programs envision inclusion in } \\
\text { the field? }\end{array}$ & $\begin{array}{l}\text { Enactment of inclusion } \\
\text { through roles, identity, } \\
\text { and text to be analyzed } \\
\text { with discourse analysis } \\
\text { (Gee, 2014) }\end{array}$ \\
\hline
\end{tabular}

Note. Prompts with full participant directions are included in Appendix D. 


\section{Participants}

Qualitative research generally uses nonprobability sampling, which is the purposeful selection of a sample to gain an in-depth understanding (Merriam \& Tisdell, 2016). To address the problem of lack of diversity within speech-language pathology, which affects the ability of the field to understand the needs of minority groups, I chose to focus on graduate training programs. Graduate training programs are a requirement to practice as a speech-language pathologist and serve as a form of socialization into the culture of speech-language pathology. Sensoy and DiAngelo (2012) described socialization as the systematic training on the norms of a culture and learning expected practices and ways to behave. Individuals may be more or less included within the socialization process, depending on how their individual identity markers are or are not reflected in the expected normative behaviors of the culture (Sensoy \& DiAngelo, 2012). Examining how minority graduate students experience inclusion within their programs reflected ways in which the field responds to diversity. Criteria for participants were participation in a graduate program in speech-language pathology and holding a minority identity marker.

Typical sampling, which is designed to provide a sample that corresponds to a general or average person who experienced a phenomenon (Merriam \& Tisdell, 2016) was used. Typical sampling involved participants who self-identify with one or more identity markers that have traditionally been underrepresented within society or within the field of speech-language pathology, specifically, the social groups of race, class, gender, sexuality, and ability. Given that the number of minority graduate students in any 
given university was likely to be a small percentage of the population, potentially $5-10 \%$, if student demographics continue to remain the same, it was important to include multiple university programs within the study. All graduate programs in the United States and its territories were included. Given that graduate school cohorts can range between 20-35 students per year within a two-year program, and approximately $10 \%$ of students might identify as minorities, each program would have two or three students who could participate. As previously noted, Portland State University was excluded from this study to avoid any potential conflict of interest, as the researcher is a faculty member within the Portland State University Speech and Hearing Sciences Program. At the time of survey distribution, there were 281 accredited speech-language pathology graduate training programs in the United States and its territories. An invitational email was sent to all department chairs, as previously described. Student participation was dependent on departmental approval and responsiveness to the study.

This study recruited minority graduate students in speech-language pathology training programs in the United States and its territories. To increase confidence that information gained was representative of the larger group of minority graduate students, I sought support from all nationally accredited graduate programs. My strategy to recruit participants included electronic requests to faculty, the national student organization group, and national faculty electronic list serves, offering a brief introduction about the research goals and methods to solicit participants. Recruitment for the study included all graduate students and was not targeted to any specific students based on any pre-existing demographic information or assumptions of minority status. The recruitment email with 
directions for department chairs of graduate training programs is located in Appendix E. The recruitment plan is shown in Figure 2.

\section{Figure 2}

\section{Recruitment Sequence}

\section{Contact Department Chairs}

- Send introductory email

- Describe purpose of study and recruitment methods

- Provide link to study to be shared with all graduate students

- Request confirmation of distribution to students

- Respond to questions, as appropriate

\section{Second Request}

-After 30 days, email a second request to all programs who did not confirm distribution

\section{Social Media}

-Share on national student site and faculty listserves

\section{Consent}

Given that all participants in research experiences are likely to encounter some degree of risk, although it may be a slight risk, the consent form in Appendix A provided detailed information about any potential risks. The consent form included information about participant rights, general study purposes, and contact information for the researcher and advisor. Participants were able to choose whether or not they would like to participate in the study. Participants received reminders that all personal documents they created within the study would be confidential. Participants were also informed that data 
would be stored in locked cabinets, on password-protected computers, and eventually destroyed.

\section{Confidentiality}

Confidentiality is an ethical consideration within qualitative research (Merriam \& Tisdell, 2016). Given that the researcher works in a faculty position within a speechlanguage pathology graduate program, and identifies as a minority within the field, it was important that there was not a conflict of interest between any participants and the researcher. A signed consent form ensured that the participants understood that all information that they contributed to the study would be analyzed without researcher knowledge of individual identities. Analysis that is based on confidentiality of participant names, and the removal all identifying information, such as geographic location, university program, faculty, and more, has the potential to free participants from any of the power dynamics that exist within graduate programs around social goods, such as receiving grades, access to practicum opportunities, invitations to participate in research labs, letters of recommendations for job applications, and more. As previously stated, Portland State University was excluded from this study due to my role as a faculty member within the graduate program in speech-language pathology.

\section{Timeline}

Recruitment for participants began in the fall of 2019 following Institution Review Board approval of the research study. Data collection of the writing prompts was completed in the fall of 2019, along with data collection for the visual representation prompt to create an inclusive recruitment flyer and a subsequent interview. Data analysis 
was conducted during fall of 2019 and winter of 2020. Completion of Chapters 4 and 5 of the dissertation were completed during spring and summer of 2020.

\section{Coding}

Within this research study, qualitative data consisted of personal documents created by participants in response to a set of writing prompts around inclusion within a graduate training program in speech-language pathology. The personal documents were used to examine a reflection of meaningful incidents for the participant, a policy recommendation, and advice to a peer. Data analysis was focused on coding and categorization to establish themes with the goal of deriving meaning from the data (Merriam \& Tisdell, 2016). The coding sequence based on Saldaña's (2016) guidelines is shown in Figure 3.

A qualitative approach allowed the voices and experiences of minority graduate students in speech-language pathology to be the main source of understanding inclusion within training programs. According to Merriam and Tisdell (2016), qualitative analysis is inductive and comparative to create a substantive theory that refers to "specific, everyday-world situations" (p. 31). Personal documents from participants were compared to each other and categorized using open coding with In Vivo coding, which labeled data within the analysis of written texts (Saldaña, 2016). In Vivo coding centered on wording directly from participant personal documents to capture authentic voices (Saldaña, 2016). Open coding was the basis for descriptive substantive categories based on participants' beliefs, and theoretical categories that reflected researcher concepts relating to a theory (Maxwell, 2013). Following Merriam and Tisdell (2016), categories came from multiple 
sources, including researcher observations of themes within the data, wording within participant responses, and external sources, specifically minority identity markers to make comparisons across minority groups. To construct meaning from the data, there were layers of interpretation where individual and collective contributions provided insight into the given phenomenon of inclusion (Guba \& Lincoln, 2005).

\section{Figure 3}

\section{Coding Sequence}

\section{Raw Data}

Personal documents: written responses and inclusion flyer Transcripts of interviews

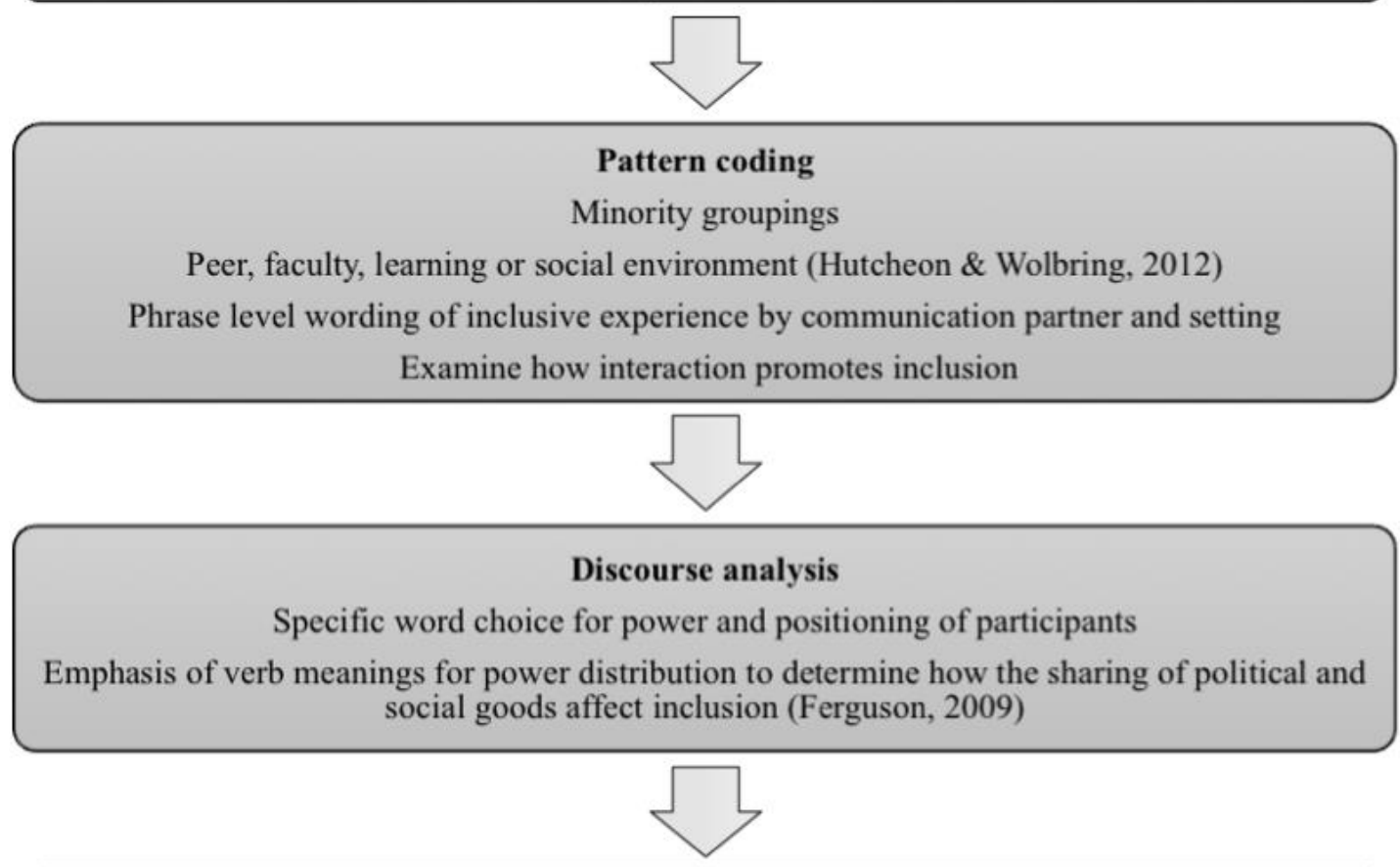

\section{General themes for recommendations}

Associations or relationships between minority groupings and experience of inclusion Recommendations for targeting inclusive practices by minority group at the peer, faculty, or learning or social environmental level 
According to Brantlinger et al. (2005) interpretation of data in qualitative research may involve the following: deconstruction and scrutiny of data, reflexive analysis of assumptions about the data, critical analysis of power disparities, and discourse analysis that provides insight into underlying social values. Additionally, credibility of findings relies on auditing of analysis methods to produce evidence showing an exploration of specific individuals within a defined context.

\section{Discourse Analysis}

Applying discourse analysis tools for written texts showed how the language in personal documents corresponded to identity roles and larger issues. Gee (2014) discussed three main tools for analyzing oral and written discourse: (a) social language, (b) big-C Conversations (with a capital C), and (c) intertextuality. Social language indicates social identity and actions of the speaker that are expressed through learned linguistic patterns. Conversations refer to familiar and divisive societal issues that have historical underpinnings. Intertextuality describes how language styles are borrowed from other specific sources or genres. These tools provide insight into how speakers and writers view themselves, how they connect their thoughts to larger issues, and the significance of mirroring other texts.

Each identity has its own social language, with the student identity as informal and containing a high level of personal statements, and the university and clinical identities using formal language with jargon specific to their roles. Examining the personal documents showed how social language reflects participant identities. In the area of Conversations, or larger societal debates, I was able to examine the significance 
of societal issues, and any assumptions of familiarity about dichotomous or polarizing viewpoints. Potential examples of societal debates that appear in the literature are the meritocracy of higher education, commodity education with students as consumers, edutainment that assumes students need to be entertained due to their lack of academic discipline, the societal constructs of ability/disability, and much more. With intertextuality, I was able to examine the borrowing of verbiage from other sources, and what this might mean for participants' understanding of their experiences. Participants' responses were examined for the use of phrases from their coursework and experiences with peer and faculty members. Both the occurrence and the origins of these intertextual elements showed their potential influence on participants' thought processes.

Discourse analysis tools showed how participant identities interacted with the social context of a graduate training program. Analysis provided participants' understanding of larger societal conversations that force people to choose sides. The repetition of another's words within written documents had the potential to show how and why participants have incorporated them into their worldview. Written discourse contains often-overlooked clues about thought patterns. An examination of visual representations of inclusion in the recruitment flyers showed how individuals enacted inclusion through demonstrations of identity. Analysis of the transcripts of the interview about the experiences creating an inclusive recruitment flyer allowed for individual examination of factors that were considered in the creation of a visual representation of inclusion within speech-language pathology. This study highlighted the presence of larger societal conversations and intertextuality, such as inclusion, diversity, minority, 
culture, and more, when prominent in participant responses. This study primarily focused on the use of specific meaningful verbs within the recommendation prompts to reflect power relationships. An example of potential coding for verbs that is based on the work of Ferguson (2009) is shown in Table 6.

\section{Table 6}

Potential Verb Discourse Coding

\begin{tabular}{lll}
\hline Potential Coding & Verb Examples & Significance \\
\hline Authority & "tell, make, have to" & Social distance \\
Collaboration & "partner, share, join" & Social positioning \\
Invitation & "offer, suggest, welcome" & Inclusion \\
Support & "encourage, help, assist" & Distribution of resources \\
Initiation & "seek, find, act" & Self-advocacy \\
& & \\
\hline
\end{tabular}

\section{Triangulation and Validity}

Triangulation encompasses data, investigator, theory, and methodology (Brantlinger et al., 2005; Gersten et al., 2005). Data triangulation included the solicitation of three mediums of data, personal documents of written texts, visual representations, and interviews with participants. Investigator triangulation was conducted by having doctoral committee members who were familiar with qualitative analysis review the coding schemes. Theory triangulation was viewed within the research of the experiences of minority postsecondary students and within the field of speech-language pathology, as both research bases provided important theories to consider when interpreting the data. Methodological triangulation was attempted by offering participants different modalities 
to express their understanding of inclusion, specifically writing, designing a visual product, and responding to questions during a telephone interview.

The structure of obtaining personal documents from participants created an account of the participants' experiences with inclusion within a graduate training program from different perspectives. I initially highlighted the words of participants with In Vivo coding to provide a basis for the analysis of their experiences (Saldaña, 2016). Visual representations of inclusion in a recruitment flyer were compared with the data from personal documents that described personal experiences and provided recommendations and advice. An audio recorded transcript of a telephone interview with a participant on the experience of creating an inclusive recruitment flyer provided details about how an individual viewed inclusion and sought to communicate the concept of inclusion to others. Triangulation was addressed through the provision of phases with the aim of establishing a collection of written, visual, and interview data. Having multiple forms of written data allowed for the extraction of themes, hierarchies, and an exploration of the interplay between internal and external factors. Within the interview process, the interviewer's role as a researcher, instructor, and doctoral student was disclosed to the participant. Member checks to review written transcripts of interviews were offered. A participant was able to examine the transcript of the interview to confirm that the interview was representative of the thoughts, ideas, and beliefs that were expressed. The participant was encouraged to provide any clarification information or make changes to the answers to represent a clear understanding of the message. 


\section{Role of the Researcher}

As a researcher, my position within the research was shaped by my position as a Clinical Assistant Professor within the Portland State University Speech and Hearing Sciences Department, a training program in speech-language pathology on an urban campus that serves undergraduate, post baccalaureate, and master's level students. I am also certified as a speech-language pathologist and have extensive experience providing clinical services in a public school setting. As a practitioner, I worked in an educational setting with children and families from racially, culturally and linguistically diverse backgrounds, as well as children and families experiencing financial hardships. Additionally, I am considered a racial and ethnic minority within the field of speechlanguage pathology due to multi-racial heritage, and I attended a high poverty school as a child. When collecting and analyzing data, I disclosed my faculty position to the participants. In analyzing the data, I acknowledged that I have bias based on my role as a speech-language pathologist, as a racial and ethnic minority, and having come from a low socioeconomic setting, and therefore have opinions regarding diversity within the field. As a clinical professor within a university, my role includes evaluating students through teaching academic coursework and clinical skills. In analyzing the data, I acknowledged how my biases influence my perceptions within this research through audit memos that describe the coding and analysis process.

\section{Audit Memos}

Audit memos and the audit trail, the collection of audit memos in qualitative research, increases transparency in methodology and enhances reliability (Maxwell, 
2013). Maxwell (2013) recommended capturing the simultaneous process of data collection and analysis through a series of written memos that reflect on the varied meanings and categorization schemes of the data, as well as to guide thoughts and decision-making. Merriam and Tisdell (2016) described how the memos form an audit trail that explains how the data led to the findings. The audit trail serves as a map or guide for consistency between the data and the conclusions.

Within qualitative research, reliability corresponds with consistency between the results and the data (Merriam \& Tisdell, 2016). A key aspect of consistency is the audit trail describing the decision-making process of research analysis. Merriam and Tisdell (2016) outline the iterative use of questions within data collection and analysis. Their questions encompass the complex tasks of coding and categorizing data based on interesting, relevant, and important aspects. Data are coded for essential elements and then categorized to foster connections that may be used to form a theory, understand a phenomenon, or bring meaning to an experience. Within coding and categorization, researchers use key words, which are subsequently used in sentences to construct interconnectedness (linkages and relationships across elements). Words and sentences can be analyzed for their own meanings and show potential underlying influences within methodology.

As a researcher, my own audit memos show my role as a researcher. Multiple social languages reflect my varied identities as a graduate student, a university professor, and my prior profession as practitioner within the field of special education, and a minority within the field of speech-language pathology and within the United States. An 
audit trail is an incredibly powerful tool in qualitative research to examine researchers' perspectives on the data, provide transparency of methods, and enhance consistency that I employed to examine my own biases within the research study. Living as a minority within the United States, and studying, practicing, and teaching as a minority in a homogenous field, made me conscious of my connection to the research. I used a journal to track my thinking and how my own role was enmeshed in the problem of practice. As reflexive researcher, it was my intention to challenge my own assumptions about the data analysis process, with the idea that questioning established beliefs can make the familiar become novel (Glesne, 2011).

\section{Conclusion}

Speech-language pathologists play an important role in providing assessment and intervention services for individuals with communication, cognition, and swallowing disorders. Although the demographics of the United States are continually changing, the demographics within the field of speech-language pathology have remained relatively constant as white, female, and monolingual English speakers (ASHA, 2017a). The lack of diversity within the field has the potential to have direct consequences on the research, policies, and practices that guide services to clients from multicultural backgrounds. To provide culturally responsive services to clients, it is important for the field to develop an understanding of the experiences of minorities who seek membership within it.

From a critical theory perspective, understanding the experience of minority groups who have been historically oppressed within society (Sensoy \& DiAngelo, 2012) is a method to address lack of diversity. Different groups receive benefits and privileges 
at the expense of other groups, and the identity markers of race, class, gender, sexuality, and ability have been the main determinants of social hierarchies (Sensoy \& DiAngelo, 2012). This study highlighted the voices of minority graduate students to examine experiences of inclusion, collect views about ways to increase inclusion, and analyze how inclusion is made visible.

Faculty members operate as leaders within graduate training programs. In attempting to address national initiatives for diversity (ASHA, 2018c), faculty members need to redefine how knowledge is obtained. Excluding the voices of minority graduate students in designing and implementing recruitment and retention methods fails to honor the underpinnings of inclusion, which may be the ultimate goal for any institution that seeks to increase student diversity. For minority graduate students, obtaining a master's degree is a significant accomplishment within a stratified society. Without understanding how minority graduate students experience inclusion, leaders within the field may be at a loss in their attempts to achieve it. 


\section{Chapter 4: Results}

\section{Introduction}

Chapter 3 provided a discussion of the research methods that I used to conduct my study on the experiences of inclusion for graduate students who are minorities within the field of speech-language pathology. This study aimed to bring the voices of minority graduate students and their lived experiences into the larger discussion of inclusion within higher education and diversity within the field of speech-language pathology. My research questions are as follows:

1. What is the experience of inclusion for minority graduate students in speechlanguage pathology training programs in relation to systems (university, field of study, department), context (classroom and social settings), and interaction (faculty, staff, community, and peers)?

2. What are the recommendations of minority graduate students in speechlanguage pathology training programs to increase inclusion to address the lack of diversity in the field?

3. How do minority graduate students in speech-language pathology training programs envision inclusion in the field?

\section{Analysis of Data}

\section{Survey Distribution}

An email invitation for graduate programs to participate in the inclusive recruitment survey was sent to the department chairs at all 281 accredited speechlanguage pathology graduate programs in the United States and its territories. Department chairs were asked to confirm distribution of the survey to the graduate students within their programs. As described in Chapter 3, an initial recruitment email message was sent 
on August 15, and was resent to all programs that did not confirm a response on September 16 . Out of a total of 281 graduate programs 29 programs confirmed distribution of the survey for a response rate of $10 \%$. It should be noted that demographic percentages were rounded to whole numbers based on a decimal portion of 0.5 and above. For example, the response rate of $10.32 \%$ was rounded down to $10 \%$. Confirmation of distribution included graduate programs in 20 states and the District of Columbia. Confirmation was received from Arizona, Indiana, Iowa, Louisiana, Massachusetts, Michigan, New Mexico, New Jersey, New York, Nebraska, North Carolina, North Dakota, Ohio, Oregon, Pennsylvania, South Carolina, Tennessee, Texas, Virginia, Wisconsin, and Washington, DC.

Information about the survey was also posted through social media on the National Student Speech Language Hearing Association and through the ASHA Special Interest Groups on Issues in Higher Education and Cultural and Linguistic Diversity in mid-August. The survey remained open until October 1, 2019. The survey was subsequently reopened and remained open for a 24-hour time period once in October and once in November, when the researcher received requests from two graduate students who wanted to complete the survey.

A total of 104 participants completed the survey out of 348 who initiated the survey, which represented a completion rate of $30 \%$. The majority of participants who did not complete the survey started the survey by providing all of their demographic information, but then did not respond to the written prompts. 


\section{Geographic Region}

Survey participants were asked about the location of their graduate program. Participants attended graduate programs across 28 states, which covered all four broad geographic regions of the United States, including Western, Midwest, North Eastern, and Southern states, as shown in Table 7. Table 7 shows the actual number of participants from each state and the percentage of the total participants by state within the sample. Given that 28 states were represented across all regions of the country, responses may be representative of the larger field of speech-language pathology, as opposed to being constrained by specific regional contexts.

\section{Graduate Level}

Most speech-language graduate programs are two years. A total of 33 participants indicated that they were in their first year of graduate school, which corresponded to $32 \%$. The majority of participants reported that they were in their second year of graduate school, for a total of 67 participants, which equaled 64\%. Three participants reported that they were in their third year of their graduate program, and one participant indicated fourth year. It is not known whether or not these students are attending programs that extend to three or four years, such as part-time or distance learning program, or whether they needed to extend their program for other reasons. A summary of participant year in their graduate programs is provided in Table 8. 
Table 7

Participant States for Graduate Programs

\begin{tabular}{|c|c|c|}
\hline$\underline{\text { State }}$ & $\begin{array}{l}\text { Number of } \\
\text { Participants } \\
\end{array}$ & $\begin{array}{c}\text { Percentage of } \\
\text { Sample }\end{array}$ \\
\hline Alabama & 1 & 1 \\
\hline Arizona & 1 & 1 \\
\hline Arkansas & 2 & 2 \\
\hline California & 6 & 6 \\
\hline Colorado & 2 & 2 \\
\hline Florida & 8 & 8 \\
\hline Indiana & 2 & 2 \\
\hline Kansas & 1 & 1 \\
\hline Kentucky & 2 & 2 \\
\hline Louisiana & 2 & 2 \\
\hline Maine & 1 & 1 \\
\hline Maryland & 2 & 2 \\
\hline Massachusetts & 2 & 2 \\
\hline Michigan & 4 & 4 \\
\hline Missouri & 2 & 2 \\
\hline New Jersey & 5 & 5 \\
\hline New Mexico & 5 & 5 \\
\hline New York & 11 & 11 \\
\hline North Carolina & 4 & 4 \\
\hline North Dakota & 1 & 1 \\
\hline Ohio & 6 & 6 \\
\hline Pennsylvania & 3 & 3 \\
\hline South Carolina & 7 & 7 \\
\hline Tennessee & 2 & 2 \\
\hline Texas & 10 & 10 \\
\hline Virginia & 3 & 3 \\
\hline Washington & 3 & 3 \\
\hline Wisconsin & 2 & 2 \\
\hline Not Stated & 4 & 4 \\
\hline
\end{tabular}




\section{Table 8}

Participant Year in Graduate Programs

\begin{tabular}{lcc}
\hline Year & $\begin{array}{c}\text { Number of } \\
\text { Participants }\end{array}$ & $\begin{array}{c}\text { Percentage of } \\
\text { Sample }\end{array}$ \\
First & 33 & 32 \\
Second & 67 & 64 \\
Third & 3 & 3 \\
Fourth & 1 & 1 \\
\hline
\end{tabular}

\section{Summary of Participant Demographics}

This survey was designed to reach graduate students who identified as minorities within the field of speech language pathology. When examining stratification within society through Sensoy and DiAngelo's (2012) classification of identities, the categories of race and ethnicity, socioeconomic status, gender, sexual orientation, and disability are considered to be the primary markers of minority status. Within speech-language pathology, which is a predominantly female field, the category of male in a female dominated field is important. Although monolingualism and bilingualism were not the specific focus of this research, information was gathered about participant language and non-native English speaker status, as this data provides a larger context for race and ethnicity. Table 9 shows the number and percentage of participants who indicated identity markers that reflected specific minority status. Although this table shows totals for each category, it does not show the presence of multiple identities or intersectionalities of participants. Multiple participants chose multiple identity markers as indicated in Table 9. 
Table 9

Minority Identity Markers of Participants

\begin{tabular}{lcc}
\hline$\underline{\text { Minority Identity Marker }}$ & $\begin{array}{c}\text { Number of } \\
\text { Participants }\end{array}$ & $\begin{array}{c}\text { Percentage of } \\
\text { Sample }\end{array}$ \\
Non-native English speaker & 20 & 19 \\
Racial ethnic minority & 48 & 47 \\
Low socioeconomic level & 21 & 20 \\
Male in female dominated field & 12 & 12 \\
Non-binary gender & 3 & 3 \\
Transgender & 1 & 1 \\
LGBTQ or non-heterosexual & 34 & 33 \\
Disability & 28 & 27 \\
\hline
\end{tabular}

\section{Languages}

The majority of participants, 84 total participants, were native English speakers, which corresponded to $81 \%$. For the 20 participants, or $19 \%$, who reported that they were non-native English speakers, 11 other languages were represented, as shown in Table 10.

\section{Table 10}

Demographics for Non-Native English Speakers

\begin{tabular}{lcc}
\hline Language & $\begin{array}{c}\text { Number of } \\
\text { Participants }\end{array}$ & $\begin{array}{c}\text { Percentage of } \\
\text { Sample }\end{array}$ \\
Arabic & 1 & 5 \\
Cantonese & 1 & 5 \\
Chamoru & 1 & 5 \\
English/Hebrew & 1 & 5 \\
English/French & 1 & 5 \\
Hindi/Marathi & 1 & 5 \\
Japanese/Chinese/English & 1 & 5 \\
Spanish & 11 & 55 \\
Spanish/English & 1 & 5 \\
Tagalog & 1 & 5 \\
\hline
\end{tabular}




\section{Race and Ethnicity}

Of the 104 participants, 56 identified as white, which included participants who chose only White to identify race, and participants who chose white and another race, in other words, mixed race. The number of participants who identified as white or partially White equaled 54\%. A total of 48 participants identified as non-white racial minorities, which equaled 47\%. The categories of Hispanic or Latinx, Black or African American, and the mixed race category of white and Asian contained the greatest number of respondents. Demographics for race and ethnicity for the 48 non-white participants are shown in Table 11.

\section{Table 11}

Race and Ethnicity Demographics for Non-White Participants

\begin{tabular}{lcc}
\hline Race and Ethnicity & $\begin{array}{c}\text { Number of } \\
\text { Participants }\end{array}$ & $\begin{array}{c}\text { Percentage of } \\
\text { Sample }\end{array}$ \\
\cline { 2 - 3 } American Indian or Alaskan Native and White & 2 & 4 \\
Asian & 5 & 10 \\
Asian and North African & 1 & 2 \\
Black or African American & 8 & 17 \\
Hispanic or Latinx & 15 & 31 \\
Hispanic or Latinx and Black or African American & 1 & 2 \\
Jewish & 1 & 2 \\
Other Egyptian & 1 & 2 \\
Other Chamoru (Pacific Islander) & 1 & 2 \\
Other India & 1 & 2 \\
White and Asian & 7 & 15 \\
White and Black or African American & 2 & 4 \\
White and Hispanic or Latinx & 3 & 6 \\
\hline
\end{tabular}




\section{Socioeconomic Status}

Middle socioeconomic level was the most common classification chosen by participants for a total of 79 participants, which corresponded to $76 \%$. Twenty-one participants indicated low socioeconomic status, equaling $20 \%$, and only 4 participants, or $4 \%$ chose high socioeconomic level as indicated in Table 12.

\section{Table 12}

Socioeconomic Level of Participants

\begin{tabular}{lcc}
\hline$\underline{\text { Socioeconomic Level }}$ & $\begin{array}{c}\text { Number of } \\
\text { Participants }\end{array}$ & $\begin{array}{c}\text { Percentage of } \\
\text { Sample }\end{array}$ \\
\cline { 2 - 3 } Low socioeconomic level & 21 & 20 \\
Middle socioeconomic level & 78 & 76 \\
High socioeconomic level & 4 & 4 \\
\hline
\end{tabular}

\section{Gender}

In order to examine the experiences of males in a female dominated field, participants were asked about gender. Participants were provided with three categories, male, female, and nonbinary. A total of 89 participants identified as female, 12 participants identified as male, and 3 participants identified as nonbinary, as shown in Table 13. 
Table 13

Gender of Participants

\begin{tabular}{lcc}
\hline Gender & $\begin{array}{c}\text { Number of } \\
\text { Participants }\end{array}$ & $\begin{array}{c}\text { Percentage of } \\
\text { Sample }\end{array}$ \\
Female/woman & 89 & 86 \\
Male/man & 12 & 12 \\
Nonbinary/gender queer & 3 & 3 \\
\hline
\end{tabular}

LGBTQ+

Participants were asked about gender identity (male, female, nonbinary), whether or not they were transgender, and sexual orientation. One participant identified as transgender (male and gay). The majority of participants, 70 total, or $67 \%$, indicated that they were heterosexual, and 34, or $33 \%$, indicated that they were not heterosexual. For participants who did not identify as heterosexual, the categories of bisexual, asexual, and gay demonstrated the highest percentages, as shown in Table 14.

\section{Table 14}

Sexual Orientation of Non-Heterosexual Participants

\begin{tabular}{lcc}
\hline Sexual Orientation & $\begin{array}{c}\text { Number of } \\
\text { Participants }\end{array}$ & $\begin{array}{c}\text { Percentage of } \\
\text { Sample }\end{array}$ \\
Asexual & 6 & 18 \\
Asexual and heterosexual & 1 & 3 \\
Bisexual & 10 & 29 \\
Bisexual and gay & 1 & 3 \\
Bisexual and heterosexual & 1 & 3 \\
Bisexual and lesbian & 1 & 3 \\
Bisexual and pansexual & 1 & 3 \\
Bisexual and queer or questioning & 1 & 3 \\
Gay & 6 & 18 \\
Gay and lesbian & 1 & 3 \\
Lesbian & 3 & 9 \\
Queer or questioning & 2 & 6 \\
\hline
\end{tabular}




\section{Disability}

Participants were asked if they identified as having a disability. A total of 76 participants, or $74 \%$, indicated that they did not have a disability. A total of 28 , or $27 \%$ of participants indicated that they had a disability and provided information about their disabilities. The disability category with the greatest number of participants was psychiatric disability, as shown in Table 15.

\section{Table 15}

Disability Types of Participants and Percentages of Total Participants With Disabilities

\begin{tabular}{lcc}
\hline Disability & $\begin{array}{c}\text { Number of } \\
\text { Participants }\end{array}$ & $\begin{array}{c}\text { Percentage of } \\
\text { Sample }\end{array}$ \\
\cline { 1 - 2 } Communication disorder & 2 & 7 \\
Hearing impairment & 3 & 11 \\
Intellectual or learning disability & 4 & 14 \\
Intellectual or learning disability and brain tumor & 1 & 4 \\
Intellectual or learning disability and chronic migraines & 1 & 4 \\
Intellectual or learning disability and psychiatric disability & 2 & 7 \\
Other disability chronic migraines & 1 & 4 \\
Other disability ADHD & 2 & 7 \\
Other disability mental illness & 1 & 4 \\
Physical disability & 1 & 4 \\
Physical disability and neurological impairment & 1 & 4 \\
Psychiatric disability & 8 & 29 \\
Psychiatric disability and hearing impairment & 1 & 4 \\
Psychiatric disability and neurological impairment & 1 & 4 \\
\hline
\end{tabular}

\section{Other Identities}

Participants were provided the option of listing other identities that were meaningful to them. A total of 16 participants, or $15 \%$ noted other identities. Other 
identities included first generation student, ethnic identity, non-traditional student, religion, and family immigration history, as shown in Table 16.

\section{Table 16}

Other Identities Provided by Participants

\begin{tabular}{|c|c|c|}
\hline$\underline{\text { Identities }}$ & $\underline{\text { Number of }}$ & $\frac{\text { Percentage of }}{\underline{\text { Sample }}}$ \\
\hline Bilingual, multicultural, and LGBTQ & 1 & 6 \\
\hline Chicana & 2 & 13 \\
\hline Child of an immigrant & 1 & 6 \\
\hline Christian & 1 & 6 \\
\hline $\begin{array}{l}\text { Daughter of a stroke survivor (mother) and an alcoholic } \\
\text { (father), non-traditional student }\end{array}$ & 1 & 6 \\
\hline $\begin{array}{l}\text { Daughter of immigrant (fields) workers, first to graduate high } \\
\text { school, BA and MS }\end{array}$ & 1 & 6 \\
\hline $\begin{array}{l}\text { English is my first/native language, but I consider myself a } \\
\text { heritage speaker of Spanish }\end{array}$ & 1 & 6 \\
\hline Evangelical Christian; Older student (50+) & 1 & 6 \\
\hline Feminist, Chinese-American & 1 & 6 \\
\hline First Generation College Graduate & 2 & 13 \\
\hline Friend, ally & 1 & 6 \\
\hline $\begin{array}{l}\text { I am left-handed, divorced, and experienced domestic violence. } \\
\text { Additionally, I only began college at } 38 \text { years in age. }\end{array}$ & 1 & 6 \\
\hline Indigenous Chamoru (Pacific Islander) & 1 & 6 \\
\hline Muslim & 1 & 6 \\
\hline
\end{tabular}

\section{Inclusion Writing Prompts}

As noted in Chapter 3, participants completed a survey using Qualtrics, the online survey collection instrument, and were asked a set of questions about experiences of inclusion. These questions served as writing prompts to gather information about inclusion for minority students within speech-language pathology graduate programs. 
Participants were able to write as much or as little as they chose in response to the prompts, which had open text boxes to enter responses. The actual survey questions, which served as writing prompts, are shown in Table 17.

\section{Table 17}

Survey Writing Prompts

Number Question

1 What was a meaningful experience that decreased your feelings of being included within your graduate training program?

2 Why was this experience important to you?

3 How did your identity/identities relate to this experience?

4 What was a meaningful experience that increased your feelings of being included within your graduate training program?

$5 \quad$ Why was this experience important to you?

$6 \quad$ How did your identity/identities relate to this experience?

$7 \quad$ To what extent have you felt included or not included in your graduate training program in speech-language pathology? Please write as much as you wish about your feelings of inclusion in general.

$8 \quad$ Why have you felt this way?

$9 \quad$ How did your identity/identities relate to these feelings?

11 What recommendations do you have for graduate training programs in speechlanguage pathology to increase inclusion for minority students based on your own experiences?

12 What advice would you give to another minority student about inclusion to prepare them for a speech-language pathology graduate training program? 


\section{Data Coding}

Data coding involved a multiple step process to organize responses to address the research questions:

1. What is the experience of inclusion for minority graduate students in speechlanguage pathology training programs in relation to systems (university, field of study, department), context (classroom and social settings), and interaction (faculty, staff, community, and peers)?

2. What are the recommendations of minority graduate students in speechlanguage to increase inclusion to address the lack of diversity in the field?

3. How do minority graduate students in speech-language pathology training programs envision inclusion in the field?

Participant Groupings. All of the participants' written responses that were gathered using Qualtrics were available within a spreadsheet. Survey questions 1-10 asked participants to describe a meaningful experience that decreased and increased inclusion, why the experience was important to them, and how it related to their identities. The 104 participant written responses that addressed personal experiences and feelings of inclusion were first sorted and grouped based on the demographic information that participants provided about holding one or more identity markers related to minority status within the field of speech-language pathology. The data in the spreadsheet was initially sorted and organized by identity markers. As previously noted, these identity markers were based on the work of Sensoy and DiAngelo (2012), and included (a) race and ethnicity, (b) socioeconomic status, (c) gender, (d) LGBTQ+, and (e) disability. As previously discussed, the identity marker of gender was adapted to reflect the demographics of the field of speech-language pathology, which is predominantly female, with more than $96.3 \%$ nationally certified speech-language pathologists identifying as 
female (ASHA, 2017a). Using a binary construct of gender, minority status was considered to be male within a female-dominated field. Non-binary gender was considered within the identity marker of LGBTQ+.

Responses were sorted into one of five categories by participant identity. In other words, the responses of all participants who marked a given identity were grouped together, e.g., all responses where the participant had indicated race or ethnicity identity were coded within a group based on race and ethnicity. In coding by groups, only experiences that were directly connected to the primary identity marker of that group were included. This required reviewing the participants' narratives of negative and positive experience of inclusion in direct connection with their response to the subsequent question about how each experience related to their identity or identities. Within each grouping, only experiences that related to the main identity for that minority group were included, e.g., experiences that were described as related to race and ethnicity were coded only within the grouping of race and ethnicity, and not within any other identity group. Since participants were asked to explain how the experience related to their identity or identities, sorting and categorizing experiences when participants held multiple identities was possible.

Participant responses about experiences were concatenated into one long narrative passage that included experiences that decreased and increased inclusion along with meaningfulness of experience and relationship to identities. Each participant's concatenated responses were considered as an entire text unit to increase understanding 
of that individual's own unique experiences within their graduate program. Once these responses were concatenated, the 104 text passages were coded using In Vivo coding, which captures the actual words of participants (Saldaña, 2016). Each participant's narrative passage was read independently.

Coding. First cycle coding was completed using verbatim quotes from participants. In Vivo coding involved identifying the sentence or sentences that best represented the main element of the experience, or key events in the narrative and its meaning to the participant. Saliency of statements was determined based on recommendations from Saldaña (2016) to highlight "impacting nouns, action-oriented verbs, evocative vocabulary, clever or ironic phrases, similes and metaphors, etc." (p. 107). Given that participants often shared short stories of events, key sentences that encompassed the main action in the event, the effect of the event, and the emotional response were marked.

All statements that were originally highlighted in first cycle coding as important were included, as there were minor and major differences in the ways that people described their experiences. Approximately 2-3 participant statements that were originally highlighted by the researcher were not repeated within the coding system, when these short statements appeared to be almost verbatim to another participant's responses, e.g., "I felt lonely." Coding focused on capturing the essence of representative events around inclusion and their effect on the participant. 
After the responses were grouped, coded, and analyzed for pattern codes, they were reviewed based their relation to systems (university, field of study, department), context (classroom and social settings), and interaction (faculty, staff, community, and peers). Each pattern code grouping was reviewed independently and then assigned to one or more levels of system, context, and interaction. Systems level was used when participants referenced the university, the field of speech-language pathology, or their graduate department. The context level was chosen based on participant responses that include a setting, such as within the classroom or within social events. Upon reviewing the responses, the area of "clinical" was added to the level of context, as participants noted experiences in clinical settings, in addition to classroom and social settings. The level of interaction was determined based on participants' descriptions of other individuals within their experiences, including faculty members, department staff, community members (supervisors and clients), and peers. Within the level of interaction, family was added, as family was important for participants from a low socioeconomic background. Coded data by theme is provided by participant identity markers in the following sections.

\section{Race and Ethnicity}

Demographic information showed that 48 of the 104 of participants identified as non-white racial minorities, which corresponded to $47 \%$. Racial and ethnic categories of participants included American Indian or Alaskan Native, Asian, Black or African American, Hispanic or Latinx, Jewish, North African, Pacific Islander, Southeast Asian, 
and mixed race, which included both white and a racial minority, and two racial minorities. Of the participants who identified as racial and ethnic minorities, the top three percentages were Hispanic or Latinx at 31\%, Black or African American at 17\%, and the mixed race category of white and Asian at $15 \%$.

Participants responded to the writing prompts about a meaningful experience that decreased and increased inclusion, why the experience was important, and how the experience related to their identity or identities. As previously noted, participant responses to the questions about their experiences were combined with their overall feelings of inclusion to form narrative passages for thematic coding of decreased and increased inclusion.

Participant responses related to decreased inclusion received the following pattern codes of racial microaggressions, white privilege, lack of representation, curriculum and resource gaps, tokenism, cultural differences, and isolation. Participant responses to increased inclusion showed pattern codes of representation, role model, curriculum and resources, connection, mission, asset, equality, and expectations. Pattern codes with participant responses are presented for decreased and increased inclusion.

\section{Race and Ethnicity Decreased Inclusion}

Racial Microaggressions. The pattern code of racial microaggressions appeared in the participant responses and also in the literature review. Racial microaggressions are considered to be brief, daily insults to people of Color that are typically unintentional or unconscious (Sue et al., 2007). The pattern code of racial microaggressions was reflected 
in the types of experiences that were shared about insults based on race and ethnicity, and also directly within one participant's response, "One of my graduate course professors, who identifies as Caucasian, praised me for being 'very articulate,' which I know is a micro-aggression towards African-Americans specifically. She said she could tell that my parents had worked with me on my speech."

Upon grouping racial microaggressions together, it became clear that there were different sources of racial microaggressions, and three subcategories were created: racial microaggressions from faculty, racial microaggressions from peers, and generalized racial microaggressions. Tables for racial microaggressions from faculty, peers, and generalized racial microaggressions are shown below.

Racial microaggressions from faculty directly cited a faculty member within the program, such as "I have a professor who has difficulty distinguishing between the four asian $[s i c]$ girls in my cohort." These racial microaggressions from faculty appeared in the context of classroom and social environments and involved interactions with faculty, staff, and community. Racial microaggressions from faculty are shown in Table 18.

Racial microaggressions from peers described the behaviors and actions of other students within the program. Participants explained the treatment that they perceived from others, such as "White girls perceive me as someone to include and as a friend when it comes to academics, potentially due to stereotypes from the model minority myth," and "When participating in group projects, there are students in my class who will not even acknowledge me when I speak." Racial microaggressions from peers appeared in the 
context of classroom and social, and involved interaction with peers, as shown in Table

19.

\section{Table 18}

Racial Microaggressions From Faculty

Daily Insults to Students of Color From Faculty

She [professor] made an international student stand up in the middle of class because she didn't know Spanish and count 1-10

Some professors, clinical supervisors, and people in my cohort consistently getting me confused with the 2 other girls in my cohort who have a similar skin tone to mine despite us being different races and having different physical features

"When you don't smile I can't tell how you are feeling" (as an African person, aggression is typically associated with darker skin. I should not have to smile for a supervisor to "read" me especially if my Caucasian clinic partner doesn't have to $[\mathrm{sic}]$ the same.)

I am not seen as my own person but instead of 1 of 3 "racially ambiguous" girls

One of my graduate course professors, who identifies as Caucasian, praised me for being "very articulate," which I know is a micro-aggression towards African-Americans specifically. She said she could tell that my parents had worked with me on my speech.

I was pointed out for being unique and being an Asian student by my graduate director in front of my whole class

I have a professor who has difficulty distinguishing between the four asian [sic] girls in my cohort

My professor told us that there was no point in being bilingual because there would be no way to meet the need of the population of bilingual clients. I felt that the professor alienated me and discredited my racial identity with her comment, despite the fact that it was intended to be humorous

My teacher chose all Caucasian students to be in the picture, and did not include me

I was confronted by my professors, telling me that the way I ask questions or make comments can sometimes be offensive or off-putting 
Table 19

Racial Microaggressions From Peers

Daily Insults to Students of Color From Their Peers

Attitudes and unconscious behaviors of the white girls in my program

They [White girls] would prefer to stay confined to their clique

White girls perceive me as someone to include and as a friend when it comes to academics, potentially due to stereotypes from the model minority myth

Perceived that the white girls in my cohort would get the most advantage or first priority in everything, whether it was in terms of clinic assignments/rotations, being called on first in class, or choice of materials for clients

Non-POC students were more likely to cluster together

Off-kilter tone from the beginning — a subtle "us" and "them"

Majority of the white women in my cohort to not acknowledge me or my friend group

I said hi to other girls (all were white) in my cohort and they didn't acknowledge me or say anything

Myself, nor the other black girls were not included on this trip at all

When participating in group projects, there are students in my class who will not even acknowledge me when I speak

I've had classmates email our professor stating that I did not complete my portion of a group assignment, when they knowingly turned it in prior to when we agreed, so that I looked bad

I am almost never included in activities our [sic] of the classroom

I am angry because I worked so hard to this point, and I still feel like others look at me as if I am not worthy to be in this program

Regardless of the fact that we [sic] while we also excelled academically and have the requirements to attend the same program, we are still not accepted into their world

Peers not even making eye contact and pretending that I don't even exist

Peer skipped me (completely ignored me) during a discussion really affected me so much that I went home and cried and questioned my enrollment in the program

My classmates often used culturally insensitive therapy materials 
Generalized microaggressions described the overall presences of racial microaggressions within the program, such as "It is in grad school that I have experienced the most frequent incidents of racism and bias" and "Countless microaggressions that occur in my program, and out in the field, can be debilitating at times." Participants shared the effects of these racial microaggressions, as in the following response, "People do not understand how their microaggressions affect people who have to work 10 times harder to be in the same position that they are in." Generalized microaggressions occurred with the system of the field of study and the department, and interactions with faculty, staff, community, and peers, as shown in Table 20.

Table 20

Generalized Racial Microaggressions

Generalized Ongoing Daily Insults to Students of Color

I did not come to this program to experience microaggressions and racism

Countless microaggressions that occur in my program, and out in the field, can be debilitating at times

People do not understand how their microaggressions affect people who have to work 10 times harder to be in the same position that they are in

It is in grad school that I have experienced the most frequent incidents of racism and bias

Sometimes when people only give credit for me being Asian. I am of mixed descent, Japanese and American/European/White

White people view me as asian $[s i c]$, and asian $[s i c]$ people view me as white 
White Privilege. The pattern code of white privilege stemmed from participants' specific use of the words "white privilege" and examples of privilege in their responses. The concept of white privilege is described by Sensoy and DiAngelo (2012) as a lack of humility about the myriad of invisible rights and advantages that are granted to white people within society. Participant responses, such as "People in power preach about diversity but they themselves are not aware of their own white privileges and use it to their advantage," and "a level of privilege, often white privilege, is needed to even be accepted into a CSD [Communication Sciences and Disorders] graduate program” reflected participants' understanding of the role of white privilege within their graduate student experiences. White privilege appeared within systems of field of study and department, the context of classroom and social settings, and in interactions with faculty, staff, community, and peers. Responses that described white privilege are shown in Table 21.

Lack of Representation. The pattern code of lack of representation refers to the absence of people of Color, and was chosen based on participants' descriptions that included the words "lack of representation," e.g., "Lack of representation of amongst minorities within my class and the field as a whole." Lack of representation refers to few or no people of Color. It should be noted that Sue et al. (2007) discussed larger macroaggressions, which are environmental, systemic level factors that signal nonbelonging to minority individuals, such as work environments in which all staff members are white. Macroaggressions extend beyond the level of an individual, as opposed to microaggressions, which describe the actions of another person (Sue et al., 2007). 
Participants noted the effects of lack of representation, such as "Not saying I will allow representation to alter my academics and studies, but it is definitely something that can affect and trigger a student emotionally and psychologically." Lack of representation was present at the system level of field of study and department, in the context of the classroom and social environments, and in interactions with faculty, staff, the community, and peers, as shown in Table 22.

\section{Table 21}

White Privilege

\section{Rights and Advantages Based on Whiteness}

People in power preach about diversity but they themselves are not aware of their own white privileges and use it to their advantage

Unspoken rule that this was a white woman's field

One of the most difficult aspects of my program is the white privilege that most of my peers and staff exceed [sic]

Sometimes its [sic] disgusting to associate with individuals that don't understand differences or take into consequences [sic] of their words on other [sic]

A level of privilege, often white privilege, is needed to even be accepted into a CSD [Communication Sciences and Disorders] graduate program

All of my professors are American born white ladies and at times I felt that they were not fair to minorities because they don't understand many of the struggles that we go through to make it to graduate school and even to complete grad school

It's very obvious that minorities are neglected in the field and many don't even make it

They were oblivious to things [sic] are currently going on in the real world of people of color and other minorities

There are some experiences that people of color, biracial, and minorities face that white people will probably never have to face, so it is hard for them to relate 
Table 22

Lack of Representation

Absence of People of Color

No people of color in the staff or faculty of our program

Not many professors, students, faculty, or staff that look like me within my program

We do not look the same

Only African-American student in my cohort

Lack of representation of amongst $[$ sic $]$ minorities within my class and the field as a whole

Not saying I will allow representation to alter my academics and studies, but it is definitely something that can affect and trigger a student emotionally and psychologically

Not being represented is upsetting

It is obvious that I am a minority in my program and the field itself

It's easy to feel like the exception when you aren't as equally represented within a group as other ethnicities

Clientele for the in-house clinic was fairly homogenous in terms of race and income (e.g., white, and middle-, or upper-middle class)

Upsetting to see the lack of diversity in our clinic

Curriculum and Resource Gaps. Participants indicated gaps in curriculum and unavailability of resources that related to course curriculum, instruction, training, and support, specifically around issues of diversity. The pattern code of curriculum and resource gaps was chosen as a summation code based on participants' descriptions of course-related elements and the use of the word "resources," as in "There are no other resources in my program favailable $[s i c]$ for me during this time." Curriculum and resources gaps were present at the system level within the field of study, university, and 
department, within the context of the classroom, and within interactions with faculty and peers, as shown in Table 23.

\section{Table 23}

\section{Curriculum and Resource Gaps}

Lack of Coursework, Training, and Resources for Diversity

Optional courses or tracts [sic] instead of incorporating issues of diversity and issues of inclusion within the curriculum for everyone

Most of the majority had a hard time working with minority individuals because the training and experience was never provided in either at an undergraduate level or graduate level

She basically told an entire cohort to apply the AAE "exceptions" when scoring diagnostic assessment for all African American children. This action could potentially exclude children from services that they actually need, because not every African American child uses AAE.

Many of the students in my cohort have not been exposed to populations different from their own

It was choking $[s i c]$ to see the difference in grades between the white students and black and latino $[$ sic $]$ students

There are no other resources in my program favailable $[$ sic $]$ for me during this time

The offer [for help] still stands but over the quarters [sic] has warped into fake pleasantries

Tokenism. The pattern code of tokenism was chosen from participant responses that included the term. Participants described tokenism by explicitly using the word "token," as in "We as minority student [sic] should not just be token poster children."

Tokenism represents the presence of a symbolic gesture or act to promote the appearance of diversity. Tokenism may be important to participants because of how it highlights how organizations can consider the presence of one person of Color as sufficient to declare 
that diversity has been achieved, and how organizations can view diversity in relationship to a minimum quota of minorities. One participant described how feeling like a token prompted her to doubt her skills, in the response, "I begin to think that I am a token candidate and lack the critical thinking skills required for the profession." Tokenism appeared within the system in field of study and department. It appeared within the context of the classroom and within interactions with faculty and peers, as shown in Table 24.

\section{Table 24}

Tokenism for Race and Ethnicity

Symbolic Appearance of Diversity

We as minority student $[s i c]$ should not just be token poster children

I begin to think that I am a token candidate and lack the critical thinking skills required for the profession

Anytime race/ethnicity/culture came up in a conversation everyone would automatically look at me and the other two ladies [minorities] for our point of view

I am in no way the spokesperson for people of color, biracial people, or minorities

Cultural Differences. The pattern code of cultural differences as a summation code was chosen based on participant responses related to cultural background and family values, prior life experiences, and inability to relate. This acknowledgement of different life experiences that occurred before entering the graduate program was exemplified by the responses, "For the most part, white students and black students grow up differently, and experience different things" and "Impossible to bridge the gap between my 
experience and the experience of white women." Cultural differences were noted at the system: level of field of study, university, and department, in the context of classroom and social, and in interaction with faculty, staff, community, and peers, with results shown in Table 25.

Table 25

Cultural Differences

\section{Acknowledgement of Different Life Experiences}

I was taught from a very young age not to question authority

Culture shock of feelings like an outsider

For the most part, white students and black students grow up differently, and experience different things

There are just some things that I cannot relate to and vice verse [sic]

Impossible to bridge the gap between my experience and the experience of white women Difficult to relate [to] other girls in my program

Isolation. Isolation was chosen as a summation pattern code that encompassed feelings of exclusion, non-belonging, and resulting negative emotions. The term isolation was chosen based on its use in participant responses, such as "One other Latinx that I can relate too which increases the feelings of isolation and anxiety" and "I am the only person of color in my cohort and I find myself feeling isolated because of it." Similar terms were related to feeling left out, separated, and being viewed differently, e.g., "separated, alone, excluded." Isolation represented pervasive feelings of lack of meaningful connections with others. Isolation appeared at the system level within the university and department, 
in the context of classroom and social, and in interactions with faculty, staff, community, and peers, with responses shown in Table 26.

\section{Table 26}

Isolation for Race and Ethnicity

Pervasive Feelings of Lack of Meaningful Connections With Others

I am the only person of color in my cohort and I find myself feeling isolated because of it

I do feel a separation

I feel torn between being uncomfortable and not enjoying myself, but still wanting to participate and be apart $[\mathrm{sic}]$ of the group

I am very much alone in this experience

One other Latinx that I can relate too which increases the feelings of isolation and anxiety

Uncomfortable to be in a program and city that is white

Stress and anxiety creates an environment where faculty and students are trying to protest [sic] themselves

Feel excluded from my class and their demeanors even though I am at a level of educational and financial privilege

Feel left out due to cultural differences, issues that I have such as making sure that I have a place to study, transportation to school, clothes, etc.

Feel like an imposter; like I don't belong in this program

Feel ostracized

It doesn't feel good to stand out, because I want to fit in and I want to make friends

I felt that a part of me was discredited and I felt unworthy to participate in class discussion

I feel pressure to hide my identity because I am afraid of people judging me based on my appearance or viewing me differently because of my diverse cultural background 


\section{Race and Ethnicity Increased inclusion}

After responding to questions about decreased inclusion, participants responded to the second set of prompts about a meaningful experience that increased inclusion, why the experience was important, and how the experience related to their identity or identities. As previously noted, overall experiences of inclusion were combined with experiences that decreased and increased inclusion to view each participant's responses as individual passages. Coding of participant responses related to increased inclusion showed pattern codes of representation, role models, curriculum and resources, connection, mission, asset, equality, and expectations.

Representation. The pattern code of representation referred to the presence of people of Color within an organization or community. The pattern code was chosen based on participant descriptions of people of Color and diversity within the learning environment. Representation as a factor that promotes inclusion is related to signaling that a setting is welcoming and not exclusively designed to exclude racial and ethnic minorities (Sue et al., 2007). Participant responses highlighted the presence of people of Color and its significance, e.g., "Professors and staff feature many POC [people of Color] diverse ethnic and linguistic backgrounds" and "Coming to a university where the majority of the student body, professors, and staff look 1 [sic] like me and have had similar experiences has been comforting." Representation was present at the system level of university and department, in the context of the classroom and social environments, and in interactions with faculty, staff, the community, and peers. Responses for the pattern code of representation are shown in Table 27. 
Table 27

Representation

Presence of People of Color

Professors and staff feature many POC [people of Color] diverse ethnic and linguistic backgrounds

Coming to a university where the majority of the student body, professors, and staff look 1 [sic] like me and have had similar experiences has been comforting

Diverse city, and so the university opens itself to this environment, welcoming minorities as assets who have a lot to offer

Many of my professors speak more than one language and are immigrants

My instructors for my multicultural and school-aged literacy courses are women of color

Happy to see the level of diversity among my colleagues

It's a positive that the faculty reflects diversity

Most significant component of my feelings of inclusion in this program is the cultural/linguistic diversity of the professors

Being around a diverse cohort no longer makes me feel like the "token multiracial person" in the program

It's just nice to be around people who have the common courtesy to not ask "so what are you?" in an invasive way

My program is a predominantly Hispanic bilingual program with open minded people

Role Models. The pattern code of role models represents an individual in leadership, specifically someone with more experience who serves as a guide. The term role model was chosen based on participant use of the word "role model" as in the participant response, "Having a role model I could identify with helped me realize that I could do it too." Responses included descriptions of how having a faculty member who 
was a person of Color was inspirational and helped students realize what was possible, e.g., "She [professor] has inspired me and reminded me that the battle to do good within the field may be more difficult as a minority, mainly because of limited resources and support, but it is not impossible." The theme of role model was present at the system level of the department, in the context of the classroom and social environments, and in interactions with faculty, as shown in Table 28.

\section{Table 28}

Role Model

Person of Color in a Leadership Position

My professor is an immigrant of the same country my parents are from

She [professor] has inspired me and reminded me that the battle to do good within the field may be more difficult as a minority, mainly because of limited resources and support, but it is not impossible

Having a role model I could identify with helped me realize that I could do it too

My instructor for the multicultural course shared her background and it was similar to my personal history

It was amazing to have someone of a similar culture to mine teach me

Curriculum and Resources. The pattern code of curriculum and resources was based on participant responses that provided information about the importance of diversity in course content, teaching practices, and resources. Participants described program design and course content, such as "Program integrates CLD and addresses throughout the program and the clients who come to the campus clinic" and "My professor touched on modern day issues-real issues of privilege, discrimination, and 
multicultural challenges when treating different populations." Curriculum encompassed content topics with corresponding instructional techniques, and resources included opportunities. The theme of curriculum and resources was present at the system level of the university and the department, in the context of the classroom, and in interactions with faculty and community, as shown in Table 29.

Table 29

Curriculum and Resources

Racial and Ethnic Diversity in Learning

Program integrates CLD and addresses throughout the program and the clients who come to the campus clinic $[$ sic $]$

Instructors make more attempts to randomly assign individuals to groups to ensure more heterogeneous pairings/groups

Emphasis within our SLP training to clearly note language input/out of our clients

Discussion about diversity, and how to interact with individuals of different backgrounds

I have a professor, who identifies as Caucasian, and she spent an entire class period discussing bias

She told the other members in my program to "check" their implicit bias at the door

She used her platform and privilege to educate others in my cohort

My professor touched on modern day issues-real issues of privilege, discrimination, and multicultural challenges when treating different populations

Class [Multicultural Issues] encouraged students to be reflective of differences, acknowledge each of our cultural backgrounds and how a multicultural background can enhance our work as clinicians working with, being respectful and inclusive of multicultural clients

I could relate to the class material on a personal level

My supervisor for my research project was supportive of me looking into cultural differences (for hispanic [sic] patients) and was eager to learn along with me 


\section{Table 29 (continued)}

\section{Racial and Ethnic Diversity in Learning}

Welcomed and encouraged questions and thoughts

International service trip with my program

Diversity and focus on skills for working with culturally and linguistically diverse populations

The program has provided me with the tools on how to best give back to the community that I live in and has also opened the door to reach other Bilingual and culturally diverse clients in any city

Many cultures have been spoken about in depth as well as how to understand Bilingual language learners

Now that I have joined a few organizations, I feel more included because I have found other students with similar backgrounds

Extension of multicultural studies and groups organized by my school

Connection. The pattern code of connection was chosen as a summary theme for concepts that were related to conversations, sharing experiences, and supportive social interactions. Participants described making supportive connections with others, such as "Meaningful conversations with the other women of color" and "Coming into contact with other African American females who experienced similar adversities here." The theme of connection was present at the system level of the department, in the context of social, and in interactions with faculty, community, and peers, as shown in Table 30. 
Table 30

Connection for Race and Ethnicity

Supportive Relationships and Shared Understanding

Meaningful conversations with the other women of color

Share similar experiences

Handful of great friends in my program that have repeatedly shown me that the type of treatment I am receiving is not universal

People in the world/future who do want to understand and relate to their clients

Department chair of my program once reached out to me and told me that, while she was a white woman, she understood that it had to be hard to be the only black person in my cohort and offered to find me a mentor

Even as a white woman, she [department chair] was thinking of how my race could affect my situation and make me feel isolated

Coming into contact with other African American females who experienced similar adversities here

I felt like someone else could finally see me, and that I wasn't alone in knowing that these issues needed to be addressed

Supervisor that shared similar experiences based on race/ethnicity when she underwent her graduate studies

Speaking to other students that went through the same issues that I went through help me let out any negative feeling and move on

They [professors] provided a safe space that made me feel welcome and included in the program

I was able to meet and bond with a lot of other students

I have found lovely classmates that I get along with very well and who make me feel included

I feel included by cohort members during coursework interactions 
Mission. The pattern code of mission was chosen as a summary theme for concepts that participants shared about the need for diversity and the importance of their presence in the field. Mission referred to a belief in one's own role in promoting diversity to support others, as in the following responses, "We are here now and we can pave the way" and "The field is white-dominated which feels discouraging and empowering at the same time." The theme of mission was present at the broad system level of the field of study, as opposed to at a specific context or interaction level as shown in Table 31.

\section{Table 31}

Mission

\section{Responsibility to Promote Diversity}

We are here now and we can pave the way

The field is white-dominated which feels discouraging and empowering at the same time

What impacted me strongly was her [professor] even mentioning the predominance of white females in our field and how we NEED diversity to treat a diverse population

Made me realize how important my voice is to the field

I have a different background that can serve others

Asset. The pattern code of asset was chosen based on participant use of the term "asset" and from the literature, as Smith-Maddox and Solorzano (2002) described assets as the strengths that minorities bring to educational settings. Participants described how their programs reinforced the benefits of racial and ethnic diversity, such as "My differences are celebrated, respected, and supported as an asset with regards to a career in SLP" and "Being told by my professors that diversity is needed in our field." The theme 
of asset was present at the broad system level of the field of study, within the context of classroom and clinical, and at the interaction level of faculty, community, and peers, as shown in Table 32.

Table 32

Asset for Race and Ethnicity

Strengths That Minorities Bring to the Field

My differences are celebrated, respected, and supported as an asset with regards to a career in SLP

I've always been encouraged by my instructors to improve upon and embrace my bilingualism as it will come in handy upon entering the workforce in my field

Being told by my professors that diversity is needed in our field

They come to me for questions regarding hispanic [sic] culture or Spanish language which has made me feel lie $[s i c]$ a valuable asset to the program as the only hispanic [sic], Spanish speaking person here

I feel that I can connect with individuals from varying backgrounds

I helped translate a session for a young Mandarin-speaking boy

Helped me connect with my second language and made me feel that I had something valuable to contribute

I appreciate my history and hard work to be able $[$ sic $]$ make it this far

Equality. The pattern code of equality was a summary term based on participant responses that included fair treatment or treatment similar to peers, e.g., "I feel as though they treat everyone very fairly." The theme of equality was present at the system level of the department, within the context of classroom and social, and at the interaction level of faculty and peers, as shown in Table 33. 
Table 33

Equality

Perception of Equal Treatment

I do not feel my "otherness" is used against me by my peers and that I am selected out by instructors to speak as a "representative"

I felt like my race/ethnicity did not matter

I feel as though they treat everyone very fairly

For some of my classmates, they see me as SMART and not just BLACK

Expectations. The pattern code of expectations was a summary term that described participant responses of prior experiences of lack of diversity, which shaped their expectations for graduate school. Their responses included references to not expecting that they would be included or represented. It should be noted that this pattern code is included with increasing inclusion because it refers to participants' formative understanding of societal and educational systems. Knowing that organizational systems are "not created for the minority way of living," as stated by one participant could reduce any new sensations of exclusion when starting a graduate program. In other words, not expecting inclusion does not decrease feelings of inclusion, and may increase feelings of familiarity with the setting. Participant responses that described expectations included references to larger societal issues, such as "I came into the program knowing that individuals of my ethnicity were not in [sic] majority if anything even represented" and "Ethnicity/race within modern American [sic] plays into all experiences which integrate ourselves into." The pattern code of expectations was present at the system level of the 
field of study, the university and the department, within the context of classroom and social, and at the interaction level of faculty, community, and peers, as shown in Table 34.

Table 34

Expectations

Prior Experiences With Lack of Diversity

I am accustomed to some level of misunderstanding and tokenism

Having to outwork the a $[$ sic $]$ system that was not created for the minority way of living

I came into the program knowing that individuals of my ethnicity were not in [sic] majority if anything even represented

Ethnicity/race within modern American [sic] plays into all experiences which integrate ourselves into

I have always been not included. Growing up I was a minority too and you notice it. It stays with you because people doubt you and what you are capable of. They make assumptions and it is hurtful.

Applying to graduate schools and interviewing with various schools, the issue of the lack of inclusion and diversity was central to my decisions

\section{Socioeconomic}

Participants were asked about their early socioeconomic status in the demographic question, "How would you describe your socioeconomic status (i.e., family income) growing up?" Participants were provided with three levels to indicate socioeconomic status, specifically high, middle, and low. Participants were not asked to respond with any form of financial information about their family background and were able to use their own judgment to determine which level matched their perception of their early life 
experiences. Demographic information showed that $76 \%$ of 104 of participants identified as middle socioeconomic level, $20 \%$ as low socioeconomic level, and $4 \%$ as high socioeconomic level.

Participant responses for participants who identified as low socioeconomic status were considered to be minorities within the field of speech-language pathology and separated for coding. In other words, having a background of low socioeconomic status was considered to be a minority marker within speech-language pathology, and the responses of students who indicated a low socioeconomic status background were grouped together for analysis. Participants responded to the writing prompts about a meaningful experience that decreased and increased inclusion, why the experience was important, and how the experience related to their identity or identities, and overall feelings of inclusion were coded within individual narrative passages for thematic coding of decreased and increased inclusion. Pattern codes for decreased inclusion for low socioeconomic status included economic privilege, financial barriers, hidden struggles, and lack of belonging. Pattern codes for increased inclusion included the codes of pride, support, community, and asset.

\section{Socioeconomic Decreased Inclusion}

Economic Privilege. The pattern code of economic privilege was chosen based on participant responses that included the term privilege, such as "The casual privilege of designer boots and branded notebook" and "Predominant participants came from privileged backgrounds and had lacking experience with the hardships of being a parent or a child in a lower socioeconomic status." Economic privilege referred to external 
markers of access to resources and lack of understanding of financial hardships. The theme of economic privilege was present at the system level of the university and the department, within the context of classroom and social, and at the interaction level of faculty, and peers, as shown in Table 35 .

\section{Table 35}

\section{Economic Privilege}

Access to Resources and Lack of Understanding of Financial Hardships

Milquetoast nature of most people's upbringings

The casual privilege of designer boots and branded notebook

Sometimes this MA-SLP degree we're all getting feels like an MRS degree for the new economy.

Majority of my program is made up of white females from middle to upper class socioeconomic status

Predominant participants came from privileged backgrounds and had lacking experience with the hardships of being a parent or a child in a lower socioeconomic status

Professor brazenly compared taking the GRE [Graduate Record Examination] the first time compared to the second as becoming easier, and that is the key to doing well in graduate school

I hadn't considered that my peers likely took their GRE more than once

Young conventionally pretty blond girls who talk about their family vacations in other countries during their free time

I heard girls in my cohort talking about going to [wealthy location] for vacation unfortunately I did not partake in the conversation because I did not feel I could relate to anything

Hard for people of privilege to relate to and meet families of lower socioeconomic backgrounds 
Financial Barriers. The pattern code of financial barriers was chosen based on participant responses about the effect of costs associated with graduate school and the profession, such as "Less practical for me to be involved in things like conferences study abroad opportunities, and organizations with membership fees or dues (including student or campus ASHA organizations)." Financial barriers referred to lack of financial resources to meet needs. The theme of financial barriers was present at the system level of the field of study, the university, and the department, within the context of classroom, and at the interaction level of faculty, staff, community, and peers, as shown in Table 36.

\section{Table 36}

Financial Barriers

\section{Lack of Financial Resources}

Sometimes the cost of materials, building an inventory of resources for the profession, and education costs can be daunting

I am hoping to secure a job placement after I finish that will pay back my loans

Less practical for me to be involved in things like conferences study abroad opportunities, and organizations with membership fees or dues (including student or campus ASHA organizations).

I could not afford to move to attend Graduate program, had to enroll in on-line program at a higher tuition rate

No masters [sic] program within 300 miles of me

Difficult to attend [the program] due to the cost

I was surprised to have [sic] by having to pay for expensive supplies, memberships, and online resources required for classes

My identity as low SES causes me to worry about costs sometimes

Although I have applied for many scholarships that correlate with my identities, I have not received any 
Hidden Struggles. The pattern code of hidden struggles was chosen based on participant descriptions of the invisibility of financial hardships through the use of words, such as "see, cover, and façade" Hidden struggles referred to the other people being unaware of an individual's life challenges. Participant responses showed their own awareness of an identity that was not known to those around them, such as "My SES is not easy to see," and "What they did not see was the financial struggle and risk behind me getting to this place in my academic career." The theme of hidden struggles was present at the system level of the field of study, the university and the department, within the context of classroom and social, and at the interaction level of faculty, community, and peers, as shown in Table 37.

Lack of Belonging. The pattern code of lack of belonging was chosen based on participant descriptions of not belonging. Participant responses referenced concepts related to belonging, such as "Felt like I did not belong in the program" and "I feel out of place." Lack of belonging referred to pervasive feelings of not being accepted and not relating to others. The theme of lack of belonging was present at the system level of the field of study and the university, within the context of classroom and social, and at the interaction level of faculty, staff, community, and peers, as shown in Table 38. 
Table 37

Hidden Struggles

Invisibility of Life Challenges

Funded my prerequisite SLP classes by moving back in with my mother and scrubbing toilets for tuition money

My SES is not easy to see

What they did not see was the financial struggle and risk behind me getting to this place in my academic career

This is a feeling I have often had throughout life, like I am a stage actor, playing a role while covering the aspects I don't want others to see.

Façade of having a higher SES

I always think that eventually someone is going to notice that I'm faking it

Reminded me of past experiences where girls who came from higher socioeconomic status would look down on me because of my repetitive clothing and outdated shoes

Each of us has a story, and even if we look like we are in the majority, there are likely unseen details that would prove otherwise

I grew up not having a lot of money and not being exposed to a lot of things (my family couldn't afford to go on vacation or buy us brand name clothes)

As far as what other students or professors see, this [low SES] does not have much of a role, many are unaware of this factor

I could only afford to take the GRE [Graduate Record Examination] once 
Table 38

Lack of Belonging

Feelings of Not Being Accepted

I cannot relate to their upbringing or keep up with social activities

I feel out of place

I've felt isolated due to my lack of experiences and lack of money

I think, "I don’t belong here!"

Felt like I did not belong in the program

Far too few people from underprivileged backgrounds

I grew up extremely poor and this, in some ways effects your self esteem and self worth

\section{Socioeconomic Increased Inclusion}

Participants were asked about an experience that increased inclusion, why the experience was important, how the experience related to the individual's identity or identities, and overall experiences of inclusion. Coding of participant responses related to increased inclusion showed pattern codes of pride, support, community, and asset.

Pride. The pattern code of pride was chosen based on participant use of the word "pride," such as "My mother is very proud of my accomplishments" and "I've felt very grateful to bring my family pride in getting my Master's degree.” Pride referred to personal pride in recognizing one's own achievements and family pride of bringing honor to the family. It should be noted that the interaction level of family was added based on participants' referencing of family and family members as interaction patterns in relation to feelings of inclusion. The theme of pride was present at the system level of the 
university and the department, within the context of the classroom, and at the interaction level of faculty, and family, as shown in Table 39.

\section{Table 39}

\section{Pride}

\section{Achievements and Honor}

My mother is very proud of my accomplishments

I've felt very grateful to bring my family pride in getting my Master's degree

Being $1^{\text {st }}$ in my family to receive diplomas in high school, BA and MS is proof that even though my parents are immigrants with elementary education and with limited resources, I could successfully accomplish my personal goals

I have received many recommendations for Dean's and Chancellor's lists

I felt proud that they [professors] were so willing to help me and that they thought I was proficient enough in the material to help with instruction

I was accepted to the program based on my hard work ethics

I remind myself that I'm half-way through with my program and will navigate towards working environments where I feel more comfortable in the future

Support. The pattern code of support was chosen based on participant use of the term support. Support referred to emotional and academic support, and availability of resources. Participant responses described support at the individual and program level, e.g., "He [advisor] is very supportive and encouraging," and "Very very very good as a department and training program—supportive — fair — and above [sic] student centered and individual." The theme of support was present at the system level of the university 
and the department, within the context of the classroom and social, and at the interaction level of faculty, as shown in Table 40.

\section{Table 40}

Support

Emotional and Academic Support and Resources

They were, as a department, very supportive

My adviser has heard and understands my background, so he knows where I'm coming from

He [advisor] is very supportive and encouraging

Very very very good as a department and training program — supportive- fair-and above [sic] student centered and individual

I have professors who regularly post scholarship and job opportunities to the class, which allows me to receive them without feeling like I am singled out

I've received mainly support and consideration for both my mental condition and financial status

I've been able to express any difficulties I'm having in any aspect of my life with my cohort and most of my professors

Able to express any difficulties I'm having across any aspect of my life

Community. The pattern code of community was chosen as a summary code based on participants' references to groups and being together. Participant responses included community through communication and interaction, such as "Cohort group message where we share everything" and "Opportunity to learn and think critically together." The theme of community was present at the system level of the department, within the context of the classroom and social, and at the interaction level of faculty and peers, as shown in Table 41. 
Table 41

Community

Shared Communication and Interaction

Cohort group message where we share everything

Professor communication and student fb groups

We are all included in a GroupMe account and share a clinic workroom

Entire cohort is open and friendly

I know most of my professors know me. Some know me by name so that makes it important.

Opportunity to learn and think critically together

Asset. The pattern code of asset was chosen as a summary code based on participant descriptions of the benefits of their unique backgrounds. Assets for socioeconomic status align with the concept of assets for race and ethnicity, which encompass strengths related to minority status within education (Smith-Maddox \& Solorzano, 2002). Asset represented participant recognition of strengths and contributions, such as "Teaching about the hardships and trying to share those perspectives to promote empathy and understanding." The theme of asset was present at the system level of the field of study and the department, within the context of the classroom and clinical, and at the interaction level of faculty and peers, as shown in Table 42. 
Table 42

Asset for Socioeconomic Status

Strengths and contributions

I feel that I can connect with individuals from varying backgrounds due to these experiences. It's important for professionals in the field to reflect the diversity of the public

Teaching about the hardships and trying to share those perspectives to promote empathy and understanding

\section{Gender}

Demographic information about gender used three categories, male, female, and nonbinary. Of the 104 participants $12 \%$ identified as male. It should be noted that $3 \%$ of participants identified as nonbinary and their responses were coded within the LGBTQ+ grouping. Male gender was considered as a minority marker within speech-language pathology. Participants responded to the writing prompts about a meaningful experience that decreased and increased inclusion, why the experience was important, and how the experience related to their identity or identities, and overall feelings of inclusion were coded within individual narrative passages for thematic coding of decreased and increased inclusion. Pattern codes for decreased inclusion for male gender included masculine stereotypes, male exclusion, and gender roles. Pattern codes for increased inclusion included welcomed and equality. Pattern codes with participant responses are presented for decreased and increased inclusion. 


\section{Male Gender Decreased Inclusion}

Masculine Stereotypes. The pattern code of masculine stereotypes was chosen based on participants' descriptions of situations and feelings in which masculine stereotypes represented maleness as different or threatening. Participant responses explained reasons for being cautious in interactions, such as "Perhaps the recent 'me too' movement has made me feel as though I have to tread more lightly around things like going over to a woman's house or sharing a hotel room," and "I told a girl I had a crush on her, and now all her friends ignore me. No male heterosexual colleagues to talk to. Made to feel like a creep." The theme of masculine stereotypes was present at the system level of the field of study and the department, within the context of the classroom and social, and at the interaction level of faculty and peers, as shown in Table 43.

Male Exclusion. The pattern code of male exclusion was chosen based on participant use of exclusion and descriptions of feeling or being left out. Exclusion was described as an inability to relate, such as "I often feel excluded from conversations and group activities, especially outside of school activities, since it is hard to relate and going to other peoples $[$ sic $]$ places is awkward since all of my classmates are female." Male exclusion also represented a lack of acknowledgement of the presence of males and the singling out of males as not part of the group. Male exclusion aligns with environmental macroaggressions (Sue et al., 2007), which encompass the broader organizational systems, such as the learning environment. Participants described repeated examples of exclusion, including "Presentations, meetings, classes, etc. would start out with 'hey ladies!' or only include information relevant to women" and "I had a professor that 
continued to refer to the class as girls throughout the course and then would take a pause and say, "And [my name].'" The theme of male exclusion was present at the system level of the field of study and the department, within the context of the classroom and social, and at the interaction level of faculty, community, and peers, as shown in Table 44.

\section{Table 43}

Masculine Stereotypes

\section{Maleness as Different or Threatening}

My classmates, all of whom are female, can share rooms and travel together

One of my classmates told me that they would feel uncomfortable sharing a room with me [at conference], which I completely understand, but it still made me feel disheartened.

Girls gel together and work on homework into the night. Those groups don't form with guys in them typically. I think it's totally fine to have groups of girls work together, I just think that I miss out on group study time. Working on stuff in community is something I have missed being in a female dominated field.

I told a girl I had a crush on her, and now all her friends ignore me. No male heterosexual colleagues to talk to. Made to feel like a creep.

Would it not be weird to invite yourself over to someones [sic] house or to ask to share a hotel room with someone of the opposite sex?

Perhaps the recent "me too" movement has made me feel as though I have to tread more lightly around things like going over to a woman's house or sharing a hotel room.

I am afraid of upsetting or offending anyone.

Seeing all of the awful things men with power have done to women over the years makes me realize how some women generalize men.

I feel as though I should play a more passive role within my class

I did not feel like I was able to ask to be included because I am a male

It's easier for women to connect with one another than it is for them to connect with a man 


\section{Table 44}

Male Exclusion

Lack of Acknowledgement of Males

When I went to the national ASHA conference in Los Angeles. I'll be candid, I describe it as being among a "sea of upper middle class white women with blond hair who all love Vera Bradley."

Presentations, meetings, classes, etc. would start out with "hey ladies!" or only include information relevant to women

I had a professor that continued to refer to the class as girls throughout the course and then would take a pause and say, "And [my name]."

At orientation, one of the professors talked about how she has three boys at home and then said, "Sorry [name] and X (the other male in my cohort, but I'm ready to be around some women."

Hard to be apart $[\mathrm{sic}]$ of the group when you're seen as the token hetero male

Adds more to the belief that men are novelty in the field and not needed

I often feel excluded from conversations and group activities, especially outside of school activities, since it is hard to relate and going to other peoples [sic] places is awkward since all of my classmates are female.

Gender Roles. The pattern code of gender roles was chosen based on participant descriptions of traditional gender expectations. Participants commented on gender expectations in how men and women are presented, along with individual experiences, such as "It gets old when women are referred to as the helpers and clients always with a male descriptor" and "As a man, I've seen other men (mostly geriatric) show me more respect than a female counterpart who displayed more knowledge/experience than I did." The theme of gender roles was present at the system level of the department, within the 
context of the classroom and clinical, and at the interaction level of faculty, community, and peers, as shown in Table 45.

\section{Table 45}

Gender Roles

Traditional Gender Roles

It gets old when women are referred to as the helpers and clients always with a male descriptor

As a man, I've seen other men (mostly geriatric) show me more respect than a female counterpart who displayed more knowledge/experience than I did.

Comparing me to women constantly

I've typically been assigned male clients for clinical rotations and I assume it's solely because I am a male

Had a professor tell me that there were certain things I could not do since I was a man (work with small children, be empathetic), but it was okay because I could do other things (more respected in the hospital setting)

Feel some extra burden to do well as a man in this field

\section{Male Gender Increased Inclusion}

Participants were asked about an experience that increased inclusion, why the experience was important, how the experience related to the individual's identity or identities, and overall experiences of inclusion. Coding of participant responses related to increased inclusion showed pattern codes of welcomed and equality.

Welcomed. The pattern code of welcomed was chosen based on participant use of the term "welcome," as in "I was generally welcomed in all regards." Welcomed represented feeling valued, included, and offered opportunities. It should be noted that 
the concept of welcomed likely implied actions taken by others, as in the following participant response, "After our July classes ended, our cohort took pictures in front of our building. I was about to get into my car and people from my cohort invited me to take pictures with them. It made me feel good because they did not have to invite me to participate in what they were doing." The theme of welcomed was present at the system level of the field of study, the university, and the department, within the context of the classroom, clinical, social and at the interaction level of faculty, community, and peers, as shown in Table 46.

\section{Table 46}

\section{Welcomed}

\section{Valued, Included, and Offered Opportunities}

Many classmates/clinical supervisors/faculty made comments about how it was nice to see men in the profession and how clients need to see more male therapists (for all sorts of different reasons).

It wasn't until I really start to bond with some girls that I felt better and began to feel included

I felt included within school activities

People are generally nice

I was generally welcomed in all regards

The faculty within my program specifically was very inclusive.

As a member of student government and a board member for a student organization, I had many opportunities to be included in the planning, organization, and participation of events.

After our July classes ended, our cohort took pictures in front of our building. I was about to get into my car and people from my cohort invited me to take pictures with them. It made me feel good because they didn't have to invite me to participate in what they were doing

Someone saw me and took the initiative to help me feel belonging 
Equality. The pattern code of equality was chosen as a summation code based on the concept of sameness and equal treatment in participant responses. Equality represents the perception of fairness in academic and clinical experiences. Participants described equal treatment as a positive feature in inclusion, as in the following, "My classmates, supervisors, and professors have been helpful. I feel like I have been treated like any other I feel like I haven't been treated any differently compared to the female students." And "I'm male and I'm treated the same. Yay." The theme of equality was present at the system level of the department, within the context of the classroom, clinical, social and at the interaction level of faculty, staff, community, and peers, as shown in Table 47.

\section{Table 47}

\section{Equality for Male Gender}

Equal Treatment

I'm male and I'm treated the same. Yay.

My classmates, supervisors, and professors have been helpful. I feel like I have been treated like any other I feel like I haven't been treated any differently compared to the female students.

The most important thing, to me, is how everybody has treated me like I am any other student or clinician. I don't want any special treatment (positive or negative) because I'm a man. I want to be judged on my skills and character

\section{LGBTQ+}

Participants were asked about gender identity using the three categories (male, female, nonbinary), whether or not they were transgender, and sexual orientation. One participant identified as transgender (male and gay). Of the 104 participants, 33\% 
indicated that they were not heterosexual. For participants who did not identify as heterosexual, the categories of bisexual (29\%), asexual (18\%), and gay (18\%) demonstrated the highest percentages. Participant responses for the participant who identified as transgender and the participants who identified not heterosexual were considered to be minorities within the field of speech-language pathology, and were separated for coding. Participants responded to the writing prompts about a meaningful experience that decreased and increased inclusion, why the experience was important, and how the experience related to their identity or identities, and overall feelings of inclusion were coded within individual narrative passages for thematic coding of decreased and increased inclusion. Pattern codes for decreased inclusion for LGBTQ+ were antagonism, fear of disclosure, microaggressions, isolation, and curriculum gaps. Pattern codes for increased inclusion were effort, openness, connection, equality, and concealment."

\section{LGBTQ+ Decreased Inclusion}

Antagonism. The pattern code of antagonism was chosen as a summary code for participant descriptions of anti-LGBTQ+ behaviors or beliefs expressed by others. Participants provided examples and shared perceptions, such as "Many of the faculty and staff openly discuss private matters such as religion and church preferences while at work, many of which are involved in openly anti-LGBTQIA affiliations," and "Most in my program were bigoted against the LGBTQ community.” The antagonism was present at the system level of the department, within the context of the classroom and social, and at the interaction level of faculty, staff, community, and peers, as shown in Table 48. 
Table 48

Antagonism

Anti-LGBTQ+ Behaviors and Beliefs

Once a classmate of mine that is still in my graduate program with me asked what she should do if she was uncomfortable providing services to an LGBTQ+ person because they "don't agree" with it. Several of my classmates echoed her concern. This experience made me realize that my classmates were not as accepting as I once thought they were.

Most of these women are not accepting of queer people

People in my program who are openly against non-binary dress

Incidents involving staff and faculty members that resulted in them having to attend sensitivity training

Many of the faculty and staff openly discuss private matters such as religion and church preferences while at work, many of which are involved in openly anti-LGBTQIA affiliations.

Most in my program were bigoted against the LGBTQ community

Fear of Disclosure. The pattern code of fear was chosen based on participant use of the term "afraid" and descriptions of anxiety about the repercussions of disclosure or other's knowledge of identity. Participants expressed concern about their presentation of their identity to others, as in "Afraid to use my proper pronouns" and "Do not think some of them [peers] would have been understanding or accepting had they known I was trans." The theme of fear of disclosure was present at the system level of the department, within the context of the classroom and social, and at the interaction level of faculty, staff, community, and peers, as shown in Table 49. 
Table 49

Fear of Disclosure

Anxiety About Disclosure of Identity

Do not think some of them [peers] would have been understanding or accepting had they known I was trans

As a queer individual, it hurt my heart to know that my own classmate, so close to actually serving real people, was looking for an excuse not to serve someone like me. It let me know that I could not come out to them. Self-conscious about how I choose to present myself

Afraid to use my proper pronouns

Spend a lot of time worrying that if my gender becomes known here, it could negatively impact my graduate studies

I do not tell everyone about my sexual orientation because of stigma and potential discrimination

Haven't wanted to tell any of the faculty because I don't want them to be biased against me

Microaggressions. The pattern code of microaggressions was chosen as a summary code to encapsulate situations and feelings that were invalidating to LGBTQ+ participants. Microaggressions, originally described for race and ethnicity (Sue et al., 2007), represent brief, daily insults to LGBTQ+ individuals. The term microaggressions has been extended from race and ethnicity to the marginalization of the LGBTQ+ community. Participants described experiences where the actions of others negatively affected them, such as "Something small like 'all of your boyfriends' or something along those lines" and "It was really jarring to be in a space where I was going to have to get to know and make friends with people who were so out of touch that they assumed that I was single, interested in men, and that I was interested in getting married in the next two 
years." The theme of microaggressions was present at the system level of the field of study, the department, within the context of the classroom and social, and at the interaction level of faculty, staff, community, and peers, as shown in Table 50.

\section{Table 50}

Microaggressions

\section{Brief, Daily Insults to LGBTQ+ Individuals}

It feels invalidating, like my identity as a queer woman doesn't matter and doesn't impact the way I navigate through the world and interact with folks.

This program wasn't designed for people like me and it's not populated by people like me

Something small like "all of your boyfriends" or something along those lines

It was really jarring to be in a space where I was going to have to get to know and make friends with people who were so out of touch that they assumed that I was single, interested in men, and that I was interested in getting married in the next two years

Entering a small, small heteronormative world for the first time

I don't want to spend my entire career talking about people's weddings or their flower beds or what cute thing their baby did or what color they're going to paint their door this year; but that seems to be what I'm up against.

Isolation. The pattern code of isolation was chosen as a summary code based on participant descriptions of feeling alone or without community. Isolation refers to pervasive feelings of not having meaningful connections with others and being the only person with a given identity. Participant responses highlighted a sense of isolation and its ramifications, such as "Quite possibly, the only queer person in my program" and "Not feeling like you have your people when ever [sic] else looks like they do is depressing and then negatively effects your academic work." The theme of isolation was present at 
the system level of the field of study, the department, within the context of the classroom and social, and at the interaction level of faculty, staff, community, and peers, as shown in Table 51.

Table 51

Isolation for LGBTQ+

Pervasive Feelings of Lack of Community

None of the members were outright homophobic, but I was definitely the token gay person to a lot of them

Quite possibly, the only queer person in my program

I believe most if not all of my classmates identify as heterosexual

As a gay man, I would feel most comfortable discussing my business with another gay man or woman

Hard to want to be friends with someone who doesn't care about my wellbeing because I'm gay

Not feeling like you have your people when ever [sic] else looks like they do is depressing and then negatively effects your academic work

Feel outcast as a queer, adult student

Curriculum Gaps. The pattern code of curriculum gaps was chosen based on participant descriptions of a lack of coursework and training around the needs of the LGBTQ+ community. Participants specifically commented on the absence of LGBTQ+ topics within courses and multiculturalism, such as "Not seeing LGBT+ issues represented in the curriculum" and "We only talk about cultural competency as it relates to race, ethnicity, and multilingualism." The theme of curriculum gaps was present at the 
system level of the department, within the context of the classroom, and at the interaction level of peers, as shown in Table 52.

\section{Table 52}

\section{Curriculum Gaps}

Lack of Coursework and Training for LGBTQ+ Needs

Not seeing LGBT+ issues represented in the curriculum

We only talk about cultural competency as it relates to race, ethnicity, and multilingualism

Professors seem lack the knowledge about what it means to have a gender-inclusive classroom and use binary and gender essentialist language on their syllabus and in their speech. They use and model language that assumes that we, and our clients, are all cisgender, heterosexual, and have families with a mom, a dad, and child(ren). It is extremely problematic and hurtful.

Case study assignments that involve married couples are always straight couples. Intake forms we receive as example model forms ask for mom's name and dad's name, or have only two gender options to choose from (Male and female)

Professors say "he or she" in their speech and when I have asked them to say "they" instead, I've been told it's "too hard"

Not being validated or considered throughout the curriculum design

No mandated education on gender identities, gender neutral language, or removing gendered language from medical lexicon

Professors sometimes accidently push heteronormative stereotypes on their students

\section{LGBTQ+ Increased Inclusion}

Participants responded to prompts to share experiences that increased inclusion, their meaning, and relationship to their identities. Pattern codes for increased inclusion for LGBTQ+ participants were effort, openness, connection, equality, and concealment. 
Effort. The pattern code of effort was chosen based on participant use of the term "effort," which described demonstrated behaviors toward the goal of meeting LGBTQ+ needs. Effort reflected outward demonstrations of understanding and modeling of LGBTQ+ needs, such as "The faculty that I trust, who have made active efforts to be inclusive (adding pronouns to their email signature, using singular they in their speech, occasionally discussing how an issue might impact LGBT families/youth, etc.), have made me feel included." The theme of effort was present at the system level of the department, within the context of the classroom and social, and at the interaction level of faculty, as shown in Table 53.

Openness. The pattern code of openness was chosen based on participant use of the term open." Openness refers to holding an interest or being open to LGBTQ+ needs. Participants described an openness to non-binary gender, and the positive effects of openness, such as "Students with which I work that are more open to non-conforming gender identities" and "As a result of this support system and open conversation, I do not feel like an outsider." The theme of openness was present at the system level of the department, within the context of the classroom and social, and at the interaction level of faculty and peers, as shown in Table 54 . 
Table 53

Effort

\section{Demonstration of Behaviors to Meet LGBTQ+ Needs}

My professors have almost all been very caring and sensitive to different identities and careful with the language they use

Within my course on ethics, there was an entire segment on serving the LGBT+ community

Newsletter and notification that presents multiculturalism consistently, frequently, and through more than one medium

The faculty that I trust, who have made active efforts to be inclusive (adding pronouns to their email signature, using singular they in their speech, occasionally discussing how an issue might impact LGBT families/youth, etc.), have made me feel included.

[Faculty] willingness to promote inclusion and incorporate learning around the gender spectrum

When I researched graduate programs, I specifically looked up ""Safe Zone"" programs for all the universities I was applying to. I made sure at least one member of the faculty from the SLP program was listed as an LGBTQ ally or I removed the program from my list.

She [department chair] used inclusive language sincerely and naturally

My professor on our first day talked about the importance of putting pronouns on our nametags

When professors introduce themselves by their pronouns

\section{Table 54}

Openness

\section{Interests in Learning About LGBTQ+ Needs}

Students with which I work that are more open to non-conforming gender identities

Fewer intolerant and mean people

I feel comfortable sharing my experiences and asking questions

As a result of this support system and open conversation, I do not feel like an outsider

Cohort is very open minded

Faculty were open to receiving this training and aware that they could improve and that they were not meeting the needs of LGBT students 
Connection. The pattern code of connection was chosen as a summary code to represent the establishment of supportive relationships. Connection represented relationships with other LGBTQ+ individuals, such as "Relate to others in a similar situation" and "Meeting a few other girls that aren't straight," as well as relationships with supportive individuals, e.g., "Finding LGBTQ allies." The theme of connection was present at the system level of the department, within the context of social, and at the interaction level of community and peers, as shown in Table 55.

\section{Table 55}

Connection for $L G B T Q+$

Establishment of Supportive Relationships

Friendship with other graduate students

Relate to others in a similar situation

My peers have made me feel included

Meeting a few other girls that aren't straight

Finding LGBTQ allies

Have friends who truly understand me

Finding things in the community that I can engage with

Equality. The pattern code of equality was chosen as a summary code based on participants' descriptions of the value of fairness or equal treatment. Participants described acceptance in terms of equality, as in "Just as accepted as someone who identifies as straight." 
The theme of equality was present at the system level of the department, within the context of classroom and social, and at the interaction level of faculty, staff, community, and peers, as shown in Table 56.

\section{Table 56}

\section{Equality for $L G B T Q+$}

Perception of Fairness or Equal Treatment

When I am performing well in class or in clinical

Just as accepted as someone who identifies as straight

I think a majority of the staff and faculty in the department make me feel like my efforts are worth while $[s i c]$ and that what I say in class is important

I was never made to feel like a token

By going to a place that already "had gay people," I didn't have to worry about "the Rosetta stone" of the LGBTQ population

Concealment. The pattern code of concealment was chosen based on participants' descriptions of employing strategies to avoid revealing LGBTQ+ identity. It should be noted that concealment involves deliberate efforts to maintain a heteronormative persona. Although participants shared how concealment increased perceptions of inclusion, it is an internal factor that requires hiding a sense of self. Participant responses for concealment described their appearance to others, such as "Stealth, so everyone in my graduate program thinks I'm a cisgender guy" and "My identities are fairly easy for me to hide so that I am able to pass as straight and 
cisgender." The theme of concealment was present at the system level of the field of study, the university, and the department, within the context of the classroom and social, and at the interaction level of faculty, staff, community, and peers, as shown in Table 57.

\section{Table 57}

\section{Concealment}

\section{Strategies to Avoid Revealing Identity}

Stealth, so everyone in my graduate program thinks I'm a cisgender guy

They have no idea I'm trans in the first place

My identities are fairly easy for me to hide so that I am able to pass as straight and cisgender

I'm only out to a handful of my classmates

Hide most physical markers of my queerness

I am able to pass as straight and cisgender

I have not advertised my sexuality, as I do not feel that it is relevant, but I also have not hidden it

I haven't came out to any of my professors as I don't feel there is a need, but I don't see them having any problems

\section{Disability}

Participants were asked whether or not they identified as having a disability, and if so, the type of disability. Of the 104 participants, $27 \%$ indicated that they had a disability and provided information about their disabilities. The most common disability categories with the greatest number of participants were psychiatric disability (29\%), intellectual or learning disability (14\%), and hearing impairment (11\%). It should be 
noted that participants were not required to report on any medical documentation related a formal diagnosis and were allowed to make their own determination of whether or not they considered themselves to identity as having a disability. Pattern codes for decreased inclusion for students with disabilities were exposure, disrespect, barriers, and reductionist. Pattern codes for increased inclusion were disability awareness, asset, equality, and formal services. The descriptions of pattern codes for decreased and increased inclusion are provided in the following tables.

\section{Disability Decreased Inclusion}

Exposure. The pattern code of exposure was chosen based on participants' use of the term "exposed," such as "Quiz failure exposed my weaknesses to the world" and "If my weaknesses are hinted at as negative, I feel exposed.” Exposure referred to feelings of vulnerability and anxiety related to revealing of disability. The theme of exposure was present at the system level of the department, within the context of the classroom and social, and at the interaction level of faculty, staff, community, and peers, as shown in Table 58. 
Table 58

Exposure

Anxiety Related to Revealing Disability

I am able to hide most of them [disabilities] in casual settings

I felt like I had to hide this [grade] from everyone or else they would think I was not smart

Quiz failure exposed my weaknesses to the world

If my weaknesses are hinted at as negative, I feel exposed

Having unseen disorders (i.e., mild cognitive delay and osteoarthritis) it is difficult for fellow students or professors to see a difference

Cautious of disclosing my mental health difficulties

I always feel like I am an outsider

Feel pressure to not appear autistic

When faculty decides to vote whether to skip over class breaks. However, it is not anonymous, you need to raise your hand if you want a break. For me, then I either have to choose between isolating myself (as my classmates don't want/ need a break, but due to my ADHD (especially hyperactive), I need that break to move), taking a break on my own and risk missing important class information, or learning almost nothing for the rest of the class.

I take Adderall XR which definitely shows up on the screens. I did not feel comfortable disclosing this information, as I know there is a stigma behind taking ADHD meds (even if it barely levels the playing field.

Choose between potentially causing animosity between me and my peers or prioritizing my learning

Never felt like I had a disability UNTIL I came to graduate school

Disrespect. The pattern code of disrespect was chosen as a summary code for participant experiences that reflected a lack of understanding, appreciation, and respect for neurodiversity. A participant described lack of respect of disabilities in multiculturalism in the following, "When I mention ideas and concerns of the autistic community, I sometimes feel as though my classmates and professors don't recognize the 
relevance to our cultural competence/humility education." One participant described faculty disrespect of an individual's disability in the classroom, as shown in the following, 'I felt very uncomfortable that my professor was using my disability to teach students about an assessment without asking my permission prior to calling me out in front of the class." The theme of disrespect was present at the system level of the department, within the context of the classroom, and at the interaction level of faculty, as shown in Table 59.

\section{Table 59}

\section{Disrespect}

Lack of Respect for Neurodiversity

I have felt like that some teachers are not as patient with my stutter than others. It takes a while to get out certain sounds and I don't like how some teachers look away or don't allow me as much time to talk as others.

I felt very uncomfortable that my professor was using my disability to teach students about an assessment without asking my permission prior to calling me out in front of the class

A couple of professors that I worked with seemed to embrace the philosophy that graduate programs should be extremely mentally stressful and did not respond appropriately to demonstrations of poor mental health by the students

When I mention ideas and concerns of the autistic community, I sometimes feel as though my classmates and professors don't recognize the relevance to our cultural competence/humility education

Professors will say something somewhat dismissive

They are not understanding my psychiatric issues. I feel they broke me rather than lifting me up and working with me

Barriers. The pattern code of barriers was chosen as a summary code based on participant descriptions of challenges related to their disability. Barriers represented the 
effects of disability on academic performance and social opportunities. Participants specifically noted differences between themselves and others, such as "I have to work 10x harder than the majority of my classmates to do something," and how their disability affects them, as in the following, "I always required extended time, was late for class, and had much difficulty paying attention in classes and being prepared." The theme of barriers was present at the system level of the field of study, the university, and the department, within the context of the classroom, and at the interaction level of faculty, staff, community, and peers, as shown in Table 60.

\section{Table 60}

Barriers

\section{Effects of Disability on Performance}

I always required extended time, was late for class, and had much difficulty paying attention in classes and being prepared

I have a diagnosed LD which affected GRE [Graduate Record Examination] performance, even with accommodations

With a physical handicap. This made it difficult to keep up during outings requiring a great degree of walking

Timelines are geared towards faster moving/thinking profiles

Struggling to put in more effort because of the environment

I have to work 10x harder than the majority of my classmates to do something

I did not feel comfortable utilizing the campus protocol for documenting disabilities in order to receive accommodations.

I don't feel I was prepared for the extent to which graduate school would affect my mental health 
Reductionist. The pattern code of reductionist was chosen as a summary code to represent participant descriptions of situations in which another person reduced the complexity of experience or identity of an individual to a single descriptor or marker. One participant used the concept of "singular thing," as in "It sucks when someone sees you as only a singular thing (a stutterer) and praises you for essentially nothing except being present." The theme of reductionist was present at the system level of the department, within the context of the classroom, and at the interaction level of faculty and peers, as shown in Table 61.

\section{Table 61}

Reductionist

\section{Reduce Complexity of an Individual}

Professor also patronized me and said things like "it's so great you are pursuing this even though you stutter," and other comments like that.

It sucks when someone sees you as only a singular thing (a stutterer) and praises you for essentially nothing except being present

Most [peers] thought of my disability as a novel thing. Which it is very rare so I kinda get it.

Fear that they would only look at me for my ADHD instead of who I am

\section{Disability Increased Inclusion}

After sharing experiences that decreased inclusion, participants shared meaningful experiences that increase inclusion. Patterns codes of increased inclusion for participants with disabilities included disability awareness, asset, equality, and formal services. 
Disability Awareness. The pattern code of disability awareness was chosen as a summary code to describe participant experiences with others who had knowledge of disabilities. Disability awareness referred to consideration in teaching, admissions, interaction methods, and availability of specialized courses. At the admissions level, a participant described the importance of interviews as follows, "Interview during application process allowed me to present my knowledge, show my personality, and express my passion." Within instruction, a participant described course design as follows, "Majority of my courses allows a variation of test, assignments, and presentations, etc." The theme of disability awareness was present at the system level of the department, within the context of the classroom, clinical, and social, and at the interaction level of faculty and peers, as shown in Table 62.

\section{Table 62}

Disability Awareness

Consideration of disabilities

One of the professors at the [university] ran a fluency certificate, which requires research and extra classes.

Interview during application process allowed me to present my knowledge, show my personality, and express my passion

Majority of my courses allows a variation of test, assignments, and presentations, etc.

One of my professors asked me to meet with her after class. Instead of being upset with me for being late to class, forgetting several due dates, etc., she genuinely asked me what was going on and worked with me to come up with some strategies to help.

My peers and professors understand it more than most because it related to cranial nerves and the auditory system

Talking with other students in my cohort about experiences in our classes and clinic work was very helpful in helping me deal with episodic anxiety and stress 
Asset. The pattern code of asset was chosen as a summary term that reflected participant responses highlighting strengths. Asset represents the recognition of strengths and contributions of individuals with disabilities and aligns with the concept of assets for minorities within educational settings (Smith-Maddox \& Solorzano, 2002). Participants described how their experiences established their beliefs in their positive contributions, such as "During one small group project, another group member recognized that though I was much slower than the rest of the group, I was good at working through the problem and catching details that others missed. I felt included because someone recognized that I had strengths to give to the group despite my weaknesses." The concept of asset was also reinforced by faculty, as in the following, "When faculty has approached me and praised me for my "creative" thinking or off-the-wall questions." The theme of asset was present at the system level of the department, within the context of the classroom and social, and at the interaction level of faculty and peers, as shown in Table 63.

\section{Table 63}

Asset for Disability

\section{Recognition of Strengths and Contributions}

During one small group project, another group member recognized that though I was much slower than the rest of the group, I was good at working through the problem and catching details that others missed. I felt included because someone recognized that I had strengths to give to the group despite my weaknesses.

Had an advantage because I could relate more to the students I'd be working worth [sic]

When faculty has approached me and praised me for my "creative" thinking or off-the-wall questions.

My brain, despite having really different wiring that can be incredibly detrimental and make me feel like I have a disability, can actually do some really neat things!

A friend asked for my input on supporting one of their clients who is on the spectrum and I was able to help 
Equality. The pattern code of equality was chosen based on participant use of the term "equally," as in "I want to be seen as a peer and equally capable by my fellow cohort members."

Equality represents the perception of fairness or equal treatment. Participants provided information about sameness in treatment and shared challenges, such as "Not singled out, either as discrimination nor as a basis for special treatment" and "Everyone has something they have to be brave about." The theme of equality was present at the system level of the department, within the context of the classroom, clinical and social, and at the interaction level of faculty, community, and peers, as shown in Table 64.

\section{Table 64}

Equality for Disability

Perception of Fairness or Equal Treatment

Not singled out, either as discrimination nor as a basis for special treatment

Everyone has something they have to be brave about

Everyone is experiencing being away from home and being out of our comfort zone. I feel like this gives everyone an opportunity to see one another as equal

Working in a special needs camp, because I felt like there was zero judgment

I want to be seen as a peer and equally capable by my fellow cohort members

I had a professor once tell me that I was just as capable as everyone else 
Formal Services. The pattern code of formal services was chosen as a summary code to represent participant experiences accessing disability services and accommodations. It should be noted that formal services require documentation, as noted in participant responses, e.g., "I provided documentation at the beginning of the program." Formal services included referrals and self-initiated services, such as "Resume counseling services and increase dosage of my medication" and "Directly provided information about counseling resources." The theme of formal services was present at the system level of the university, within the context of the classroom, and at the interaction level of faculty and community, as shown in Table 65.

\section{Table 65}

Formal Services

\section{Accessing Disability Resources and Accommodations}

I provided documentation at the beginning of the program

Resume counseling services and increase dosage of my medication

Directly provided information about counseling resources

She [professor] also directed me to other resources to get official disability accommodations if needed. She stood up for me and communicated with other faculty about our discussions and made adjustments as needed to help me do well in the program. 


\section{Other Identity Themes}

Five other main identity themes were described in participant responses: religion, political, family/parental role, age, and female dynamics. Although these identities were not the focus of this study, they are areas for further consideration in upcoming studies. Religion and political occasionally appeared in conjunction with LGBTQ+ identity. It is important to note that religious discrimination may extend beyond a single individual's experiences, as in the following participant response, "In terms of being Jewish, I came across an aphasia assessment in my course's resource area that had Hitler as a stimulus. I do not know why an assessment creator would choose a mass murderer as a stimulus item and I can only imagine the trauma this could bring to a Jewish patient."

The identity of family/parental role occasionally appeared with low socioeconomic status. It may be important for future research to examine the experiences of graduate students who are parenting children while attending graduate school. Age referred to older and returning students, and female dynamics described concerns around cliques and possible female relational aggression or bullying. Given that the field of speech-language pathology is a female-dominated field, future research into cliques and "mean girls," as stated by participants, may be beneficial.

Tables for the other identity themes are provided as follows, as shown in Tables 66 through 69 . 


\section{Table 66}

Religion

Religious Faith as Identity Marker

The Religion I practice is New-Age Paganism

I felt weird because I was the only one in my class that doesn't have a religion and is not a Christian. my entire class is Christian and I feel like I can't say anything that might offend them or anything that's not Christianity just because I would be the only one seeing it that way. of course I could talk about being non-religious, but it's just not the popular point of view.

My Christian identity tells me that it's good that I feel a part of the group. In the Christian system of belief, God exists and operates out of community. God exists as a group, distinct but also as one.

I am agnostic so girls who LOVE JESUS make me feel uncomfortable.

In terms of being Jewish, I came across an aphasia assessment in my course's resource area that had Hitler as a stimulus. I do not know why an assessment creator would choose a mass murderer as a stimulus item and I can only imagine the trauma this could bring to a Jewish patient

\section{Table 67}

Political Views

Political Affiliations and Beliefs

I also have seen a lot of trump [sic] supporters which isn't something I agree with

The majority of women in this program are highly competitive, from a conservative background

I did my undergraduate in a more liberal and urban area where I could express myself and be accepted however I came because it was normalized.

The other university I considered is conservative, so I would have most likely kept my sexual orientation private

Many students have a more conservative mindset without being taught that Liberalistic point of views are "fact."

There are going to be white, conservative, and inexperienced classmates who may not have the same views as you. 


\section{Table 68}

Age

Older and Returning Students

I hold the age of 43 and have two young adult sons. The only way I have felt a decrease in my feelings of being included has been the awkwardness I have occasionally felt from this age difference and from my own life experience differences than my younger cohort (most of whom I could be a parent due to the age gap). I have also felt slight awkwardness at times with professors for these differences.

I have experienced times when I've wondered if I would feel more psychologically included if I were 20 years younger.

I was uncomfortable being among my graduate program peers who are mostly in their early 20s. I'm currently 41 and have small children, unlike my young peers who don't have children.

I feel uncomfortable knowing that I'm much older than my classmates and I'm grateful to be able to assume they either don't realize I'm in my early forties or they don't care.

I didn't even know that the field existed until I was much older.

I feel I am older and have a significantly different set of life experiences than most students in my program.

I am older and more informed of how my identity has shaped my lived experience in meaningful ways

Older student (50+)

College programs are designed for the "average" college students' age range (20s to 30s) without a thought that older students may return to school or be interested in these types of programs.

As an older (graying) student, these young men treated me as though I was geriatric, even to the extent of commenting about how easily bones can break when you are older.

Being in my late thirties, single parent with two children, made me feel a separation (a little bit) to begin with

I needed accommodations because I had a more complicated life as a parent, they were as a department very supportive 
Table 69

Female Dynamics

Navigating Female Relationships

Everyone was cliquey [sic]

There were cliques formed already of their previous undergraduate students and as an out of state student it was very discomforting.

I think generally, the program has its clicks [sic]

It is very clicky [sic]

Being targeted by a couple of 'mean girls' who stole a part of a project, then turned me in to professors for 'unprofessionalism' when I reacted.

I didn't come to my program to experience the nonsense of girls who act like they're in high school.

\section{Peer Advice}

All participants were asked to provide advice to a peer through the survey question, "What advice would you give to another minority student about inclusion to prepare them for a speech-language pathology graduate training program?" Participant responses to this question were addressed collectively, without separating participants into groups based on identity, in order to provide an overall understanding of how minorities within speech-language pathology viewed their own experiences and their ideas for supporting others. Discourse analysis (Gee, 2014) that focused on meaningful verbs was used to show how graduate students positioned themselves within their programs, with advice to a peer as a means of preparation for a social role. Discourse analysis includes position design, which shows how language use places a writer and a 
reader into specific positions in relationship to accessing of social goods and services (Gee, 2014). Positioning shows the ways that speakers or writers influence listeners and readers to think and behave in certain ways (Gee, 2014).

All participant responses to the writing prompt for peer advice were coded using meaningful verbs, in other words, verbs that carried important information about the role of the writer and reader. For example, the verbs "attend, prepare, look, ask" appeared for the pattern code for choosing a graduate program. These verbs place the reader as the individual who is required to assume responsibility for ensuring a positive outcome. Initial coding involved highlighting meaningful verbs in phrases and sentences within each participant's response. These phrases and sentences were then grouped by category in relation to shared concepts to be used for pattern coding, along with their list of verbs. Verbs and their accompanying phrases and sentences were examined for positioning and agency. Positioning (Gee, 2014) is part of language power and shows how the speaker or writer gives identity to the listener or reader. Agency is part of social cognitive theory, which illustrates connections between cognitive processes and how people behave at the individual level, with others, and within environments to show cultural context (Bandura, 2002). Bandura described three fundamental types of agency, or self-efficacy: personal, proxy, and collective. Personal agency is the belief that one's own actions further one's goals, and proxy agency is the belief that another person can help further one's own goals. Collective agency is a recognition that groups of people can work collaboratively to achieve a shared common goal. Agentic action is considered a form of adaptability and flexibility (Bandura, 2002). Bandura described how people 
"create styles of behavior that enable them to realise [sic] desired outcomes and pass on the effective ones to others by social modeling and other experiential means” (p. 272). Using positioning, how the participants used language to place a peer in a specific position in relation to social goods and power, and agency provided information about how the participants viewed their own roles in relation to inclusion within their graduate training programs. Verbs, which showed positioning, indicated types of agency and who held political power in the granting of social goods. A description of the themes for peer advice, their meaningful verbs, and the positioning of the writer and reader are described in the following section.

\section{Themes for Peer Advice}

The 12 themes for peer advice were choosing a graduate program, planning and expectations, seeking support, fortitude, perseverance, advocacy, diversity, mission, education, relationships, self-worth, self-awareness. As noted, each theme was evaluated based on how the writer described the role of the reader, which related to how the current graduate students considered their own roles in order to provide guidance to a hypothetical peer.

Choosing a Graduate Program. The pattern code of choosing a graduate program was based on participant advice in the decision-making process for prospective graduate students. Participant responses provided specific examples related to making decisions, such as "Decide what your priorities are when selecting a program" and "Choose a program that will satisfy that requirement [diversity]." Participants gave advice about actions to take to gather information, including "Ask about what the 
programs are doing to directly address issues of inclusion within their programs," and "Do research before you decide where to go." Participants placed prospective students in the position of needing to act as individual agents with personal agency to gain their own social and political power through acquiring knowledge of programs and making decisions. Meaningful verbs frequently showed actions of preparation, including "worry, attend, prepare, move, go, research, visit, commit, decide, select, choose, look, do, ask, consider," which reflected individual responsibility of seeking out social goods in relation to others, as shown in Table 70.

Planning and Expectations. The pattern code of planning and expectations was chosen based on participant responses related to future events and environments. Participants described the potential future feelings for incoming graduate students, such as "Prepare to be very much a minority in this field, but make sure you speak a second or third language," and "You are going to feel like your culture and language are not typical considerations." Preparations also included advice on ways of viewing the world and managing beliefs, including "Assume people are generally nice," and "Develop an inner strength." Participant responses showed the use of personal agency to manage or mitigate potential loss of social goods that resulted from being a minority within the field. Participants' advice acknowledged that others would likely take social goods away from them. Meaningful verbs frequently showed actions of internal thought processes, including "predict, assume, develop, learn, encounter, foster, invest, be, warn, prepare, hide, become, make, feel, have, deal," which reflected individual responsibility of managing this loss of social goods in relation to others, as shown in Table 71. 
Table 70

Choosing a Graduate Program

\begin{tabular}{|c|c|}
\hline Meaningful Verbs & Participant Responses for Choosing a Program \\
\hline \multirow{14}{*}{$\begin{array}{l}\text { Worry, attend, } \\
\text { prepare, move, go, } \\
\text { research, visit, } \\
\text { commit, decide, } \\
\text { select, choose, } \\
\text { look, do, ask, } \\
\text { consider }\end{array}$} & $\begin{array}{l}\text { Not to worry about attending a program where the majority of students } \\
\text { are women }\end{array}$ \\
\hline & Financially prepare to move or go to a local program \\
\hline & Research and visit the program you're enrolling in before you commit \\
\hline & Decide what your priorities are when selecting a program \\
\hline & Choose a program that will satisfy that requirement [diversity] \\
\hline & $\begin{array}{l}\text { Look for representation within the demographic make up of the } \\
\text { instructors and staff }\end{array}$ \\
\hline & Do their research an $[s i c]$ a program that doesn't just look good on paper \\
\hline & Attending schools in metropolitan areas will probably be more diverse \\
\hline & Go where you will be the happiest \\
\hline & $\begin{array}{l}\text { Ask about what the programs are doing to directly address issues of } \\
\text { inclusion within their programs }\end{array}$ \\
\hline & Do research before you decide where to go \\
\hline & Visit their program and talk to gradate $[$ sic $]$ current graduate students \\
\hline & $\begin{array}{l}\text { Consider schools who are willing to provide adequate funding and } \\
\text { research opportunities }\end{array}$ \\
\hline & $\begin{array}{l}\text { Look for the most diverse programs when applying because mine } \\
\text { definitely isn't }\end{array}$ \\
\hline
\end{tabular}


Table 71

Planning and Expectations

Meaningful Verbs Participant Responses for Planning and Expectations

Predict, assume, Predict that you will not be judged

develop, learn,

encounter, foster, Assume people are generally nice

invest, be, warn,

prepare, hide, become, make,

Develop an inner strength

feel, have, deal

Learn how to move forward from moments that may jolt their peace of mind

May encounter clients or employers that do not foster inclusive environments

Invest the time to learn more about the gender spectrum, gender variant identities, nonbinary language

Be ready for a changing world by learning how to serve people of all identities

Warn them to be prepared to have to hide it or become the token

Be aware to be overrun by entitled white women

Prepare to be very much a minority in this field, but make sure you speak a second or third language

You are going to feel like your culture and language are not typical considerations

You may even have feelings about the lack of literature in this profession regarding language development, cultural considerations

Be prepared to work hard

There are going to be white, conservative, and inexperienced classmates who may not have the same views as you.

You'll have to deal with the usual dumb questions and microaggressions 
Seeking Support. The pattern code of seeking support was chosen based on participant advice to their peers to take action to find support. Participants gave specific recommendations for actions, such as "Create a support system," "Search for and join university groups that revolve around diversity," and "Find peers that share your identities or values." Peer advice for seeking support showed personal agency with each student needing to take responsibility to gain social goods, such as locating potential individuals for social relationships, gaining entrée into a group, and finding support. Seeking support implied that social goods, in the form of supportive relationships, would not be readily available without individual action. Meaningful verbs frequently showed actions of hunting, building, or creating, including "create, find, search, join, talk, make, need, connect, seek, weed, apply, get, put, know, locate, try, build, survive," which reflected individual responsibility of using a deliberate process to establish social goods, as shown in Table 72 .

\section{Table 72}

Seeking Support

Meaningful Verbs Participant Responses for Seeking Support

Create, find, search, Create a support system join, talk, make, need, connect, seek, Finding people who are open-minded weed, apply, get, put, know, locate, Search for and join university groups that revolve around diversity try, build, survive Find peers that share your identities or values

Find a mentor

Find people who have had similar life experiences as you 


\section{Table 72 (continued)}

Meaningful Verbs
Participant Responses for Seeking Support

Create, find, search, Find other avenues of support outside of your program join, talk, make, need, connect, seek, Talk to people because you are likely to find similarities weed, apply, get, put, know, locate, Make friends outside your program

try, build, survive

Find your people and stick with them

Find the people in your class who have similar interests to you

Find community to plug into

We need the group

Finding a good therapist has helped

They [faculty member] more than likely have the ability to connect you with someone who might have similar experiences

Seek help from peers and professors

Make sure to they have another minority confident, in or outside of the program

Weed out the people who are not culturally accepting and eventually they will find classmates that value them and their background

Join a cultural group on campus outside of SLP

Apply for the MSLP program

Find your group

Get involved and make friends

Put yourself out there and make sure your professors know you and network

Create a strong network of others who feel strongly about cultural and linguistic diversity

Seek out related resources 


\section{Table 72 (continued)}

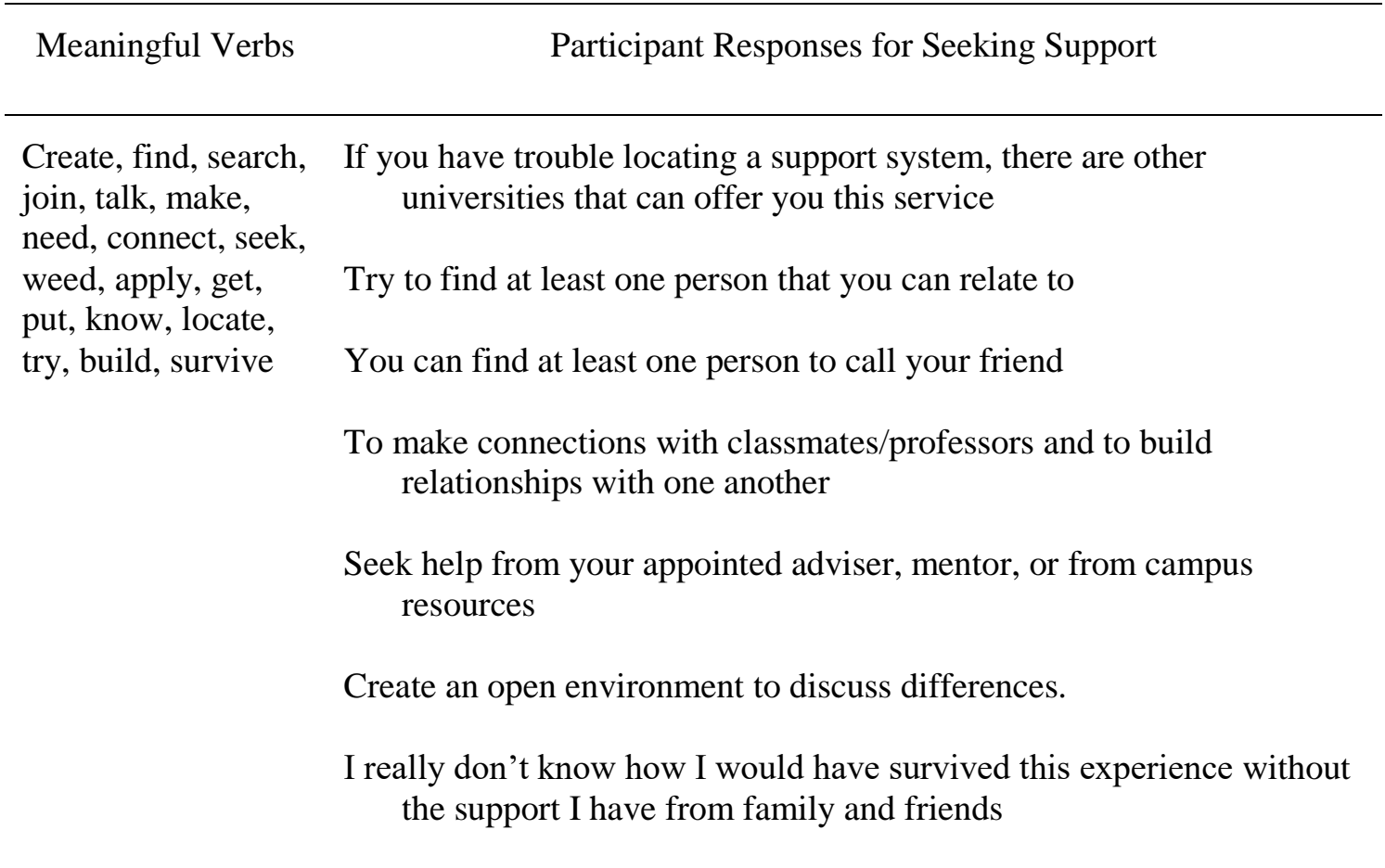

Fortitude. The pattern code of fortitude was chosen as a summary term to represent peer advice that described maintaining an internal state of being that fostered success. Participants' responses described character attributes or virtues, such as "Be mentally strong," "Have some patience," "Be //tactful in all your requests and connections," and "Be proud of who you are." Fortitude was chosen to encompass the idea of strength under adversity, as exemplified in participant responses such as, "Don't be afraid," "Be resilient," and "Be brave." Prospective graduate students were positioned as responsible for their own internal state, which represented personal agency, as opposed to receiving the granting of social goods in the form of moral support from others. Meaningful verbs frequently showed internal states, including "be, have, let, see, embrace, continue, feel, get, discourage, worry, make, stay, take, neglect," which implied 
a personal agency of monitoring and maintaining a given emotional state when threatened with the potential loss of social goods through the loss of support, as shown in Table 73.

\section{Table 73}

\section{Fortitude}

\section{Meaningful Verbs Participant Responses for Fortitude}

Be, have, let, see, $\quad$ Be mentally strong embrace, continue, feel, get,

Be strong $(2 \mathrm{x})$

discourage, worry, make, stay, take, neglect

Have some patience

Don't let your fears or insecurities get in the way of pursuing your education

Be yourself (6x)

Be tactful in all your requests and connections

Be proud of who you are

Don't be afraid to show your personality and your strengths

If someone sees you as lesser, they are not worth your time

Letting people see that you are kind, respectful, and helpful is the best way to ease any tension

Embrace the awkward

Continue to love and continue to learn

Tell them not to feel alone

Don't get downy [sic] you will find your people

Be ready to work hard

Be willing to step out of your comfort zone

Not to let their race make them insecure 


\section{Table 73 (continued)}

\begin{tabular}{ll}
\hline \multicolumn{1}{c}{ Meaningful Verbs } & \multicolumn{1}{c}{ Participant Responses for Fortitude } \\
\hline $\begin{array}{l}\text { Be, have, let, see, } \\
\text { embrace, continue, } \\
\text { feel, get, } \\
\text { discourage, worry, } \\
\text { make, stay, take, } \\
\text { neglect }\end{array}$ & Don't be afraid \\
& Don't [let] implicit discrimination discourage you \\
& Be brave \\
& Don't be intimidated, or feel out of place \\
& Do not worry about the people that make you feel left out \\
& Don't be a snowflake \\
& Don't complicate it [graduate school] with issues \\
& Stay positive \\
& Don't worry about fitting in \\
& Take care of yourself and don't neglect your mental health \\
Worry about you
\end{tabular}

Perseverance. The pattern code of perseverance served as a summary term to represent participant responses that focused on continuation and completion of a graduate degree. Participant responses for perseverance used concepts of continuing and not stopping, such as "Continuing your education is a business transaction," "Please never give up because it is not like we ever had the upper hand," and "Do not let you being outnumbered stop you." Current minority graduate student participants positioned future minority graduate students as needing encouragement to continue. This type of peer-topeer support may represent a form of collective agency, where students work together in order to ensure that all of them achieve the goal of graduating. Participant responses 
showed the expectation of need for the social goods of emotional support and encouragement and provided these social goods to a peer. Meaningful verbs frequently showed movement toward a goal, including "continue, give up, can, let, stop, roll, know, fake, make, power, overcome, graduate, keep," which implied a personal agency of individual action for positive outcomes when experiencing challenges, as shown in Table 74.

Advocacy. The pattern code of advocacy was based on participant responses that used the term "advocate," such as "Be an advocate for yourself and others with diverse characteristics." Participant responses represented acts of advocating, including "Communicate with your professors about where you might need some grace or assistance," "Speak up," and "Stand up to anyone within the program who may try to make them feel as though they don't belong." Participants positioned prospective students as individual agents who should view themselves as capable of making a claim to social goods through self-advocacy. It should be noted that the need to advocate is typically predicated on an individual's experience of not having access to social goods. In other words, current minority graduate students implied that graduate programs will not provide an environment in which social goods are easily accessible. Meaningful verbs frequently showed actions related to communication and interaction, including "know, stand, show, walk, listen, consider, rely, communicate, speak, be, take, advocate, request, try, dignify, educate, find, voice, use, regard, express, care, disagree," which reflected individual responsibility of navigating social goods through communicative acts with others, as shown in Table 75. 
Table 74

Perseverance

Meaningful Verbs Participant Responses for Perseverance

Continue, give up, Continuing your education is a business transaction can, let, stop, roll, know, fake, make, Never give up and do everything you can power, overcome, graduate, keep

Please never give up because it is not like we ever had the upper hand

Do not let you being outnumbered stop you

Roll with the punches

Never give up on what you know you can accomplish

Know that your program and experiences with your professors are temporary

Fake it until you make it

Power through

You will overcome all the challenges you face

You will graduate

Keep your head up

Never give up

You can do it

Do not let other people make you feel bad about our speed at completing tasks/needing extra time 


\section{Table 75}

\section{Advocacy}

Meaningful Verbs

\section{Participant Responses for Advocacy}

\begin{tabular}{l}
\hline Know, stand, \\
show, walk, listen, \\
consider, rely, \\
communicate, \\
speak, be, take, \\
advocate, request, \\
try, dignify, \\
educate, find, \\
voice, use, regard, \\
express, care, \\
disagree
\end{tabular}

Know your rights and the laws

Stand up for yourself

Show who I am and show my dedication

Walk a line of listening to their criticism, considering it, but relying on intuition after that

Communicate with your professors about where you might need some grace or assistance

Speak up

Be an advocate for yourself and others with diverse characteristics

Take a role in educating their peers

Advocate for yourself and request diverse clinical opportunities

Try to explain kindly why what they said or did was inappropriate

Explain kindly why what they said or did was inappropriate and a better way of expressing themselves

Don't be afraid to stand up for yourself

Always advocate for yourself

Stand up to anyone within the program who may try to make them feel as though they don't belong

Educate others on your needs

Stand your ground and show that you have just as much right to be there

You will find yourself capable in advocating and find what information/tools we do have available

SPEAK UP! $(2 \mathrm{x})$

Do not be afraid to voice your opinion 
Table 75 (continued)

\begin{tabular}{|c|c|}
\hline Meaningful Verbs & Participant Responses for Advocacy \\
\hline \multirow{6}{*}{$\begin{array}{l}\text { Know, stand, } \\
\text { show, walk, listen, } \\
\text { consider, rely, } \\
\text { communicate, } \\
\text { speak, be, take, } \\
\text { advocate, request, } \\
\text { try, dignify, } \\
\text { educate, find, } \\
\text { voice, use, regard, } \\
\text { express, care, } \\
\text { disagree }\end{array}$} & $\begin{array}{l}\text { Use your experience to help educate others in classes, but do not expect } \\
\text { others to regard you as an expert }\end{array}$ \\
\hline & Be an advocate for yourself and for inclusion \\
\hline & Speak up if you need to \\
\hline & EXPRESS YOUR OPINONS \\
\hline & Do not care if they disagree with you \\
\hline & $\begin{array}{l}\text { Teach about the positives that come along with neurodiversity, not just } \\
\text { the negatives. }\end{array}$ \\
\hline
\end{tabular}

Diversity. The pattern code of diversity was chosen based on participant responses that used the term "diversity," such as "Acknowledge their diversity and hold onto [sic] it and be proud of it." Participant responses described culture and life circumstances, including "Proudly represent your background/culture," "Be proud of where you came from," and "Your background strengthens your experience and makes you more marketable. Consider and integrate it into your clinical lens." Participants framed the concept of diversity as a social good unto itself, which subsequently positioned the minority graduate students as having an intrinsic social good. In some ways, this served as a form of collective agency, as minority students are able to collaboratively illuminate how diversity is itself something of value. Meaningful verbs frequently showed metaphorical actions that represented reification of diversity, including "embrace, acknowledge, hold, be, walk, reflect, change, conform, represent, strengthen, consider, integrate, stand, know, include, hold, understand, make, get, come, 
stand, reduce," which reflected the collective responsibility of making diversity a social good, as shown in Table 76.

\section{Table 76}

Diversity

Meaningful Verbs Participant Responses for Diversity

Embrace, $\quad$ Embrace your ethnicity/culture/race/gender etc.

acknowledge, hold, be, walk, reflect, change, conform, represent, strengthen, consider, integrate, stand, know, include, hold, understand, make, get, come, stand, reduce

Acknowledge their diversity and hold onto it and be proud of it

Be proud of their culture

Walking a fine line between identities is okay

Be proud of who they are

While your cohort may not reflect your culture, ethnicity, skin color, there is a large population of minority SLPs

Do not change who you are to conform to your peers

Proudly represent your background/culture

Be proud of where you came from

Your background strengthens your experience and makes you more marketable. Consider and integrate it into your clinical lens.

Don't be afraid to stand out

Despite others not being inclusive you should be because you know what it feels like to not be included

Be willing to respectfully share your perspective

Be confident in the beliefs and values that you hold

Understand that each person's experience is unique and important to them

Your particular minority status does not make you better or more entitled than anyone else

If I were talking to another queer student, I might recommend just getting it over with and coming out on Day 1. It'1l help people know where you stand and reduce feelings of discomfort at being lumped in with the others. 
Mission. The pattern code of mission was chosen as a summary term to represent minority graduate students being engaged in a greater purpose, such as "Time for you to pave the way for someone else just like us." Participant responses showed empowerment of a larger community, including "Knowing you helped make a change," and "You will add to this profession what it most desperately needs." Additionally, one participant commented on the value of research into the experiences of minority students as a form of mission, "I don't know what I can do to change the experiences for those who come after me; other than participating in studies like this one.” Participants positioned themselves and prospective minority graduate students as engaged in the same mission of diversification of the field through collective agency, with group responsibility to give social goods to others through their own actions. Meaningful verbs frequently showed actions of creating and showing, including "pave, know, help, make, change, participate, need, use, shine, seek, want, reflect, add, be, make," which reflected the collective responsibility of taking action, as shown in Table 77.

Education. The pattern code of education was chosen as a summary code to represent efforts involved in learning and acquiring knowledge. Participant responses described the future importance of academic pursuits, including "Learn and understand the best way to help our future clients and community," and "Show up, participate, learn, execute in clinic, and grow your clinical skills." Participants positioned future minority graduate students as having personal agency for self-improvement with the intention of becoming experts who provide social goods in the form of clinical expertise to others. Education itself was considered as a means of acquiring the social goods of knowledge 
and skills, which could then be granted to future clients. Meaningful verbs frequently showed actions of metacognitive processes, including "learn, understand, apply, travel, experience, connect, manage, study, be, show, participate, execute, grow, need, feel," which reflected individual agency in cognitive changes within the learning process, as shown in Table 78.

\section{Table 77}

Mission

Meaningful Verbs Participant Responses for Mission

Pave, know, help, Time for you to pave the way for someone else just like us make, change, participate, need, Knowing you helped make a change use, shine, seek, want, reflect, add, I don't know what I can do to change the experiences for those be

who come after me; other than participating in studies like this one

More minorities are needed in Speech Path and they should use their uniqueness to shine

They should absolutely seek to help kids with a dual lingual home

I desperately want our field to reflect the rest of the population

You will add to this profession what it most desperately needs

Your differences and experiences are necessary

They would be making a huge impact on future clients because few SLPs are minority members

Minority students are valuable in this field 


\section{Table 78}

\section{Education}

\begin{tabular}{|c|c|}
\hline Meaningful Verbs & Participant Responses for Education \\
\hline \multirow{9}{*}{$\begin{array}{l}\text { Learn, understand, } \\
\text { apply, travel, } \\
\text { experience, } \\
\text { connect, manage, } \\
\text { study, be, show, } \\
\text { participate, execute, } \\
\text { grow, need, feel }\end{array}$} & Learn everything you can \\
\hline & $\begin{array}{l}\text { Learn and understand the best way to help our future clients and } \\
\text { community }\end{array}$ \\
\hline & Apply that knowledge in a setting that excites you \\
\hline & Travel abroad and experience other cultures \\
\hline & Connecting with individuals from various backgrounds \\
\hline & Manage your time to study hard regardless of your living circumstances \\
\hline & Everyone can learn something from you and vice versa \\
\hline & Be open to any and all experiences \\
\hline & $\begin{array}{l}\text { Show up, participate, learn, execute in clinic, and grow your clinical } \\
\text { skills }\end{array}$ \\
\hline
\end{tabular}

Relationships. The pattern code of relationships was chosen based on participant use of the word "relationships," in "Concentrate on your cohort relationships," and descriptions of positive interactions. Participants described supportive relationships, such as "There will be kind accepting people that make you feel welcome," "There is always someone else who can support you and understands you," and "Vent as needed to someone who will understand." The focus on relationships reflected collective agency, as future minority graduate students were positioned within a community. Supportive relationships involve the sharing of social goods, such as camaraderie and understanding, 
between people. Meaningful verbs frequently showed actions involving two or more people including "respect, concentrate, be, feel, support, understand, vent, connect, go, experience," which reflected connectedness with others within collective agency, as shown in Table 79.

\section{Table 79}

Relationships

Meaningful Verbs Participant Responses for Relationships

$\begin{array}{ll}\begin{array}{l}\text { Respect, } \\ \text { concentrate, be, } \\ \text { feel, support, } \\ \text { understand, vent, } \\ \text { connect, go, } \\ \text { experience }\end{array} & \begin{array}{l}\text { Highly respect all of my classmates } \\ \text { Concentrate on your cohort relationships }\end{array} \\ & \begin{array}{l}\text { There will be kind accepting people that make you feel welcome } \\ \text { Vent as needed to someone who will understand }\end{array} \\ & \begin{array}{l}\text { It is reassuring to connect with like-minded individuals } \\ \text { It's easier going through the ups and downs with someone who is also } \\ \text { experiencing them }\end{array}\end{array}$

Self-Worth. The pattern code of self-worth was chosen as a summary code to represent participant responses that served as positive affirmations of intrinsic traits, and recognition of accomplishments. Participant responses included character attributes, such as "You are smart and capable," and "Know that you are enough and that you deserve to be there," and statements about prior hard work and equality, such as "You have earned your spot there," and "You deserve to be where you are and you are just as awesome, intelligent, and amazing as everyone else." These types of self-worth statements served as 
a form of proxy agency with participants granting social goods in the form of affirmation and belonging to peers. Current minority graduate students positioned themselves as having social goods to others, who may be in need. It should be noted that the need for self-worth affirmations implies an environment in which one's own beliefs about their self-worth are challenged or questioned. Meaningful verbs frequently showed metacognitive process about accomplishment including "know, deserve, be, earn, remember, succeed," which reflected current minority graduate students having proxy agency to give social goods to others, as shown in Table 80.

\section{Table 80}

Self-Worth

\section{Meaningful Verbs $\quad$ Participant Responses for Self-Worth}

Know, deserve, be, Knowing that they got into their program because they deserved to earn, remember, academically succeed

You are smart and capable

Your $[s i c]$ good enough

Know that you are enough and that you deserve to be there

You have earned your spot there

You deserve to be where you are and you are just as awesome, intelligent, and amazing as everyone else

Remember why you have fought hard to earn a seat in your graduate program

Know that you have the knowledge and capacity to succeed

You are important 
Self-Awareness. The pattern code of self-awareness was chosen as a summary code to reflect participant responses that described understanding oneself. Participant response noted the need for introspection and self-reflection of one's beliefs and actions, such as "Know your strengths and know where you might fall short," and "Listen to your gut when it tells you where you fit the best and let that feeling guide you throughout your graduate school experience." Participant responses positioned other minority graduate students as having social goods in the form of internal wisdom. Participant responses showed personal agency as taking action to understand oneself. Meaningful verbs frequently featured metacognitive concepts, including "know, believe, isolate, listen, fit, let, remember, be," which showed how thought processes themselves provide power and serve as a social good, as shown in Table 81.

\section{Table 81}

Self-Awareness

Meaningful Verbs Participant Responses for Self-Awareness

Know, believe, Know your strengths and know where you might fall short isolate, listen, fit, let, remember, be I believe you are only isolated if you isolate yourself

Listen to your gut when it tells you where you fit the best and let that feeling guide you throughout your graduate school experience

Remember who you are

Know who you are 
Self-Disqualification and Non-Response for Peer Recommendations. Of the

104 participants, three stated that they were not qualified to provide advice to a peer. One participant self-disqualified due to passing, which means appearing to be a non-minority, as noted in the response "I don't think I'm qualified to do that, I pass as a straight cisgendered person." Another participant questioned minority identity in relationship to privilege and stated, “I don't feel like a minority in the same sense as I am privileged, so I am not sure." The third participant who self-disqualified stated, "I am not a minority student." It may be interesting to consider whether or not this third participant considered the term "minority" to represent only race and ethnicity, as opposed to other markers representing a form of minority status within society. Twelve of the 104 participants did not provide a peer recommendation. Two participants noted lack of ideas, specifically, "I really don't know" and "I'm not sure." Eight participants used N/A to indicate not applicable, and two participants left the response field blank.

\section{Program Recommendations}

All participants were asked to provide programmatic recommendations to speechlanguage pathology graduate programs through the survey question, "What recommendations do you have for graduate training programs in speech-language pathology to increase inclusion for minority students based on your own experiences?" Participant responses to this question were addressed collectively, without separating participants into groups based on identity, in order to provide an overall understanding of 
the needs of minority graduate students within speech-language pathology and ways that programs could promote inclusion for all students. Discourse analysis (Gee, 2014) that focused on meaningful verbs was used to show the positioning of the roles of participants within programmatic recommendations. Language use of meaningful verbs was analyzed through position design in discourse analysis, which show specific positions of individuals in the accessing and granting of social goods and services (Gee, 2014). Writers and speakers position themselves and others as having or not having social goods, or things within society that are valuable or important (Gee, 2014).

All of the participant responses to the writing prompt for programmatic recommendations were coded using meaningful verbs in the same manner as the responses for the peer recommendations. As previously stated, meaningful verbs in phrase and sentences were highlighted in initial coding, and then sorted into categories with pattern coding. Positioning (Gee, 2014) showed relationships to social goods and how the students viewed power within their graduate programs. There were seven themes for programmatic recommendations: recruitment, curriculum and clinical, awareness, connection, faculty education, resources, and tokenism. A description of the themes for programmatic recommendations, their meaningful verbs, and the positioning of the participants are described in the following section. 


\section{Recruitment}

The pattern code of recruitment was chosen based on the participants' use of the term "recruit" and examples of potential recruitment strategies. Recruitment recommendations encompassed both students and faculty, such as "Advertise/recruit at different types of undergraduate institutions" and "Hire more diverse faculty." Responses included strategies and areas for growth such as "Our profession is not advocated for in high school as a viable option and especially with our bilingual communities," and "More males need to be informed about the nature of the work that SLPs perform." Recruitment positioned faculty and university programs as having the ability, or social goods, to change the composition of the profession to increase diversity. Meaningful verbs frequently showed actions related to promotion and employment, including "advertise, recruit, expose, promote, spread, serve, inform, enroll, share, increase, diversify, reach, hire, broaden, encourage." Recommendations for recruitment provided guidance to departments on the need to increase knowledge of the profession, with knowledge as a form of social goods. Minority graduate students positioned themselves as having social goods by placing themselves as experts with specific recommendations to share.

Positioning was complex, as students positioned themselves as having expertise and positioned faculty in graduate programs as having the power to grant or withhold the role of student or faculty member to a minority individual through admissions and hiring processes, as shown in Table 82 . 
Table 82

Recruitment

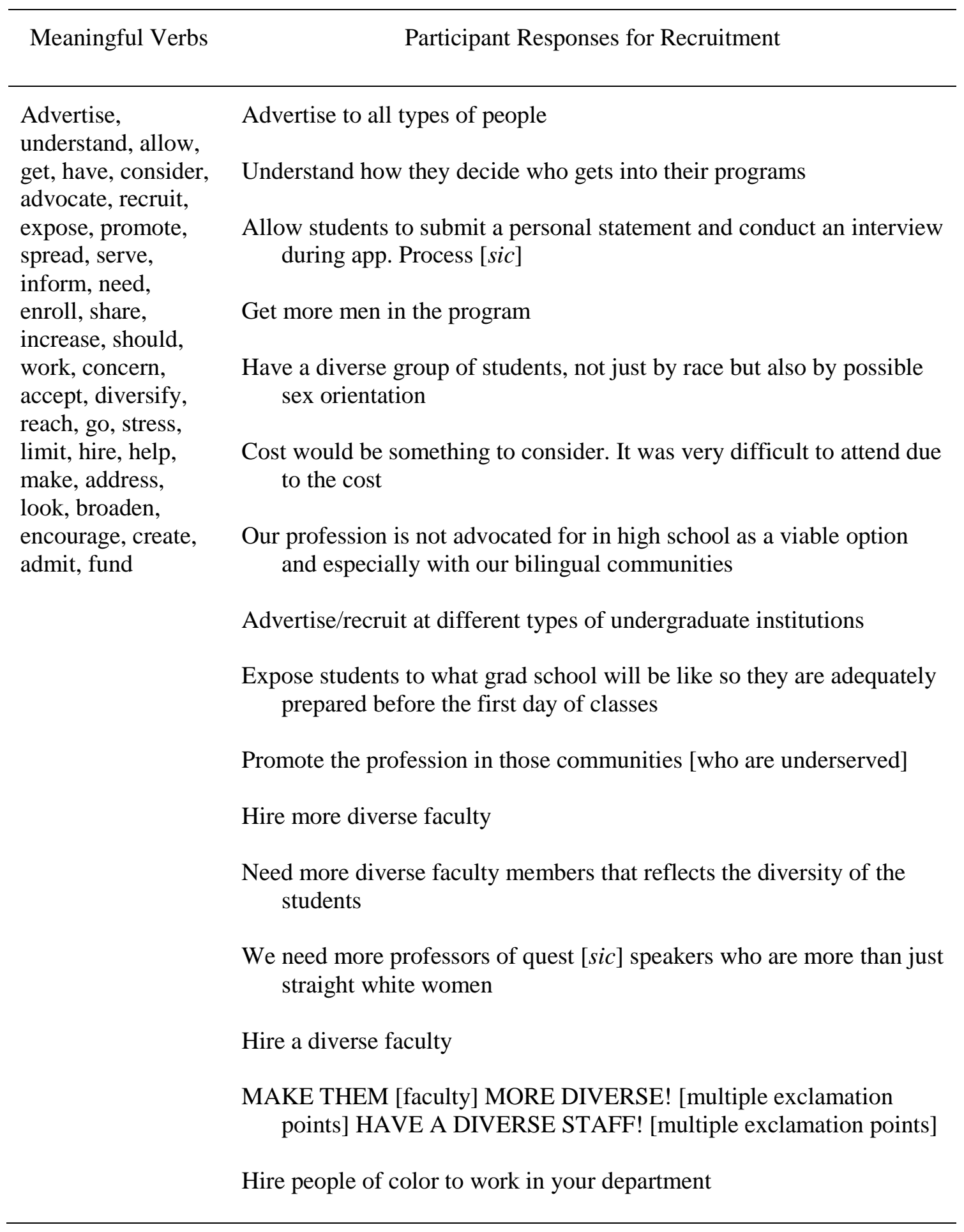




\section{Table 82 (continued)}

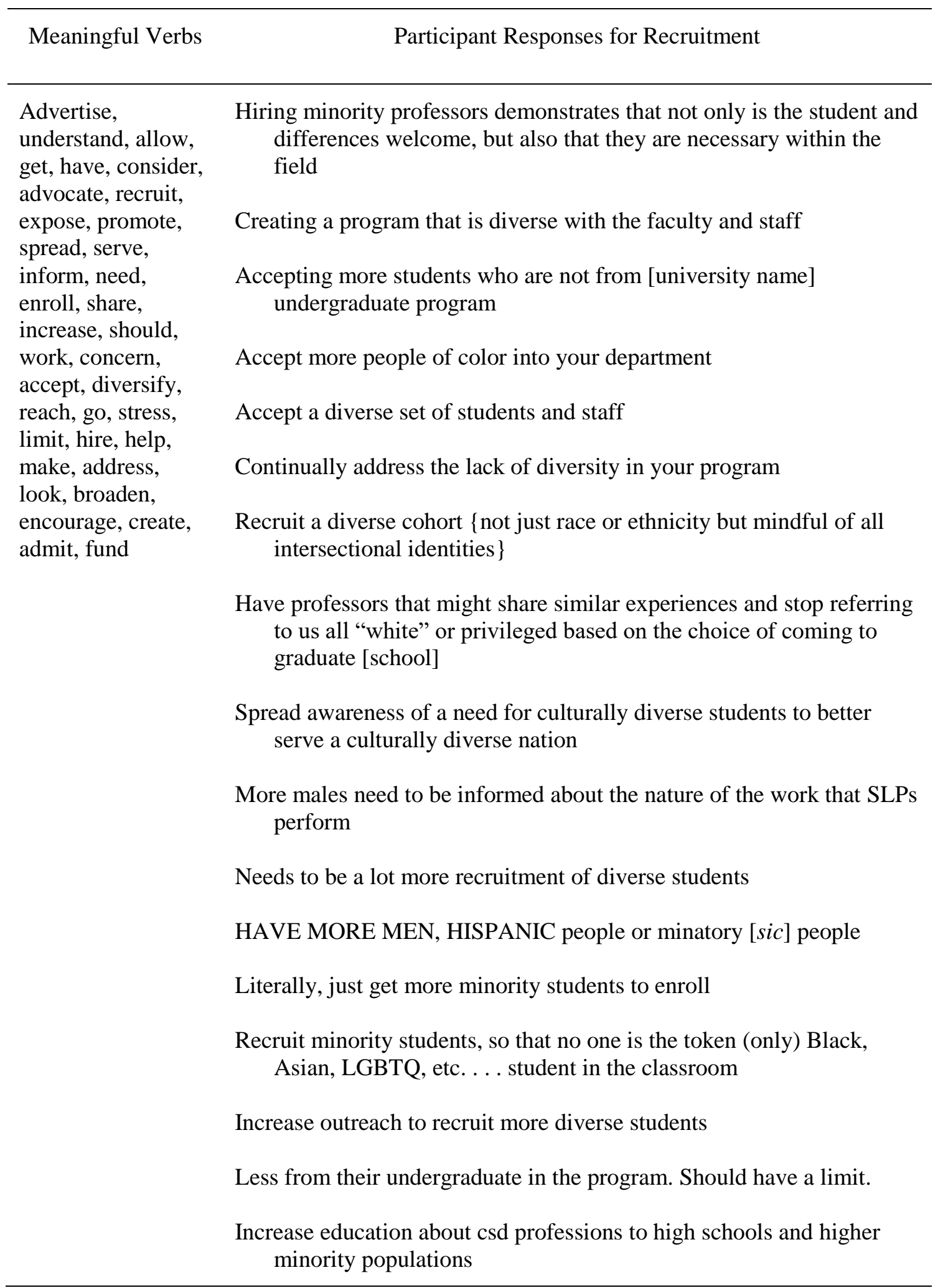




\section{Table 82 (continued)}

\begin{tabular}{l}
\hline Meaningful Verbs \\
\hline Advertise, \\
understand, allow, \\
get, have, consider, \\
advocate, recruit, \\
expose, promote, \\
spread, serve, \\
inform, need, \\
enroll, share, \\
increase, should, \\
work, concern, \\
accept, diversify, \\
reach, go, stress, \\
limit, hire, help, \\
make, address, \\
look, broaden, \\
encourage, create, \\
admit, fund
\end{tabular}

Participant Responses for Recruitment

Work to increase diversity in the cohort

The limited availability of seats for graduate programs is a separate issue I'm more concerned about

Accept more minority students

By diversifying the field we allow our clients to see themselves reflected in us

Reaching out to low-income minority communities

Advertising and promoting and going to job fairs in places that are not mostly populated by middle to upper class white people

Accept more minority students

They stress the need for bilingual SLPs yet limit the number of minority students accepted, who can speak other languages

Education about our field as early as middle school or high school would help

Multicultural therapists are needed to relate to and treat multicultural clients

Accept more students of different races, social classes, sexes, and sexual orientations

Look beyond grades and tests [sic] scores to see the person. To see what they have to offer

Broaden your perspective beyond the "typical" enrollee

Make graduate programs more accessible for minorities

Encourage people of color to become SLPs

Admit and fund more non-traditional, poor, disabled, and culturally and linguistically diverse students

Diversifying the student body in general is bound to bring in more queers

Diversify your program 


\section{Curriculum and Clinical}

The pattern code of curriculum and clinical was chosen as a summary code based on descriptions of potential changes to classroom and clinic content, practice, and policies. Participants positioned faculty as having social goods, through the power of their roles, to make changes. Participants provided specific recommendations, such as "Attempt to make clinic policies and language less hetero-normative," and "Encourage minority student $[$ sic $]$ to share their stories with their peers." Participants positioned themselves as having the power to give recommendations, a form of social goods, and as faculty members as recipients, who could in turn actively make changes in teaching. Meaningful verbs including actions related to teaching, such as "encourage, establish, provide, talk, discuss, give, assign, create, require, and teach." The theme of curriculum and clinical showed how faculty communication and behaviors could be malleable, which could allow for a redistribution of social goods, through practices that recognized diversity, as shown in Table 83.

\section{Table 83}

\section{Curriculum and Clinical}

Meaningful Verbs Participant Responses for Curriculum and Clinical

$\begin{array}{lr}\begin{array}{l}\text { Implement, work, } \\ \text { go, treat, } \\ \text { experience, attempt, } \\ \text { encourage, apply, }\end{array} & \begin{array}{r}\text { More courses on how to work with minority children's [sic], how to go } \\ \text { aware, need, be, }\end{array} \\ \begin{array}{l}\text { establish, provide, } \\ \text { talk, respect, learn, }\end{array} & \begin{array}{r}\text { You have to experience certain things you have never experienced to } \\ \text { make the best impact possible }\end{array} \\ \begin{array}{l}\text { express, discuss, } \\ \text { give, assign, create, } \\ \text { make, require, } \\ \text { intertwine, avoid, } \\ \text { teach }\end{array} & \text { Attempt to make clinic policies and language less hetero-normative } \\ \end{array}$




\section{Table 83 (continued)}

Meaningful Verbs Participant Responses for Curriculum and Clinical

Implement, work, go, treat, experience, attempt, encourage, apply, aware, need, be, establish, provide, talk, respect, learn, express, discuss, give, assign, create, make, require, intertwine, avoid, teach
More aware of cultural differences, which is knowledge they can apply on their own patients/clients and also with other staff

Be inclusive in your language

Training and education around the gender spectrum, identities, and language to use needs to standard across programs

Cultural differences need to be taken into account

We need to be more open minded as a whole towards other cultures and people of different backgrounds or gender identities and sexual orientations

Establishing a baseline of how we are expected to treat each other or the assumptions we make about each other

Provide different perspectives in your courses

Talk about dialect differences and why they matter

Talk about differential diagnosis and how to assess those who are minorities

Discussions about diversity within the cohort and how we can all respect ad learn to understand each other

Openly expressing how each of us views our identity, fears regarding how others might view that identity, discussing behaviors and communication strategies that might facilitate diverse relationships

Give time to students to give the response they want to give to question

Be aware of the groups that you are assigning us to (not all people are welcoming or friendly)

Talk to your students about implicit bias because it exists!

Create a class specifically about different minority groups, which would feature guest speakers who come from those minority groups

Graduate programs need to make sure there are placement opportunities with all populations 


\section{Table 83 (continued)}

\begin{tabular}{|c|c|}
\hline Meaningful Verbs & Participant Responses for Curriculum and Clinical \\
\hline \multirow{12}{*}{$\begin{array}{l}\text { Implement, work, } \\
\text { go, treat, } \\
\text { experience, attempt, } \\
\text { encourage, apply, } \\
\text { aware, need, be, } \\
\text { establish, provide, } \\
\text { talk, respect, learn, } \\
\text { express, discuss, } \\
\text { give, assign, create, } \\
\text { make, require, } \\
\text { intertwine, avoid, } \\
\text { teach }\end{array}$} & $\begin{array}{l}\text { Provide more courses on cultural competency because most of these } \\
\text { students will end up working with a population that includes } \\
\text { minority clients }\end{array}$ \\
\hline & $\begin{array}{l}\text { Give students of different backgrounds the opportunity to work with } \\
\text { one another and learn from each other }\end{array}$ \\
\hline & $\begin{array}{l}\text { Require anti-oppression training for students at the beginning of the } \\
\text { program }\end{array}$ \\
\hline & Provide more training on cultural competence \\
\hline & $\begin{array}{l}\text { Efforts to learn more about the marginalized groups and issues of } \\
\text { equity that all SLPs will likely encounter-not as an "optional } \\
\text { course," but integrated throughout the program }\end{array}$ \\
\hline & Exposure regarding how culture and identity intertwine with language \\
\hline & $\begin{array}{l}\text { Require students to take an ethics course that teaches the proper way to } \\
\text { include and serve diverse populations }\end{array}$ \\
\hline & Provide multi modal access to materials, activities, and supports \\
\hline & Avoid requiring classes or assignments that add cost \\
\hline & Students in our field need more training on the big 8 identities \\
\hline & Create an open environment to discuss differences \\
\hline & $\begin{array}{l}\text { Teach about the positives that come along with neurodiversity, not just } \\
\text { the negatives }\end{array}$ \\
\hline
\end{tabular}

\section{Awareness}

The pattern code of awareness was chosen based on participants' use of the term "aware" and descriptions of the importance of social consciousness, or the recognition of social issues for minorities. Participant responses noted specific examples related to 
realizations, such as "Be aware of what areas they are not being as inclusive as they could be in and seek training to improve," "Recognize your microaggressions and realize that I've been going through this my whole life," and "Be aware \& supportive of students who may have minority status that is not visible." Additionally, responses included the antonym to awareness in the form of ignorance, e.g., "Do not be ignorant to the REAL issues that affect minorities daily." Participants positioned faculty members needing to reflect on their social and political power to consider their own roles in interactions. This positioning placed social goods, in the form of expertise, as flawed and fluid. In other words, the assertion of faculty as experts and rightful holders of social goods based on status could be considered questionable due to a lack of knowledge, which could then imply an inappropriate use of power. In other words, students highlighted how faculty members do not automatically understands the needs of minority students, and lack of awareness can negatively affect students' inclusion. Meaningful verbs frequently showed reflective actions, including "acknowledge, respect, exhibit, assume, pay attention, treat, affirm, recognize, realize, increase, understand," which highlighted the responsibility of holding social goods in relation to others, as shown in Table 84. 


\section{Table 84}

Awareness

Meaningful Verbs Participant Responses for Awareness

Bring,
acknowledge,
respect, exhibit,
be, seek, assume,
steer, pay
attention, call,
should, use,
celebrate, speak,
treat, affirm,
recognize, realize,
increase,
understand

Every student brings something unique to our field

Acknowledging and respecting that international or minority students can have a different take on a situation

Staff that exhibits cultural/linguistic diversity

Be aware of what areas they are not being as inclusive as they could be in and seek training to improve

Don't assume every student is fresh out of high school and an undergraduate program

Don't make generalized comments regarding typical college students

Steer away from the "women" help and "men" are the ones in need of "help"

Pay attention to your students of color, because our experiences are often much different than others around us

Call out Micro-Aggressions when you hear them

We should use language that doesn't exclude or make it sound like men aren't supposed to be SLP's

Celebrate holidays, included [sic] different cultures, speak different languages

Treat your students like you want them to treat you if they were your speech-language pathologists

Have more of an open mind

Affirm their [students'] experience and acknowledge that their experiences hold value in the field

Recognize your microaggressions and realize that I've been going through this my whole life

Do not be ignorant to the REAL issues that affect minorities daily 


\section{Table 84 (continued)}

\begin{tabular}{|c|c|}
\hline Meaningful Verbs & Participant Responses for Awareness \\
\hline $\begin{array}{l}\text { Bring, } \\
\text { acknowledge, } \\
\text { respect, exhibit, } \\
\text { be, seek, assume, } \\
\text { steer, pay } \\
\text { attention, call, } \\
\text { should, use, } \\
\text { celebrate, speak, } \\
\text { treat, affirm, } \\
\text { recognize, realize, } \\
\text { increase, } \\
\text { understand }\end{array}$ & $\begin{array}{l}\text { Actively respecting and celebrating differences promotes a safe and } \\
\text { welcoming environment } \\
\text { Be aware \& supportive of students who may have minority status that is } \\
\text { not visible } \\
\text { Increase awareness about learning disabilities/differences/disorders } \\
\text { Help people understand that people with learning disabilities are not } \\
\text { stupid }\end{array}$ \\
\hline
\end{tabular}

\section{Connection}

The pattern code of connection was chosen based on participant use of the term "connect" and descriptions of opportunities to create community. Participant responses noted ways in which faculty members could bring students together, such as "Colleges that were close to each other helped connect the men so that they could have the option to go to conferences together," and "Orientations, retreats, any opportunity for people to come together and learn about one another." Participants positioned faculty members having the social and political power to connect individuals, which placed students dependent on the efforts of faculty to grant opportunities for social interactions. Meaningful verbs related to expending of effort, including "try, create, provide, connect, put, assign, allow, spend, interact," which represented the role of someone who grants social goods, as shown in Table 85. 
Table 85

Connection for All Groups

Meaningful Verbs Participant Responses for Connection

Try, create, be, come, learn, provide, connect, put, have, be, focus, hire, do, assign, allow, spend, interact, offer, access, encourage
Try to get to know people at an individual level

Create more opportunities for socializing outside of the classroom, such as study groups or group projects

Be more intentional about creating a community

Orientations, retreats, any opportunity for people to come together and learn about one another

Providing more public space for student get-togethers would be nice

Colleges that were close to each other helped connect the men so that they could have the option to go to conferences together

Put us in a Facebook page with our classmates and have a retreat so we get to know each other

Be a support

Focus on icebreaker activities so we can get to know each other on deeper levels

Have someone hired as an activity counselor to create "get together" programs

Do more phone calls to check in

Assign a mentor

Allow students to spend more time together socially before more serious work begins

Opportunity to interact with most if not all students in the program

Offer groups where people of similar backgrounds/identities can create an online community where they are comfortable sharing whatever they want to with each other

Mentorship programs would be helpful

Access to role models within the program

Encourage your faculty to find ways to be supportive 


\section{Faculty Education}

The pattern code of faculty education was chosen based on participant use of the term "education" and descriptions of the types of training needed. Participant responses noted specific minority identities, such as "Think critically when you talk about disability, for once!" and "Open to further education about different identities and perspectives," and the value of student voices, e.g., "Solicit feedback from students on a regular basis and students should be able to provide this feedback anonymously without any fear of retaliation." Participants positioned faculty members as needing to relinquish social and political power to assume the roles of learners, which placed social goods, in the form of expertise with students. Meaningful verbs frequently showed actions of learners, including "learn, solicit, work, ask, think, understand," which highlighted the receiving of social goods, as shown in Table 86.

\section{Resources}

The pattern code of resources was chosen based on participant use of the term "resources" and included descriptions of different types of resources that students need. Participant responses noted university level and national services, such as "Make students aware of the minority alliance services offered by the university" and "Students be directly provided information about counseling resources and financial assistance." Participants positioned faculty members as having the social and political power to offer or withhold information that served as a social good, which was essential for students. Meaningful verbs showed actions of giving, including "provide, offer, solve, create, make," which highlighted the granting of a social good, as shown in Table 87. 
Table 86

Faculty Education

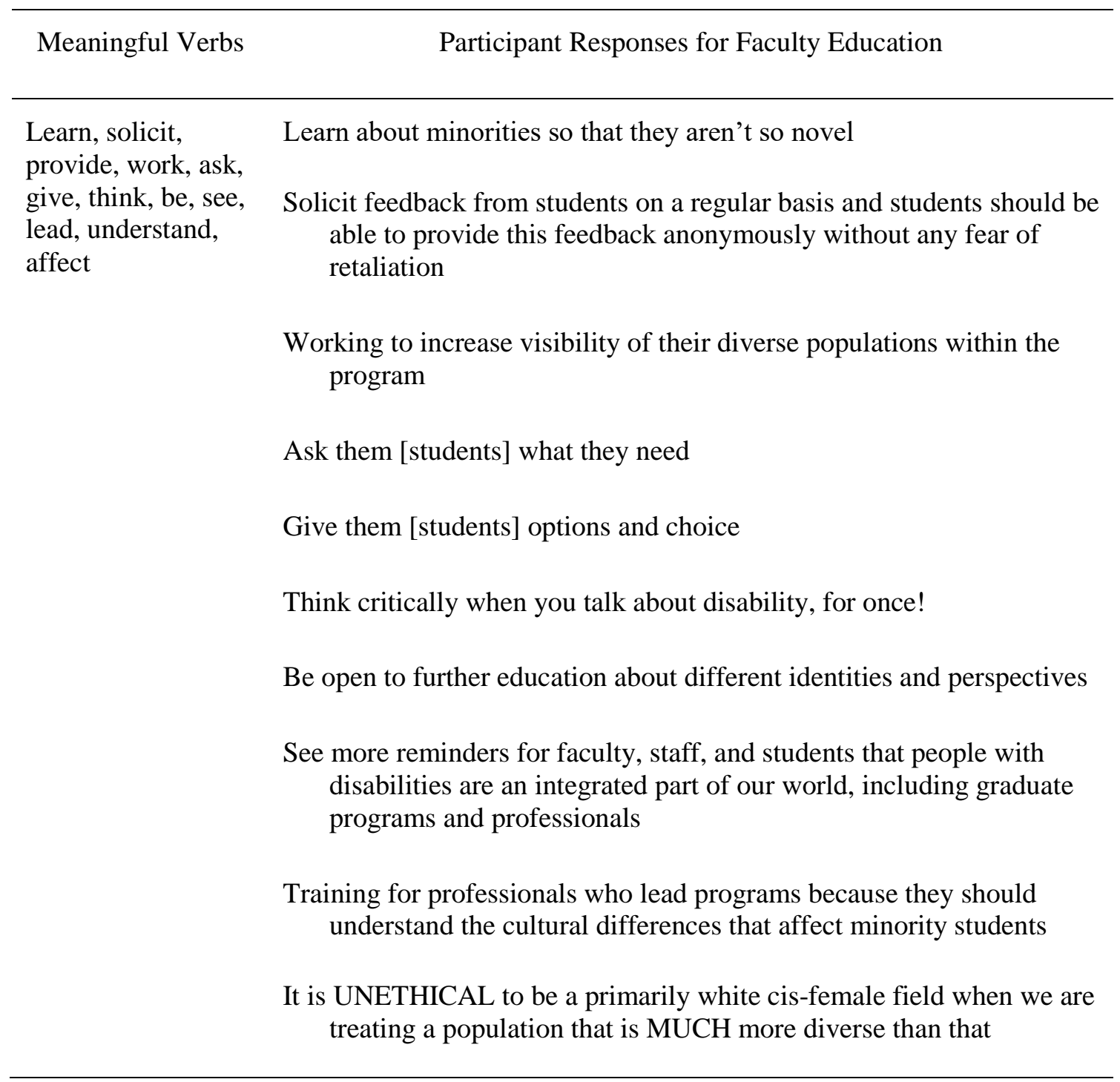


Table 87

Resources

Meaningful Verbs $\quad$ Participant Responses for Resources

Provide, offer, Students be directly provided information about counseling resources solve, create, make, and financial assistance are, access, offer, coordinate, reward Offer scholarships and local opportunities

More aid would solve a lot of those [access] problems

Create scholarships for minority students pursuing speech-language pathology

Make students aware of the minority alliance services offered by the university

Scholarships are the biggest help

Making it easy for students to access resources that serve their identities

Vast support system that offers a healthy space for them [students] to collaborate

Coordinate with other professors to reduce textbook costs for students

Rewarding students with a percentage of dues paid for national professional affiliations

Offer scholarships, aid, GA positions to those who need it

\section{Equality}

The pattern code of equality was chosen based on participant use of the term "equally" and included concepts of fairness and sameness. Participants positioned faculty as having the social and political power to grant differing levels of social goods to students. In other words, faculty members had the ability to give or remove privileges as 
they chose, as opposed to offering the same level of social goods to all students. Participant recommendations included representation and treatment, such as "Equally represent all and not place focus on those that are common" and "Treat everyone the same and offer the same opportunities to every student." Meaningful verbs showed actions toward others and verbs related to believing, including "treat, give, represent, place, and view," as shown in Table 88.

\section{Table 88}

Equality for Program Recommendations

Meaningful Verbs Participant Responses for Equality

Treat, give, $\quad$ Treat everyone fairly represent, place, view

Give people the same opportunities

Equally represent all and not place focus on those that are common

Viewing them [minority students] as worthy as anyone else

Treat everyone the same and offer the same opportunities to every student

\section{Tokenism}

Tokenism was chosen as a summation pattern code based on descriptions of minority students being singled out or required to be a spokesperson. Participants positioned faculty as having power within classroom situations to make a student feel like a token, or only included to meet a diversity requirement or initiative. Participants provided recommendations such as, "Do not single out students for any reason," and "Do not have a student of a different ethnicity speak for their whole ethnicity in class." 
Participants positioned themselves as having the power to give recommendations, a form of social goods, and as faculty members as recipients. Meaningful verbs focused on the act of communication, such as "speak, call, and address." The theme of tokenism showed how faculty communicative acts had the power to position students as tokens, as shown in Table 89.

\section{Table 89}

Tokenism for Program Recommendations

\begin{tabular}{ll}
\hline \multicolumn{1}{c}{ Meaningful Verbs } & \multicolumn{1}{c}{ Participant Responses for Tokenism } \\
\hline $\begin{array}{l}\text { Speak, call, single, } \\
\text { address }\end{array}$ & $\begin{array}{c}\text { Do not have a student of a different ethnicity speak for their whole } \\
\text { ethnicity in class }\end{array}$ \\
& Don't call the difference out \\
& Do not single out students for any reason \\
& $\begin{array}{l}\text { While you may need to address a disability that may affect professional } \\
\text { performance, do so in a manner that lets the potential student know } \\
\text { that you will be supportive of him or her }\end{array}$ \\
\hline
\end{tabular}

\section{Lack of Problem and Non-Response for Programmatic Recommendations}

Of the 104 participants, three participants stated that there were no problems, specifically, "I don't see this as a problem. One of my friends in the program is gay, it doesn't interfere in any aspect of our educational training," and "I have never experienced minority students being excluded," and "I have not [sic] recommendation at this time." Six of the 104 participants did not provide a programmatic recommendation. One participant noted a lack of ideas, specifically, "I'm not sure." Three participants used 
N/A to indicate not applicable, and two participants left the response field blank. It should be noted that one participant appeared to express concern about attention to minority students, as expressed by the following, "Many modern day minorities demand equal right considerations while at the same time opposing and diminishing the rights of others (i.e., conservative or elder populations)."

\section{Inclusive Recruitment Flyer}

Participants were asked if they would like to complete an inclusive recruitment flyer to promote diversity within the field of speech-language pathology using the following question:

"Would you like to continue in the study and complete a one-page inclusive recruitment flyer with words and images to encourage minority students to pursue the field of speechlanguage pathology? Creating a flyer may take approximately 30 minutes, and will entail individually creating an inclusive recruitment flyer to encourage minority students to pursue the field of speech-language pathology." Although a total of 18 participants, or $17 \%$ indicated that they would like to complete an inclusive recruitment flyer, only two participants, or $2 \%$ completed and submitted a flyer. The two flyers are featured in Figures 4 and 5. 


\section{Figure 4}

\section{Inclusive Flyer 1}

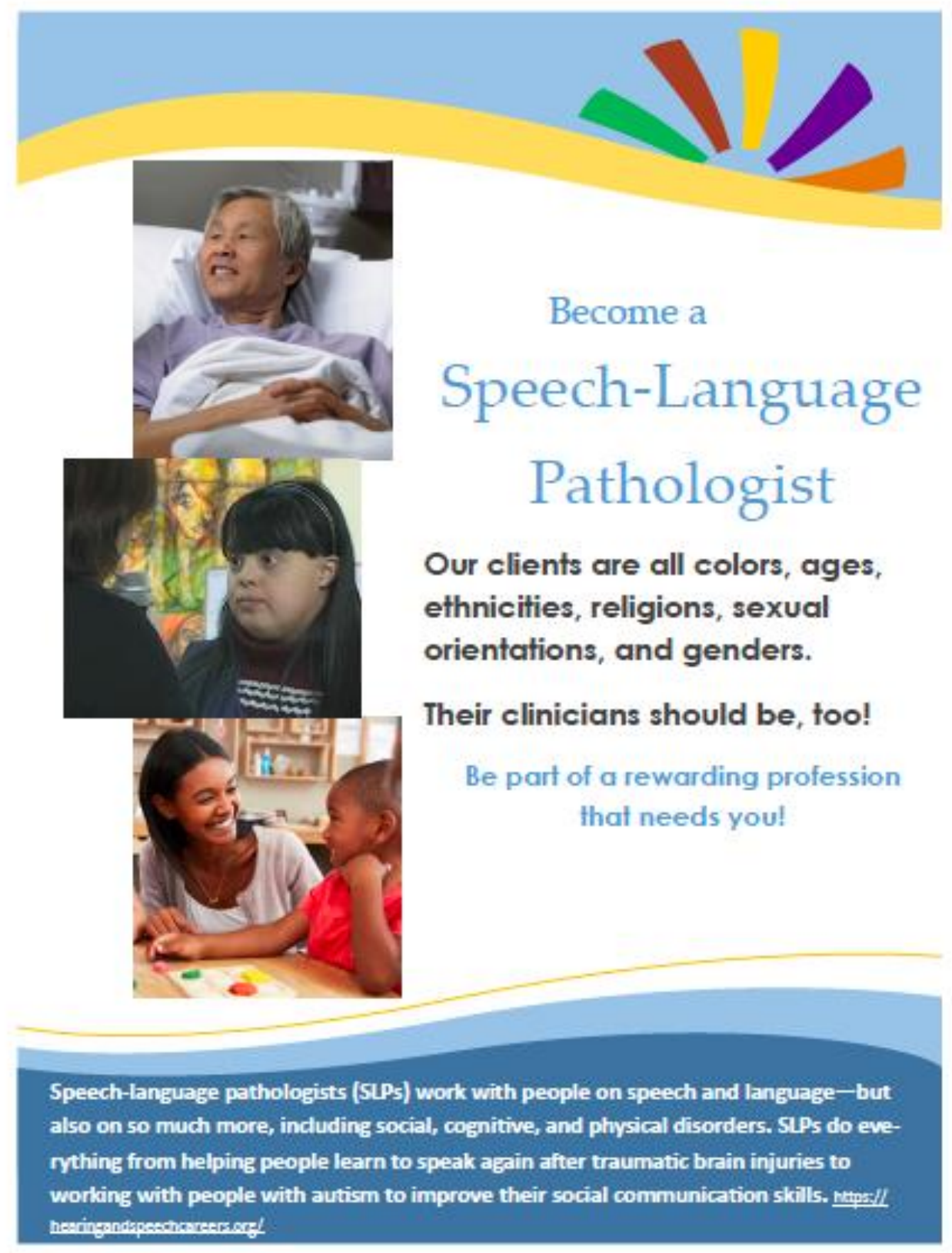




\section{Figure 5}

\section{Inclusive Flyer 2}

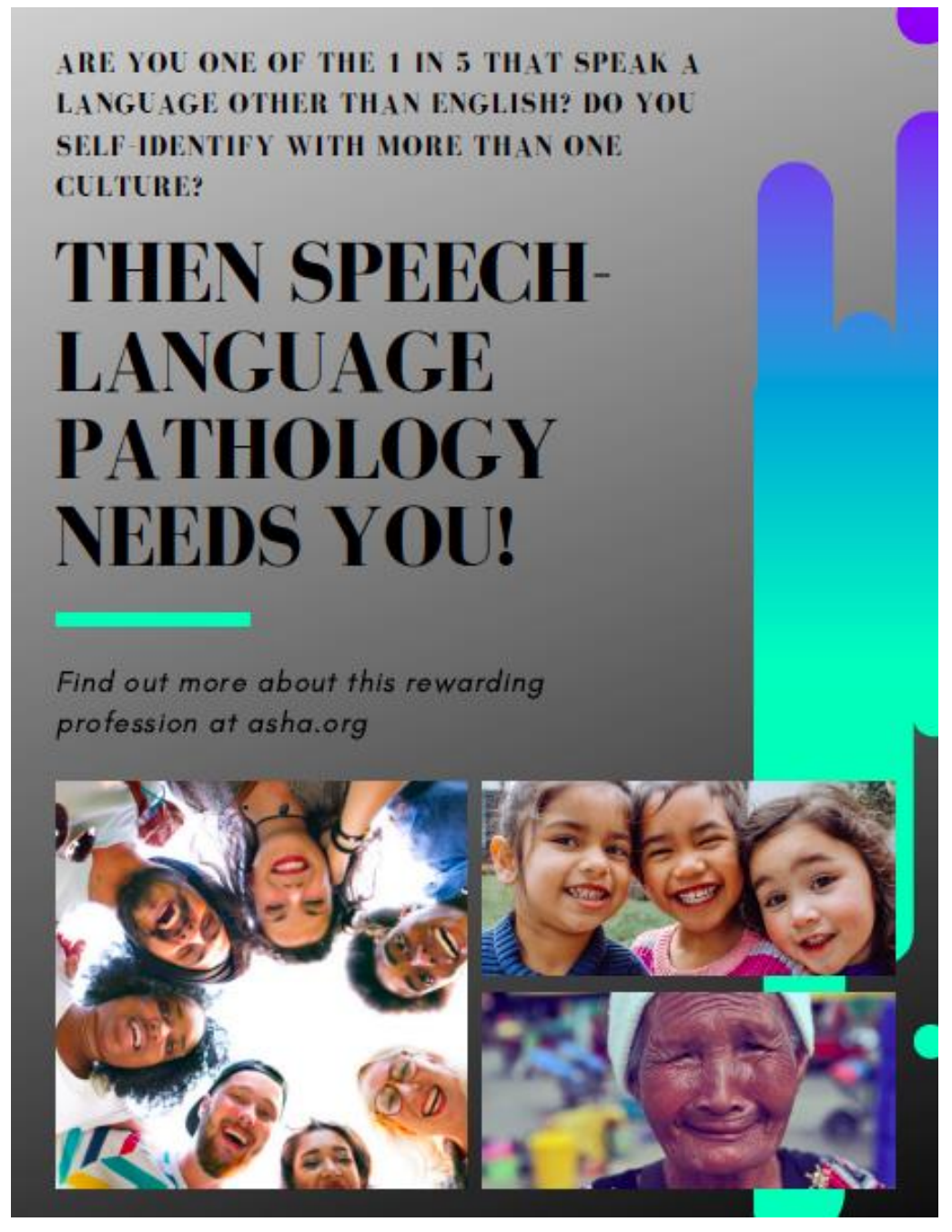

In examining the two inclusive recruitment flyers, I followed Saldaña's (2016) guidance to describe the flyers and my responses to them, and used Gee's (2014) elements of discourse building to analyze the flyers. Saldaña described how analysis for visual data uses "a holistic, interpretive lens guided by intuitive inquiry and strategic questions" (p. 57) to create notes that contain descriptive language of visual elements related to content and imagery, which can be connected to tone and meaning. 
Additionally, Saldaña noted that discourse analysis methods are appropriate for visual data.

From a holistic perspective, both flyers featured photographs of multiple racial and ethnic minorities, or people of Color, who were smiling and appeared happy or content. One flyer used multiple colors on a white background and the other flyer used color blending to fade one color into another color on a dark background. The use of multiple people of Color represented diversity of clients and clinicians and the use of multiple color elements appeared similar to a rainbow, which could symbolize the beauty of plurality or multiculturalism. In a general sense, both flyers equated happiness with diversity. Additionally, the second flyer modeled community through images of a group of people of Color standing in a circle and a picture multiple children of Color standing together.

The text for flyer 1 is

Become a Speech-Language Pathologist Our clients are all colors, ages, ethnicities, religions, sexual orientations, and genders. Their clinicians should be, too! Be part of a rewarding profession that needs you! Speech-language pathologists (SLPs) work with people on speech and language — but also on so much more, including social, cognitive, and physical disorders. SLPs do everything from helping people learn to speak again after traumatic brain injuries to working with people with autism to improve their social communication skills. https://hearingandspeechcareers.org/

The text for flyer 2 is as follows, "ARE YOU ONE OF THE 1 IN 5 THAT

SPEAK A LANGUAGE OTHER THAN ENGLISH? DO YOU SELF-IDENTIFY

WITH MORE THAN ONE CULTURE? THEN SPEECH-LANGUAGE PATHOLOGY

NEEDS YOU! Find out more about this rewarding profession at asha.org.” Table 90 
provides descriptions of the flyers in relation to discourse analysis building tasks (Gee, 2014).

\section{Table 90}

Discourse Analysis of Flyers Using Building Tasks

\begin{tabular}{|c|c|}
\hline Building Tasks & Analysis of Flyers \\
\hline Significance & $\begin{array}{l}\text { Both flyers made the career significant through the font size and } \\
\text { prominence in the text. }\end{array}$ \\
\hline Practices & $\begin{array}{l}\text { Both flyers showed the practices of speech-language pathology } \\
\text { through images of old and young clients, and descriptions of } \\
\text { serving individuals from diverse backgrounds. }\end{array}$ \\
\hline Identities & $\begin{array}{l}\text { Identities were implied through the use of images of clinical } \\
\text { contexts, such as a patient, or a child at school, and } \\
\text { descriptions of intervention services. }\end{array}$ \\
\hline Relationships & $\begin{array}{l}\text { Relationships between people were shown with images that } \\
\text { represented clinician and client, and also cohort or community } \\
\text { with a group of smiling people. }\end{array}$ \\
\hline Politics & $\begin{array}{l}\text { Social goods placed diversity as valuable and something that could } \\
\text { benefit others. The use of the verb "need" appeared in both } \\
\text { flyers, which alluded to a collective mission or a moral } \\
\text { imperative. }\end{array}$ \\
\hline Connections & $\begin{array}{l}\text { Both flyers connected diversity with speech-language pathology by } \\
\text { describing the need for clinicians from multicultural } \\
\text { backgrounds. }\end{array}$ \\
\hline Signs and knowledge & $\begin{array}{l}\text { Both flyers were written in English. The first flyer provided } \\
\text { descriptive information about the field of speech-language } \\
\text { pathology, and the second flyer prompted the reader to seek } \\
\text { more information with an internet web link. }\end{array}$ \\
\hline
\end{tabular}

From a discourse analysis standpoint, the flyers tied diversity to the field of speech-language pathology and focused on the clinician and client relationship. It should 
be noted that both flyers used the national speech-language pathology association, ASHA, as the source or authority to learn more about the profession. Given that references to the ASHA website were the only means the participants provided on their flyers to increase an understanding of the profession, a discussion of how the ASHA introductory career information webpages reflect the diversity of potential future clinicians they strive to recruit may be important.

Two additional discourse analysis tools from Gee (2014) were used: (a) Conversations (with a capital C), which are the use of a word or phrase that represents a larger national topic or issue, and (b) Intertextuality, which represents the use of quotes or styles that reference or allude to another text. At the level of Conversations, the use of the words "rewarding profession," which represents a larger understanding of serving a public good through one's work to benefit society, was present. At the intertextuality level, both texts used "need," as in "profession that needs you," and "speech-language pathology needs you.” This phrasing harkens back to the World War I military recruitment poster featuring Uncle Sam as the federal government with the message of wanting or needing recruits. The concept of being needed or vital to achieve a goal speaks to a collective or greater common good.

\section{Participant Interview}

One of the two participants who completed an inclusive recruitment flyer volunteered to be interviewed about the experience of creating a flyer. The participant was interviewed on October 16, 2019. The interview was recorded and I took handwritten 
notes during the telephone interview. The participant was asked about the process of

completing an inclusive recruitment flyer and shared the following:

I looked for a template that seemed friendly and speech therapy oriented and then I tried to find some pictures of people that could look like patients or clients that didn't have white skin that looked like they might be Asian, or Hispanic, or, um, you know, Indian, or something, you know, not so pale, um, and also therapists, which was really hard to find, um, so I think that I have one picture with an African-American woman with an African-American child, um, but most of the pictures of, like, speech pathologists have very light skin, um, and so I found like three pictures I think, and then I just like put what I was thinking in my head that, you know, the field is dominated by Caucasians, a lot, and, I mean, at least where I live the clientele is really diverse, and doesn't necessarily ref-, you know, the, the therapists don't, or even the teachers in schools, whatever, don't reflect the, uh, the kids or the clients.

When asked about considerations or important aspects of the process, the

participant elaborated on her own connections:

Well, like I said, I tried to find pictures of people that did not look pale, like me, um, the like skin tone, and then, um, I wanted the template to look kinda friendly, and, I guess I was just kinda trying to think of a way to entice people. I don't know, um, what, you know, makes people of different backgrounds and ethnicities motivates them to become a speech pathologist, or if they don't, I mean maybe they never heard of it, and so I'm just trying to think of something I can say that would be enticing, you know, like "oh, people need me, like, okay, well maybe that's something that I should think about," or there's, you know, a lot of people out there, kids like I was, that are getting, you know, this kind of service, and the people who work with them don't look like who they are, like maybe I should do something about that.

Themes that emerged from the interview included the recruitment concepts of positivity through friendliness and enticement, lack of representation of people of Color, lack of public awareness of the field, and the racial mismatch between clinicians and the clients who they serve. The participant emphasized the idea of positivity and friendliness in her choice of a "friendly template" and the goal of enticing people to attract them to the field. The theme of lack of representation was apparent in the participant's 
explanation of how difficult it was to locate pictures of clinicians who were not white. The theme of lack of public awareness was explained with the statements that people might not have heard of the field, which likely reflected a larger issue about general societal awareness of the role of SLPs. The theme of racial mismatch was tied to mission with the idea that the clinicians did not look like the clients, and the statement that "maybe I should do something about that," which formed the basis for individual decisions that could contribute to a larger goal of diversity of the field. Mission as collective agency implies how people of Color who work as SLPs increases clients' ability to have clinicians who relate to their own experiences as minorities.

The participant who shared her experiences creating an inclusive recruitment flyer provided information that aligned with themes that emerged in the narrative data gathered from the questions about experiences with inclusion. Although only one participant was interviewed in this study, interviews about the experiences of creating an inclusive recruitment flyer provided rich data, and a potential model for similar future studies.

\section{Audit Memos}

As described in Chapter 3, audit memos were completed throughout the data collection and analysis process to capture reflections on the meanings of data and the categorization schemes used (Maxwell, 2013). Audit memos provided a record of my thoughts and decision-making processes as a researcher. Reflective questions were used to examine interesting, relevant, and important aspects of the process, as recommended by Merriam and Tisdell (2016). Specific prompts from Saldaña (2016) served as the basis for reflection, along with Saldaña's recommendation that audit memos be written in the 
style of a letter to a friend. Upon reviewing the audit memos, two important concepts emerged based on attention to use of "heart" and "welcome."

\section{Heart}

The term "heart" came to my attention when reading about the experiences of LGBTQ+ students in the participant response, "As a queer individual, it hurt my heart to know that my own classmate, so close to actually serving real people, was looking for an excuse not to serve someone like me." I was struck by the emotional tenor of the use of "hurt my heart," which prompted me to attend to other uses of heart, such as "I was disheartened by the lack of racial diversity in both the students and staff of my program." The use of heart served as the basis to search out other emotional words, both negative and positive.

Within my audit memos, I posed questions to myself based on connecting the emotional responses of participants to their experiences of inclusion and the ramification of these feelings. Given that there have been historical shortages in the number of master's level clinicians who seek a doctoral degree in speech-language pathology (ASHA, 2020), I was struck by how feelings of inclusion within master's level graduate programs could be related to the $\mathrm{PhD}$ shortage. One participant clearly delineated this connection with the following description, "I have been afraid to use my proper pronouns at work because I feel that it could seriously impact my ability to pursue a $\mathrm{PhD}$ at this program." Even when these connections were not as clearly specified, it was possible to extrapolate how painful emotions related to one's academic program could affect a person's educational trajectory. A question that I posed to myself within my audit memos 
related to the concept of heart was "How am I supposed to tell people who aren't interested in diversity that they are hurting people's hearts and deterring them from $\mathrm{PhD}$ programs?" This question related to both the emotional effects of faculty, staff, and peer actions, and the direction of the field as a whole through who does or does not pursue a doctoral degree and conduct research. The imagery within the use of the word "heart" started linkages between the emotional aspects of experiences of inclusion. Emotional pain was represented through the ideas of "heart" and the feelings of "angry, sad, upsetting, afraid, annoying, discomforting, desperate," as shown in Table 91.

\section{Table 91}

Heart and Painful Emotions

Participant Responses That Included Heart and Painful Emotional Terms

One of my classmates told me that they would feel uncomfortable sharing a room with me, which I completely understand, but it still made me feel disheartened.

I was disheartened by the lack of racial diversity in both the students and staff of my program.

As a queer individual, it hurt my heart to know that my own classmate, so close to actually serving real people, was looking for an excuse not to serve someone like me. It let me know that I could not come out to them.

Also, I am almost never included in activities our side of the classroom like study groups, "Friendsgiving" (a Thanksgiving celebration), and other social events. These experiences make me angry and sad. I am angry because I have worked so hard to get to this point, and I still feel like others look at me as if I am not worthy to be in this program. It makes me sad because I know that no matter how hard I work, there will always be people who treat me this way.

Our field is mainly white women. It is sad. 


\section{Table 91 (continued)}

\section{Participant Responses That Included Heart and Painful Emotional Terms}

It makes me angry. It truly makes me angry because I am also Chinese, and it's unbelievable someone with so much power in an institute that preaches diversity in [city location and description] still acts with her white privilege and uses her power inappropriately.

Further, it was upsetting to see the lack of diversity in our clinic.

It's upsetting, honestly. Not being represented is upsetting. It made me think of my father, a man from Central America who faced a lot of discrimination, and I wonder - would my classmates discriminate against him too?

I sometimes get called out about my accent but i always feel included. It upsets me.

Its $[s i c]$ upsetting because they point out my flaws but you only grow from it

I feel pressure to hide my identity because I am afraid of people judging me based on appearances or viewing me differently because of my diverse cultural background.

I guess I feel as though I should play a more passive role within my class. It's an interesting feeling, and one that is hard to explain. I am afraid of upsetting or offending anyone.

At first I was afraid I did not fit in

It was really annoying to be continually left out because the majority of students were women.

I sometimes get annoyed, not always, but sometimes when people only give credit for me being Asian. I am of mixed descent, Japanese and American/European/White.

Being a part of a minority ethnicity and religion, it was annoying to see people make these assumptions. [culturally insensitive therapy materials]

It is so annoying that majority of the white women in my cohort do not acknowledge me or my friend group.

I can literally feel their stares and it's annoying that they wanna talk smack and they don't even know me.

There were cliques formed already of their previous undergraduate students and as an out of state student it was very discomforting.

You will graduate and you will add to this profession what it most desperately needs. 
In addition to examining painful emotions, participant use of positive emotional terms was explored. Positive emotional words included "kind" and "happy," as shown in Table 92. It should be noted that participants did not appear to use the same level of metaphorical terminology and variety of word choices about emotion when describing positive feelings, as when describing negative emotions. The negative repercussions of inclusion may evoke more intense sensations than feelings of being included. Further research that focuses specifically on the emotional components of inclusion may provide additional insight into how inclusion affects graduate students' emotional wellbeing, as shown in Table 92.

\section{Table 92}

\section{Heart and Positive Emotions}

Participant Responses That Included Heart and Positive Emotional Terms

People are kind at heart. They may say or do something that offends you. Instead of shutting down or throwing up your defenses, try to explain kindly why what they said or did was inappropriate and a better way of expressing themselves.

It showed me how happy I can feel when I don't feel like people are looking at me or judging me for who I I sic] am, because I am more than my appearance and the choices that I make.

Finding things in the community that I can engage with. being personally happy made a difference in my ability to feel included within my program

It made me happy to see so many intelligent women gathered in one place.

I am an Egyptian and Muslim so there typically a lot of faculty or students that relate. But I am still happy to see other minorities teaching

I am very happy with my program. For example, the professors and staff feature many POC with diverse ethnic and linguistic backgrounds. A 1/3 ratio of POC to whites is higher than many of the schools that I decided against.

I was happy to see the level of diversity among my colleagues. 


\section{Welcome}

The term "welcome" appeared as prominent for the minority group of male gender, and also as a potential larger theme throughout all groups. For a male participant, the concept of not welcome appeared to reflect being excluded, as in "It was really annoying to be continually left out because the majority of students were women. As it happens repeatedly, it makes me feel like I am not welcome in the profession because I'm a guy." This idea of welcome as based on the actions of others prompted me to seek out responses that featured "welcome." For a racial minority student, the concept of welcome related to faculty, as in "My instructors for my multicultural and school-aged literacy courses are women of color. They provided a safe space that made me feel very welcomed and included in the program."

Within my audit memos, I posed questions about the idea of welcome around the commonly associated meanings of host and guest. Questions included roles of hosts, such as "Who are the hosts of graduate school? Is it faculty, staff, or peers? Do they know that they are the hosts?" Questions also focused on the metaphor of house, as in "Is there a house of academia? Who allows people into this house and how do they do it? Do some people automatically believe that it is their house?" and "What happens when no one takes responsibility for hosting? How do the guests feel? Does the abdication of the role of host result in exclusion?" Given that staff and faculty tend to remain relatively constant within a program, while graduate student cohort change at regular intervals, it is likely to consider them to be the hosts, however, students themselves create their own culture. The concept of welcome may be related to the design of academia, as well as the 
field of speech-language pathology, and specific graduate programs. Participant responses that featured the term "welcome" are shown in Table 93.

\section{Table 93}

\section{Welcome}

\section{Participant Responses That Included Welcome}

It's one think [sic] to make a student work hard (because this is graduate school), but it is different to make someone, who is working against the world, work harder due to personal beliefs. Inclusion included welcoming, fair treatment, fair display of academic integrity, awarding all for academic achievements.

A welcome back event with new and returning graduate students

As for the overall inclusion, the welcomed and encouraged questions and thoughts are fantastic!

Her tone and choice of vocabulary (e.g., "your partner" or "anyone moving here with you" vs assuming heteronormative husband/wife) made me feel that more than "tolerant" she was welcoming and supportive.

The professors are very welcoming and accepting of diverse personalities and backgrounds and genuinely seek to understand in order to learn.

They [the students] are who I am so I was glad to feel welcomed and accepted.

Being in my cohort with a diverse group of people. I feel really welcomed, included, and not the minority.

I was generally welcomed in all regards

It was really annoying to be continually left out because the majority of students were women. As it happens repeatedly, it makes me feel like I am not welcome in the profession because I'm a guy.

I felt welcomed and included. I felt like a part of the group. [invited to be in photo]

I have felt very welcomed. I feel like a known part of the cohort, and I feel that my voice is recognized and valued.

I enjoy that I have others that want me there, but I also realize that if I am not always welcome, that it's okay. 
Table 93 (continued)

Participant Responses That Included Welcome

Not all people are welcoming or friendly

Faculty was welcoming and willing to help. The offer still stands but over the quarters that has warped into fake pleasantries.

Moment when I felt less welcome, and my discomfort level was a 2 on a scale of 1-10. So, it wasn't a big deal. [professor joke about males]

Even if there is no one else like you, there will be kind accepting people that will make you feel welcome.

Our professors are welcoming and encourage student participation.

Everyone in my program has been kind, welcoming, and supportive.

All students worked in the clinic for the first year this created a collaborative and welcoming environment

I felt welcomed

I was able to have meaningful conversations with the other women of color and one male in my cohort and they made me feel welcome.

I feel welcomed and accepted.

I felt very welcomed and included by the faculty and staff on campus.

My instructors for my multicultural and school-aged literacy courses are women of color. They provided a safe space that made me feel very welcomed and included in the program.

[city name and description], and so the university opens itself to this environment, welcoming minorities as assets who have a lot to offer.

I think hiring minority professors demonstrates that not only is the student and their differences are welcome, but also that they are necessary within the field.

Most of the time I do feel include and a part of the cohort and welcome/wanted to participate in activities.

[University name] held a brunch welcome event for incoming graduate students and it was awful. 
Table 93 (continued)

Participant Responses That Included Welcome

All of the students who were apart [sic] of this support group were African American females. We were not welcomed to our peers support/ resource personally group chat.

An unwelcome stream of updates on new boyfriends ... I could go on. It all leads back to the base assumption that everyone is going to do the same thing in the same order: get a grad degree, get married, work for a little while, have babies, and then do part-time or contingent work while relying on a husband's higher income and health insurance coverage.

\section{Limitations and Constraints of the Study}

This qualitative study was designed to study the experiences, perceptions, beliefs, and recommendation of current minority graduate students training to become SLPs. I collected data through a series of narrative writing prompts, an inclusive recruitment flyer, as a form of visual media, and through a participant interview about creating the flyer. Multiple forms of data were chosen, including writing prompts to different audiences, to show how the participants interpreted their own experiences and described their social contexts (Maxwell, 2013). Participants completed a 12-question survey that was designed to prompt reflection on negative, positive, and overall feelings of inclusion, provide advice to a peer, and offer programmatic recommendations. Participant responses were examined through the framework of UDL with critical theory (Waitoller \& King Thorius, 2016). The UDL framework contributed to an understanding of how programs were designed, including factors and belief systems related to the design. Responses were coded using In Vivo coding and pattern coding methods (Saldaña, 2013). Two participants completed an inclusive recruitment flyer and one of the two participants who 
created a flyer participated in an interview about the experience of designing the flyer. Participants were provided with three means of communicating information, specifically written narratives with different hypothetical audiences, visual representation, and verbally in an interview.

The purpose of this study was to examine how minority students in speechlanguage pathology graduate training programs experience inclusion and implications of inclusion relating to how the field of speech-language pathology addresses lack of diversity of its members. This section examines the background, limitations, and constraints of this study, in addition to my connection to the research and the positions that I hold as a researcher. Limitations should be addressed. Limitations relate to participant recruitment, survey completion, the time period in which the survey was conducted, terminology for concepts, and the role of the researcher.

Participant recruitment limitations included graduate program responsiveness and student responsiveness. A total of 281 speech-language graduate program department chairs received a direct email request from the researcher to distribute the survey. A total of 29 programs confirmed distribution for a response rate of $10 \%$. A possible limitation is the response rate of graduate programs in sharing the survey information with their students. Given that department chairs may receive numerous emails daily and multiple requests for surveys, they may not considered these types of requests to be priorities.

Recruitment was also conducted using social media on the National Student Speech Language Hearing Association to recruit students directly, and through the ASHA Special Interest Groups on Issues in Higher Education and Cultural and Linguistic 
Diversity to bring the survey to the attention of faculty. Although information about the survey was also present on national faculty listservs, and national student social media, it is not possible to determine whether students received the request to participate from their graduate programs, social media, a peer, or other source.

Additionally, there may be limitations due to student decisions to participate in the study. Given that the topics of diversity and inclusion may be considered complex or emotional, it is possible that only students who had strong views related to inclusion in their graduate school experiences may have chosen to complete the survey. In other words, students who did not necessarily view diversity and inclusion as a factor in their graduate programs may not have chosen to complete the survey. It should also be noted that this study only included graduate students, and another study that includes the perspectives of undergraduate and post baccalaureate students could provide valuable information about stages in the academic journey.

In regard to survey completion, it is important to examine differences between the number of students who initiated the survey and the number of students who actually completed it. Although 347 participants initiated the survey, only 104 participants completed it, which resulted in a completion rate of $30 \%$. On the whole, students who abandoned the survey stopped answering questions at the point in which open-ended questions were introduced. Many students responded to multiple-choice questions about demographics and then did not provide written examples of their own experiences. Individuals who initiated the survey answered demographic information across the minority markers of race and ethnicity, socioeconomic status, gender, LGBTQ+, 
disability, and other identities, as well as languages, geographic region of their graduate program, and year within graduate program. Given that 348 potential participants initiated the survey and responded to short multiple-choice demographic questions, completion rates may have been affected by time needed to provide written responses. A higher completion rate would have produced a larger quantity of data and more information. The time requirements of composing responses to open-ended questions about experiences may have been a deterrent for some students. Given the large number of students who originally initiated the study and provided basic demographic information, it is possible that a survey that used multiple-choice or other rating or choice metrics for quantitative data, and did not require narrative responses, may have encouraged a larger response rate. The findings of this study may be suitable for design of a follow-up quantitative study that does not expect participants to provide short written narratives. A potential future quantitative study using rating scales and a larger sample size could provide insight into the breadth and depth of overall experiences of inclusion.

The main survey offered participants the opportunity to continue in the study and complete an inclusive recruitment flyer. Time could also have been a factor in participant completion of an inclusive recruitment flyer. Only 2 of the 104 participants chose to complete an inclusive recruitment flyer, and of the 2 , only 1 participant chose to participate in a recorded telephone interview about creating an inclusive recruitment flyer. Creating a flyer, which was subsequently uploaded into the Qualtrics survey platform, required either completing the entire process in one sitting, or returning to the survey platform after a time delay. 
Completing the written narrative prompts and the flyer in one sitting required dedicating uninterrupted time to the task while returning to the survey after competing a flyer required effort to remember to schedule and allocate time to this task. Student schedules and academic demands could have affected their available time to dedicate to this process. Completing a visual project may also have appeared unusual, as the majority of assignments and expectations for graduate students studying speech-language pathology use a written format, such as research papers and clinical reports. Possible considerations could be related to whether or not participants would have benefitted from a structured time to create an inclusive recruitment flyer, or if automated or personalized follow-up prompts to complete the task.

Only one student participated in a telephone interview about creating an inclusive recruitment flyer. When offered the opportunity to confirm themes from the interview via email message, the participant did not respond. It should be noted that there was a time delay between the initial interview and the offer to confirm themes, and that significant changes within society had occurred during that time, including the coronavirus global pandemic. Even though only two participants chose to complete an inclusive recruitment flyer, their flyers showed congruence between themes from responses to the survey questions, and also showed that studying inclusive recruitment flyers, which were created by minority students, yielded valuable information.

Timing of the study is an important consideration within limitations. This study was conducted during Fall Term 2019, prior to the global coronavirus and COVID-19 pandemic and the social activism of the Black Lives Matter movement. The pandemic 
caused substantial social changes that affected daily routines, habits, and life circumstances, while the Black Lives Matter drew attention to systemic racism and its widespread effects within society. The outcomes of these phenomena are yet to be known. Graduate programs have undergone changes related to remote learning using virtual mediums and an examination of racism within higher education. Speech-language pathology graduate programs are likely to continue to experience changes due to these factors that may change multiple facets of academic and clinical instruction.

Along with the importance of the general time period of the study, terminology or word use is also situated within specific time periods and settings. Terminology used to describe groups who have been historically considered minorities or marginalized groups carries nuanced connotations that reflect societal beliefs. Terminology used in this research may not reflect current or upcoming changes and should be considered within the context of a particular time period and an academic setting. Future research may use similar or different words to encompass, clarify, or expand identity markers and concepts represented in this study.

As this was a qualitative study, the role of the researcher is of interest. In my own role as a researcher, I was conscious of how I have multiple identities, as a faculty member, a prior minority graduate student, and a mixed-race individual within society. In my goal to be a reflexive researcher, I followed Glesne's (2011) recommendations and considered how the data analysis process could challenge my assumptions. I hoped to question my established beliefs and consider how information that might initially be considered familiar could be examined with new perspectives to become novel (Glesne, 
2011). I took measures to question my own assumptions and monitor my subjectivity using audit memos to track my thoughts and feelings. I reflected on how reading the participants' experiences affected me on a personal and professional level. I posed questions to myself to increase reflexivity (Glesne, 2011, Saldaña, 2016). In analyzing the data in conjunction with my own audit memos, I was able to explore alternate ways to view the information and possible future directions.

In conducting this study, I recognized and reflected on my own identities through the use of audit memos that described my own responses to the research. In studying minority students, I came to this research holding two of the five identities studied, specifically low-income background and mixed race minority. Although I attended a speech-language pathology graduate program as the only racial and ethnic minority in the program, that situation and those circumstances were not new to me. I was personally aware of the concepts of socialization, assimilation, and passing, or attempts to have one's own identity appear closer, or as close as possible to that of the dominant group. This perspective may have prompted my recognition of the significance of prior experiences with discrimination and oppression, and decisions about identity presentation as factors in inclusion.

As a clinician I entered a predominantly white field and primarily served children and families from racial and ethnically diverse backgrounds in public school settings in low-income communities. As a clinical assistant professor, I am conscious of the role of power that I hold in relation to student learning and student outcomes. I advocate for inclusive teaching practices and increased diversity within the field. Although there are 
limitations to this study based on the role of the researcher, these limitations may be balanced by an emic, or semi-insider perspective, which reflects a personal connection to the research (McLaughlin \& Tierney, 1993).

This study was designed to place minority graduate students in speech-language pathology as a central group in broader discussions of diversity within the field. Participants' own experiences and how these experiences related to their identities were highlighted. Their thoughts and feelings were presented to better understand how minority graduate students experience inclusion within their academic and clinical training in speech-language pathology. The study also places minority graduate students as holding a position of expertise about diversity and inclusion, and potentially showing the strengths that minority graduate students bring to higher education and the field as a whole.

The next chapter contains a synthesis and analysis of the results that were presented in this chapter. Synthesis and analysis also forms the basis for investigation of the implications of this study for future research, along with the meaning of these findings for graduate speech-language pathology training programs, and diversity within the field. 


\section{Chapter 5: Discussion}

\section{Introduction}

The field of speech-language pathology, which provides clinical services for individuals with communication, cognition, and swallowing disorders across the lifespan (ASHA, 2018g), is comprised of more than 90\% white, female members (ASHA, 2017a). The demographics of the field are predominantly white and female, which is in direct contrast to the gender and race of the general public. These demographic differences create a mismatch between SLPs and the individuals who they serve. The lack of representation of males and racial and ethnic minorities has prompted national initiatives from the ASHA (2018c), the national organization of SLPs, with goals focused on inclusive policies and practice, increased diversity, and recruitment efforts for underrepresented minority student groups.

Although race and gender are important, diversity is more expansive than these two identity groupings. In regard to societal issues of equity and representation, Sensoy and DiAngelo (2012) include five minority identity categories, specifically, race and ethnicity, socioeconomic status, gender, LGBTQ+, and disabilities based on historical marginalization, discrimination, and oppression. When examining diversity in speechlanguage pathology with a broader perspective of minority identity categories, there is relatively limited data and likely limited representation of ASHA members who identify as being from a low socioeconomic background, LGBTQ+, and/or disabled. Lack of demographic information and prominent representation across minority identity markers 
likely further illustrates the mismatch between the practitioners and clients who they serve.

To address diversity of clinicians in speech-language pathology and the lack thereof, a focus on university training programs is necessary. Nationally accredited university training programs are the sole method for individuals to receive training and certification to become licensed SLPs. University training programs provide undergraduate, post baccalaureate, and graduate coursework in speech-language pathology. Given that completion of a master's degree is required for certification to practice, the graduate program experience provides a rich environment to examine diversity. Speech-language pathology graduate programs, which are required to follow the guidelines of ASHA, should be in alignment with ASHA initiatives addressing diversity through recruitment and retention efforts for students from minority communities.

Increasing diversity is directly related to student experiences of inclusion and the provision of an inclusive learning environment. Training programs in which students do not feel included run the risk of unsuccessful completion of any diversity goals that they may set. Recruitment and retention efforts that are devoid of an understanding of the perspectives of minority graduate students are inherently limited. A confounding factor when examining diversity and inclusion is the historical context of higher education, which has placed more emphasis on content, as opposed to pedagogy and meeting the needs of learners from diverse backgrounds (Bok, 2013). The common pre-existing university structure of daytime courses with mandatory attendance, lecture format, rigid 
guidelines for course requirements, and limited flexibility for life circumstances, prior experiences, and student identities harkens back to prior time periods when only affluent young white men attended college (Bok, 2013).

Universities play a vital role in diversification of the field and university programs should understand how lack of diversity within the field of speech-language pathology negatively affects many layers of the field including clinical practice, research, policy, and even the actual recruitment and retention efforts that could increase diversity. Within clinical practice, lack of diversity of clinicians affects understanding of the experiences of clients based on race, gender, socioeconomic status, LGBTQ+, and disability. In regards to race, awareness of white privilege within the speech-language pathology is a relatively new concept (Kohnert, 2013), and speech-language pathology students have previously shown minimal to limited awareness of white privilege and the experiences of minority groups (Ebert, 2013). The inability to recognize white privilege and how it disenfranchises minority groups could negatively affect clinical outcomes due to challenges with rapport, understanding of client needs and experiences, and complicity in systemic educational and health inequities.

Lack of diversity of socioeconomic status limits understanding of societal patterns of distribution of resources for education and healthcare (Kent, 1994), and the short-term, long-term, and generational effects of financial hardships on individuals and families. Lack of diversity of males in a female-dominated field, within a binary biological perspective of gender, impairs the field's ability to relate to the concerns of males (Litosseliti \& Leadbeater, 2013). Furthermore, SLPs provide important therapeutic 
services to military veterans and would highly benefit from an understanding of male perspectives. An inability to understand how males experience communication, cognition, and swallowing disorders, restricts and limits aspects of care. Additionally, the predominance of females in speech-language pathology affects male practitioners, as this situation likely mirrors similar concerns within nursing and education, which include reinforcement of societal gender expectations, gender identity threats, and reduced prestige and salary (Forsman \& Bart, 2017). In other words, lack of male clinicians affects care to male clients, negatively affects male clinicians, and likely influences societal recognition and understanding of the field.

Lack of diversity in regard to LGBTQ+ contributes to larger systemic issues in educational and medical outcomes for clients (Frazier, 2009; Hancock \& Haskin, 2015). LGBTQ+ children and families face challenges related to heteronormative instructional and intervention practices (Frazer, 2009), while LGBTQ+ children and adolescents experience significant safety risks in the educational setting (Kosciw et al., 2018). In the medical setting LGBTQ+ individuals experience lack of safety in their relationships with providers, which is exacerbated by SLPs' limited understanding and beliefs in their own competency to serve LGBTQ+ clients (Hancock \& Haskin, 2015; Kelly \& Robinson, 2011).

Lack of diversity in relation to disability is a unique issue as the field itself is dedicated to serving individuals with disabilities within a biomedical model of disability, which assumes expertise of providers in order to categorize people as meriting services (Hutcheon \& Wolbring, 2012). For a profession that is dedicated to providing therapeutic 
intervention, there has been an historical paradigm of clinic provider as expert, who may not respect the lived experiences of individuals with disabilities and even hold negative views of disabilities (Baladin \& Hines, 2011).

This broad view of lack of diversity across societal minority identity markers limits growth, change, and progress at the client, practitioner, and research and policy levels. In regard to client well-being, clients who do not see themselves represented by their clinicians may not feel safe to share their needs and concerns. Clients whose own lived experiences are not recognized as valid may even choose to forgo clinical services. When clinicians provide culturally inappropriate services, clients are further subjected to societal marginalization within systems, which are supposed to provide therapeutic care.

Through negative experiences based on stereotypes about marginalized groups, minority practitioner well-being is harmed within both professional and clinical settings. For example, minority clinicians who advocate for clients from diverse backgrounds may not receive the support and resources needed for these goals. Additionally, minority clinicians may experience microaggressions from colleagues, staff, and clients. To be a minority clinician within a field dominated by white women may require daily efforts to navigate a system that is not conducive to one's needs.

Within research and policy, lack of diversity across minority identities has far reaching effects in the goals and direction of the field, and affects the types of recommendations provided to practitioners for clinical practice (Frazier, 2009; Hancock \& Haskin, 2015; Kohnert, 2013; Litosseliti \& Leadbeater. 2013). Sadly, the field has frequently considered research from a reference point of white, middle class individuals 
and families, with little attention given to minorities (Inglebret et al., 2017). When the research community does not prioritize or include the experiences of minority communities, their findings may not be relevant, and may even be directly harmful to clients and communities (Sensoy \& DiAngelo, 2012). Diversity is needed to form partnerships with many communities to advance goals of inclusive care. Furthermore, the creation of policies and procedures, which are primarily founded in research, could inadvertently perpetuate pre-existing inequities in access to speech-language pathology services and the ability to provide culturally responsive preventative, assessment and intervention services.

Given the lack of diversity within the field, a focus on training from the perspective of the experiences of minority graduate students would be an important first step. How minority graduate students experience inclusion directly informs potential recruitment and retention efforts for diversification of the field. When addressing inclusion within higher education, the framework of UDL provides a guide on how to examine inclusive practices. UDL, which emerged from inclusive architecture to meet the needs of many different users of a physical space, was adapted to educational settings (Meyer et al., 2014). The UDL framework is based on the neurocognitive science of learning and uses multiple means of representing the content, engaging with the content, and expressing learning (Meyer et al., 2014). UDL was initially designed to address learning differences and the range of potential learning disabilities and learning challenges that students may experience. Proactively designing learning settings for 
diversity of student learning profiles is a method to build inclusion, however, a focus on learning alone without an understanding of student identities is insufficient.

To expand UDL to the realm of student identities, societal practices of minority categorizations, and historical inequities in educational access, Waitoller and King Thorius (2016) described how to combine, or cross-pollinate UDL with critical theory. Applying critical theory to UDL expands the underlying tenets of inclusion and access via UDL principles to encompass the needs and perspectives of minority students. In other words, proactive planning of inclusive learning environments should include awareness of historical minority identity markers. UDL can serve as an asset pedagogy that honors the unique contributions and strengths that minority students bring to the learning environment (Smith-Maddox \& Solorzano, 2002), and may even aspire to become an emancipatory pedagogy, which releases students from the need to adhere to narrowly prescriptive minority identity categories when engaging in their studies (Waitoller \& King Thorius, 2016). Asset pedagogies would use a proactive design to anticipate the needs of diverse learners and emancipatory pedagogies would strive to reject societal hierarchies of student identities within the learning environment.

To promote diversity in speech-language pathology through inclusive UDL learning environments, it is critical to understand the experiences and recommendations of minority students within the field. Within critical theory and social justice frameworks, five identity categories are considered to be minority markers within society, specifically, race and ethnicity, socioeconomic status, gender, LGBTQ+, and disabilities (Sensoy \& DiAngelo, 2012), and these categories apply to graduate training programs. Within 
speech-language pathology, a female-dominated field, the limited number of males changes male-gender into a field-specific minority category. All five categories of identity need to be considered in diversity and inclusion research, both as individual groups and collectively.

This study sought to contribute to larger national discussions on the need for diversity in speech-language pathology by capturing the voices of minority students and examining inclusive learning environments within a UDL and critical theory framework. An understanding of the experiences of minority graduate students will enable university programs, faculty, staff, and university partners to design, create, and implement meaningful targeted and broad inclusive practices.

As described in Chapter 4, this qualitative study was conducted in the fall of 2019 and includes minority student experiences of decreased and increased inclusion in their graduate training programs for 104 students across 28 states within the United States. A total of $10 \%$ of 281 nationally accredited speech-language pathology graduate programs confirmed sharing the survey with their students. The survey was also shared on the National Student Speech-Language Hearing Association student group social media site. In addition to experiences about inclusion, participants provided advice to a hypothetical minority peer and recommendations to departments. Results include representation across geographic locations, including 28 states, graduate level within the program, racial or ethnic minority, socioeconomic status, binary gender, LGBTQ+, and disability. It should be noted that participants included other identity markers, specifically religion, political 
affiliation, family/parental role, age, and roles within female dynamics, such as cliques and female relational aggression.

This study addressed the following research questions:

1. What is the experience of inclusion for minority graduate students in speechlanguage pathology training programs in relation to systems (university, field of study, department), context (classroom and social settings), and interaction (faculty, staff, community, and peers)?

2. What are the recommendations of minority graduate students in speechlanguage to increase inclusion to address the lack of diversity in the field?

3. How do minority graduate students in speech-language pathology training programs envision inclusion in the field?

Themes for decreased inclusion by identity group are shown in Table 94 and themes for increased inclusion by identity group are shown in Table 95 . The themes for each identity group will be discussed individually and connected to the larger context.

\section{Table 94}

Themes for Decreased Inclusion by Identity Groupings

Identity Group Themes for Decreased Inclusion

\footnotetext{
Race and ethnicity Racial microaggressions from faculty, from peers, and generalized racial microaggressions, white privilege, lack of representation, curriculum and resource gaps, tokenism, cultural differences, and isolation
}

Socioeconomic status

Economic privilege, financial barriers, hidden struggles, and lack of belonging

Male gender

Masculine stereotypes, male exclusion, and gender stereotypes

GBTQ+

Antagonism, fear of disclosure, microaggressions, isolation, and curriculum gaps

Disability

Exposure, disrespect, reductionist, and barriers 
Table 95

Themes for Increased Inclusion by Identity Groupings

\begin{tabular}{lc}
\hline \multicolumn{1}{c}{ Identity Group } & \multicolumn{1}{c}{ Themes for Increased Inclusion } \\
\hline Race and ethnicity & $\begin{array}{c}\text { Representation, role model, curriculum and resources, connection, } \\
\text { mission, asset, equality, and expectations }\end{array}$ \\
Socioeconomic status & Pride, support, community, and asset \\
Male gender & Welcomed and equality \\
LGBTQ+ & Effort, openness, connection, equality, and concealment \\
Disability & Disability awareness, asset, equality, and formal services \\
\hline
\end{tabular}

The research questions were designed to elicit graduate student experiences of both decreased and increased inclusion, as well as graduate student recommendations to departments to increase inclusion. This research sought to contribute to larger discussions on ways to meet the needs of a diverse client population by increasing clinician diversity within the field of speech-language pathology. The research questions worked together to gain different types of data. Students' experiences of decreased and increased inclusion showed both situations and factors that related to student feelings of being included. Students' advice to a peer provided insight into how the students viewed their own roles, power, and agency within their programs, to explore potential ways to provide support. Student recommendations to university programs directly sought specific guidance from students about changes that they would like to happen with their graduate programs. These multiple forms of data allowed for an examination of congruence, shared themes across minority identity groupings, and unique needs and concerns. 


\section{Synthesis of Findings}

In the broadest sense, this study showed how many speech-language pathology graduate programs were designed and operate from a privileged perspective that is white, middle-class, female, cisgender and heterosexual, and neurotypical and able-bodied. In neutral terms, this perspective limits programs from understanding the needs of racial and ethnic minorities, students from low socioeconomic backgrounds, male students, LGBTQ+ students, and students with disabilities. When applying critical theory and social justice concepts (Sensoy \& DiAngelo, 2012), this perspective serves as a form of privilege that oppresses minority students through multiple practices that grant benefits and opportunities to a dominant identity group. A summary of the themes in relation to the research questions is shown in Table 96.

\section{Table 96}

Summary of Minority Student Themes in Relation to Research Questions

\begin{tabular}{lc}
\hline \multicolumn{1}{c}{ Research Question } & \multicolumn{1}{c}{ Summary of Themes } \\
\hline Experiencing inclusion & $\begin{array}{c}\text { Inclusion increased with specific faculty and student } \\
\text { efforts to mitigate or counter the existing design of } \\
\text { graduate programs based on privileged identities of } \\
\text { white, middle-class, female, cisgender, heterosexual, } \\
\text { able-bodied and neurotypical student identity profile }\end{array}$ \\
Recommendations to programs & $\begin{array}{c}\text { Increase diversity through minority student and faculty } \\
\text { recruitment, expansion of curriculum and clinical } \\
\text { topics and services, faculty education and training, } \\
\text { student and faculty connections, availability of } \\
\text { resources, and equal opportunities }\end{array}$ \\
Envisioning inclusion & Representation, mission, public awareness, and \\
happiness
\end{tabular}


The first research question sought information about how minority students experience inclusion. Inclusion was related to the experiences that illustrated the absence of a privileged perspective, efforts to mitigate the effect of the privileged perspective, and efforts to counter this perspective. When considering UDL and design of learning environments, the privilege perspective, and its accompanying beliefs, may serve as the source or underlying problem from which policies, practices, and behaviors that decrease inclusion emerge. Although it may be tempting to focus solely on the underlying perspective, it may not be possible to determine the complex relationship between initiatives or changes at the level of underlying belief, practices, and mitigating factors. In other words, it could be equally beneficial to consider interception at any or all of the three levels, such as faculty training on diversity, small group or team-based teaching, and student affinity groups.

The second research question was a specific request for minority student recommendations to graduate programs. Specific recommendations encompassed different areas of academia, including recruitment of students, faculty, staff, and clients, clinical aspects, education, and connection. As with the first research question, levels of interception existed, which could be addressed through recruitment, training and education, policies and behaviors, and mitigating factors, such as interpersonal connections and shared communication. The specific recommendations to graduate programs reflected similar themes to experiences of inclusion, with a greater emphasis on recruitment. 
The third research question related to visual representations of inclusion. Although there were severely limited responses for this portion of the survey, themes from this portion of the study mirrored themes from other areas and added new elements. Student-created inclusive recruitment flyers emphasized representation, public awareness, asset, and mission, and added the concept of happiness. The addition of positive emotion likely aligns with asset and mission as personal satisfaction from contributing to greater societal good.

\section{Situating the Research in a Larger Context}

The following section provides a discussion of the analyses initially separated by minority identity markers, followed by a discussion of the similarities across groupings and the unique differences between groups. The discussion begins with themes that address the first research question about how minority speech-language pathology students experience inclusion in their graduate programs, followed by themes from the second and third research questions relating to recommendations to programs and envisioning inclusion. In discussing the themes, it is important to note how words and phrases have been used to encapsulate entire events and their resulting emotional content for minority groups. Although themes serve a valuable role that allows for an examination of the complex phenomenon of inclusion, the themes themselves should also be understood within the context of individuals, their well-being, and how inclusion affects their lives, their goals, and their identities. 


\section{Race and Ethnicity}

A total of $47 \%$ of participants identified as non-white racial minorities. Of this $47 \%$, the racial grouping of Hispanic or Latinx was the highest at $31 \%$, with Black or African American at $17 \%$, and the mixed race category of white and Asian at $15 \%$. Themes for race and ethnicity for decreased and increased inclusion are in shown in Table 97.

\section{Table 97}

Themes for Race and Ethnicity

\begin{tabular}{cc}
\hline Inclusion & \multicolumn{1}{c}{ Themes for Race and Ethnicity } \\
\hline Decreased inclusion & $\begin{array}{c}\text { Racial microaggressions from faculty, from peers, and generalized } \\
\text { racial microaggressions, white privilege, lack of representation, } \\
\text { curriculum and resource gaps, tokenism, cultural differences, } \\
\text { and isolation }\end{array}$ \\
Increased inclusion & $\begin{array}{c}\text { Representation, role model, curriculum and resources, connection, } \\
\text { mission, asset, equality, and expectation }\end{array}$ \\
\hline
\end{tabular}

Decreased Inclusion for Race and Ethnicity

In examining the themes for race and ethnicity, themes relating to decreased inclusion are addressed first, and then compared to themes that increased inclusion. The themes for decreased inclusion were combined and encapsulated as microaggressions within interactions and microaggressions at the macro-level within the environment. The themes of lack of representation, curriculum and resource gaps, and tokenism were considered macro-level microaggressions that extend beyond the level of the individual and reflect overall structure and design of a learning environment. White privilege and its 
neutral correlate of cultural differences served as a vantage point from which to view microaggressions, and isolation was the resulting effect. Microaggressions, which are automatic, unconscious, and subtle insults toward people of Color and other minority groups, are part of a significant pattern of devaluation and disrespect within society (Sue et al., 2007). For people of Color, microaggressions may have been present since a child of Color was young and continue to have a strong presence throughout their lifetime. These daily subtle verbal and nonverbal insults, which can come from any other person at any point in time and in any environment, have a cumulative negative affect on an individual. Within an educational setting these insults are disruptive to learning and inclusion (Gay, 2002; Paris, 2012).

Microaggressions. Within the themes of decreased inclusion, the concept of microaggressions was prominent within the responses, and can actually be extended to encompass multiple themes. Microaggressions can occur within specific interactions and behaviors, and also extended to the macro-level, which reflects systemic issues (Sue et al., 2007). Viewing larger environmental issues as representative of microaggressions at the macro-level shows how pervasive they are. The themes of lack of representation, curriculum and resources gaps, and tokenism are forms of macro-level microaggressions. Microaggressions within interactions are discussed at the specific level of faculty and peers, as well as general occurrence in interactions within the graduate training program. Microaggressions can be classified into different types that carry specific meanings (Sue et al., 2007), which help explain the messages that they impart on 
minority groups. Students described microaggressions from faculty related to pathology of cultural styles, ascription of intelligence, and microinvalidations.

Pathology of cultural styles uses a dominant white cultural interaction style as an idealized reference point and serves as a directive to assimilate (Sue et al., 2007). Pathology of cultural styles microaggressions were exemplified by the following, "I was confronted by my professors, telling me that the way I ask questions or make comments can sometimes be offensive or off-putting," and "“When you don't smile I can't tell how you are feeling' (as an African person, aggression is typically associated with darker skin. I should not have to smile for a supervisor to "read" me especially if my Caucasian clinic partner doesn't have to [sic] the same.)." These examples send the message that students of Color have a negative cultural interaction style that they need to change. When faculty, who hold positions of power over students in regard to grades, clinical opportunities, and career outcomes, covertly state expectations for cultural assimilation, they are casting one type of interaction style as normal and another as abnormal or problematic. For a field that determines the presence or absence of communication disorders based on client language use and understanding, any implications that certain cultural interaction styles are not typical is especially concerning. Faculty members who reinforce the idea of one cultural style as superior model a lack of understanding and respect for cultural diversity within communication.

The microaggression type of ascription of intelligence is predicated on the notion that people of Color are presumed to be less intelligent in comparison to white people (Sue et al., 2007). Ascription of intelligence often appears within praise, as in the 
following, "one of my graduate course professors, who identifies as Caucasian, praised me for being 'very articulate,' which I know is a micro-aggression towards AfricanAmericans specifically. She said she could tell that my parents had worked with me on my speech." This example contains multiple issues, including the underlying belief that it is unusual for an African-American person to be intelligent, intelligence is marked by cultural speaking style, and that it is unusual for African-American parents to help their children succeed. Although the microaggression of ascription of intelligence may appear to be complimentary, in actuality it is a form of oppression in which a dominant group has pre-determined the dialect and cultural interaction style that are valued. The supposed compliment reinforces the assertion of linguistic dominance with the implication that a person of Color should be commended for achieving a social speaking register that matches the dominant group. Additionally, it should be noted that participants felt that they needed to label and explain why certain actions were microaggressions, which likely reflected concerns that readers would not understand their significance.

Faculty also demonstrated forms of microinvalidations, including lack of individuality and exclusion. Microinvalidations dismiss, deny, or discount how people of Color feel and experience the world (Sue et al, 2007) Lack of individuality was related to sameness, as noted in the following, "Some professors, clinical supervisors, and people in my cohort consistently getting me confused with the 2 other girls in my cohort who have a similar skin tone to mine despite us being different races and having different physical features." Exclusion was noted through actions, such as "My teacher chose all Caucasian students to be in the picture, and did not include me." Microinvalidations from faculty 
showed that students of Color were not viewed as unique individuals, and that they did not deserve to be represented.

Racial microaggressions from peers described painful experiences within graduate cohort interactions for students of Color. Racial microaggressions included classifications of ascription of intelligence, myth of meritocracy, and second-class citizen (Sue et al., 2007). Within peer interactions, ascription of intelligence, related to assumptions about Asians, such as "White girls perceive me as someone to include and as a friend when it comes to academics, potentially due to stereotypes from the model minority myth." The model minority myth, in which Asians are commonly considered to be intelligent, is problematic for multiple reasons. The term "Asian" conflates multiple distinct countries, promotes stereotypes of intrinsic traits, and falsely elevates one minority group above others, which contributes to separating people of Color in understanding and sharing struggles, and working collectively to address systemic inequities (Oluo, 2018).

The microaggression of myth of meritocracy represents the idea that people of Color receive "unfair benefits because of their race (Sue et al., 2007, p. 276). A student described this situation in the following way, "I am angry because I worked so hard to this point, and I still feel like others look at me as if I am not worthy to be in this program." The microaggression of second-class citizen represents the idea that people of Color are not welcome and are not worthy. A student described this situation in peer interactions, "when participating in group projects, there are students in my class who will not even acknowledge me when I speak." When students of Color are confronted with evidence that their peers stereotype them based on race, do not think that they 
deserve to be within the program, and do not consider them as equals, they are forced to persevere in a hostile environment.

Generalized microaggressions represented broad reflections on student experiences within the graduate program and also included actions of faculty and peers. Students noted that their graduate programs were particularly problematic, "it is in grad school that I have experienced the most frequent incidents of racism and bias" and also represented aspects of white privilege, e.g., "perceived that the white girls in my cohort would get the most advantage or first priority in everything, whether it was in terms of clinic assignments/rotations, being called on first in class, or choice of materials for clients." Additionally, generalized microaggressions included clinical situations, e.g., "my classmates often used culturally insensitive therapy materials," and extended beyond the program, e.g., "countless microaggressions that occur in my program, and out in the field, can be debilitating at times." It should be noted that students sought to provide explanations of the effects of microaggressions, such as "people do not understand how their microaggressions affect people who have to work 10 times harder to be in the same position that they are in."

Microaggressions can be extended beyond specific interactions to the macro-level as a way to show systemic issues. The presence of systemic issues may indicate underlying beliefs that govern the entire design of an environment. Microaggressions at the macro-level encompass the themes of lack of representation, curriculum and resource gaps, and tokenism. 
Lack of representation reinforces that people of Color are outsiders or do not belong (Sue et al., 2007). The theme of lack of representation appeared in relationship to faculty and students, e.g., "no people of color in the staff or faculty of our program" and “only African-American student in my cohort," and extended to the field as a whole, e.g., "it is obvious that I am a minority in my program and the field itself." When students of Color do not see themselves represented within their academic setting, they receive a message of exclusion. A student explained these feelings, as follows "not saying I will allow representation to alter my academics and studies, but it is definitely something that can affect and trigger a student emotionally and psychologically."

Curriculum and resource gaps appeared in both coursework and clinical experiences. Coursework concerns showed that programs did not value teaching diversity and did not adequately address diversity, e.g., "optional courses or tracts [sic] instead of incorporating issues of diversity and issues of inclusion within the curriculum for everyone," and that "most of the majority had a hard time working with minority individuals because the training and experience was never provided in either at an undergraduate level or graduate level." Compounding the issue of the curriculum and resource gaps was the student lack of prior experiences with diversity, e.g., "many of the students in my cohort have not been exposed to populations different from their own." In regard to clinical training, students may even have been given incorrect information about serving racial and ethnic minority clients. A student expressed concern about a professor stereotyping of African American clients, "she basically told an entire cohort to apply the AAE 'exceptions' when scoring diagnostic assessment for all African 
American children. This action could potentially exclude children from services that they actually need, because not every African American child uses AAE." AAE is an acronym for African American English, a dialect with the level of complexity of a language that has historically been marginalized and disrespected. Not every individual who is African American uses African American English and clients' linguistics background should not be determined based on their physical appearance.

The third macro-level microaggression was tokenism, which aligns with the myth of meritocracy. Tokenism implies that a person of Color is only included to prove a claim of diversity or to meet a quota, such as receiving unfair preferential treatment in admissions. Student responses about tokenism included assertions, self-doubt, and rejection of the role of spokesperson. The student response, "we as minority student [sic] should not just be token poster children" rejected how the department was viewing students of Color. Sadly, the student response, "I begin to think that I am a token candidate and lack the critical thinking skills required for the profession," showed how tokenism affects self-esteem and belief in one's own capacities. Student responses explained and countered the idea of being a spokesperson, "anytime race/ethnicity/culture came up in a conversation everyone would automatically look at me and the other two ladies [minorities] for our point of view" and "I am in no way the spokesperson for people of color, biracial people, or minorities." Being perceived as a token negatively affects individuals' sense of self and limits inclusion. Tokenism separates individuals from those around them, invalidates individuals as a deserving member of a community, 
assumes a level of diversity not truly present, and can undermine how people of Color view themselves.

White Privilege. Although microaggressions may appear to be a main problem, they are perhaps actually embedded within a larger issue of white Privilege, representing a lack of awareness or humility about the invisible rights and advantages that white people hold within society (Sensoy \&DiAngelo, 2012). White privilege was described as a dominating force within the field, as in “unspoken rule that this was a white woman's field," and "it's very obvious that minorities are neglected in the field and many don't even make it." At the level of the graduate program, students described how white privilege was present within the admissions process and within faculty and peer interactions. Within admissions, a student shared that "a level of privilege, often white privilege, is needed to even be accepted into a CSD [Communication Sciences and Disorders] graduate program." At the faculty level, white privilege led to lack of understanding of the experiences of people of Color and potential abuses of power, as exemplified by the following responses, “ people in power preach about diversity but they themselves are not aware of their own white privileges and use it to their advantage," and "all of my professors are American born white ladies and at times I felt that they were not fair to minorities because they don't understand many of the struggles that we go through to make it to graduate school and even to complete grad school." The lack of awareness was viewed both sympathetically and with anger as shown in the following contrasting responses, "there are some experiences that people of color, biracial, and minorities face that white people will probably never have to face, so it is 
hard for them to relate," and "sometimes its [sic] disgusting to associate with individuals that don't understand differences or take into consequences [sic] of their words on other $[$ sic]."

The presence of white privilege and the lack of awareness of its very existence echoed the work of Ebert (2013), who showed how many graduate students had an abysmal lack of understanding of white privilege, and its effects clinically. Placing white privilege as a vantage point in relationship to microaggressions illustrates how microaggressions arise from an inability to recognize the need to seek out and understand the experiences of students of Color. Lack of awareness of white privilege harms students and their future clients. Preis (2013) argued that teaching students about white privilege is an issue of ethics in client welfare, given that lack of understanding of bias, prejudice, and discrimination negatively affect client care.

Both white faculty members and white students were described as having a lack of understanding of white privilege. Faculty demonstrations of white privilege aligned with the work of Kohnert (2013), who described how the field of speech-language pathology uses white culture as the standard of comparison, with racial minorities marginalized, and considered as others. The common practice of considering white as a standard and non-white as diversity solidifies how entrenched white privilege is within speech-language pathology, as whiteness serves as the consistent frame of reference.

Along with specific descriptions of white privilege, some students offered a relatively neutral view of cultural differences, as opposed to labeling privilege itself as a factor. These relatively neutral views focused on different backgrounds based on race. 
One student of Color wrote about the "culture shock of feelings like an outsider," while other students of Color stated differences as a logical consequence of societal structures, as in the following, "for the most part, white students and black students grow up differently, and experience different things," and "there are just some things that I cannot relate to and vice verse [sic]." Unfortunately, the differences were considered by one student of Color to be intractable, "impossible to bridge the gap between my experience and the experience of white women." Even though privilege was removed in descriptions of cultural differences, resulting effects appeared similar in that students of Color were separated from the white community.

Isolation. Isolation appeared as the resulting effect of microaggressions, white privilege, and cultural differences. Isolation was shared by multiple students of Color, "I am the only person of color in my cohort and I find myself feeling isolated because of it," and "one other Latinx that I can relate too which increases the feelings of isolation and anxiety." Students wrote about isolation in terms of "separation, uncomfortable, alone, excluded, left out, don't belong, ostracized, discredited, and unworthy." One student shared the social and emotional toll, “it doesn't feel good to stand out, because I want to fit in and I want to make friends," while another student shared about conformity and the concept of passing, or appearing to not be a minority, "I feel pressure to hide my identity because I am afraid of people judging me based on my appearance or viewing me differently because of my diverse cultural background."

Feelings of isolation for students of Color are a reflection of existing in a noninclusive environment. Increased inclusion should therefore decrease isolation. Factors 
that decreased inclusion and led to isolation were similar to those cited by Quaye et al. (2009), specifically racial identity development, negative stereotypes, lack of faculty representation, and dominant culture views within the curriculum. Racial identity development, which refers to an individual's exploration of race within a dominant culture, was especially concerning in regards to tokenism, with students expressing fears of not being worthy of being in a graduate program. Isolated students are unlikely to feel a strong sense of school belonging, which has been linked to positive psychological adjustment for students who are racial minorities (Gummadam et al., 2016). Earlier research on belonging also focused on acceptance versus alienation (Goodenow, 1993). Isolation that results from far reaching microaggressions, white privilege, and its relatively neutral frame of cultural differences negatively affects students of Color.

\section{Increased Inclusion for Race and Ethnicity}

Themes for increased inclusion for race and ethnicity included representation, role model, curriculum and resources, connection, mission, asset, equality, and expectation. The themes of representation, role model, and curriculum and resources show how macro-level diversity increases inclusion for students who are racial and ethnic minorities. In many ways, representation, role model, curriculum and resources, and equality directly counter the factors that decreased inclusion, however there are slight differences. Furthermore, the themes of connection, mission, asset, and expectations speak to specific factors that promoted inclusion.

Representation. Representation, or the presence of people of Color was important in increasing inclusion within university levels of faculty, staff, and students, 
and within the community. At the level of faculty, student valued faculty diversity, as described in the following "professors and staff feature many POC [people of Color] diverse ethnic and linguistic backgrounds," and "coming to a university where the majority of the student body, professors, and staff look 1 [sic] like me and have had similar experiences has been comforting." Having faculty of Color was also noted to be important for certain courses, as in "my instructors for my multicultural and school-aged literacy courses are women of color." Notably, one student described faculty diversity as paramount, "most significant component of my feelings of inclusion in this program is the cultural/linguistic diversity of the professors."

Diversity of students was a positive factor that was also related to the absences of microaggressions. A student reported racial diversity of students within the program as an emotionally positive experience, "happy to see the level of diversity among my colleagues." Student diversity was further connected to the reduced presence of microaggressions types, specifically tokenism and assumptions of being foreign or not American (Sue et al., 2007). One student noted that "being around a diverse cohort no longer makes me feel like the 'token multiracial person' in the program," and another stated that, "it's just nice to be around people who have the common courtesy to not ask 'so what are you?' in an invasive way." When people of Color are continually asked questions about their racial identity, they are receiving the message that they are unusual, foreign, or not American. Additionally, the location of the graduate program may play a role in inclusion, as a student described a "diverse city, and so the university opens itself to this environment, welcoming minorities as assets who have a lot to offer." Graduate 
programs that have racial and ethnic minority faculty and students and connect themselves to the racial and ethnic diversity of their communities increased student experiences of inclusion.

Role Model. Although similar to the theme of representation, the concept of role model extended beyond the mere presence of racial and ethnic minority faculty to their ability to inspire their racial and ethnic minority students. Students described shared backgrounds and seeing themselves in their professors, such as "my professor is an immigrant of the same country my parents are from" and "my instructor for the multicultural course shared her background and it was similar to my personal history." Role models were described as being both inspirational and realistic, as in the following, "she [professor] has inspired me and reminded me that the battle to do good within the field may be more difficult as a minority, mainly because of limited resources and support, but it is not impossible."

At the most basic level, role models show racial and ethnic minority students that there is a path for them in academia, e.g., "having a role model I could identify with helped me realize that I could do it too." The themes of both representation and role model aligned with research from Quaye et al. (2009) about the importance of racial and ethnic minority faculty in inclusion. When racial and ethnic minority students see themselves in their professors, believe that minorities can be successful in academia, and are given guidance and advice, they are able to envision their success in graduate school and as future clinicians. 
Curriculum and Resources. Racial and ethnic minority students reported valuing how their programs addressed diversity, including academic content, teaching practices, clinical training, and opportunities. In regard to academic content, students described both department level, and course specific commitments to diversity. One student shared how the "program integrates CLD [cultural and linguistic diversity] and addresses throughout the program and the clients who come to the campus clinic [sic]." At the individual course level, a student described the importance of a course dedicated to multiculturalism as follows: "class [Multicultural Issues] encouraged students to be reflective of differences, acknowledge each of our cultural backgrounds and how a multicultural background can enhance our work as clinicians working with, being respectful and inclusive of multicultural clients." Students appeared to appreciate having diversity as a prominent topic in their courses and clinics.

Academic content that promoted inclusion and was focused on diversity was powerful when it occurred in conjunction with elements of social justice, such as bias, privilege, and discrimination. Students noted the importance of diversity in their future work as in "discussion about diversity, and how to interact with individuals of different backgrounds." Students also valued discussions of societal inequities, as in "an entire class period discussing bias," "modern day issues-real issues of privilege, discrimination, and multicultural challenges when treating different populations," and the ability to "relate to the class material on a personal level."

Students described teaching practices and clinic training that promoted diversity. "instructors make more attempts to randomly assign individuals to groups to ensure more 
heterogeneous pairings/groups." Within clinical training, the theme of curriculum and resources had elements of the theme of mission, with the positive contribution to the outcomes of future clients as paramount, as in "emphasis within our SLP training to clearly note language input/out of our clients," and "the program has provided me with the tools on how to best give back to the community that I live in and has also opened the door to reach other Bilingual and culturally diverse clients in any city." Inclusion was connected to student academic and clinical training that ensured preparation for a diverse client population, as in "many cultures have been spoken about in depth as well as how to understand Bilingual language learners.” Additionally, access to departmental or university organizations was meaningful. Students listed involvement as related to inclusion, as in the following, "now that I have joined a few organizations, I feel more included because I have found other students with similar backgrounds," and "extension of multicultural studies and groups organized by my school.” Curriculum that covered diversity, connected it to clinical work, and addressed social justice and inequities promoted inclusion.

Connection. The theme of connection in increasing inclusion focused on having the opportunity to interact with others with similar backgrounds. In some ways the theme of connection had a parallel relationship to the themes of representation and role model, in that role model and connection are both an extension of representation. Connection included shared identities and experiences, shared beliefs and values, and validation. Shared identities related to race, e.g., "meaningful conversations with the other women of color," and "coming into contact with other African American females who experienced 
similar adversities here." Shared beliefs and values related to goals, such as "people in the world/future who do want to understand and relate to their clients." Validation reflected finally being understood, and having hardships recognized. Students noted the role of others in validation, as in "handful of great friends in my program that have repeatedly shown me that the type of treatment I am receiving is not universal" and "I felt like someone else could finally see me, and that I wasn't alone in knowing that these issues needed to be addressed." Sometimes validation was necessary due to microaggressions or discriminatory practices. Inclusion was increased when racial and ethnic minority students' feelings and experiences were recognized and understood.

Students highlighted how faculty members can foster connection in specific and broad ways. One student shared how deliberate actions were taken to provide connection, as in, "department chair of my program once reached out to me and told me that, while she was a white woman, she understood that it had to be hard to be the only black person in my cohort and offered to find me a mentor." In broader ways, faculty positively affected student inclusion through deliberate attention to establishing inclusive environments, as in "they [professors] provided a safe space that made me feel welcome and included in the program." The theme of connection was an important extension to theme of representation because the presence of other people of Color fostered shared understandings that increased inclusion. The theme of connection matched with Quaye et al. (2009) recommendations on increasing engagement for racial and ethnic minorities through peer networks. Peer networks ensured that racial and minority students were not isolated and that they had relationships with others who validated their experiences. 
Mission, Asset, and Equality. The themes of mission, asset, and equality are unique because of how they align with culturally responsive pedagogy, which focuses on the strengths that minority students bring to the learning environment (Gay, 2002; Paris, 2012). For the theme of mission, students described their own ability to be role models, as in "we are here now and we can pave the way" and "the field is white-dominated which feels discouraging and empowering at the same time." In some ways mission works in tandem with asset, because asset was positioned in regard to future work. For example, students described the following, "my differences are celebrated, respected, and supported as an asset with regards to a career in SLP," and "I have a different background that can serve others." Mission and asset themes showed how racial and ethnic minority students were able to see their value within the field of speech-language pathology and the positive roles they will have in their future clinical practice.

The theme of equality relates to the themes of mission and asset by removing race and ethnicity as a negative identity marker. Equality referred to the absence of judgments based on race, as in "I felt like my race/ethnicity did not matter," and "I feel as though they treat everyone very fairly." Equality also extended to being seen as having multiple identities, such as "for some of my classmates, they see me as SMART and not just BLACK." Even though equality is not necessarily focused on strengths, it is related to asset because equality within a graduate program recognizes how each student is part of the learning community and has meaningful contributions to share.

Faculty members played a vital role in promoting mission, asset, and equality. A student noted the role of the professor in the development of mission, "what impacted me 
strongly was her [professor] even mentioning the predominance of white females in our field and how we NEED diversity to treat a diverse population." Racial and ethnic minority students appreciated having their languages valued, as in the following, "I've always been encouraged by my instructors to improve upon and embrace my bilingualism as it will come in handy upon entering the workforce in my field," and "they come to me for questions regarding hispanic [sic] culture or Spanish language which has made me feel lie [sic] a valuable asset to the program as the only hispanic [sic], Spanish speaking person here." Faculty members have power in creating culturally sustaining pedagogy that situates racial and ethnic diversity as an area of strength, instead of marginalizing it to increase inclusion (Paris, 2012).

Expectations. In many ways, the theme of expectations as a factor in promoting inclusion is paradoxical because it is low expectations for diversity within graduate programs that increased inclusion. In other words, racial and ethnic minority students who did not expect to be included and did not expect to have diversity valued were less likely to feel excluded. Students who had already encountered significant experiences of exclusion entered into graduate programs without positive expectations. Expectations included past experiences, as in "I am accustomed to some level of misunderstanding and tokenism," and a pre-existing understanding of systemic issues, e.g., "having to outwork the a $[$ sic $]$ system that was not created for the minority way of living" and "I came into the program knowing that individuals of my ethnicity were not in [sic] majority if anything even represented." Even though students had already dealt early experiences with discrimination, and had low expectations for inclusion, they still expressed pain, 
such as "I have always been not included. Growing up I was a minority too and you notice it. It stays with you because people doubt you and what you are capable of. They make assumptions and it is hurtful." Understanding the backgrounds of racial and ethnic minority students, specifically in regards to their prior experiences with discrimination and their assumptions about diversity in graduate school, could help differentiate between which students would be more or less inured to these challenges and which students might be experiencing them for the first time.

In summation for race and ethnicity, factors that decreased inclusion appeared to be nested within white privilege as a central force. White privilege encompasses viewing the world from the reference point of white culture as typical and does not require consideration of the experiences of racial and ethnic minorities (Olou, 2018; Sensoy \& DiAngelo, 2012). White privilege enables a graduate program and its white faculty and white students to engage in a variety of microaggressions at the individual and environmental or macro-level in an oblivious manner. Even when white privilege was described in less direct ways, through the use of term cultural differences, it still places those with power within society, specifically the white faculty and white students in a position where they are incapable of understanding the needs of racial and ethnic minority students. White privilege breeds microaggressions, which cause isolation for racial and ethnic minority students, which then decreases inclusion.

By contrast, factors that increased inclusion for racial and ethnic minority students, were primarily based on the presence of other racially and ethnically minorities. Environmental or macro-level diversity of faculty, students, and community ensured 
representation within the learning environment, role models, multicultural concepts within curriculum, and meaningful connections with others. At the basic level, the mere presence of racial and ethnic minorities within the graduate student experience increased inclusion. Although racial and ethnic diversity alone was a positive factor in inclusion, even programs with limited diversity were able to increase diversity through connecting students with mentors, and engaging in culturally responsive pedagogy (Gay, 2002; Paris, 2012). Connecting students with mentors contributed to the themes of role model and connection. Culturally sustaining pedagogy situated discussions of privilege as relevant in understanding the needs of diverse clients and fostered student beliefs in their own value to the field. Faculty members who reinforced the need for racial and ethnic minority SLPs helped their students see themselves as assets who had an important mission to serve. Believing in one's worth and wanting to contribute to a greater cause increased inclusion.

Within race and ethnicity, one specific theme deserves attention, specifically, the theme of expectations. A factor that increased inclusion was low expectations or a preexisting understanding of how white privilege and race are commonly enacted within organizations and institutions. Racial and ethnic minority students who did not expect to be entering into a safe or supportive environment reported that this knowledge increased their inclusion. Unfortunately, being informed, or perhaps even jaded was a factor in increased inclusion. Given that background experiences and underlying beliefs about race within society affected inclusion in graduate programs, further examination of ways to understand expectations and differing levels of vulnerability would be beneficial. 


\section{Socioeconomic Status}

Low socioeconomic status was considered a marginalized group within academia, and within speech-language pathology. National admission and tuition systems that require financial resources and access to academic and social opportunities that facilitate entry into a graduate degree program are barriers to entering the field. Additionally, significant financial resources are required throughout the preparation and admission process and throughout the graduate program itself. College students from low-income backgrounds face multiple challenges within higher education that affect academic success and graduation rates (Engle \& Tinto, 2008; Scott et al., 2003). Furthermore, the field of speech-language pathology has limited representation of socioeconomic status within research (Inglebret et al., 2017), and lack of awareness of societal patterns that cause barriers to care based on socioeconomic status (Kent, 1994). Within this study, a total of 21 out of the 104 participants, or approximately $20 \%$, indicated that they had a low socioeconomic status background. Themes for low socioeconomic background for decreased and increased inclusion are in shown in Table 98. Decreased inclusion themes are addressed first, and then compared to themes that increased inclusion.

\section{Table 98}

Themes for Low Socioeconomic Background Inclusion Themes for Low Socioeconomic Background

Decreased inclusion Economic privilege, financial barriers, hidden struggles, and lack of belonging

Increased inclusion Pride, asset, support and community 


\section{Decreased Inclusion for Socioeconomic Status}

Themes for decreased inclusion are centered on the economic privilege that is present within graduate programs. This economic privilege is juxtaposed to financial barriers and hidden struggles of the students from low socioeconomic backgrounds, resulting in lack of belonging.

Economic Privilege. The theme of economic privilege represented how faculty members and most students had access to financial resources, the assumptions that were made about the affluence of others, and a general lack of awareness of the existence of financial hardships or barriers. In some ways, economic privilege appeared similar to macro-level microaggressions (Sue et al., 2007) in that the larger environment reinforced the idea of financial advantages as typical and expected. Economic privilege relates to the concept of white Privilege in that there is a lack of awareness or lack of humility about the advantages that financial resources give people within society, and little understanding of how systemic inequities have negatively affected access to economic gains for minority groups (Sensoy \& DiAngelo, 2012).

At the level of faculty, professors assumptions of financial privilege of the students was especially enlightening to students from low social economic status backgrounds, as these assumptions facilitated a new understanding of advantages in admissions process that many students had and others did not. A student reported that the "professor brazenly compared taking the GRE [Graduate Record Examination] the first time compared to the second as becoming easier, and that is the key to doing well in graduate school' and 'I hadn't considered that my peers likely took their GRE more than 
once." The idea that students would only come to recognize the advantages that their peers had through the casual assumptions of faculty could prompt students to reassess their entire understanding of the graduate school process. The professor's casual comment, which may have been designed to be encouraging, separated students from low socioeconomic backgrounds from their peers and highlighted inequities that biased the admissions process.

At the level of peer interactions students described economic privilege of peers through physical artifacts, comments, and belief systems. Physical markers or artifacts, such as "the casual privilege of designer boots and branded notebook," showed how the external markers of wealth served to separate students from each other. Conversations between students also contained comments that divided groups, as in "I heard girls in my cohort talking about going to [wealthy location] for vacation unfortunately I did not partake in the conversation because I did not feel I could relate to anything." Economic privilege was further connected to belief systems, such as "sometimes this MA-SLP degree we're all getting feels like an MRS degree for the new economy," meaning that the female students were seeking a husband, with the assumption that they were only pursuing a degree in speech-language pathology in order to have as a part-time job while raising children and being supported by their husband. This casual approach to a career was in contrast to students from low socioeconomic backgrounds who were expecting to work full-time to support themselves and their families.

Students from low socioeconomic backgrounds also reported lack of representation, "majority of my program is made up of white females from middle to 
upper class socioeconomic status," and a lack of understanding, "privileged backgrounds and had lacking experience with the hardships of being a parent or a child in a lower socioeconomic status." Furthermore, this privilege was noted to affect clinical practice, as in "hard for people of privilege to relate to and meet families of lower socioeconomic backgrounds." Economic privilege ensured that faculty and students of middle and high socioeconomic status did not need to consider how their behavior affected others.

Financial Barriers. Along with expected hardships based on low socioeconomic status, such as poverty, lack of family background with higher education, and lack of college preparation (Engle \& Tinto, 2008; Scott et al., 2003), students described issues specific to their graduate training programs. The theme of financial barriers encompassed the worry, missed opportunities, and constraints related to not having enough money. Students described concerns about loan repayments, lack of scholarships, and the need for gainful employment upon graduation. Missed opportunities were related to learning and social communities, as in "less practical for me to be involved in things like conferences study abroad opportunities, and organizations with membership fees or dues (including student or campus ASHA organizations)." Any additional fees were financially problematic, as in the following, "I was surprised to have [sic] by having to pay for expensive supplies, memberships, and online resources required for classes" and "sometimes the cost of materials, building an inventory of resources for the profession, and education costs can be daunting." Constraints related to financial barriers which determined which schools they could attend, such as "I could not afford to move to attend [university name] program, had to enroll in on-line program at a higher tuition rate." At 
the most basic level financial hardships reduced access and had an emotional toll on students.

Hidden Struggles. The theme of hidden struggles relates to invisibility of identity. In many ways hidden struggles connects to the concept of passing, or appearing to belong to the dominant group. Students described hidden struggles in specific and metaphoric terms, such as, "my SES is not easy to see" and "this is a feeling I have often had throughout life, like I am a stage actor, playing a role while covering the aspects I don't want others to see." This secret identity caused concern about discovery and reinforced prior trauma, such as "I always think that eventually someone is going to notice that I'm faking it" and "past experiences where girls who came from higher socioeconomic status would look down on me because of my repetitive clothing and outdated shoes." Hidden struggles included substantial hard work and sacrifice, as in "funded my prerequisite SLP classes by moving back in with my mother and scrubbing toilets for tuition money" and "what they did not see was the financial struggle and risk behind me getting to this place in my academic career." Having unacknowledged accomplishments and taking effortful steps to appear to belong to a higher socioeconomic group reduced inclusion.

Lack of Belonging. The overarching theme of economic privilege, which leads to systems level financial hardships and hidden struggles, resulted in lack of belonging. Students' lack of belonging was stated directly, as in "I think, 'I don't belong here."” Lack of belonging reduced inclusion, and was described as an inability to relate, such as "I feel out of place," and "I cannot relate to their upbringing or keep up with social 
activities." Students shared feelings of isolation, "I've felt isolated due to my lack of experiences and lack of money" and insecurity, "I grew up extremely poor and this, in some ways effects your self esteem and self worth." Students were affected by the ways that graduate school operated through economic privilege, imposed financial barriers, and prompted them to hide their identities, as well as how this situation mirrored their past experiences.

\section{Increased Inclusion for Socioeconomic Status}

Factors that increased inclusion for students from low socioeconomic backgrounds were pride, asset, support and community. Pride and asset worked together as strength-based factors. Support included emotional elements and access to opportunities, while community represented regular contact with others.

Pride and Asset. The themes of pride and asset have importance because of how they relates to hidden struggles and financial barriers. Pride serves as a corollary to the hardships, struggles, and barriers that students experienced by focusing on overcoming obstacles and succeeding. The theme of asset shows how prior hardships are beneficial in clinical work. Students described character values, "I was accepted to the program based on my hard work ethics," and achievements, "I have received many recommendations for Dean's and Chancellor's lists." It is also important to note that the theme of pride included discussion of family, as in the following, "I've felt very grateful to bring my family pride in getting my Master's degree," and "my mother is very proud of my accomplishments." The role of family was further connected to other identities, such as immigration status, "being 1 st in my family to receive diplomas in high school, BA and 
MS is proof that even though my parents are immigrants with elementary education and with limited resources, I could successfully accomplish my personal goals.” Additionally, students from low socioeconomic backgrounds viewed their own prior struggles as beneficial, or an asset, in relationship to their clinical role with future clients. This related theme of asset is connected to culturally responsive pedagogy that views minority students as having important strengths (Gay, 2002; Paris, 2012). Students from low socioeconomic backgrounds described being able to connect with clients, and inform others, as in "I feel that I can connect with individuals from varying backgrounds due to these experiences," and "teaching about the hardships and trying to share those perspectives to promote empathy and understanding." Students from low socioeconomic backgrounds described feeling more included when reflecting on how much they had accomplished, the significance of their efforts to their families, and how their experiences would enrich their clinical work.

Support. The theme of support included emotional support and financial opportunities. Emotional support related to feeling understood or acknowledged, such as "my adviser has heard and understands my background, so he knows where I'm coming from," and "I've been able to express any difficulties I'm having in any aspect of my life with my cohort and most of my professors." Financial support was present through sharing information about potential opportunities that did not require direct identification of need, as in "I have professors who regularly post scholarship and job opportunities to the class, which allows me to receive them without feeling like I am singled out." 
Additionally, department level approaches, such as "student centered and individual" increased inclusion.

Community. The theme of community reflected being part of a group.

Community was established through communication, such as "cohort group message where we share everything," and "professor communication and student fb [Facebook] groups." Community was part of working in proximity, "share a clinic workroom" and through positive interactions, "entire cohort is open and friendly." A noteworthy aspect of community was connection to faculty, as in "I know most of my professors know me. Some know me by name so that makes it important." Students from low socioeconomic status reported feeling more included when they had regular contact with peers and their professors knew who they were.

\section{Male in Female Dominated Field}

Using a binary construct of gender, males were considered to be minorities within a female-dominated field that has more than $95 \%$ female members (ASHA, 2019). A total 12 of the 104 participants, or approximately $12 \%$ indicated that they identified as male. A field that is female-dominated has inherent limitations in regards to clinical, research, and policies that affect male clients and clinicians (Litosseliti \& Leadbeater, 2013). Themes for males for decreased and increased inclusion are in shown in Table 99. 
Table 99

Themes for Males in a Female-Dominated Field

\begin{tabular}{cc}
\hline \multicolumn{1}{c}{ Inclusion } & \multicolumn{1}{c}{ Themes for Males in a Female-Dominated Field } \\
\hline Decreased inclusion & Masculine stereotypes, gender stereotypes, male exclusion \\
Increased inclusion & Welcomed and equality \\
\hline
\end{tabular}

\section{Decreased Inclusion for Males}

Factors for decreased inclusion were based on stereotypes, specifically masculine stereotypes and traditional gender roles, which lead to male exclusion.

Masculine Stereotypes and Gender Roles. Male students explained how masculine stereotypes and beliefs about gender roles functioned by assigning inherent traits or attributes to males. A particular concern is the way that masculine stereotypes resulted in female peers perceiving their male peers as threatening and unsafe. Male students described the missed opportunities and exclusion that arose from these stereotypes, such as "One of my classmates told me that they would feel uncomfortable sharing a room with me [at conference], which I completely understand, but it still made me feel disheartened," and "girls gel together and work on homework into the night. Those groups don't form with guys in them typically." The stigma of males as threatening lead to an overall lack of inclusion, as in "working on stuff in community is something I have missed being in a female dominated field." In regard to dating, a male student reported negative repercussions and resulting isolation, "I told a girl I had a crush on her, and now all her friends ignore me. No male heterosexual colleagues to talk to. Made to feel like a creep." It is important to note that masculine stereotypes may have been 
exacerbated by political events, as noted in the following, "perhaps the recent "me too" movement has made me feel as though I have to tread more lightly around things like going over to a woman's house," and "seeing all of the awful things men with power have done to women over the years makes me realize how some women generalize men." These masculine stereotypes appeared to prompt men to be highly self-conscious of their behavior, as demonstrated by the following, "I am afraid of upsetting or offending anyone," and "I feel as though I should play a more passive role within my class."

The themes of masculine stereotypes and gender roles aligned with societal gender expectations within professions where women are considered to be nurturing and males analytical (Forsman \& Barth, 2017). Student experiences also aligned with portions of the work of Michel et al. (2015), which described how males in counseling programs were treated in four different ways, specifically as leaders, stigmatized, invisible, and nurtured. Views of males as leaders, stigmatized, and invisible were present in student responses for decreased inclusion in the themes of masculine stereotypes and gender roles. When the concept of males as leaders was present, it was primarily restricted to clinical settings and represented negative reinforcement of stereotypes.

Male Exclusion. In some ways, the theme of male exclusion is related to the concept of privilege, in this case female privilege within the field. Female privilege was demonstrated by lack of male representation, tokenism, and comments that specifically excluded males. Male student experiences reported male exclusion within the entire field of speech-language pathology, within classes, and socially. At the level of the field, a student described seeing only women represented, "when I went to the national ASHA 
conference in Los Angeles. I'll be candid, I describe it as being among a 'sea of upper middle class white women with blond hair who all love Vera Bradley."' Within classes, professor addresses to the entire class were a specific concern, as demonstrated by the following, "presentations, meetings, classes, etc. would start out with 'hey ladies!' or only include information relevant to women," and "I had a professor that continued to refer to the class as girls throughout the course and then would take a pause and say, 'And [male student's name]."' Although ignoring males in classroom introductions was problematic, the lack of presentation of information relevant to males showed that shortcoming in academic and clinical training because the content did not relate to the concerns of males (Litosseliti \& Leadbeater, 2013).

Exclusion based on ways that professors addressed their students started immediately upon attending graduate school, as in "at orientation, one of the professors talked about how she has three boys at home and then said, "Sorry [male student's name] and X (the other male in my cohort, but I'm ready to be around some women." Male students further reported tokenism, "hard to be apart [sic] of the group when you're seen as the token hetero male," and "belief that men are novelty in the field and not needed." This tokenism reflected the research of Michel et al. (2015), which also showed tokenism of males in counseling training programs. As previously noted, exclusion from activities with peers was based on masculine stereotypes "I often feel excluded from conversations and group activities, especially outside of school activities, since it is hard to relate and going to other peoples $[$ sic] places is awkward since all of my classmates are female." Male students experienced lack of inclusion due to environments and behaviors that 
showed females as typical and expected within the graduate program, and males as outsiders or unusual, and at worst threatening.

\section{Increased Inclusion for Males}

The two main themes for increased inclusion of welcomed and equality are interesting because due to their underlying connotations. The concept of welcomed implies a setting in which an individual is a guest, and equality represents being treated the same.

Welcomed. The theme of welcomed primarily described situations in which male students reported that efforts were made by others to include them. Male students described general comments and actions that showed welcoming behaviors, such as the following, "Many classmates/clinical supervisors/faculty made comments about how it was nice to see men in the profession and how clients need to see more male therapists (for all sorts of different reasons)," and "after our July classes ended, our cohort took pictures in front of our building. I was about to get into my car and people from my cohort invited me to take pictures with them. It made me feel good because they didn't have to invite me to participate in what they were doing." The situations that male students shared are interesting because they appear to signal that welcoming acts were noteworthy, unusual, or unexpected. In addition to specific acts, the theme of welcome included general sentiments of attitudes, such as "people are generally nice," and "the faculty within my program specifically was very inclusive.” Male students shared also that they felt included when they established friendships and became involved in student organizations. Although the theme of welcomed relates to increased inclusion, it still 
deserves further examination as it may reflect underlying beliefs males are unexpected guests and entering into a social environment that is not designed for them.

Equality. The theme of equality represented inclusion based on perceptions of equal treatment and not receiving any special or different treatment. Male students specifically described their desire for equality, as follows, "the most important thing, to me, is how everybody has treated me like I am any other student or clinician. I don't want any special treatment (positive or negative) because I'm a man. I want to be judged on my skills and character," and "my classmates, supervisors, and professors have been helpful. I feel like I have been treated like any other I feel like I haven't been treated any differently compared to the female students." Male students appeared to value equality as a major factor in inclusion, which in many ways serves as the counterpoint to masculine stereotypes and gender roles. It is worth noting that male students may have recognized the potential for preferential treatment based on a pre-existing understanding of how males have privilege within the general society.

\section{LGBTQ+}

Of the 104 students, 34 students indicated that they were LGBTQ+. Within the $33 \%$ of students who were not heterosexual, the categories of bisexual (29\%), asexual (18\%), and gay (18\%) demonstrated the highest percentages. One student identified as transgender (male and gay). Given the clinical roles that SLPs play in medical and educational settings, an understanding of the needs of LGBTQ+ clients and barrier to services is highly important. LGBTQ+ graduate student experiences of inclusion are a reflection of the broader field and also show the extent to which programs do or do not 
train new clinicians to serve the LGBTQ+ community. Themes for LGBTQ+ for decreased and increased inclusion are in shown in Table 100.

\section{Table 100}

Themes for $L G B T Q+$

\begin{tabular}{cc}
\hline Inclusion & Themes for LGBTQ+ \\
\hline Decreased inclusion & $\begin{array}{c}\text { Antagonism, microaggressions, curriculum gaps, fear of disclosure, } \\
\text { and isolation } \\
\text { Increased inclusion }\end{array}$ \\
Effort, openness, connection, equality, and concealment \\
\hline
\end{tabular}

\section{Decreased Inclusion for LGBTQ+}

Themes for decreased inclusion for LGBTQ+ students show an underlying environment that is designed around heteronormativity, or the assumption of heterosexuality as the normative state of being. The themes of antagonism, microaggressions, and curriculum gaps can be combined on a continuum with antagonism at the extreme end with visible anti-LGBTQ+ sentiments, to microaggressions in interactions and corresponding environmental or macro-level lack of representation in curriculum gaps.

Antagonism. The theme of antagonism or openly LGBTQ+ actions and settings is especially concerning given the ongoing presence of homophobia on college campuses (Schueler et al., 2009), and discrimination of LGBTQ+ clients in healthcare (Hancock \& Haskin, 2015), and educational settings (Frazier, 2009). If graduate training programs in speech-language pathology do not promote inclusive environments for LGBTQ+ 
students, they have little chance at being successful addressing societal inequities in accessing and provision of speech-language pathology services.

LGBTQ+ students described antagonism from peers, faculty, and staff. Within peer interactions, these types of experiences decreased inclusion and contributed to subsequent isolation, such as

once a classmate of mine that is still in my graduate program with me asked what she should do if she was uncomfortable providing services to an LGBTQ+ person because they "don't agree" with it. Several of my classmates echoed her concern. This experience made me realize that my classmates were not as accepting as I once thought they were.

Students noted visibly apparent beliefs, as in "most in my program were bigoted against the LGBTQ community," and "people in my program who are openly against non-binary dress.” LGBTQ+ antagonism was even apparent in casual conversations through proxy indicators of religion, such as "many of the faculty and staff openly discuss private matters such as religion and church preferences while at work, many of which are involved in openly anti-LGBTQIA affiliations." Furthermore, students described, "incidents involving staff and faculty members that resulted in them having to attend sensitivity training." This overall hostile environment was more explicit than the microaggressions, which also occurred.

Microaggressions, and Curriculum Gaps. Microaggressions based on assumptions of heteronormativity occurred with interactions with peers and faculty. Assumptions of heterosexuality as a shared normative state from peers was described within initial peer interactions, such as "it was really jarring to be in a space where I was going to have to get to know and make friends with people who were so out of touch that they assumed that I was single, interested in men, and that I was interested in getting 
married in the next two years." Apparently microaggressions related to heteronormativity may be prone to occur in social settings before students are even actively engaged in their courses, which then set the stage for further separation from the dominant group.

Students described how peers' conversational topics appeared similar to microaggressions in the form microinvalidations, which discounted any other life experiences, and negatively affected peer relationships, such as "I don't want to spend my entire career talking about people's weddings or their flower beds or what cute thing their baby did or what color they're going to paint their door this year."

Faculty interactions included off-hand comments in the classroom to all students that assumed heterosexuality, such as "something small like 'all of your boyfriends' or something along those lines," and more significant pronoun errors, "professors say 'he or she' in their speech and when I have asked them to say 'they' instead, I've been told it's 'too hard." It should be noted that pronoun errors reinforce a strict gender binary, which is a core feature of discrimination against transgender and gender diverse individuals and reflects a lack of awareness of LGBTQ+ issues and concerns (Hancock \& Haskins, 2015). Students explained how microaggressions appeared at the larger systems level in academic and clinical instructions, as follows, "professors seem lack the knowledge about what it means to have a gender-inclusive classroom and use binary and gender essentialist language on their syllabus and in their speech. They use and model language that assumes that we, and our clients, are all cisgender, heterosexual, and have families with a mom, a dad, and child(ren). It is extremely problematic and hurtful." Additionally, "case study assignments that involve married couples are always straight couples. Intake 
forms we receive as example model forms ask for mom's name and dad's name, or have only two gender options to choose from (Male and female)." The presence of heteronormative beliefs in clinical settings is especially problematic because of how it affects clients.

Microaggressions at the macro-level were reflected in the theme of curriculum gaps. Students specifically noted lack of representation, including "not being validated or considered throughout the curriculum design," "no mandated education on gender identities, gender neutral language, or removing gendered language from medical lexicon," and "we only talk about cultural competency as it relates to race, ethnicity, and multilingualism.” The exclusion of LGBTQ+ issues within cultural diversity perpetuates SLPs' lack of awareness and understanding of LGBTQ+ clients (Sawyer et al., 2014). Even though some students noted how these microaggressions may have been unintentional, as in "professors sometimes accidently push heteronormative stereotypes on their students," the cumulative effect was significant. LGBTQ+ students reported feeling invalidated in a program that "wasn't designed for people like me and it's not populated by people like me but that seems to be what I'm up against." Unfortunately, the presence of microaggressions was similar to those that LGBTQ+ student experience in middle school and high school (Kosciw et al., 2018), which shows how these negative message persist throughout an individual's educational career.

Fear of Disclosure. The microaggressions and curriculum gaps prompted a fear of disclosure. The theme of fear of disclosure was noteworthy because of the use of emotional terms. LGBTQ+ students described concern for themselves, as in "do not think 
some of them [peers] would have been understanding or accepting had they known I was trans," and concern for future clients, "as a queer individual, it hurt my heart to know that my own classmate, so close to actually serving real people, was looking for an excuse not to serve someone like me. It let me know that I could not come out to them. Selfconscious about how I choose to present myself." Fear was connected to identity markers, as exemplified by being "afraid to use my proper pronouns" and "worrying that if my gender becomes known here, it could negatively impact my graduate studies." This fear changed LGBTQ+ students' behavior, including "I do not tell everyone about my sexual orientation because of stigma and potential discrimination," and "haven't wanted to tell any of the faculty because I don't want them to be biased against me." Feelings of fear also echo GLSEN (Kosciw et al., 2018) research of LGBTQ+ experiences from middle school and high school students, who reported feeling unsafe at school.

Isolation. The themes of antagonism, microaggressions, and curriculum gaps caused fear and they also caused isolation. LGBTQ+ students reported loneliness from lack of representation, "quite possibly, the only queer person in my program," and tokenism, which reduced community, as in "none of the members were outright homophobic, but I was definitely the token gay person to a lot of them." Emotional content words were also present that reflected negative feelings, such as "not feeling like you have your people when ever [sic] else looks like they do is depressing and then negatively effects your academic work," and "feel outcast as a queer, adult student." In the most neutral terms, an LGBTQ+ student described general lack of shared experiences, "as a gay man, I would feel most comfortable discussing my business with another gay 
man or woman.” By contrast, when active discrimination was present, isolation was viewed as insurmountable, "hard to want to be friends with someone who doesn't care about my wellbeing because I'm gay." The theme of isolation that decreased inclusion and caused negative emotions coexisted with other powerful feelings of fear and worry based on needing to function within the antagonism of anti-LGBTQ+ environments.

\section{Increased Inclusion for LGBTQ+}

Effort and Openness. The themes of effort and openness described faculty, courses, peers, and environmental markers in support of LGBTQ+ students. Students indicated a direct awareness of how professors represented LGBTQ+ language in their interactions, such as "my professors have almost all been very caring and sensitive to different identities and careful with the language they use," and "she [department chair] used inclusive language sincerely and naturally." In addition to faculty making specific efforts, students felt included when faculty sought additional training, as in "faculty were open to receiving this training and aware that they could improve and that they were not meeting the needs of LGBT students.”

Peers were considered to be inclusive when they were receptive to gender diversity and did not demonstrate microaggressions. Students described positive settings where "students with which I work that are more open to non-conforming gender identities," and "fewer intolerant and mean people." The description of "cohort is very open minded" appears to capture an inclusive environment where people were willing to learn, and also shows how inclusion can emerge from efforts to seek training and knowledge about LGBTQ+ needs. 
Connection. The theme of connection focused on establishing meaningful relationships with peers, and included allies, and community. Students reported friendship and feeling understood. Having contact with others with shared identities and allies promoted inclusion, as in "meeting a few other girls that aren't straight," and “finding LGBTQ allies." Connection was related to the broader community, such as "Finding things in the community that I can engage with." Given that friendships and allies were inclusive factors, examining ways to provide students with opportunities to show their support for one another may promote inclusion.

Concealment. The theme of concealment is noteworthy because of how it represents inclusion based on personal decisions to hide identity. LGBTQ+ students described both their efforts and others' perceptions as an important factor, such as "stealth, so everyone in my graduate program thinks I'm a cisgender guy," and "my identities are fairly easy for me to hide so that I am able to pass as straight and cisgender." Students described taking deliberate efforts to conceal identity and pass as the dominant group, e.g., "hide most physical markers of my queerness," and "I am able to pass as straight and cisgender." Concealment also included not telling others, as in "I'm only out to a handful of my classmates." It should be noted that some students expressed that they did not anticipate any issues with having their identities known, yet still chose not to disclose, as in "I haven't came out to any of my professors as I don't feel there is a need, but I don't see them having any problems." Although concealment was related to increased inclusion, concealing identity may indicate underlying concerns about acceptance, and concealment itself could require significant additional social and 
emotional effort to maintain. For LGBTQ+ student, the presence of potential antiLGBTQ+ antagonism, its resulting microaggressions, and fear of disclosure, may make concealment a viable potential strategy to employ, regardless of how it may affect an individual's sense of self.

\section{Disability}

Of the 104 graduate students within the study 28 , or $27 \%$ indicated having a disability. Of the students with a disability, the following disability types were reported: psychiatric disability (29\%), intellectual or learning disability (14\%), and hearing impairment (11\%). Students self-identified and were not required to provide any documentation verifying or attesting to the presence of a disability. Themes for disability for decreased and increased inclusion are in shown in Table 101.

\section{Table 101}

Themes for Disability

\begin{tabular}{cc}
\hline Inclusion & Themes for Disability \\
\hline Decreased inclusion & Exposure, disrespect, reductionist, and barriers \\
Increased inclusion & Disability awareness, asset, equality, and formal services \\
\hline
\end{tabular}

\section{Decreased Inclusion for Disabilities}

Exposure. The theme of exposure reflected efforts to hide the presence of a disability or to pass as non-disabled. Students described specific concerns related to the perception of others, such as, "if my weaknesses are hinted at as negative, I feel exposed," "feel pressure to not appear autistic," and "cautious of disclosing my mental 
health difficulties." Students described conscious awareness of hiding disabilities, as in "I am able to hide most of them [disabilities] in casual settings," and "having unseen disorders (i.e., mild cognitive delay and osteoarthritis) it is difficult for fellow students or professors to see a difference." This desire to hide disabilities and fear exposure was directly related to the work of Kranke et al. (2013), who described how students with disabilities continually navigated feelings of vulnerability based on the perceptions of others and stress related to fear of academic failure. Seeking assistance was considered to be a risky endeavor, as it might mean disclosure of a disability, while not seeking assistance could lead to increased learning challenges (Kranke et al., 2013).

Students experienced heightened emotions when placed in situations that forced them to expose their identities in a public environment. The following example reflects a classroom situation that put a student into an unwinnable bind, "when faculty decides to vote whether to skip over class breaks. However, it is not anonymous, you need to raise your hand if you want a break. For me, then I either have to choose between isolating myself (as my classmates do not want/ need a break, but due to my ADHD (especially hyperactive), I need that break to move), taking a break on my own and risk missing important class information, or learning almost nothing for the rest of the class." At the departmental policy level, graduate programs also set up these same issues, as exemplified the following example about required drug screenings without a policy related to medications, "I take Adderall XR which definitely shows up on the screens. I did not feel comfortable disclosing this information, as I know there is a stigma behind taking ADHD meds (even if it barely levels the playing field." Unfortunately, the 
environment of graduate school may actually reinforce feelings of minority status due to disability, as in "never felt like I had a disability UNTIL I came to graduate school." Students' experiences of stress related to effortful behavioral changes to hide a disability mirrored Barga's (1996) and Greenbaum et al. (1995) research on student decisions about disclosure, and the emotional toll of attempting to hide a disability.

Disrespect and Reductionist. The themes of disrespect and reductionist are related to exposure because of how they reflect concern over negative perceptions from others. Students reported negative responses from faculty related to student disabilities, as in "I have felt like that some teachers are not as patient with my stutter than others. It takes a while to get out certain sounds and I don't like how some teachers look away or don't allow me as much time to talk as others." Disrespect due to communication disorders, such as stuttering, may be related to beliefs about clear speech and language as a predominant paradigm speech-language pathology practice (Ferguson, 2009) and negative attitudes about disabilities (Baladin \& Hines, 2011), which were found to be common for speech-language pathology students. Ironically, for a field that focuses on services for communication disorders, disrespect of students with communication disorder would not have been unexpected.

Disrespect for disabilities as a theme appeared within overall faculty beliefs about the rigors of graduate school, as in "a couple of professors that I worked with seemed to embrace the philosophy that graduate programs should be extremely mentally stressful and did not respond appropriately to demonstrations of poor mental health by the students." General faculty lack of understanding of disabilities appeared similar to the 
work of Murray et al. (2008) and Shaw and Dukes (2001), who described how faculty often lack understanding of modification and accommodations and have limited disability awareness. Although lack of understanding of disabilities may not be uncommon in higher education, it is especially noteworthy within speech-language pathology graduate programs, given how the field itself is founded on serving individuals with disabilities. Barriers. The theme of barrier represented difficulties related to disabilities or related to environments that were not designed for neurodiversity and disability. Students described barriers within the graduate school application process, the disability resource verification process, and within classes. Within the application process, the focus on GRE scores was a concern, "I have a diagnosed LD which affected GRE performance, even with accommodations." Within the disability resource verification process, a student described challenges, as in "I did not feel comfortable utilizing the campus protocol for documenting disabilities in order to receive accommodations." Within the classroom setting, students described multiple concerns, "I always required extended time, was late for class, and had much difficulty paying attention in classes and being prepared," "timelines are geared towards faster moving/thinking profiles," and "struggling to put in more effort because of the environment." Students recognized and described their efforts to be successful, including, "I have to work 10x harder than the majority of my classmates to do something," and "with a physical handicap. This made it difficult to keep up during outings requiring a great degree of walking." A student described the negative effects of the graduate school environment, "I don't feel I was prepared for the extent to which graduate school would affect my mental health." 


\section{Increased Inclusion for Disabilities}

Asset. The theme of asset related to culturally responsive pedagogy (Gay, 2002;

Paris, 2012) and showed how disability could be viewed as a strength that would be beneficial in the learning environment and as a practitioner. Both faculty and peers increased inclusion for students with disabilities by highlighting assets and strengths. Faculty acknowledgement of the benefits of disability included an appreciation of unique attributes, such as "when faculty has approached me and praised me for my 'creative' thinking or off-the-wall questions," and "had an advantage because I could relate more to the students I'd be working worth [sic]." Peers validated the concept of asset through acknowledgement and seeking guidance, as in "during one small group project, another group member recognized that though I was much slower than the rest of the group, I was good at working through the problem and catching details that others missed. I felt included because someone recognized that I had strengths to give to the group despite my weaknesses," and "a friend asked for my input on supporting one of their clients who is on the spectrum and I was able to help." When an asset view was emphasized, students described a new appreciation for their own skills, as in "my brain, despite having really different wiring that can be incredibly detrimental and make me feel like I have a disability, can actually do some really neat things!”

Equality. The theme of equality represented equal treatment and shared appreciation for the universality of individual differences and challenges. Students noted feeling included when they were "not singled out, either as discrimination nor as a basis for special treatment," and when they were considered equal to others, such as "I had a 
professor once tell me that I was just as capable as everyone else." Equality as a universal state was established through statements of shared challenges "everyone has something they have to be brave about," and "everyone is experiencing being away from home and being out of our comfort zone. I feel like this gives everyone an opportunity to see one another as equal.” It should be noted that one student connected equality with environment, as in "working in a special needs camp, because I felt like there was zero judgment," which may represent the benefits of representation of individuals with disabilities in relation to equality.

\section{Shared Themes}

This study included graduate students in speech-language pathology representing five minority identities, as opposed to a study that focused on only one minority identity. The distinct advantage of including multiple minority identities is the ability to examine student identity groups separately and collectively. Separating groups allows for an understanding of unique concerns, while examining shared themes shows potential underlying belief systems that affect multiple groups and encourages broader changes in programs to meet the needs of many minority students of different identities. Given intersectionality, or the holding of multiple privileged and oppressed identities within society, graduate students do not enter into their programs with a single identity. Themes for inclusion from students across multiple identities groupings reflect how diversity and inclusion can be broad concepts that relate to historically marginalized groups. With an understanding of inclusion that recognizes privileges based on identities, it may someday be possible to remove the need to label individuals (Waitoller \& King Thorius, 2016). As 
described by Waitoller and King Thorius (2016), inclusion that comes from combining critical theory with UDL fosters the design of learning environments that could free students from environmentally prescribed identities. In examining themes for decreased and increased inclusion, recognition of diversity of student identities and multiple perspectives is essential.

\section{Shared Themes for Decreased Inclusion for Minority Students}

Shared themes for decreased inclusion related to specific ways in which graduate programs viewed their environments and constituents, and perhaps even society. Speechlanguage pathology graduate programs appeared to operate from the perspective of white, middle-class, female, cisgender and heteronormative, as well as the neurotypical and able-bodied perspective. From a critical theory perspective (Sensoy \& DiAngelo, 2012), all of these identities, with the exception of female, represent privilege within society, meaning that correlate identities using binary categorization systems experience oppression. Although male gender may receive privilege within the broader society, the predominance of females and a female-centric viewpoint grants females privilege within the field of speech-language pathology.

The overarching theme of societal privilege connects the experiences of decreased inclusion for minority graduate students, with privilege demonstrated through microaggressions, stereotypes, barriers, and resulting isolation. Privilege represented lack of awareness and lack of humility of the needs of others who hold different identities, and enabled a range of microaggressions at the macro or environmental and the individual level. In many ways, factors that decreased inclusion were nested within privilege. For 
racial and ethnic minority students, white privilege was central to a range of microaggressions, beliefs of inherent cultural differences, and subsequent isolation. For students from low socioeconomic backgrounds, middle-class and potentially upper class privilege caused similar forms of microaggressions through the devaluation of hidden struggles, related feelings of non-belonging, as well as actual barriers to participation due to financial costs. For male students in a female-dominated field, male and gender-based stereotypes were exclusionary factors. For LGBTQ+ students, cisgender and heterosexual privilege caused microaggressions and antagonism that prompted fear of disclosure and isolation. For students with disabilities, neurotypical and able-bodied privilege resulted in disrespect and reductionist views that lead to fear of exposure, in addition to specific barriers to learning and engaging.

Important shared themes connected certain groups. The theme of hiding, concealment, stealth, and passing as a member of the dominant group was present for students from low socioeconomic backgrounds, LGBTQ+ students, and students with disabilities. Student responses reflected awareness, worry, concern, and outright fear of having their identities known. Students from low socioeconomic backgrounds attended to markers of economic privilege around them and avoided interactions that would show their differences. Of particular concern was how students with disabilities could be placed into situations by policies and faculty member actions that required them to expose that they had a disability in order to receive support. LGBTQ+ students reported a heightened awareness of the significance of environmental and interaction makers, such as the rainbow flag and pronoun use, which related to LGBTQ+ safety and inclusion. 
Even though racial and ethnic minority student and male student responses did not show themes of concealment, they still showed an awareness of the need for behavioral changes. It could be argued that race and ethnicity and male gender are visible identities, whereas low socioeconomic background, LGBTQ+, and disabilities may be more easily hidden. Both racial and ethnic minority students and male students described either being explicitly told to make changes to their interaction style or intuiting that they needed to do so. Given that students reported making specific changes to their behaviors and the emotional toll of trying to keep their identities secret, it may be important to consider how graduate programs do or do not understand this continual demand that students face in their attempts to match privileged identities by adopting the behaviors and mannerisms of the dominant group.

Unfortunately, multiple minority students appeared to begin to understand societal privileges and oppression based on their identities solely from their experiences within their graduate programs. For some racial and ethnic minority students from diverse communities, being in a white-dominated field with continual microaggressions was a new experience. For some students from low socioeconomic backgrounds, they only gained a full appreciation of the financial and opportunity advantages that others had received once they learned more about the admissions and graduate program processes. Some LGBTQ+ students reported existing within a heteronormative environment for the first time, while some students with disabilities directly stated that they did not feel that they had a disability until they were functioning within their graduate school environments. Interestingly, male students, who are considered to have privilege within 
society, appeared to be more subject to the negative stereotypes about masculinity than supposed positive stereotypes related to leadership.

Although multiple themes were shared, it is important to note unique elements for male students and LGBTQ+ students related to fear. Male students reported feeling viewed as a threat by others, whereas LGBTQ+ reported feeling fear of harm from others. The presence of fear, either being feared or being fearful are significant because of the intensity of the emotion and its potential negative effects in learning environments. Male students also shared themes with disability, in that both groups reported situations in which they felt that their identities were reduced to one identity marker, or they were not seen as complex individuals. Both male students and students with disabilities received what may have been intended to be compliments for their presence in the field, but in actuality were microaggressions that emphasized non-belonging.

\section{Shared Themes for Increased Inclusion for Minority Students}

Shared themes for increased inclusion showed the different ways in which graduate programs supported minority students. Speech-language pathology graduate programs that increased minority student inclusion appeared to take deliberate steps to demonstrate recognition of multiple identities by fostering opportunities for students to show their strengths and ensuring connections between students. Students frequently noted efforts, actions, or situations that countered narrow or limited identity perspectives, or reduced any appearance of privileges being granted to certain identities over others. Although different themes for inclusion emerged for each of the identity groupings, there were shared themes related to asset, connection, and equality. 
A highly important theme across identity groupings was the concepts of asset, which aligned with culturally responsive pedagogy (Gay, 2002; Paris, 2012). Asset, which represented a conscious recognition of the strengths that minority students bring to the field, was present for race and ethnicity, low socioeconomic background, and disability. Students described how their presence was an asset to the field and how they would be able to understand and relate to clients from diverse backgrounds. Beliefs about being an asset to the field were validated through experiences in which minority students could share their knowledge and through direct statements, often from faculty members, about how they were needed in the field. Positive experiences related to being able to provide guidance or teach peers and clinical opportunities to serve clients with similar backgrounds. When academic discussions and clinical work enabled students to play a role as having expertise based on their life experiences, they felt included and valued.

The shared theme of connection or community also appeared across multiple identity groups, specifically race and ethnicity, low socioeconomic background, and LGBTQ+. Student responses showed how connection and community were centered on relationships with peers with similar identities, peers who had a general understanding or were accepting of diversity, and positive personal contact with faculty members. Even when there were a limited number of students with shared identities, opportunities for connection were made when students were able to show their support for one another, and when students were engaged with university and community level resources. The themes of connection and community directly countered student isolation and nonbelong. 
The shared theme of equality appeared for race and ethnicity, male within speechlanguage pathology, LGBTQ+, and disability. In some ways, equality could be viewed as the absence of privileged identities, in that equality represented students' belief that there were no identity groups were receiving more or less advantages or benefits than any other identity groups. Equality was described through the concepts of fairness, sameness, and being treated equally to one's peers. When examining the theme of equality through UDL and critical theory, the absence of majority and minority identities allows students to enter into the learning environment knowing that they will be recognized as individuals without pre-existing or environmental prescribed identities (Waitoller \& King Thorius, 2016).

One additional set of themes is of interest. The similarity between the themes of expectations for race and ethnicity, and concealment for LGBTQ+, are unique, as these themes both reflect a pre-existing understanding of societal inequities and expectation of the likelihood of discrimination. Themes of inclusion that relate to a prior life experiences with systemic oppression are in some ways paradoxical, as students connected increased inclusion with not expecting to be included or hiding their identities. Within race and ethnicity, students who did not have high expectations for inclusion appeared to report greater inclusion, as did LGBTQ+ students who concealed their identity. Knowledge of larger systemic issues within institutions may serve as a meaningful factor in how students experience inclusion in their graduate programs. Given that knowledge itself allowed for measuring of expectations and conscious choice in presentation of identity, graduate programs could explore student understanding of larger societal issues. 
Shared themes for increased inclusion across identity groups showed an interesting combination of factors, which may initially appear to contain contradictions. Factors that decreased inclusion related to privileged identities; however factors for increased inclusion appeared to be related to differences in treatment, addressing the end result of privilege, and the release of identities. One of the themes for increased inclusion, asset, was related to highlighting minority students' unique contributions (Paris, 2012), which although positive, could be argued as a form of different treatment. When students are specifically shown or told that their life experiences and skills offer a needed perspective, this potentially positive experience may actually be a form of differential treatment or separates students from each other. Even though the theme of asset shows how to challenge who should receive privileges, it may benefit from more investigation to explore the significance of separating students by their identities, even in positive ways.

By contrast the theme of equality showed how students felt included when they felt that all of students in their program were treated the same. Even though asset and equality may seem at odds with each other, they may both be methods that address the underlying factor of program design through privileged identities. The theme of asset addressed privileged identities by deliberately demonstrating to minority students that their identities were wanted and needed, when this information would not otherwise have been apparent. The theme of equality addressed privileged identities through the removal of outward markers of privileged treatment so that students felt that they were judged on their own individual merits and not through their identities. Furthermore, a similar set of 
themes related to support for low socioeconomic background and disability services for students with disabilities could also appear to be differentiating identities, however, from an equity perspective, these supports and formal services promoted equality by providing resources where needed. Students reported increased inclusion with supports and services, which could have been related to increased likelihood of receiving equal treatment, or being perceived as equal to others.

In many ways, the third theme for increased inclusion, which was the combination of connections and community, could be construed as addressing the symptom or resulting condition, as opposed to the underlying problem or larger issue. The themes of isolation and non-belonging within decreased inclusion could be considered as the resulting effects of privileged identity perspectives. Connections and community reduced this isolation and non-belonging. Even without attempts to enact changes that could challenge privileges within a system, positive relationships with others that included shared understanding, support, and being part of a community were beneficial.

Although shared themes for increased inclusion provide valuable information, these themes should not be viewed independently from shared themes for decreased inclusion. In order to address the first research question of how minority students experience inclusion in their graduate programs, comparing the relationship between themes for decreased and increased inclusion offers more information. When combining themes across identity groups, central factors for inclusion were related to the privileging of identities and attempts to address or mitigate this privilege. From a UDL and critical theory perspective, purposeful planning for multiple identities within the learning 
environment, i.e., preparing for different student identities, recognizing the forces of privilege within society, and working to mitigate systemic privileges are part of increasing inclusion for minority students.

\section{Peer Advice}

An additional aspect of understanding the first research questions of minority student experiences of inclusion was examined through peer advice. Minority graduate students were prompted to offer advice to another minority graduate student. The advice that students provided to a hypothetical minority peer was analyzed collectively with all identity groups together. Analysis focused on meaningful verb use to gain an understanding of how minority students positioned themselves in relation to social goods (Gee, 2014) and their agency (Bandura, 2002) within the graduate program experience.

Positioning shows how the use of language places a writer and a reader as having degrees of access to social goods and services, which are tangible and intangible commodities of value in society (Gee, 2014). A social good could be money, material objects, friendship, influence, and more (Gee, 2014). Positioning showed student beliefs about their relative access to social goods and services within their graduate programs. Agency referred to three types of agency: personal agency as the belief that one's own actions further one's goals, proxy agency as the belief that another person can help further one's own goals, and collective agency of ho groups of people can work collaboratively to achieve a shared common goal (Bandura, 2002). Positioning and agency enable an examination of how graduate students view themselves in relation to others within the learning environment, and the ways in which they attempt to meet their 
goals. Access to social goods may relate to social standing, status, and privilege, and agency may relate to efforts and ability to exert control within the environment. An understanding of how students view themselves and their means of exerting influence within their graduate programs in relationship to inclusion provides important information. Examinations of position and agency show how the environment does or does not grant students social access and does or does not foster beliefs in their own ability to make changes. The 12 themes for peer advice are shown in Table 102. These themes in relation to positioning and agency are discussed in the following section.

\section{Table 102}

Themes in Peer Advice to Another Minority Student

\begin{tabular}{lc}
\hline Writing Prompt & Themes \\
\hline Peer Advice & $\begin{array}{c}\text { Choosing a graduate program, planning and expectations, seeking } \\
\text { support, fortitude, perseverance, advocacy, diversity, mission, } \\
\text { education, relationships, self-worth, self-awareness }\end{array}$ \\
\hline
\end{tabular}

\section{Choosing a Graduate Program and Expectations}

The themes of choosing a graduate program and expectations reflected advice prior to beginning a graduate program. It is noteworthy that students offered advice to other students that began within the graduate application process, which may indicate the importance of this stage. The theme of choosing a graduate program showed students as in need of the social goods of information and being required to use personal agency to acquire knowledge of graduate programs, such as "ask about what the programs are doing to directly address issues of inclusion within their programs," and "do research before 
you decide where to go." The theme of expectations was similar to the theme of choosing a graduate program in that it referred to personal agency in preparing for the upcoming graduate school experience. The theme of expectations showed that students recommended the use of personal agency to manage beliefs about social interaction, gain knowledge, and mitigate threats to loss of social goods. Students were advised to use personal agency to maintain positive beliefs systems and manage emotional responses based on implied upcoming lack of access to social goods, such as "assume people are generally nice," and "develop an inner strength." Students were advised to use personal agency to acquire knowledge in considerations of diversity, such as "be ready for a changing world by learning how to serve people of all identities" In some instances, advice openly acknowledged that loss of social goods should be expected, such as "be aware to be overrun by entitled white women," "you'll have to deal with the usual dumb questions and microaggressions," and "warn them to be prepared to have to hide it or become the token." In choosing a graduate program and understanding what to expect in a graduate program, minority students advised a peer to exert personal agency to gain knowledge, manage beliefs, and navigate loss of social goods. In regard to inclusion, minority students showed how the graduate school environment requires them to exert personal agency to mediate lack of access to social goods. An inclusive environment would not contain expected threats to lack of social goods and require personal agency to bear these threats. 


\section{Seeking Support, Fortitude, and Perseverance}

The themes of seeking support, fortitude, perseverance all showed personal agency and personal responsibility to gain social goods, maintain an internal state, and cultivate a belief system. The theme of seeking support placed minority students as active agents in seeking out social goods, such as "find a mentor," "make friends outside your program," "try to find at least one person that you can relate to," and "seek help from your appointed adviser, mentor, or from campus resources." Seeking support showed how students are required to engage in effortful work to access social goods. Similarly, the themes of fortitude and perseverance positioned students as needing to use personal agency to maintain a positive internal state and managing beliefs.

The theme of fortitude encompassed personal agency to manage potential or expected loss of social goods, such as "tell them not to feel alone," "don't get downy [sic] you will find your people," "not to let their race make them insecure, and "do not worry about the people that make you feel left out." As with the theme of fortitude, the theme of perseverance positioned students as having a lack of social goods, and in need of support or encouragement, which could be internal as personal agency or from a peer as form of collective agency. Interestingly, the theme of perseverance placed the writers in the position being in allegiance with the reader, as in "please never give up because it is not like we ever had the upper hand," which showed a collective agency with minority students understanding and supporting each other. Advice included strategies to depersonalize the graduate school experience and maintain a focus on goals. Depersonalizing the experience may be a method to mitigate significant loss of social 
goods, as in, "continuing your education is a business transaction," and "know that your program and experiences with your professors are temporary." Goal focused advice may have been a strategy to ignore external lack of access to social goods for a greater purpose, such as "power through," "never give up and do everything you can, and "you will overcome all the challenges you face." On the whole, the themes of seeking support, fortitude, and perseverance, all placed students as losing social goods and needing to use personal agency to navigate these losses. The encouragement that appeared within the theme of perseverance also spoke to the potential for collective agency within minority communities.

\section{Advocacy, Diversity, and Mission}

The themes of advocacy, diversity, and mission all centered on diversity as a main concept and addressed diversity in different ways. With the theme of advocacy, students acknowledged diversity and how the presence of diversity required advocacy, such as "be an advocate for yourself and others with diverse characteristics." Students positioned themselves as needing to use personal agency to address diversity, and to increase access to social goods for others within collective agency, such as "educate others on your needs," "explain kindly why what they said or did was inappropriate and a better way of expressing themselves," and "teach about the positives that come along with neurodiversity, not just the negatives."

The theme of diversity directly placed diversity as an asset, as in "proudly represent your background/culture," and "your background strengthens your experience and makes you more marketable. Consider and integrate it into your clinical lens." 
Within the theme of diversity, minority graduate students repositioned diversity as a valuable social good, which directly contrasted with beliefs that diversity prompted a loss of social goods. In connection to diversity as a meaningful social good, the theme of mission, reflected collective agency in that minority students described goals to bring social goods, such as access and opportunity to a larger community. Students described moral imperatives of grading of social goods and restated how diversity was itself a valuable social good, such as "time for you to pave the way for someone else just like us," "you will add to this profession what it most desperately needs," and "they would be making a huge impact on future clients because few SLPs are minority members." The themes of advocacy, diversity, and mission included placed minority students as having intrinsic valuable social goods and showed collective agency with peer-to-peer support as a method to improve outcomes for minority students.

\section{Education and Relationships}

The themes of education and relationships have connections in regard to a larger community. The theme of education described personal agency to acquire the social goods of knowledge; however, the outcomes of this learning in the form of clinical expertise were placed in the service of others. Even though education may initially appear focused on personal agency, it could also serve as a form of collective agency with students anticipating serving positive role in a larger community, such as "learn and understand the best way to help our future clients and community," "be open to any and all experiences," and "apply that knowledge in a setting that excites you." The theme of relationships described community, and emphasized collective agency, as in "concentrate 
on your cohort relationships," and "it's easier going through the ups and downs with someone who is also experiencing them." Collective agency in relationships appeared related to sharing trials and supporting others. Both education and relationships empower students by recognizing how their actions benefit themselves and others. In other words, students could view their academic program and their peer interactions as serving important dual purposes.

\section{Self-Worth and Self-Awareness}

The themes of self-worth and self-awareness reflected both personal and proxy agency. Minority students provided affirmations to peers as a form of proxy agency to counter negative external forces and to encourage positive belief systems and manage one's own self-understanding with personal agency. For the theme of self-worth, students positioned peers as having intrinsic social goods, in the form of personal strengths, such as "you deserve to be where you are and you are just as awesome, intelligent, and amazing as everyone else," and validated their presence within the program, "know that you are enough and that you deserve to be there." Sadly, these types of encouragements show an understanding of significant lack of social goods for minority students within their graduate programs. This lack of social goods may cause self-doubt, which prompted assertions of worthiness, such as "you have earned your spot there" and "knowing that they got into their program because they deserved to academically." The theme of selfawareness also involved positioning minority students as having intrinsic social goods or value that was related to their identities, as in "remember who you are." Students encouraged peers to increase their own self-awareness, such as "know your strengths and 
know where you might fall short," and "listen to your gut when it tells you where you fit the best and let that feeling guide you throughout your graduate school experience." The themes of self-worth and self-awareness showed that students are required to use personal agency to maintain positive beliefs in their positions with their graduate programs, and likely have the desire to provide encouragement to others.

\section{Peer Advice and Inclusion}

The themes for peer advice provide corroborating views of the graduate school experience as a place where multiple factors decrease inclusion. Peer advice showed how graduate school could be a setting in which minority students are expected to lose social goods and need to use personal and collective agency to manage these losses. Analysis of peer advice showed how minority students must use personal agency to attempt to locate graduate programs that value diversity and plan for loss of social goods once they are in their programs. The themes for seeking support perseverance, and fortitude showed personal agency and purposeful efforts to mitigate lack of social goods through seeking out connections and maintaining positive belief systems. The themes of advocacy, diversity, and mission repositioned minority students as having intrinsic social goods by describe diversity as a social good in its own right. When diversity was reframed as a social good, students then used collective agency to maintain this new understanding and promote this view. The themes of education and relationships furthered the collective agency related to diversity with students positioning themselves as helping each other and positively supporting a future community. The themes of self-worth and selfunderstanding reflected the results of lack of inclusion, as significant lack of inclusion 
could be a causal factor in self-doubt. Advice related to self-worth and self-understanding asserted that minority students had intrinsic social goods in the form of internal characteristics and that they should use personal agency to connect with these strengths.

Minority graduate students offering recommendations to peers to navigate their graduate school programs show how students are experiencing inclusion. Giving advice to a peer is an alternate means for examining the individual's own experiences. When giving advice, students were prompted to reflect on situations that have occurred, their coping mechanisms, and perhaps what they wish that they had known. In reviewing the themes for the peer advice, minority students described a setting where they needed to believe in themselves, redefine diversity as a positive characteristic, support each other, and validate their own presence within their programs.

\section{Program Recommendations}

To answer the second research question, minority students provided recommendations for graduate programs to increase inclusion. Minority students' recommendations were analyzed collectively to provide an overall understanding of ways to promote inclusion for students regardless of identity. As with peer advice, analysis focused on meaningful verbs to show positioning in regard to social goods. Themes for program recommendations are shown in Table 103. 
Table 103

Themes in Student Recommendations to Program

\begin{tabular}{cc}
\hline Writing Prompt & \multicolumn{1}{c}{ Themes from the Prompts } \\
\hline Recommendations to programs & $\begin{array}{c}\text { Recruitment, curriculum and clinical, awareness, } \\
\text { connection, faculty education, resources, equality } \\
\text { and tokenism }\end{array}$ \\
\hline
\end{tabular}

\section{Recruitment}

The theme of recruitment positioned faculty and university program has having the ability, or social goods, and in some cases, the moral obligation to make efforts to change the demographics of students and faculty to increase diversity. Recruitment recommendations included public awareness, the student and faculty diversity, and access. For public awareness, within the theme of recruitment, students recommended general outreach, such as "advertise to all types of people," along with targeted outreach to specific groups. Recommendations for targeted outreach included different educational levels and communities. Educational levels extended across school settings, "education about our field as early as middle school or high school would help," "our profession is not advocated for in high school as a viable option and especially with our bilingual communities," and "advertise/recruit at different types of undergraduate institutions."

Targeted recruitment for communities showed broad and focused groups, such as "recruit a diverse cohort \{not just race or ethnicity but mindful of all intersectional identities \}," and "more males need to be informed about the nature of the work that SLPs perform." Recommendations for recruitment specifically countered limited efforts to reach only privileged groups, such as "reaching out to low-income minority 
communities" and "advertising and promoting and going to job fairs in places that are not mostly populated by middle to upper class white people." Furthermore, recruitment was also described as a method to address lack of representation and recognize intersectionality, as in "recruit minority students, so that no one is the token (only) Black, Asian, LGBTQ, etc. . . . student in the classroom," and "diversifying the student body in general is bound to bring in more queers."

For the student and faculty diversity, students recommended an examination of admissions procedures, changes in who is admitted, and changes in hiring practices. Minority students recommended procedures that addressed underlying systems and provided more holistic assessments of students, such as "understand how they decide who gets into their programs," "look beyond grades and tests [sic] scores to see the person. To see what they have to offer," and "allow students to submit a personal statement and conduct an interview during app. Process [sic].” Additionally, students recommended changes to who is admitted in specific and general ways, as in "get more men in the program," "Accept more students of different races, social classes, sexes, and sexual orientations," and "accept more people of color into your department." The recommendations for diversification included rationales or moral imperatives, such as "by diversifying the field we allow our clients to see themselves reflected in us," and "multicultural therapists are needed to relate to and treat multicultural clients." Along with declarations of the need for diversity of students, students recommended changes in hiring to prioritize diverse faculty, such as "hire more diverse faculty" and "hire people of color to work in your department. As with student diversity, faculty diversity 
contained rationales, as in "hiring minority professors demonstrates that not only is the student and differences welcome, but also that they are necessary within the field."

For access, financial requirements, limited availability of programs, and preparation were concerns. Students recommended addressing costs, as in "cost would be something to consider. It was very difficult to attend due to the cost," "admit and fund more non-traditional, poor, disabled, and culturally and linguistically diverse students" and "make graduate programs more accessible for minorities." Along with cost, competitiveness due to availability was problematic, as in "the limited availability of seats for graduate programs is a separate issue I'm more concerned about." Furthermore, students also recommended increased access through the provision of information about expectations, such as, "expose students to what grad school will be like so they are adequately prepared before the first day of classes."

\section{Curriculum and Clinical}

The theme of curriculum and clinical positioned faculty as having the social goods, through the power of their roles and their knowledge base, to make changes in the presence of diversity within courses and clinical work. Recommendations focused on specific courses, course content, teaching practices, and clinical interactions.

Students made recommendations for specific courses that addressed diversity and provided a rationale for their purpose, and suggestions about the content and design. Students focused recommendations on future clinical work, such as "more courses on how to work with minority children's [sic], how to go into a minority household and treat our kids the same way" and "provide more courses on cultural competency because most 
of these students will end up working with a population that includes minority clients." Students recommended course design that included guest speakers and ethics, as in “create a class specifically about different minority groups, which would feature guest speakers who come from those minority groups," and "require students to take an ethics course that teaches the proper way to include and serve diverse populations."

In addition to recommending specific courses, students made recommendations about specific course content that included different topics related to diversity. Students recommended content related to minority identities, systemic inequities, and timing of content. Examples of content for minority identities included "training and education around the gender spectrum, identities, and language to use needs to [be] standard across programs," "talk about dialect differences and why they matter," and "talk about differential diagnosis and how to assess those who are minorities." It is worth noting that students recommended comprehensive methods to address diversity and equity, such as "provide more training on cultural competence," "efforts to learn more about the marginalized groups and issues of equity that all SLPs will likely encounter-not as an 'optional course,' but integrated throughout the program," and "talk to your students about implicit bias because it exists!" Additionally, students noted the timeliness of information on societal inequities, specifically, "require anti-oppression training for students at the beginning of the program."

In the area of teaching practices, students made recommendations related to faculty language use, minority student contributions, peer interactions, activities, and finances. Recommendations on language use focused on faculty use of inclusive 
language. Recommendations for minority student contributions valued the experiences that minority students bring to the learning environment, such as "encourage minority student to share their stories with their peers," and "give students of different backgrounds the opportunity to work with one another and learn from each other." Peer interactions included an understanding of positive and negative dynamics, such as "discussions about diversity within the cohort and how we can all respect and learn to understand each other," and "be aware of the groups that you are assigning us to (not all people are welcoming or friendly)." For classroom activities, students recommended that faculty "provide multi modal access to materials, activities, and supports," and "give time to students to give the response they want to give to question." Additionally, students noted the need for faculty to "avoid requiring classes or assignments that add cost."

In the area of clinical interactions, students recommended policy changes, cultural awareness training, and diversity in externship placements. For policies and clinical training, student recommendations included "attempt to make clinic policies and language less hetero-normative," and training for students to be "more aware of cultural differences, which is knowledge they can apply on their own patients/clients and also with other staff." Students appeared to recognize larger level concerns, such as externships, as in "graduate programs need to make sure there are placement opportunities with all populations.”

\section{Awareness}

The theme of awareness represented recommendations for faculty to gain an understanding or recognition of social issues for minorities. Faculty members were 
positioned as both holding and lacking social goods. Faculty members lacked expertise in regard to knowledge of the needs of minorities, yet held social and political power. The contrasting presence of power and lack of knowledge meant that intended or unintended abuses of power were possible, which reduced inclusion for minority students. On a positive level, student recommended that faculty "affirm their [students'] experience and acknowledge that their experiences hold value in the field," and shared how "actively respecting and celebrating differences promotes a safe and welcoming environment." In response to negative situations, student recommendations highlighted harm from lack of awareness, such as "recognize your microaggressions and realize that I've been going through this my whole life," and "do not be ignorant to the REAL issues that affect minorities daily." Furthermore, students recommended understanding of visible and invisible minority identities and advocacy, as in "be aware \& supportive of students who may have minority status that is not visible," "increase awareness about learning disabilities/differences/disorders," and "help people understand that people with learning disabilities are not stupid."

\section{Connection}

The theme of connection described how programs and faculty members could establish community and facilitate connections. Faculty members were positioned as having the social and political power to grant opportunities to students.

Recommendations for connections were at the individual faculty level, community building events, and communication. At the individual faculty level, recommendations 
related to personal connections and mentorship, such as "try to get to know people at an individual level," "do more phone calls to check in," and "assign a mentor."

For community building events, students recommended that faculty "create more opportunities for socializing outside of the classroom, such as study groups or group projects," "orientations, retreats, any opportunity for people to come together and learn about one another," and "providing more public space for student get-togethers would be nice." Students provided specific strategies for community building, such as "focus on icebreaker activities so we can get to know each other on deeper levels" and "have someone hired as an activity counselor to create 'get together' programs." It should be noted that male student recommendations recognized lack of representation and offered suggestions, as in "colleges that were close to each other helped connect the men so that they could have the option to go to conferences together."

In regard to communication, students recommended online mediums and affinity groups. Online groups through social media were considered to be a form of community, such as "put us in a Facebook page with our classmates and have a retreat so we get to know each other," and "offer groups where people of similar backgrounds/identities can create an online community where they are comfortable sharing whatever they want to with each other." Students appeared to acknowledge that faculty had the power to ensure that students were given the "opportunity to interact with most if not all students in the program." 


\section{Faculty Education}

The theme of faculty education positioned faculty members as lacking expertise or lacking social goods related to information about diversity. Positioning faculty members as learners challenged the social and political power that they have within academia and positioned students has having the social goods of knowledge of diversity. This reversal of roles placed students as resources, while still acknowledging hierarchies within the academic system, such as "solicit feedback from students on a regular basis and students should be able to provide this feedback anonymously without any fear of retaliation." Faculty education related to viewing students as resources, openness to learning, and training about diversity.

Recommendations included "be open to further education about different identities and perspectives," "learn about minorities so that they aren't so novel," and "see more reminders for faculty, staff, and students that people with disabilities are an integrated part of our world, including graduate programs and professionals." Students placed faculty as needing training at the programmatic level, as in "training for professionals who lead programs because they should understand the cultural differences that affect minority students" and "working to increase visibility of their diverse populations within the program." At the core of the faculty education recommendations was the rationale of the importance of diversity, as stated by a student, "it is UNETHICAL to be a primarily white cis-female field when we are treating a population that is MUCH more diverse than that." 


\section{Resources}

The theme of resources focused on program creation of supports and faculty provision of information about university and national or federal level resources. Faculty members were positioned as having the social and political power to offer or withhold information, which was an essential social good that students needed. Financial resources related to scholarships and student resources related to university supports.

Recommendations related to creating supports included "offer scholarships and local opportunities," "create scholarships for minority students pursuing speech-language pathology," "offer scholarships, aid, GA positions to those who need it." Faculty were advised to "coordinate with other professors to reduce textbook costs for students" and find ways of "rewarding students with a percentage of dues paid for national professional affiliations." Faculty roles in providing information were related to finances and affinity identity groups, such as "students be directly provided information about counseling resources and financial assistance," "make students aware of the minority alliance services offered by the university," and "making it easy for students to access resources that serve their identities."

\section{Equality and Tokenism}

The themes of equality and tokenism worked together to show how faculty have the ability to grant different levels of social goods to students, meaning that faculty can give or remove privileges to students. Faculty members demonstrated tokenism when they singled out students within the classroom or required them to serve as a spokesperson. Student described tokenism in direct terms, such as "don't call the 
difference out," and "do not single out students for any reason." Tokenism was a concern in relation to race and ethnicity, as in "do not have a student of a different ethnicity speak for their whole ethnicity in class." By contrast, faculty members demonstrated equality when they made efforts to show that all students have equal opportunities and equal value. Students provide recommendation to "treat everyone the same and offer the same opportunities to every student," and "equally represent all and not place focus on those that are common." It should be noted that the use of the term "common" may be indicative of minority student awareness of a typical or common student profile that aligns with dominant identities within society and within the field.

\section{Envisioning Inclusion}

The third research question sought to answer the question of how minority graduate students envisioned inclusion through the creation of an inclusive recruitment flyer. A total of two students, or $2 \%$ of the participants completed and submitted an inclusive recruitment flyer, although 18 students originally expressed interest. The two flyers were examined through Saldaña's (2016) guidelines on analyzing visual data for the imagery, and Gee's (2014) discourse analysis for the written text and accompanying images.

Visually, themes from the two flyers related to photographs of racial and ethnic minorities, smiling individuals, multiple colors and color elements, and people of different ages. In a general sense, both flyers appeared to present diversity through positive images of happy people and bright color combinations. Information from written text was analyzed for visual presentation and content. Visually, both flyers used a large 
font size to feature the career title of "speech-language pathologist" as a prominent feature and showed prospective young and old clients. It is noteworthy that both flyers ensured that audiences would recognize that the career featured across the lifespan care with clients of different ages. One flyer emphasized clinical care and featured a medical setting, while the other flyer emphasized community or camaraderie and featured a group of college-age people together. Only one of the two flyers featured individuals who likely be perceived as male.

In analysis of the written text, both flyers placed diversity as valuable social good, and used moral imperative or collective language, specifically, "be part of a rewarding profession that needs you" and "speech language pathology needs you." These directives aligned with mission and asset-based view of diversity. Specific terms used also showed larger belief systems. The use of the term "rewarding" to describe the profession reflect a belief system of positive feelings about employment in relation to benefiting society. The verb "need" connected to a larger cause and may represent collectivist beliefs about achieving a common good together.

The flyers featured different aspects of identity. One flyer described client profiles based on race and ethnicity, age, religion, sexual orientation and gender, while the other flyer used text that focused on speakers of multiple languages. It is of interest that both flyers featured text that was only in English and that both flyers provided links to the national association. If students view ASHA as a source of valuable information or an entry point in the recruitment process, it may be beneficial to examine if and how topics of diversity are featured on ASHA career information webpages. 
One of the two students who completed an inclusive recruitment flyer participated in an interview about the experience of creating a flyer. Themes form the interview included positivity, friendliness, and enticement to foster interest, visual representation of people of Color, increased public awareness and focused recruit in minority communities, and mission to ensure that clients had clinicians of Color to provide services. During the interview the student described the importance of having clinicians who reflected the diversity of clients, as in "the field is dominated by Caucasians, a lot, and, I mean, at least where I live the clientele is really diverse, and doesn't necessarily ref-, you know, the, the therapists don't, or even the teachers in schools, whatever, don't reflect the, uh, the kids or the clients."

On the whole, analysis of the inclusive recruitment flyers showed that representation and mission might be essential to envisioning inclusion. Representation through the presence of people of Color and corresponding visual use of color, and language that related to a mission, or larger purpose portrayed a field where diversity was an asset within diverse communities. Although only two students created a flyer and only one student participated in an interview, their participation provided important information that aligned with the other data sources. A potential follow-up study focused exclusively on the creation of an inclusive recruitment flyer could provide interesting data that could be used by university programs and the national association in their recruitment efforts. 


\section{Implications}

This study examined minority student experiences of inclusion in speechlanguage pathology graduate programs to answer the research questions of how minority students in speech-language pathology graduate programs experience inclusion, recommendations that minority students have for graduate programs to increase inclusion, and how minority students envision inclusion. Student responses for each question were analyzed to determine themes, and examine potential similarities across minority groups and potential congruence across research questions. Based on analysis of the data, it is important to describe the underlying design of speech-language pathology graduate programs in relation to inclusion in order to answer the research questions.

\section{Underlying Design}

Student responses showed that in many ways their graduate programs appeared to be designed and operate from the privileged identity perspective of white, middle-class, female, cisgender, heterosexual, able-bodied and neurotypical. As previously shown in the synthesis portion, a summary of themes for each research question, as shown in Table 104, revealed restricted privileged identities, which formed a narrow or prescribed student identity profile. 
Table 104

Summary of Minority Student Themes in Relation to Research Questions

\begin{tabular}{lc}
\hline Research Question & \multicolumn{1}{c}{ Summary of Themes } \\
\hline Experiencing inclusion & $\begin{array}{c}\text { Inclusion increased with specific faculty and student efforts to } \\
\text { mitigate or counter the existing design of graduate } \\
\text { programs based on privileged identities of white, middle- } \\
\text { class, female, cisgender, heterosexual, able-bodied and } \\
\text { neurotypical student identity profile }\end{array}$ \\
Program recommendations & $\begin{array}{c}\text { Increase diversity through minority student and faculty } \\
\text { recruitment, expansion of curriculum and clinical topics } \\
\text { and services, faculty education and training, student and } \\
\text { faculty connections, availability of resources, and equal } \\
\text { opportunities }\end{array}$ \\
Envisioning inclusion & Representation, mission, public awareness, and happiness \\
\hline
\end{tabular}

Programs operating solely from the perspective of the set of privileged identities of white, middle-class, female, cisgender, heterosexual, able-bodied and neurotypical were not inherently inclusive to minority students because of systems, policies, behaviors, and interactions that made false assumptions about students, granted privileges to certain groups over others, and did not show awareness of the needs of minorities.

Factors that increased inclusion appeared related to the absence of the privileged identity perspective, efforts to mitigate the effects of this perspective, and efforts that deliberately countered this perspective. The absence of the privileged identity perspective appeared in the themes of equality, representation, and resources, in that all students had equal opportunities, felt represented, and had access to the resources that they needed. Efforts to mitigate the effect of the privileged identity perspective represented actions that addressed improving feelings of separation or isolation that arose from this perspective, 
such as developing community, making connections, finding role models, and receiving support. Efforts to counter the privileged identity perspective related to a repositioning of diversity as an asset, an integral part of academic coursework and clinical training, and an important role in a greater mission, or as a means for collective improvement in client outcomes.

\section{UDL and Critical Theory}

The three research questions of minority student experiences of inclusion, program recommendations, and envisioning inclusion were founded within UDL and critical theory. In answering these research questions, shared themes emerged that connected to UDL and critical theory in regards to design and identities. UDL includes three key elements exemplified in its name (Meyer et al., 2014). Universal refers to an expansive view of learning and learners. Design, which originates in architecture, is the purposeful creation of a space, which in this case is a leaning environment, with learning as the ultimate goal for student success. UDL considers the learners, the learning process, and the learning environment. Based on student responses, speech-language pathology graduate programs appeared to be mainly designed for singular learners, as exemplified by a student program recommendation, "broaden your perspective beyond the 'typical' enrollee."

\section{Levels for Interception}

From a UDL and critical theory framework it is possible to consider levels of interception in promoting inclusion. The UDL and critical theory framework show how narrowly defining the identities of students perpetuates historic inequities. In answering 
the research questions related to inclusion, it appeared as if inclusion was increased through the absence of the privileged identity perspective or an inclusive identity perspective, efforts to mitigate behaviors based on this perspective and their effects on students, and efforts to counter this perspective. These three factors could be viewed through levels of interception or layers within the problem. Efforts to increase inclusion could be viewed through levels of interception or layers in which to interrupt this system, specifically underlying social constructs, environment, and symptoms. As a sequence, the underlying social constructs of privileged identities create an environment with behaviors that decrease inclusion, which result in minority student lack of opportunities, identity threats, and isolation. Each level or layer could have different types of recommendations.

To address underlying social constructs, graduate programs would want to examine how their very design constructed hierarchical identity categories and inherently limited perspectives to those of privileged identities. In considering examinations of privilege and identity, recommendations were related to faculty education and training, and faculty hiring practices. In contrast to addressing underling beliefs, changes at the level of environment related to policies and practices that demonstrated inclusion. Changes to policies and practices, such as diversity topics within coursework and clinical experiences, as well as teaching practices that encouraged interaction and valued minority student contributions, could increase inclusion. It should be noted that more information would be needed to examine interactions between changes in the environment and their potential role in any changes in belief systems. 
At the level of addressing symptoms resulting from exclusion, interception would address the negatives effects of the behaviors faculty and peers that originated from a privileged identity perspective. Minority student experiences of decreased inclusion were mitigated through connections with others, support systems, resources, and connections. It could be possible to address inclusion with a focus on mitigating negative effects of the privilege identity perspective without directly addressing any other elements of the larger system.

Although the levels of interception may be an interesting method for examining how beliefs govern behaviors and actions, and how these behaviors and actions affect minority students, more information may be beneficial to understand the possible relationships between beliefs, actions, and their resulting effects. In other words, intercepting or making changes at any level in the system could prompt changes at other levels, and/or contribute to promoting overall positive outcomes in increased inclusion. Additionally, graduate programs may be interested in examining inclusion through constituent groups, as opposed to levels within a causal relationship.

\section{Recommendations}

When considering recommendations, it is important to note that student responses were provided to an outside party, the researcher, which removed any situational constraints that related to their current student status and relationship to their program. The survey format allowed students to share their experiences, thoughts, and feelings outside of the hierarchies of the academic environment. Student responses were submitted individually and were not connected to their specific graduate programs and 
were not available to faculty members within their programs. Removing student responses from the immediate academic environment allowed students to share without concerns of their responses being associated with any aspects of their academic studies, clinical training and externships, and peer relationships. Unlike studies that exist within the immediate academic context, students would not need to be concerned of their responses affecting faculty relationships, or any factors related to grades, clinical externship opportunities, future job opportunities, and other current or future interactions. Allowing for individual responses let students share information about peer interactions without concerns of peer reactions and factors related to current and future collegial relationships.

Recommendations are not specific to any one program and are the result of the multiple data points from themes across the three research questions within the UDL and critical theory framework. In other words, recommendations relate to graduate program design that expects and prepares for the needs of multiple student identities. Themes from the three research questions worked together to provide insight into inclusion. Recommendations are primarily centered on larger shared themes across minority identity groups and across research questions.

Recommendations are provided at the level of the program, faculty members, and students themselves. Separating recommendations into these levels allows for different potential audiences to advocate for or actively implement changes based on their constituent group or position within the system. As graduate school programs have hierarchies, offering recommendations that match the social standing and sphere of 
influence for different roles within the system may allow for multiple groups of people to engage in collective work to promote inclusion.

\section{Recommendations for Programs}

Recommendations for programs are related to larger policies and broader changes that would likely require administrative approval and action. Areas for program recommendation are recruitment, clinical, education, and connection, as shown in Table 105.

\section{Table 105}

Program Recommendations

\begin{tabular}{ll}
\hline \multicolumn{1}{c}{ Area } & \multicolumn{1}{c}{ Actions } \\
\hline Recruitment & Faculty, staff, guest speakers, students, clients, externships \\
Clinical & Clinical requirements, client forms, treatment materials \\
Education & Faculty and student training on diversity and systemic issues \\
Connection & Resources, mentorship, student groups, student connections \\
\hline
\end{tabular}

Recruitment. The area of recruitment encompasses faculty, staff, students, clients, externship opportunities, and guest speakers. Although graduate students may have limited understanding of the complexity of faculty hiring processes, they still recommended that programs prioritize and take deliberate steps to hire faculty members with minority identities. In addition to faculty members, hiring staff members with minority identities within the department was important. Recruitment of minority faculty 
and staff could ensure representation, which unto itself could be a major factor in inclusion. Even if programs were not able to ensure faculty member diversity, recruiting minority guest speakers and seeking out partnerships within the community could increase representation.

Along with diversification of faculty and staff, increasing student diversity could be accomplished through an examination of student recruitment methods and the admission process. Targeted advertising and recruitment across educational levels, starting in high school, and within underrepresented communities could increase awareness of the field. Lack of knowledge of the existence of speech-language pathology within many communities and for students with minority identities may be a limiting factor within overall diversity efforts. In regard to admissions, programs may want to examine their admissions procedures in the use of the GRE and how they ensure that students are able to show and share their unique experiences. When creating recruitment materials, programs may want to consider themes of asset and mission that place diversity as valued in contributing to collective goals of serving minority communities. Outward displays of diversity, such as welcoming symbols for LGBTQ+, describing a commitment to diversity, and showing diversity courses and clinical opportunities on university webpages may increase recruitment efforts. In addition to students, these recruitment efforts could also involve clinical opportunities, including recruiting clients from diverse backgrounds for on-campus clinics and externships serving minority clients.

Clinical. Within the area of clinical training, policies related to students and clients could ensure an inclusive environment. Needs related to student minority 
identities were important. For students with disabilities clinical requirements, such as a mandatory drug screening, could force disclosure of a disability due to medications. Policies that include confidential methods for students to report on the use of medication could reduce fear and stigma related to disclosure, as a student described confusion and distress when no policies were in place regarding medications. For LGBTQ+ students, policies related to pronoun use, clinician identity, and inclusive or LGBTQ+ friendly client intake forms would increase inclusion. Training and facilitated student discussion about ethical implications in the provision of services for LGBTQ+ clients showed a commitment to inclusive practices. An examination of the treatment materials provided in campus clinics is also an essential component, which was poignantly illustrated by a minority student who decried how Adolf Hitler was featured on a stimulus card in materials designed for senior citizens with neurogenic disorders. Sadly, this student described not receiving support in having this stimulus card removed and being counseled in relation to speaking style. Policies and practices related to clinical training, including student requirements, on-campus clinics, and clinical materials would promote inclusion in this essential part of the graduate school experience

Education. Faculty, staff, and student training education and training may seem familiar, as diversity training has become widespread. In this study, training was related to teaching about the needs and concerns of multiple minority identities in relation to privilege and systems of power. Faculty and staff training that focuses on recognizing and identifying behaviors that are representative of privileged perspectives could help make connections between belief systems and behaviors. Furthermore, similar 
recommendations for student diversity training that focused on equity and taught about biases and microaggressions early in the graduate program could provide students with skills and strategies to advocate for changes. Since minority students reported the presence of microaggressions in social events with peers before even beginning courses, programs may want to consider including information about diversity and equity in their initial information to incoming students. Based on the analyses of the data, diversity training that helped faculty examine the significance of their behaviors, provide students with skills, and connected the information with clinical practice are recommended, or as encapsulated by a student, education and training that covers "modern day issues-real issues of privilege, discrimination, and multicultural challenges when treating different populations."

Connection. In the area of connection, programs could facilitate student connections within their departments, within the university, and through shared communication systems. Student connections include welcoming and social events, which provide opportunities for social interaction. It should be noted that male students specifically noted the advantages of connections across universities, such as connecting male students who are attending nearby programs or other programs in the state. Connections could be made with faculty and community through formalized mentorship programs, while student connections could be created through minority affinity groups and partnerships with university student groups. Communication plays a role in connection, as programs could provide regular communication systems for students, such 
as shared social media, online methods for sharing of resources at the university and community level, and scheduled check-in or guidance meetings.

\section{Recommendations for Faculty}

Faculty members are central factors in graduate students' experiences of inclusion within speech-language pathology programs. Areas for action for faculty members are teaching practices, content, asset, and connection, as shown in Table 106.

\section{Table 106}

Faculty Recommendations

\begin{tabular}{ll}
\hline \multicolumn{1}{c}{ Area } & \multicolumn{1}{c}{ Actions } \\
\hline Teaching practices & $\begin{array}{r}\text { Multiple methods, learning groups, addressing the class, } \\
\text { demonstrations, non-student resources (avoid tokenism) } \\
\text { Content }\end{array}$ \\
Asset & Diversity as valuable and essential in field \\
Connection & Student individuality, peer interaction, mentorship \\
\hline
\end{tabular}

Teaching Practices and Content. In the area of teaching practices and content, recommendations encompass general concepts that are illustrated through specific examples. Students valued multiple methods within teaching, and collaborative learning models, which aligned with UDL teaching practices. Of note are specific behaviors that exemplified inclusion, including introductions and greeting statements, classroom demonstrations, student contributions, class breaks, clinical descriptions, class breaks, and costs. Class introductions that excluded males, positioned males as tokens, or made 
assumptions about female-centric experiences, and did not include pronouns decreased inclusion. Classroom demonstrations where faculty members chose students to perform tasks negatively affected minority students who reported disclosure of a disability to peers without consent, and tokenism in displays of bilingualism. When minority students chose to contribute, faculty members did not consistently value their contributions about diversity as meaningful or related to the content.

As with student demonstrations, class breaks also set up situations in which student identities were threatened. When faculty members ask the class if they want a break, a student with a disability is forced to disclosure learning needs at the risk of negative responses and judgments from peers. Clinical descriptions of cases that showed restricted client identities, family structures, and only showed females as clinicians and males as client were concerning. Diversity of clients within clinical and academic cases, and content that showed equity issues for client and communities showed a commitment to inclusion. Financially, faculty members need to consider the costs of any related activities and tasks, inform students as early as possible about these fees, and consider ways to reduce costs. Although it may not be fully possible to examine all of the assumptions that exist within a privileged identity perspective, faculty members may want to consider how even off-hand or casual comments related to the graduate school process, clinical work, and the parameters of academic content reflect white, middleclass, female, cisgender, heterosexual, able-bodied and neurotypical.

Asset and Connection. Asset pedagogy is part of culturally responsive pedagogy (Paris, 2012; Smith-Maddox \& Solorzano, 2002), which places diversity as a central 
feature and as a strength specifically were counter to privileged perspectives. Faculty members who designed courses that included diversity within clinical and academic content showed that diversity was part of the field of speech-language pathology. Furthermore, faculty members who made positive statements about the benefits of diversity of identities and life experiences showed how diversity was an asset and fostered a sense of mission or desire to contribute.

In addition to asset, connection ensured that students had supportive relationships and were acknowledged as individuals with unique contributions to enhance the field. Connections could be accomplished through peer interaction opportunities, such as collaborative learning groups, individual faculty connections, structured mentorship, and outside community partnerships. Faculty members whose actions increased student inclusion accomplished these goals by learning student's names, recommending mentors, and by seeking opportunities for students to engage within the greater speech-language community

\section{Recommendations for Students}

Minority graduate students themselves are an important and powerful group in advancing inclusion with speech-language pathology programs. Areas for action based on an analysis of the three research questions are asset, support, resources, and connection, as shown in Table 107. 
Table 107

Recommendations to Minority Students

\begin{tabular}{ll}
\hline \multicolumn{1}{c}{ Area } & \multicolumn{1}{c}{ Actions } \\
\hline Asset & Diversity as valuable, seek peer expertise \\
Support & Encouragement to self and peers, positive relationships \\
Resources & Accessing resources at the university, in the community, and Beyond \\
Connection & Affinity groups, university groups, future mentorship \\
\hline
\end{tabular}

Asset and Support. The area of asset involved repositioning diversity as a strength, which is needed and valued within the field. Minority students can promote asset-based beliefs through collaborative efforts in which they seek guidance from each other in serving clients and demonstrate the value of their own identity and experiences. Students can seek the advice and guidance of minority peers in serving clients with shared backgrounds, which elevates students to experts who have valuable information to share. Given intersectionality, minority students may consider their own privileges in regard to their different identities to offer assistance and seek assistance from peers in understanding different perspectives. Together, minority students can adopt an assetsbased approach where they redefine diversity and work collectively to address further knowledge of diversity in the field while simultaneously meeting client needs and supporting clients from diverse backgrounds.

Students who are aware of shared backgrounds and shared struggles can also provide meaningful support, such as highlighting pride and accomplishment. Given that 
family and community were important to many minority students, opportunities to engage with peers in ways that are connected family and community are a form of support. Validating and affirmative statements, such as self-talk and encouragement to peers, may be essential in mitigating the effects of persevering within an environment designed from a privileged perspective.

Resources and Connection. The area of resources and connections, minority students can work together to seek out and share resources and establish student affinity groups. Students can access university and community resources and share this information with each other, thus making themselves conduits in connections. Students can establish or participate in student groups, including communicating through social media, creating student groups, and connecting with pre-existing university groups, or community groups. Resources may be related to financial assistance, professional opportunities, volunteerism, or other areas of clinical, academic, and professional interest, or related to social and emotional support and promoting well-being. Connections could be virtual, in-person, or both and could include the sharing of resources, as well as a source of friendship and collegiality. When students have positive connections with each other and share resources, they may also start to see their future roles as mentors and embrace mentorship as part of their careers.

\section{Next Steps}

A positive aspect of this research is how it shows multiple potential paths for study and further exploration. This study focused on one time period from the vantage point of one constituent group, graduate students within their programs. Future 
scholarship could be related to new time periods related to the educational journey and elapsed time both individually and within society, constituent groups, research methods, and replication of the inclusive flyer portion of the study.

\section{Timing of Study}

Since this study was conducted during Fall 2019, it took place before the global COVID-19 pandemic, the national shift to remote education, and the Black Lives Matter social movement. If remote learning and online programs continue to become central to higher education, a study that examined inclusion in virtual spaces would add valuable information. The Black Lives Matter social movement within the spring of 2020 brought needed attention to anti-Black racism and systematic inequities within society. As a result of national protests, organizations sought to examine their own practices. The national speech-language pathology association, university departments, researchers, and clinicians have become involved in these efforts, including offering providing diversity trainings, making changes to policies, and seeking student input. A study that explored potential changes in the field resulting from these efforts may be beneficial.

This study also focused on one time period within the educational journey to becoming a SLP. Graduate students reported on their experiences of inclusion while they were in the midst of managing all of the academic and clinical demands of their program. There may be benefits of examining circumstances before and after graduate school. Studies that examined inclusion at the undergraduate and post baccalaureate level could provide information related to retention and recruitment, while studies at the post- 
graduation or clinical fellowship level could allow for participants to reflect on the significance of the graduate school experience in their preparedness for clinical practice.

\section{Constituent Groups}

Focusing exclusively on the experiences of minority graduate students did not allow for comparisons with the experiences of students from dominant groups. It is possible that students from dominant groups may also experience challenges with inclusion related to other factors, such as peer relationships and female relational aggression, academic expectations, course demands, clinical training, and more. It could be beneficial to explore inclusion from both minority and dominant identity perspectives. Additionally, perspectives from other minority identities may be beneficial, including religion, first generation students, veteran status, and more.

Students are obviously not the only constituent group when examining inclusion in graduate school programs. A focus on the faculty members and community members could provide information about reported beliefs, system constraints, and goals for inclusion. Faculty and community member beliefs about inclusion would provide information about their roles in fostering inclusion in academic training and clinical externships. Faculty and community members could share information about system constraints that affect their ability to engage in the amount and types of inclusive initiatives that they may hope to provide. This research could also show the goals that faculty and community members have for inclusion and ways that programs may help them to reach these goals. Combining research across constituent groups could allow for an examination of causal relationships. Research, which combined faculty and student 
perspectives, could shed light on the potential relationship between faculty beliefs, faculty behaviors, and student experiences.

\section{Research Methods}

As this was a qualitative study, a potential next step would be a quantitative study, which used numerical rating and ranking metrics to examine experiences, feelings of inclusion, and recommendations. Given that many participants initiated the study, but stopped responding when written responses were required, a quantitative study might have a higher completion rate and yield interesting information for comparison. This study was also conducted across the country, and specific regions may seek information about student experiences of inclusion related to geographic locations, public versus private universities, online versus in-person programs and more.

\section{Replication}

Although only two participants completed inclusive recruitment flyers, these flyers provided helpful data that highlighted diversity as an asset and the concept of mission or serving a greater collective purpose within inclusion. A replication of this study could be based on the inclusive recruitment flyer portion of the study. This type of study could have a smaller number of potential participants and use a focus group approach to allow for discussion of factors throughout the process of creation. Visual mediums, such as images, graphics, colors, and font styles add information to the discussion of inclusion in relation to recruitment for increased diversity. 


\section{Future Directions}

The national and global issues of COVID-19 and the Black Lives Matter Movement in the spring of 2020 may play a role in decisions about future directions. In considering future scholarship, it may be necessary to examine how speech-language pathology programs have changed and are changing to address systemic inequities and racism within higher education. Additionally, collaborative initiatives that connected and united researchers interested in examining diversity and inclusion could help shape the direction of future study.

\section{Conclusion}

From a UDL (Meyer et al., 2014) and critical theory framework (Waitoller \& King Thorius, 2016), a learning environment that is designed from a privileged perspective of white, middle-class, female, cisgender, heterosexual, and neurotypical and able-bodied is automatically inclusive to only those students whose identities match this narrow prescriptive view. Graduate school is the sole means of becoming a licensed SLP, and serves as a formative time period of academic learning and clinical training. Given the lack of diversity of the field of speech-language pathology, this study offers graduate programs and faculty the opportunity to reflect on the experiences of minority students and inclusion. Considering the extent to which they do or do not feel included, and factors that contribute to inclusion, allows programs to make decisions about their own commitment to diversity and inclusion.

This study considered the five identity markers of minority of race and ethnicity, low-income background, male in female-dominated field, LGBTQ+, and disability. 
Results showed the benefits of designing and planning for multiple student identities to increase inclusion. This approach recognized intersectionality and strove to work toward the goals of universality within UDL and address historical marginalization described within critical theory. Recommendations for programs and faculty interested in increasing inclusion to promote diversity can be implemented to support needs across minority identities, with the intention of mitigating or challenging an underlying limited student perspective.

When considering lack of diversity in speech-language pathology, this study centered the issue within graduate training programs. Analysis of the research questions of experiences of inclusion, programmatic recommendations for inclusion, and envisioning inclusion showed how students navigated their identities and existence within an environment that could be unaware of their identities, threaten their identities, or recognize and value their identities. Efforts to address a privileged identity perspective increased inclusion. Instead of solely viewing administration and faculty as the only groups with power, this study offers recommendations to minority graduate students as having power in promoting inclusion. Whether addressing underlying belief systems, behaviors resulting from these beliefs, or the effects of these behaviors, the different constituent groups within graduate program administration, faculty, and student levels can all participate in increasing inclusion.

Even though the field of speech-language pathology as a whole lacks diversity, graduate programs can be a central means of addressing this issue. As with many complex issues, addressing a singular root problem may not be feasible. Efforts to change 
the belief systems that underlie privilege are not the only option. Designing graduate program policies, teaching practices, and student interactions in ways that promote inclusion could have positive results. Graduate programs, faculty, and student may want to examine and consider methods of mitigating privilege and addressing its resulting negative effects. Planning for the needs of multiple student identities and implementing policies that encourage actions, which recognize multiple identities would accomplish two goals. Specifically, these goals would establish diversity as inherent within graduate programs and model diversity as valuable within the field. Although this research was conducted within speech-language pathology graduate training programs, other related fields, such as education and social work may be interested in considering these recommendations and examining their own programs.

As a clinical assistant professor, as a SLP, and as a mixed race individual from a low-income background, it is my hope that minority student experiences of inclusion can become a central component of diversity initiatives. Without understanding factors that contribute to inclusion for minority graduate students, any changes may not serve specific student identity needs, and may not achieve intended results. Graduate students are future SLPs who will shape their professional landscapes. Graduate programs can model how diversity and multiple minority identities are inherent to the practice of speech-language pathology and encourage and empower minority students, or they can continue to hold onto a privileged identity perspective, which is a disservice to the good they strive to achieve or the good that they profess to do in the world. 


\section{References}

Abell, M. M., Jung, E., \& Taylor, M. (2011). Students' perceptions of classroom instructional environments in the context of "Universal Design for Learning." Learning Environments Research, 14, 171-185. https://doi.org/10.1007/s10984011-9090-2

American Speech-Language-Hearing Association. (1993). Definitions of communication disorders. https://www.asha.org/policy/rp1993-00208/

American Speech-Language-Hearing Association. (2003). Evaluating and treating communication and cognitive disorders: Approaches to referral and collaboration for speech-language pathology and clinical neuropsychology. https://www.asha.org/policy/TR2003-00137/

American Speech-Language-Hearing Association. (2010). Roles and responsibilities of speech-language pathologists in schools [Professional Issues Statement]. https://www.asha.org/policy/PI2010-00317/

American Speech-Language-Hearing Association. (2016a). 2014 Standards and implementation procedures for the certificate of clinical competence in speechlanguage pathology. https://www.asha.org/certification/2014-speech-languagepathology-certification-standards/

American Speech-Language-Hearing Association. (2016b). Scope of practice in speech language pathology. https://www.asha.org/policy/SP2016-00343/

American Speech-Language-Hearing Association. (2017a). Highlights and trends: Member and affiliate counts, year-end 2017. https://www.asha.org/uploadedFiles/ 2017-Member-Counts.pdf

American Speech-Language-Hearing Association. (2017b). History of ASHA. https://www.asha.org/about/history/

American Speech-Language-Hearing Association. (2017c) Issues in ethics: Cultural and linguistic competence. https://www.asha.org/Practice/ethics/Cultural-andLinguistic-Competence/

American Speech-Language-Hearing Association. (2018a). Adult dysphagia. https://www.asha.org/certification/CCC_history/

American Speech-Language-Hearing Association. (2018b). ASHA state-by-state. https://www.asha.org/advocacy/state/ 
American Speech-Language-Hearing Association. (2018c). ASHA 's envisioned future. https://www.asha.org/About/ASHAs-Envisioned-Future/

American Speech-Language-Hearing Association. (2018d). A chronology of changes in ASHA certification standards. https://www.asha.org/Practice-Portal/ClinicalTopics/Adult-Dysphagia/

American Speech-Language-Hearing Association. (2018e). Cultural competence practice portal. https://www.asha.org/PRPSpecific Topic.aspx?folderid=8589935230\& section=Key_Issues/

American Speech-Language-Hearing Association. (2018f). Demographic profile of ASHA members providing bilingual services. https:/www.asha.org/uploadedFiles/ Demographic-Profile-Bilingual-Spanish-Service-Members.pdf

American Speech-Language-Hearing Association. (2018g). General information about ASHA certification. https://www.asha.org/Certification/ AboutCertificationGenInfo/

American Speech-Language-Hearing Association. (2018h). Multicultural Issues Board. https://www.asha.org/About/governance/committees/CommitteeSmartForms/Mult icultural-Issues-Board/

American Speech-Language-Hearing Association. (2018i). Office of Multicultural Affairs. https://www.asha.org/practice/multicultural/about/

American Speech-Language-Hearing Association (2019). Minority student recruitment and retention. https://www.asha.org/practice/multicultural/recruit/03initiative.htm

American Speech-Language-Hearing Association. (2020). Selected higher education reports and surveys. https://www.asha.org/academic/reports/

Americans With Disabilities Act of 1990 (1990). https://www.eeoc.gov/americansdisabilities-act-1990-original-text

Artiles, A., J., Harris-Murri, N., \& Rostenberg, D. (2006). Inclusion as social justice: Critical notes on discourses, assumptions, and the road ahead. Theory Into Practice, 45, 260-268. https://doi.org/10.1207/s15430421tip4503_8

Artiles, A. J., Kozleski, E. B., Trent, S. C., Osher, D., \& Ortiz, A. (2010). Justifying and explaining disproportionality, 1968-2008: A critique of underlying views of culture. Exceptional Children, 76, 279-299. https://doi.org/10.1177/ 001440291007600303 
Baer, R. M., Flexer, R. W., Beck, S., Amstutz, N., Hoffman, L., Brothers, J., Stelzer, D., Zechman, C. (2003). A collaborative followup study on transition service utilization and post-school outcomes. Career Development and Transition for Exceptional Individuals, 26, 7-25. https://doi.org/10.1177/088572880302600102

Baladin, S., \& Hines, M. (2011). The involvement of people with lifelong disability and communication impairment in lecturing to speech-language pathology students. International Journal of Speech-Language Pathology, 13, 436-445. https://doi.org/10.3109/17549507.2011.513738

Bandura, A. (2002). Social cognitive theory in cultural context. Applied Psychology: An International Review, 51(2), 269-290.

Barga, N. (1996). Students with learning disabilities in education: Managing a disability. Journal of Learning Disabilities, 29, 413-421. https://doi.org/10.1177/ 002221949602900409

Bok, D. (2013). Higher education in America. Princeton University Press

Brantlinger, E., Jimenez, R., Klingner, J. K., Pugach, M., \& Richardson, V. (2005). Qualitative studies in special education. Exceptional Children, 71, 195-207. https://doi.org/10.1177/001440290507100205

Brown v. Board of Education of Topeka, 347 U.S. 483 (1954).

Campbell, T., Dollaghan, C., Needleman, H., \& Janosky, J. (1997). Reducing bias in language assessment. Journal of Speech, Language, and Hearing Research, 40, 519-525. https://doi.org/10.1044/jslhr.4003.519

Campos, I., Skiados, M., \& Flynn, P. (2018). The unicorn: The rarity of males in speechlanguage pathology. Perspectives of the ASHA Special Interest Groups, 3, 29-37. https://doi.org/10.1044/persp3.SIG17.29

Colby, S. L., \& Ortman, J. M. (2015). Projections of the size and composition of the U.S. population: 2014 to 2060. https://www.census.gov/content/dam/Census/library/ publications/2015/demo/p25-1143.pdf

Council on Academic Accreditation. (2018a). Accreditation milestones. https://caa.asha. org/about/accreditation-milestones/ 
Council on Academic Accreditation. (2018b). Graduate degrees in Speech-Language Pathology accredited by ASHA's Council on Academic Accreditation in Audiology and Speech-Language Pathology (CAA). https://www. speechpathologygraduateprograms.org/caa-accredited-slp-graduate-programs/

Council on Academic Accreditation. (2018c). Standards for accreditation. https://caa.asha.org/reporting/standards/

Creswell, J. W. (2014). Research design: Qualitative, quantitative, and mixed methods approaches. Sage.

Duchan, J. F. (2002). What do you know about your profession's history? The ASHA Leader, 7, 4-29. https://doi.org/10.1044/leader.FTR.07232002.4

Duchan, J. F. (2011). A history of speech-language pathology. http://www.acsu.buffalo. edu/ duchan/new_history/ancient_history/greece.html

Ebert, K. D. (2013). Perceptions of racial privilege in prospective speech-language pathologists and audiologists. Perspective on Communication Disorders and Sciences in Culturally and Linguistically Diverse Populations, 20(2), 60-70. https://doi.org/10.1044/cds20.2.60

Edyburn, D. L. (2010). Would you recognize universal design for learning if you saw it? Ten propositions for new directions for the second decade of UDL. Learning Disabilities Quarterly, 33, 33-41. https://doi.org/10.1177/073194871003300103

Engle, J., \& Tinto, V. (2008). Moving beyond access: College success for low-income, first generation college students. Pell Institute for the Study of Opportunity in Higher Education. http://files.eric.ed.gov/fulltext/ED504448.pdf

Ferguson, A. (2009). The discourse of Speech-Language Pathology. International Journal of Speech-Language Pathology, 11(2), 104-112. https://doi.org/10.1080/ 17549500802412651

Fixsen, D., Blase, K., Metz, A., \& Van Dyke, M. (2013). Statewide implementation of evidence-based programs. Exceptional Children, 79, 213-230. https://doi.org/10.1177/001440291307900206

Forsman, J. A., \& Barth, J. M. (2017). The effect of occupational gender stereotypes on men's interest in female-dominated professions. Sex Roles, 76, 460-472. https://doi.org/10.1007/s11199-016-0673-3 
Frattali, C., \& Lux, J. B. (1998). Outcomes measurement and management: Towards a common language for functioning and disablement: ICIDH-2 (The International Classification of Impairments, Activities, and Participation). Perspectives on Administration and Supervision, 8(2), 7-8. https://doi.org/10.1044/aas8.2.7

Frazier, A. M. (2009). Culturally and linguistically diverse populations: Serving GLBT families in our schools. Perspectives on Communication Disorders and Sciences in Culturally and Linguistically Diverse Populations 16(1), 11-19. https://doi.org/10.1044/cds16.1.11

Freire, P. (1970). Pedagogy of the oppressed. Continuum.

Gabel, S. L. (2010). A disability studies framework for policy activism in postsecondary education. Journal of Postsecondary Education and Disability, 23, 63-71. https://www.ahead.org/uploads/publications/JPED/jped_23_1/JPED\%2023_1_Ful $1 \% 20$ Document.pdf

Gay, G. (2002). Culturally responsive teaching in special education for ethnically diverse students: Setting the stage. International Journal of Qualitative Studies in Education, 15, 613-629. https://doi.org/10.1080/0951839022000014349

Gee, J. P. (2014). An introduction to discourse analysis: Theory and method (4th ed). Routledge.

Gersten, R., Fuchs, L. S., Compton, D., Coyne, M., Greenwood, C., \& Innocenti, M. S. (2005). Quality indicators for group experimental and quasi-experimental research in special education. Exceptional Children, 71, 149-164.

Glesne C. (2011). Becoming qualitative researchers: An introduction. Allyn \& Bacon.

Goering, S. (2014). Rethinking disability: The social model of disability and chronic disease. Current Reviews in Musculoskeletal Medicine, 8, 134-138. https://doi.org/10.1007/s12178-015-9273-z

Goodenow, C. (1993). Classroom belonging among early adolescent students: Relationships to motivation and achievement. Journal of Early Adolescence, 13, 21-43. https://doi.org/10.1177/0272431693013001002

Gradel, K., \& Edson, A. (2009). Putting universal design on the higher ed agenda. Journal of Educational Technology Systems, 38, 111-121. https://doi.org/ 10.2190/ET.38.2.d

Greenbaum, B., Graham, S., \& Scales, W. (1995). Adults with learning disabilities: Educational and social experiences during college. Exceptional Children, 61, 460471. https://doi.org/10.1177/001440299506100505 
Guba, E. G., \& Lincoln, Y. A. (2005). Paradigmatic controversies, contradictions, and emerging confluences. In N. K. Denzin \& Y. S. Lincoln (Eds.), The Sage handbook of qualitative research (3rd ed.; pp. 191-215). Sage.

Gummadam, P., Pittman, L. D., \& Ioffe, M. (2016). School belonging, ethnic identity, and psychological adjustment among ethnic minority college students. The Journal of Experimental Education, 84, 289-306. https://doi.org/10.1080/ 00220973.2015.1048844

Hancock, A., \& Haskin, G. (2015). Speech-language pathologists' knowledge and attitudes regarding lesbian, gay, bisexual, transgender, and queer (LGBTQ) populations. American Journal of Speech-Language Pathology, 24, 206-221. https://doi.org/10.1044/2015_AJSLP-14-0095

Henderson, C. (1995). College freshman with disabilities: A triennial statistical profile. American Council on Education, HEALTH Resource Center.

Higher Education Opportunities Act of 2008 (2008). https://www.cga.ct.gov/2008/rpt/ 2008-R-0470.htm

Hutcheon, E. J., \& Wolbring, G. (2012). Voices of "disabled" post secondary students: Examining higher education "disability" policy using an ableism lens. Journal of Diversity in Higher Education, 5, 36-49. https://doi.org/10.1037/a0027002

Individuals With Disabilities Education Act (2004). https://sites.ed.gov/ dea/ statuteregulations/

Inglebret, E., Bailey, S., Clothiaux, J. A., Skinder-Meredith, A., Monson, K., \& Cleveland, L. (2017). Reporting of socioeconomic status in pediatric language research. American Journal of Speech-Language Pathology, 26, 1042-1052. https://doi.org/10.1044/2017_AJSLP-16-0229

Jimenez, T. C., Graf, V. L., \& Rose, E. (2007). Graining access to general education: The promise of universal design for learning. Issues in Teacher Education, 16 (2), 41-54. https://www.itejournal.org/back-issues/fall-2007/10jimenez.pdf

Joshi, G. S., \& Bouck, E. C. (2017). Examining postsecondary education predictors and participation for students with learning disabilities. Journal of Learning Disabilities, 50, 3-13. https://doi.org/10.1177/0022219415572894 
Kanno, Y., \& Varghese, M. M. (2010). Immigrant and refugee ESL students' challenges to accessing four-year college education: From language policy to educational policy. Journal of Language, Identity \& Education, 9, 310-328. http://wwwtandfonline-com.proxy.lib.pdx.edu/doi/abs/10.1080/15348458.2010.517693

Kelly, R. J., \& Robinson, G. C. (2011). Disclosure of membership in the lesbian, gay, bisexual, and transgender community by individuals with communication impairments: A preliminary web-based survey. American Journal of SpeechLanguage Pathology, 20, 86-94. https://doi.org/10.1044/1058-0360(2011/100060)

Kent, R. D. (1994). Implications of socioeconomic trends for speech-language pathology. American Journal of Speech-Language Pathology, 3, 45-47. https://doi.org /10.1044/1058-0360.0303.45

Kohnert, K. (2013). One insider's reflections on white privilege, race, and their professional relevance. SIG 14 Perspectives on Communication Disorders and Sciences in Culturally and Linguistically Diverse (CLD) Populations, 20, 41-48. https://doi.org/10.1044/cds20.2.41

Kosciw, J. G., Greytak, E. A., Zongrone, A. D., Clark, C. M., \& Truong, N. L. (2018). The 2017 National School Climate Survey: The experiences of lesbian, gay, bisexual, transgender, and queer youth in our nation's schools. GLSEN. https://www.glsen.org/sites/default/files/GLSEN\%202017\%20National\%20Schoo 1\%20Climate\%20Survey\%20\%28NSCS\%29\%20-\%20Full\%20Report.pdf

Kranke, D., Jackson, S. E., Taylor, A. E., Anderson-Fye, D. A., \& Floersch, J. (2013). College student disclosure of non-apparent disabilities to receive classroom accommodations. Journal of Postsecondary Education and Disability, 26, 35-51. https://www.ahead.org/publications/jped\#archived

L'GASP. (2019). About L'GASP. http://www.noglstp.net/LGASP/about-lgasp/

Leake, D. W., \& Stodden, R. A. (2014) Higher education and disability: Past and future of underrepresented populations. Journal of Postsecondary Education and Disability, 27, 399-208. https://www.ahead.org/uploads/publications/ JPED/JPED\%2027_4/JPED27_4_FULL\%20DOCUMENT_UPDATED.PDF

Lenz, B. K., \& Deshler, D. D. (2004). Teaching and academic diversity. In B. K. Lenz \& D. D. Deshler (Eds.), Teaching content to all: Evidence-based inclusive practices in middle and secondary schools (pp. 1-17). Pearson.

Litosseliti, L., \& Leadbeater, C. (2013). Speech and language therapy/pathology: Perspectives on a gendered profession. International Journal of Communication Disorders, 48(1), 90-101. https://doi.org/10.1111/j.1460-6984.2012.00188 
Lof, G. L, Mullen, R., \& Rabinowitz, L. (1999). A comparison of characteristics of males and females in graduate student speech-language pathology programs.

Contemporary Issues in Communication Sciences and Disorders, 26, 137-149. https://www.asha.org/uploadedfiles/asha/publications/cicsd/1999facomparisonofc haracteristics.pdf

Maier, K. (2103, August 13). Why the scarcity of male SLPs—and what can be done? https://blog.asha.org/2013/08/13/why-the-scarcity-of-male-slps-and-what-can-bedone/

Maxwell, J. A. (2013). Qualitative research design: An interactive approach ( $\left.3^{\text {rd }} \mathrm{ed}.\right)$. Sage.

McLaughlin, D., \& Tierney, W. G. (1993). Naming silenced lives. Routledge.

Merriam, S. B., \& Tisdell, E. J. (2016). Qualitative research: A guide to design implementation ( $4^{\text {th }}$ ed.). Jossey-Bass

Mertens, D. M. (2010). Research and evaluation in education and psychology: Integrating diversity with quantitative, qualitative, and mixed methods. Sage.

Meyer, A., Rose, D. H., \& Gordon, D. (2014). Universal design for learning: Theory and practice [Digital ed.]. http://www.cast.org/our-work/publications/2014/universaldesign-learning-theory-practice-udl-meyer.html\#.WELtna6eaL9

Michel, R. E., Hays, D. G., \& Runyan, H. I. (2015). Faculty member attitudes and behaviors toward male counselors in training: A social cognitive career theory perspective. Sex Roles, 72, 308-320. https://doi.org/10.1007/s11199-015-0473-1

Mull, C., Sitlington, P. L, \& Alper, S. (2001). Postsecondary education for students with learning disabilities: A synthesis of the literature. Exceptional Children, 68, 97118. https://doi.org/10.1177/001440290106800106

Murray, C., Wren, C. T., \& Keys, C. (2008). University faculty perceptions of students with learning differences: Correlates and group differences. Learning Disabilities Quarterly, 31, 95-113. https://doi.org/10.2307/25474642

Musu-Gillette, L., Robinson, J., McFarland, J., KewalRamani, A., Zhang, A., \& Wilkinson-Flicker, S. (2016). Status and trends in the education of racial and ethnic groups in 2016. https://nces.ed.gov/pubs2016/2016007.pdf

National Center for Education Statistics. (2016a). Fast facts: English language learners. https://nces.ed.gov/fastfacts/display.asp?id=96

National Center for Education Statistics. (2016b). Fast facts: Enrollment. http://nces.ed. gov/fastfacts/display.asp?id=98 
National Center for Education Statistics. (2016c). Fast facts: Graduation rates. https://nces.ed.gov/fastfacts/display.asp?id=40

National Center for Education Statistics. (2016d). Fast facts: Public school students eligible for free or reduced-price lunch. https://nces.ed.gov/fastfacts/ display.asp?id=898

National Center for Education Statistics. (2016e). Fast facts: Racelethnicity of college faculty. https://nces.ed.gov/fastfacts/display.asp?id=61

National Center for Education Statistics. (2016f). Fast facts: Students with disabilities. https://nces.ed.gov/fastfacts/display.asp?id=60

National Institute on Deafness and Other Communication Disorders. (2016a). Quick statistics about voice, speech, language. https://www.nidcd.nih.gov/health/ statistics/quick-statistics-voice-speech-language

National Institute on Deafness and Other Communication Disorders. (2016b). Statistics on voice, speech, and language. https://www.nidcd.nih.gov/health/statistics/ statistics-voice-speech-and-language

Newman, L., Wagner, M., Knokey, A., Marder, C., Nagle, K., Shaver, S., Wei , S., Cameto, R., Contreras, E., Ferguson, K., Greene, S., \& Schwarting, M. (2016). The post-high school outcomes of young adults with disabilities up to 8 years after high school: Key findings from the national longitudinal transition study-2 (NLTS-2). http://www.ncd.gov/rawmedia_repository/c19e795f_e7da_4628_a673_ 86e2d0c6f951.pdf

Novak, K., \& Rodriguez, K. (2016). Universally designed leadership: Applying UDL to systems and school. CAST.

Olou, I. (2018). So you want to talk about race. Seal Press

Paris, D. (2012). Culturally sustaining pedagogy: A needed change in stance, terminology, and practice. Educational Researcher, 41, 93-97. https://doi.org/ 10.3102/ 0013189X12441244

Preis, J. (2013). The effects of teaching about White privilege in speech-language pathology. SIG 14 Perspectives on Communication Disorders and Sciences in Culturally and Linguistically Diverse (CLD) Populations, 20, 72-83. https://doi.org/10.1044/cds20.2.72

Quaye, S. J., Tambascia, T. P., \& Talesh, R. A. (2009). Engaging racial/ethnic minority students in predominantly White classroom environments. In S. J. Quaye \& S. R. Harper (Eds.), Student engagement in higher education (pp. 157-168). Routledge. 
Rao, K., Edelen-Smith, P., \& Wailehua, C. (2015). Universal design for online courses: applying principles to pedagogy. Open Learning, 30, 35-52. https://doi.org/10.1080/02680513.2014.991300

Rehabilitation Act of 1973 (1973). https://www.eeoc.gov/rehabilitation-act-1973original-text

Saldaña, J. (2016). The coding manual for qualitative researchers ( $3^{\text {rd }}$ ed.). Sage.

Sawyer, J., Perry, J. L., Dobbins-Scaramelli, A. (2014). A survey of the awareness of speech services among transgender and transsexual individuals and speechlanguage pathologists. International Journal of Transgenderism, 15, 146-163. https://doi.org//10.1080/15532739.2014.995260

Schelly, C. L., Davies, P. L., \& Spooner, C. L. (2011). Student perceptions of faculty implementation of universal design. Journal of Postsecondary Education, 24, 17-30. https://files.eric.ed.gov/fulltext/EJ1026883.pdf

Schueler, L. A., Hoffman, J. A., \& Peterson, E. (2009). Fostering safe, engaging campuses for lesbian, gay, bisexual, transgender, and questioning students. In S. J. Quaye \& S. R. Harper (Eds.), Student engagement in higher education (pp. 6179). Routledge.

Scott, S. S., McGuire, J. M., \& Shaw, S. F. (2003). Universal design for instruction: A new paradigm for adult instruction in postsecondary education. Remedial and Special Education, 24, 369-379. https://doi.org/10.1177/07419325030240060801

Sensoy, O., \& DiAngelo, R. (2012). Is everyone really equal? An introduction to social justice education. Teachers College Press

Sharatta, C. A., Tirpak, D. M., \& Schlosser, L. Z. (2015). Male-male advising relationships in graduate psychology: A diminishing dyad. Sex Roles, 72, 335-348. https://doi.org/10.1007/s11199-015-0466-0

Shaw, S. F., \& Dukes, L. L. (2001). Program standards for disability services in higher education. Journal of Postsecondary Education and Disability, 14, 81-90. https://www.ahead.org/publications/jped

Shen-Miller, D., \& Smiler, A. P. (2015). Men in female-dominated vocations: A rationale for academic study and introduction to the special issue. Sex Roles, 72, 269-276. https://doi.org/10.1007/s11199-015-0471-3

Smith, F. G. (2012). Analyzing a college course that adheres to the universal design for learning framework. Journal of Scholarship of Teaching and Learning, 12, 31-61. http://josotl.indiana.edu/article/viewFile/2151/2058 
Smith-Maddox, R., \& Solorzano, D. G. (2002). Using critical race theory, Paulo Friere's problem posing method, and case study research to confront race and racism in education. Qualitative Inquiry, 8, 66-84. https://doi.org/10.1177/ 107780040200800105

Sparks, R. L., \& Lovett, B. J. (2009). College students with learning disability diagnoses: Who are they and how do they perform? Journal of Learning Disabilities, 42, 494-510. https://doi.org/10.1177/0022219409338746

Steckly, R. G. (2009). Gay, lesbian, bisexual, and transgender people: An introductory discussion of terminology and demographics. Perspectives on Communication Disorders and Sciences in Culturally and Linguistically Diverse Populations, 6(1), 4-10. https://doi.org/10.1044/cds16.1.4

Sue, D. W., Capodilupo, C. M., Torino, G. C., Bucceri, J. M., Holder, A. M. B., Nadal, K. L., \& Esquilin, M. (2007). Racial microaggressions in everyday life. American Psychologist, 62(4), 271-286. https://doi.org/10.1037/0003-066X.62.4.271

Thompson, D. (2013). The 33 Whitest jobs in America. The Atlantic Magazine. https://www.theatlantic.com/business/archive/2013/11/the-33-whitest-jobs-inamerica/281180/

Trans Student Educational Resources. (n.d.). LGBTQ+ definitions. http://www. transstudent.org/definitions/

Uhl-Bien, M., Marion, R., \& McKelvey, B. (2007). Complexity leadership theory: Shifting leadership industrial age to the knowledge era. The Leadership Quarterly, 18, 298-318. https://doi.org/10.1016/j.leaqua.2009.04.002

U.S. Census Bureau. (2018). Quick facts. https://www.census.gov/quickfacts/fact/table/ US/PST045218

U.S. Department of Education. (1973). The civil rights of students with hidden disabilities under section 504 of the Rehabilitation Act of 1973. http://www2.ed.gov/about/ offices/ list/ocr/docs/hq5269.html

Voyzey, G. A. (2015). Meeting the cultural, therapeutic, and individual needs of the lesbian, gay, bisexual, or transgendered patient. Perspectives on Gerontology, 20(3), 85-103. https://doi.org/10.1044/gero20.3.85

Waitoller, F. R., \& King Thorius, K. A. (2016). Cross-pollinating culturally sustaining pedagogy and universal design for learning: Toward an inclusive pedagogy that accounts for dis/ability. Harvard Educational Review, 86, 366-389. https://doi.org/10.17763/1943-5045-86.3.366 


\title{
Appendix A: Participant Consent Form
}

\author{
Consent to Participate in Research \\ Informed Consent Letter for Study Participants
}

Consent to Study Title: How Minority Graduate Students in Speech-Language

Pathology Graduate Training Programs Experience Inclusion

Study Title: How Minority Graduate Students in Speech-Language Pathology Graduate Training Programs Experience Inclusion

Principal Investigator:

Randall De Pry

Graduate School of Education

Special Education

PO Box 751

Portland, OR 97207-0751

Email address: rdepry@pdx.edu
Co-Investigator:

Teresa Roberts

Graduate School of Education

Special Education

PO Box 751

Portland, OR 97207-0751

Email address: robertst@pdx.edu

\section{Introduction to the Study:}

You are invited to participate in a research study with researcher Teresa Roberts from the Department of Special Education, Graduate School of Education, at Portland State University. The purpose of this study is to examine how minority students in speechlanguage pathology graduate training programs experience inclusion, and explore the implications of inclusion associated with how the field of speech-language pathology addresses lack of diversity of its members.

You are being asked to participate in this study because it is important to highlight the unique voices of minority students who are entering into a profession that is predominantly homogenous and reflects a dominant majority.

This form will explain the research study and will also explain the possible risk as well as the possible benefits to you. If you have any questions, please contact one of the study investigators.

\section{What will happen if I choose to participate?}

As a minority student in a speech-language pathology graduate training program, you will be sharing your experiences about inclusion as you work toward your professional 
degree. I am interested in exploring, from your perspective, what are the factors that promote inclusion, as well as your recommendations for increasing inclusion for minority students. As a participant in the study, you will be asked to:

1. Complete a consent form.

2. Take part in completing four writing prompts about your experiences of inclusion, and your recommendations for increasing inclusion.

3. Chose to participate in creating an inclusive recruitment flyer to encourage minority students to pursue the field of speech-language pathology.

4. Take part in a one-on-one, telephone interview with the researcher to discuss your recruitment flyer.

The data collected include participant demographic characteristics representing identities and participant writings. Participation in the writing prompt study will take approximately 20-30 minutes. Participation in the inclusive recruitment flyer will take approximately 45 minutes.

\section{What are the risks or side effects of being in this study?}

There are no known risks in this study, however some individuals may experience discomfort when writing responses to questions. In some instances, reflecting on prior experience can cause emotional responses. The researcher is available to provide recommendations for resources to support your emotional needs. You are encouraged to communicate with the researcher if you would like help with finding emotional support within your university program. Every effort will be made to minimize any risks.

\section{What are the benefits to being in this study?}

There will be no direct benefit from this study, aside from the value of sharing your experiences as a minority within a speech-language pathology graduate training program. Your academic standing will not be affected in any way. Your voice will contribute to the research on diversity and minority experiences within speech-language pathology. You will help inform the conversation on the lack of diversity of speech-language pathologists, and inclusion, as it relates to recruiting and retaining minorities. This study will recognize and validate your voice and the voices of other minority students in speech-language pathology graduate programs.

\section{How will my information be kept confidential?}

Participants' confidentiality is a primary goal. All written responses will be confidential. All data and material will be kept for three years in a locked file or electronically password protected in the researcher's home and work office, and then destroyed. Your name will not be used in published reports of this study. Please note that the researcher is 
legally obligated to report child abuse, child neglect, harm to self or others, or any lifethreatening situation to the appropriate authorities.

\section{Institutional Review Board:}

If you have questions regarding your rights as a research participant, you may contact the PSU Office for Research Integrity at (503) 725-5484. The Office of Research Integrity supports the PSU Institutional Review Board, which ensures independent safety and ethical oversight of research involving human participants. For more information, you may access the Institutional Review Board website at: https://sites.google.com/a/pdx.edu/research/integrity

\section{Voluntary Participation:}

Participation in this research study is voluntary. You have the right to withdraw from the study at any time or refuse to participate entirely without jeopardizing your academic standing.

\section{Cost to Participate:}

There is no cost to participate in this study.

\section{Consent:}

You are deciding to participate in this study. Your electronic signature indicates that you have read the information provided. By signing this consent form, you are not waiving any rights as a research participant. Your electronic signature will be separated from your responses to ensure confidentiality. In order to ensure confidentiality, please do not include the actual names of individuals or locations in your responses. If names are present, they will be removed.

You have had the opportunity to ask questions and all questions have been answered to your satisfaction. By electronically signing this consent form, you agree to participate in this study. 


\section{Appendix B: Demographic Questionnaire}

- In which state is your graduate program located?

- List of U.S. states and territories

- What year are you in your graduate program?

- First year, second year, or other

- Is English your native or home language?

- Yes, or if no, please provide your native or home language(s)

- How would you describe your race and/or ethnicity? Check all that apply

- White, Hispanic/Latinx, Black or African American, Asian, American Indian or Alaska Native, Native Hawaiian or Other Pacific Islander, Other racial or ethnic identity

- How would you describe your socioeconomic status (i.e., family income) growing up?

- Low socioeconomic, middle socioeconomic, high socioeconomic, other socioeconomic status

- How would you describe your gender identity?

- Male/man

○ Female/woman

○ Nonbinary/gender queer

○ Other gender identity

- Do you identify as transgender?

○ Yes or no

- How would you describe your sexual orientation?

- Asexual, bisexual, gay, heterosexual, lesbian, queer or questioning, other sexual orientation 
- Do you identify as having a disability? Check all that apply

○ No, I do not identify as having a disability

- Physical disability, intellectual or learning disability, psychiatric disability, visual impairment, hearing impairment, communication disorder, neurological impairment, other disability

- Is there another identity (or identities) that is meaningful to you? 


\section{Appendix C: Writing Prompts}

\section{First Writing Prompt: Decreased Inclusion}

a. What was a meaningful experience that decreased your feelings of being included within your graduate training program?

b. Why was this experience important to you?

c. How did your identity/identities relate to this experience?

\section{Second Writing Prompt: Increased Inclusion}

a. What was a meaningful experience that increased your feelings of being included within your graduate training program?

b. Why was this experience important to you?

c. How did your identity/identities relate to this experience?

\section{Third Writing Prompt: Overall Inclusion}

a. To what extent have you felt included or not included in your graduate training program in speech-language pathology? Please write as much as you wish about your feelings of inclusion in general.

b. Why have you felt this way?

c. How did your identity/identities relate to these feelings?

\section{Fourth Writing Prompt: Programmatic Recommendation}

What recommendations do you have for graduate training programs in speech-language pathology to increase inclusion for minority students based on your own experiences?

\section{Fifth Writing Prompt: Peer Advice}

What advice would you give to another minority student about inclusion to prepare them for a speech-language pathology graduate training program? 


\section{Appendix D: Visual Representation Prompt and Interview Prompt}

\section{Visual Representation Prompt}

Thank you taking the time to complete a flyer to increase understanding of diversity within speech-language pathology.

Creating a flyer may take approximately 30 minutes. You can save the survey and finish it at a later time by coming back to it in the same internet browser.

On your own, individually create an inclusive recruitment flyer to encourage minority students to pursue the field of speech-language pathology. If you create your flyer by drawing by hand, please take a picture or scan your document.

Please upload your flyer as a pdf, jpeg, or png document.

\section{Interview Prompt}

1. How would you describe the process of creating an inclusive recruitment flyer?

2. What did you consider when designing an inclusive recruitment flyer?

3. How do you feel about the inclusive recruitment flyer that you designed? 


\title{
Appendix E: Email Invitation for Faculty Chairs
}

\author{
Re: Graduate Inclusion Research Survey
}

Hello, my name is Teresa Roberts. I am a doctoral student, and a clinical faculty member at Portland State University in the Speech and Hearing Sciences Department. I am conducting research on experiences of inclusion within speech-language pathology graduate programs with the intent of increasing diversity within the field. Results of this study are designed to serve as a basis for recommendations for inclusive departmental practices to improve diversity in recruitment and retention. Your department's participation in this study has the potential to shape future policy, practice, and research that support multicultural and diversity initiatives within the field of speech-language pathology. This study has Institution Review Board approval: HRPP \# 196470-18.

Please share this information and the survey link with all graduate students in your program. This survey information is being shared with all accredited speech-language pathology master's programs in the U.S. If possible, please respond to this email with a confirmation of survey distribution to the students in your program to track the percentage of participating master's programs.

- Are you currently enrolled in a master's program in speech-language pathology?

- Do you hold one or more of the following identities: racial or ethnic minority, low-income background, male in female-dominated field, LGBTQ+, disability, or other minority marker? If so, you are eligible to participate in the study.

- Sharing your experiences will increase understanding of student needs and benefit diversity efforts within speech-language pathology graduate programs.

- Click here to access the study: https://portlandstate.qualtrics.com/jfe/form/SV_agEQqc547FPp5Qx

Thank you for your consideration. If you have any questions, I can be reached at robertst@pdx.e`du or 503-725-3533. 